US Army Corps

of Engineers $S_{\circledast}$

Engineer Research and

Development Center

Navigation Systems Research Program

\title{
Corrosion Induced Loss of Capacity of Post- Tensioned Seven Wire Strand Cable Used in Multistrand Anchor Systems Installed at Corps Projects
}

Robert M. Ebeling, Barry C. White, James A. Evans,

December 2016

Richard W. Haskins, and Ernest L. Miller

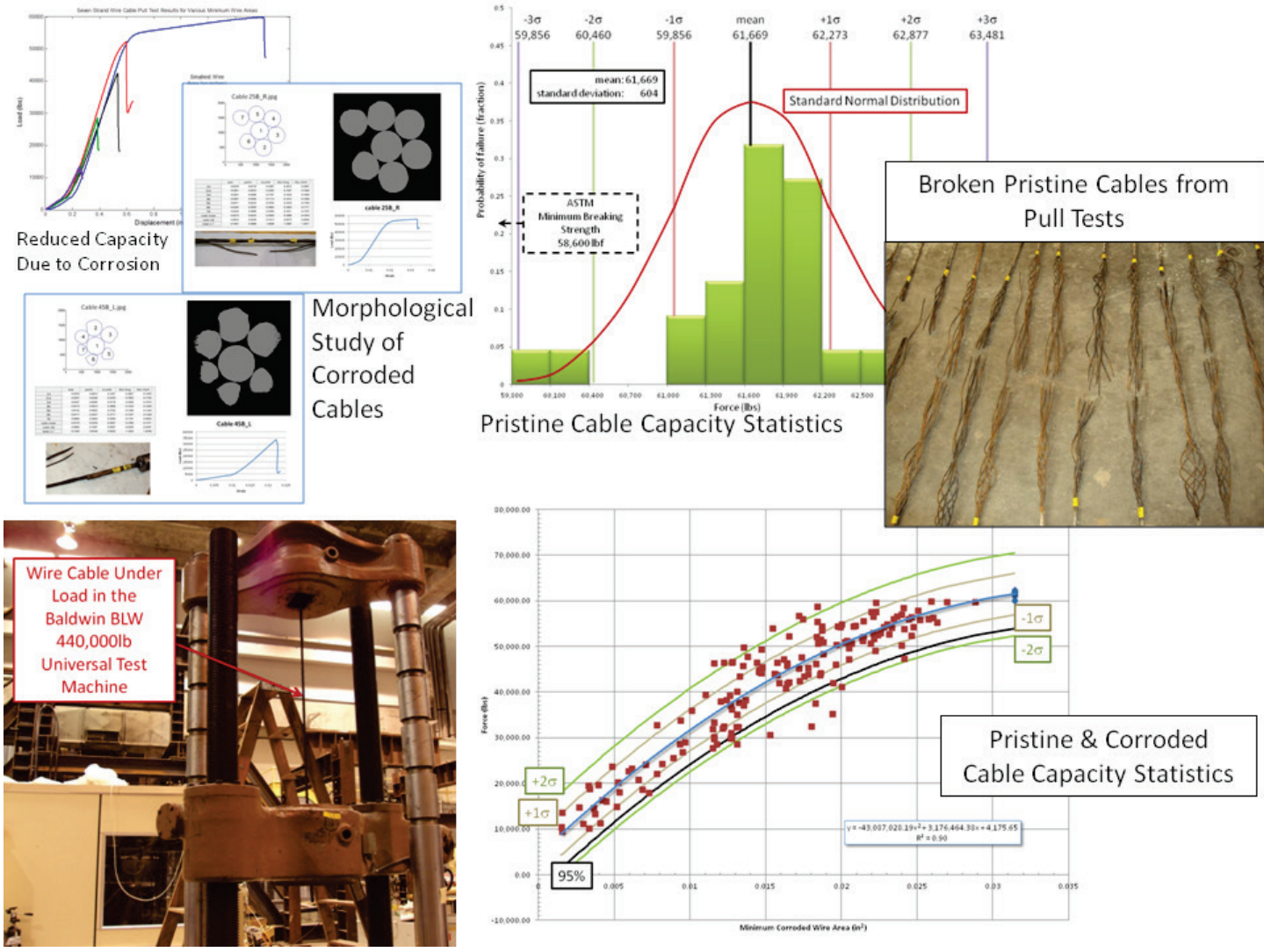


The US Army Engineer Research and Development Center (ERDC) solves the nation's toughest engineering and environmental challenges. ERDC develops innovative solutions in civil and military engineering, geospatial sciences, water resources, and environmental sciences for the Army, the Department of Defense, civilian agencies, and our nation's public good. Find out more at www.erdc.usace.army.mil.

To search for other technical reports published by ERDC, visit the ERDC online library at http://acwc.sdp.sirsi.net/client/default. 


\section{Corrosion Induced Loss of Capacity of Post- Tensioned Seven Wire Strand Cable Used in Multistrand Anchor Systems Installed at Corps Projects}

Robert M. Ebeling, Barry C. White, James A. Evans, Richard W. Haskins, and Ernest L. Miller

Information Technology Laboratory

U.S. Army Engineer Research and Development Center 3909 Halls Ferry Road

Vicksburg, MS 39180-6199

Final report

Approved for public release; distribution is unlimited. 


\section{Abstract}

Over the past five decades, the U.S. Army Corps of Engineers has been upgrading its projects by installing high-capacity, post-tensioned foundation anchors, typically with seven-wire strand cables. The purpose of these anchors has been to achieve structural stability for Corps hydraulic concrete structures (e.g., locks, dams, approach walls) and/or to remediate cracked concrete monoliths. Substantial improvements to protect multistrand anchor systems from corrosion have been made in the past five decades, but the corrosion of older multistrand anchorage systems is still a major concern.

This report discusses a laboratory-testing program for the estimation of post-tensioning (PT), seven-wire strand cable strength as a function of corroded cross-sectional material loss. Pull tests were performed to gather reduced cable strength measurements. An innovative morphological procedure using digital photography was developed by U.S. Army Engineer Research and Development Center (ERDC) researchers for quantifying the cross-section geometrical properties of cables near their failure locations. The laboratory-testing program also included a successful series pull test to failure on pristine specimens for a control set of data, and the issues encountered are detailed. A statistical assessment of pull-test data to failure of pristine and corroded cables is used to establish a correlation between cross-section properties, corroded and pristine, and the cable strength.

An overview of the corrosion process and the variables, ranked by contribution in Corps structures, which determine corrosion rate at each of the multistrand cables, is provided. Further, methods for estimating cable capacity under load were developed using the provided best-fit curves from the laboratory pull tests.

DISCLAIMER: The contents of this report are not to be used for advertising, publication, or promotional purposes. Citation of trade names does not constitute an official endorsement or approval of the use of such commercial products. All product names and trademarks cited are the property of their respective owners. The findings of this report are not to be construed as an official Department of the Army position unless so designated by other authorized documents. 


\section{Contents}

Abstract.................................................................................................................................. if

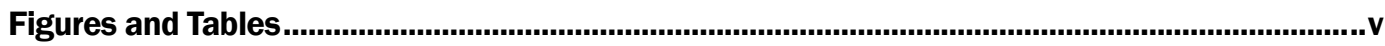

Unit Conversion Chart ..............................................................................................................................

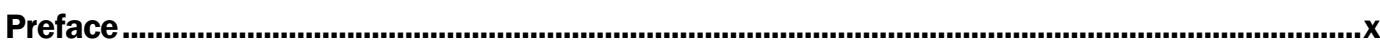

1 Introduction......................................................................................................................... 1

1.1 Introduction to the Problem and This Phase of Research..................................... 1

1.2 Report Contents................................................................................................ 6

2 Pristine Post-Tensioning, Seven-Wire Strand Cable............................................................ 7

2.1 Seven-wire strand cable used in testing program ............................................ 7

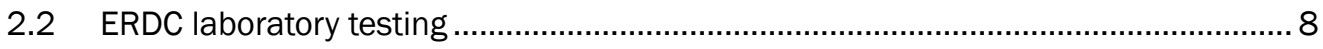

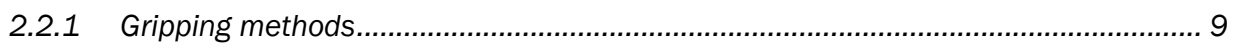

2.2.2 Pull-Test Results............................................................................................. 22

3 Optical Imaging System to Determine Morphological Properties.......................................28

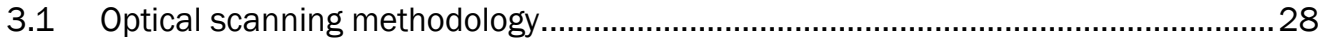

3.2 Measures of morphological data from optical scanning .....................................32

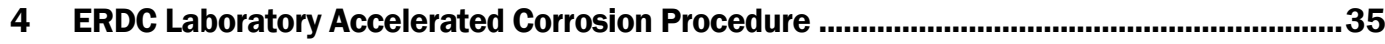

5 Pull-Test Results for Pristine and Corroded PT Seven-Wire Strand Cable ............................39

6 Estimation of Embedded Seven-Strand Cable Post-Tension Capacity Loss Due to

Corrosion ................................................................................................................................52

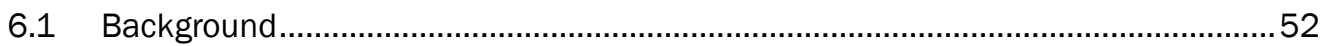

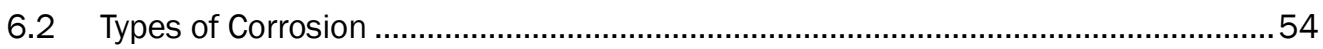

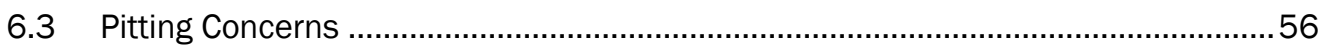

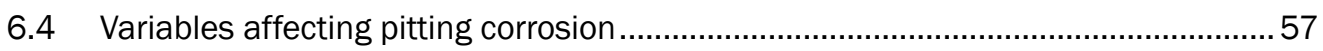

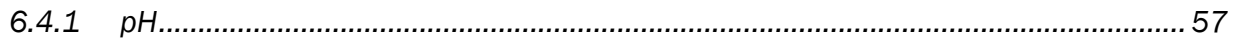

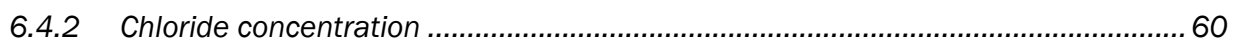

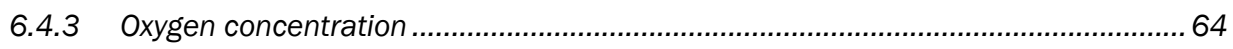

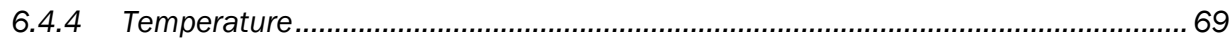

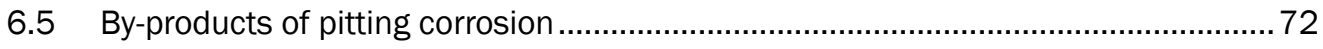

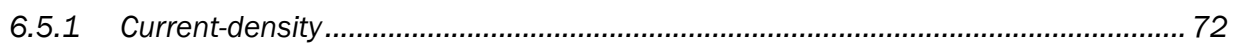

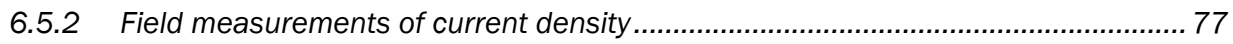

6.6 Predictive models for corrosion ................................................................. 81

6.6.1 Expert evaluation of standard deviation for corrosion rate ..................................... 81

6.6.2 Pitting corrosion prediction using current density ................................................... 88

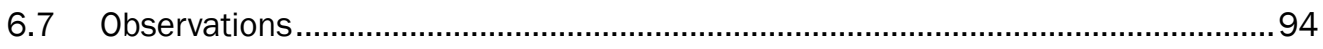




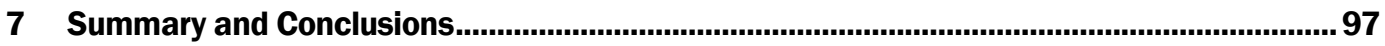

7.1 Summary

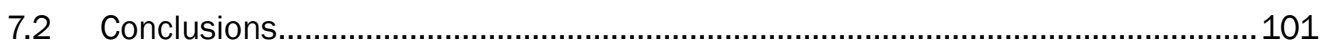

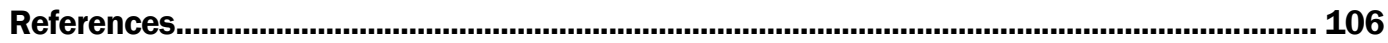

Appendix A: Table of Capacity and Optical Post-Processed Pull Test Results for the 161 Corroded and 22 Pristine Specimens.

Report Documentation Page 


\section{Figures and Tables}

\section{Figures}

Figure 1.1. Post-tensioned anchorage system remediation of John Day Lock in 1981 using 73 tie-down anchors.

Figure 1.2. The installation of a post-tensioned anchor system at John Day Lock, pictures of its (then) new anchor head and its current corroded anchor head spewing water, and rate of anchor loss with time due to corrosion

Figure 1.3. Inspection results for lift-off tests at the south lock wall at John Day Lock.

Figure 1.4. Example of a lift-off test for anchor 11-32 at the south lock wall at John Day Lock.

Figure 1.5. Results of pull tests to first failure of pristine and PT seven-wire strand cable with various levels of corrosion. 5

Figure 2.1 Pull tests performed on a Baldwin BLW 440,000 lb Universal Test Machine.................. 7

Figure 2.2. Pull-test results of PT seven-wire strand cable surrounded by a quickset, steelreinforced epoxy and the wedges.

Figure 2.3. Pull-test results of PT seven-wire strand cable surrounded by epoxy putty and the wedges.

Figure 2.4. Pull-test results of PT seven-wire strand cable surrounded by aluminum wire mesh and the wedges.

Figure 2.5. Pull-test results of PT seven-wire strand cable surrounded by copper sheet layers and the wedges

Figure 2.6. Pull-test results of PT seven-wire strand cable surrounded by bronze shim stock and the wedges.

Figure 2.7. Pull-test results of PT seven-wire strand cable surrounded by a quickset, steelreinforced epoxy and $70 \%$ reduced wedges

Figure 2.8. Pull-test results of PT seven-wire strand cable with $40 \%$ reduced wedges.

Figure 2.9. Pull-test results of PT seven-wire strand cable surrounded by a thick layer of quickset, steel-reinforced epoxy and with 40\% reduced wedges.

Figure 2.10. Spreader to be driven on the king wire with a steep slope............................................ 15

Figure 2.11. Altered wedge and wire with spreader after pull test.................................................. 16

Figure 2.12. Connection details of wire with spreader and the interface with the wedge.

Figure 2.13. The addition of hose clamps to keep the spreader from being pushed off the king wire.

Figure 2.14. A better view of the spreader surrounding the king wire.

Figure 2.15. PT seven-wire strand cable surrounded by grout and conduit. ................................... 18

Figure 2.16. An adapter added to assist in wedging the grouted cable.

Figure 2.17. Examples of the grout turning to dust as the cable attempted to twist at the connection.

Figure 2.18. Tests made with different consistencies of grout.

Figure 2.19. Hammering aluminum strips into the wedges to form grip points with the serrations. 
Figure 2.20. Hammered grip point details for the wedges. Note how the aluminum strip was hammered and the gripping surface, respectively.

Figure 2.21. Detail of the cables being restrained with the aluminum strips and wet sand mixture.

Figure 2.22. Aluminum strips with sand mixture restraining the PT seven-wire strand cable and being held in place by wedges.

Figure 2.23. Example of "bird cage" effect for pulled cables. ............................................................22

Figure 2.24. Successful pull-test results for corroded specimen. ........................................................23

Figure 2.25. Statistical distribution data of failure strength for 22 successful tests with a mapped normal distribution for comparison.

Figure 2.26. Pull tests were performed for a number of pristine samples, with uniform results for successful tests.

Figure 3.1. Preparing a cable for optical scanning. The final cut and polished sample is on the left and a pulled-together, unsmoothed cable to the right.

Figure 3.2. Optical scanning platform (also with a loaded sample and the thin dot template)

Figure 3.3. Optical scanning platform showing the scanning software.

Figure 3.4. Using digital image processing to separate the wire ends from the background

Figure 3.5. Using software to demark the individual cables in the image.

Figure 3.6. Using computational graphic techniques to complete the map of individual wires.

Figure 3.7. The results of optical scanning for PT seven-wire strand cable to determine loss of area and alteration of geometry due to corrosion. 31

Figure 3.8. Optical scan data from the pull-test data for lightly corroded cable 25B_R.

Figure 3.9. Optical scan data from the pull-test data for moderately corroded cable 45B_L

Figure 4.1. The first mechanism used for the accelerated corrosion of PT seven-wire strand cable.

Figure 4.2. 10-amp generator connected to $3.5 \mathrm{ft}$ long corrosion specimen in the static saltwater tanks. 36

Figure 4.3. The mechanism and process for the corrosion of long specimen.

Figure 4.4. Before and after images of the short wire corrosion platform corroding several specimen simultaneously.

Figure 5.1. Corroded and pristine data plotted by peak capacity and the area of the wire in the cable with the least area.

Figure 5.2. Corroded and pristine data plotted by peak capacity and the short axis diameter of the wire in the cable with the least short axis diameter...

Figure 5.3. Linear trend line fitting minimum wire area data. .........................................................4 42

Figure 5.4. Linear trend line fitting minimum wire diameter data................................................... 42

Figure 5.5. Second order polynomial trend line fitting minimum wire area data...........................43

Figure 5.6. Second order polynomial trend line fitting minimum wire diameter data...................... 43

Figure 5.7. Third order polynomial trend line fitting minimum wire area data................................ 44

Figure 5.8. Third order polynomial trend line fitting minimum wire diameter data...........................44 
Figure 5.9. Power function trend line fitting minimum wire area data. .......................................... 45

Figure 5.10. Power function trend line fitting minimum wire diameter data................................... 45

Figure 5.11. The selected data trend line (polynomial order 2) for the minimum wire area correlation and its standard deviation $(\sigma)$ information and the 95\% CDF level information. ............ 49

Figure 5.12. The selected data trend line (polynomial order 2) for the minimum wire diameter correlation and its standard deviation $(\sigma)$ information and the 95\% CDF level information 49

Figure 6.1. The process of pitting corrosion (after Lee and Zielske 2014) 56

Figure 6.2. Corrosion rate as a function of $\mathrm{pH}$ (after Charng and Lansing 1982 and Uhlig 1948).

Figure 6.3. Corrosion rate as a function of sodium chloride concentration (after Roberge 2008 and Berry 1984)

Figure 6.4. Cable capacity in relation to chloride concentration in solution (derived from Trejo et al. 2009).

Figure 6.5. Corrosion rate as a function of oxygen concentration (Charng and Lansing 1982).

Figure 6.6. Corrosion rate as a function of solution velocity (after Charng and Lansing 1982).

Figure 6.7. Linear interpolation of corrosion rate with respect to temperature for various $\mathrm{pH}$ values.

Figure 6.8. Corrosion rate in tap water with respect to dissolved oxygen at three different temperatures (after Roberge 2008 and Berry 1984).

Figure 6.9. Change of corrosion rate as temperature increases (derived from the data used for Figure 6.8)

Figure 6.10. (1) exponential current curve related to potential voltage, (2) semi-logarithmic

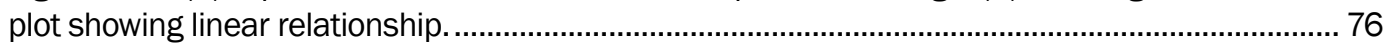

Figure 6.11. Equivalent electrical circuit measurement system for corrosion monitoring................ 79

Figure 6.12. Laboratory setup for polarization measurement (Ahmad et al. 2014). ........................80

Figure 6.13. Measurement probe with guard ring shown (after Kinghoffer 2014). ......................... 81

Figure 6.14. Probability-density plot from Darmawan and Stewart (2007) equations for Table 6.7 Wire 2 properties. 92

Figure 6.15. Relationship of the corrosion area with respect to the wire.......................................92

Figure 6.16. Probability density versus remaining wire area. ........................................................92

Figure 6.17. Probability density versus remaining estimated minimum second-moment wire diameter.

Figure 7.1. Bounding the minimum corroded wire area measure with the limiting force values of 41 kips and 36.5 kips. 103

Figure 7.2. Bounding the minimum corroded wire short axis diameter measure with the limiting force values of 41 kips and 36.5 kips.

Figure 7.3. A rough indication of the maximum and minimum time in years to cable failures as a function of loss rate in mils per year. 105

\section{Tables}

Table 2.1. Pull-test methods assessed for new post-tensioning seven-wire strand cables . 
Table 2.2. Pristine PT seven-wire strand cable pull-test peak results for 22 pull tests. ................... 24

Table 2.3. Additional data for pristine PT seven-wire strand pull tests. ............................................. 27

Table 5.1. Trend line mapping of extent data for full minimal area data set.................................... 47

Table 5.2. Trend line mapping of extent data for corroded-only minimal area data set................... 47

Table 5.3. Trend line mapping of extent data for full minimal diameter data set........................... 47

Table 5.4. Trend line mapping of extent data for corroded-only minimal diameter data set............ 48

Table 5.5. Basis for standard error of minimum wire area data...................................................... 51

Table 5.6. Basis for standard error of minimum wire diameter data. ................................................5 51

Table 6.1. Corrosion rates for different $\mathrm{pH}$ levels at different temperatures for carbon steel tendon wires (after Charng and Lansing 1982)................................................................................59

Table 6.2. Corrosion of tendon wires in different environments with restricted access to

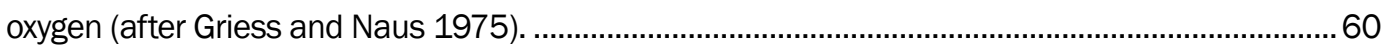

Table 6.3. Corrosion rates on coastal steel structures as a function of depth (after The Overseas Coastal Area Development Institute of Japan 2009).

Table 6.4. Mean, coefficient of variation (COV), and mean percentage loss (CLoss)* of

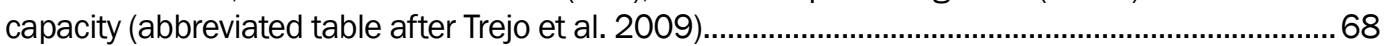

Table 6.5. Corrosion-rate criteria (after Lee and Zielske 2014).................................................... 73

Table 6.6. Divisors for different ranges on the normal distribution.....................................................8 88

Table 6.7. Darmawan et al. (2003-2010) base test results ...............................................................89

Table A.1. Optically Post-Processed, Pull-Test Results. ..................................................................110 


\section{Unit Conversion Chart}

\begin{tabular}{|c|c|c|}
\hline Multiply & By & To Obtain \\
\hline British thermal units (International Table) & $1,055.056$ & joules \\
\hline degrees (angle) & 0.01745329 & radians \\
\hline degrees Fahrenheit & $(F-32) / 1.8$ & degrees Celsius \\
\hline feet & 0.3048 & meters \\
\hline foot-pounds force & 1.355818 & joules \\
\hline inches & 0.0254 & meters \\
\hline inch-pounds (force) & 0.1129848 & newton meters \\
\hline microinches & 0.0254 & micrometers \\
\hline microns & $1.0 \mathrm{E}-06$ & meters \\
\hline mils & 0.0254 & millimeters \\
\hline kips (force) & $4,448.222$ & newtons \\
\hline pounds (force) & 4.448222 & newtons \\
\hline pounds (force) per foot & 14.59390 & newtons per meter \\
\hline pounds (force) per inch & 175.1268 & newtons per meter \\
\hline pounds (force) per square foot & 47.88026 & pascals \\
\hline pounds (force) per square inch & 6.894757 & kilopascals \\
\hline pounds (mass) & 0.45359237 & kilograms \\
\hline pounds (mass) per cubic foot & 16.01846 & kilograms per cubic meter \\
\hline pounds (mass) per cubic inch & $2.757990 \mathrm{E}+04$ & kilograms per cubic meter \\
\hline pounds (mass) per square foot & 4.882428 & kilograms per square meter \\
\hline pounds (mass) per square yard & 0.542492 & kilograms per square meter \\
\hline slugs & 14.59390 & kilograms \\
\hline square feet & 0.09290304 & square meters \\
\hline square inches & 6.4516 E-04 & square meters \\
\hline square miles & $2.589998 \mathrm{E}+06$ & square meters \\
\hline square yards & 0.8361274 & square meters \\
\hline tons (force) & $8,896.443$ & newtons \\
\hline tons (force) per square foot & 95.76052 & kilopascals \\
\hline yards & 0.9144 & meters \\
\hline
\end{tabular}




\section{Preface}

The investigation and report was authorized by Headquarters, U.S. Army Corps of Engineers (HQUSACE), and was performed from October 2013 to December 2014. It was published under the Navigation Systems Research Program, Work Unit "Probabilistic Assessment of the Reduced Capacity of Multistrand Post Tensioned Ground Anchorage Due to Tendon Corrosion.” Jeff McKee was the HQUSACE Navigation Business Line Manager. The Program Manager for the Navigation Systems Research Program was Charles Wiggins, Coastal and Hydraulics Laboratory (CHL), U.S. Army Engineer Research Development Center (ERDC). Jeff Lillycrop was Technical Director, CHL-ERDC. The research investigation was led by Dr. Robert M. Ebeling, Information Technology Laboratory (ITL), under the general supervision of Dr. Reed L. Mosher, Director, ITL; Patti S. Duett, Deputy Director, ITL. This work effort was also done under the general supervision of Dr. Robert M. Wallace, Chief, Computational Science and Engineering Division (CSED), ITL, during the initial laboratory testing stage. During the data interpretation and report writing stages, Elias Arredondo, Dr. Kevin Abraham, and Dr. Jerrell R. Ballard were Acting Division Chiefs. Ebeling was Principle Investigator of the "Probabilistic Assessment of the Reduced Capacity of Multistrand PostTensioned Ground Anchorage Due to Tendon Corrosion" work unit.

The ERDC Laboratory testing effort was led and conducted by James A. Evans, Richard W. Haskins, and Ernest L. Miller of the Sensor Integration Branch (SIB), ITL. The Sensor Integration Branch Chief is Dan Eng.

At the time of publication, COL Bryan S. Green was the Commander of ERDC, and Jeffery P. Holland was Director. 


\section{Introduction}

\subsection{Introduction to the problem and this phase of research}

Over the past five decades, the U.S. Army Corps of Engineers (USACE) has worked to upgrade its projects by installing high-capacity, post-tensioned foundation anchors. One example is at John Day Lock and Dam, shown in Figure 1.1. John Day Lock and Dam Project is 216 miles upriver from the mouth of the Columbia River near the city of Rufus, OR. These stressed steel tendons were used to strengthen hydraulic structures and improve their serviceability and stability. Each John Day anchor head (Figure 1.2) contains 37 seven-wire strand cables that were locked-off at approximately 1,518 kips, or $70 \%$ of the Specified Minimum Tensile Strength (SMTS) (Ebeling et al. 2012, 2013). The goal has been to achieve structural stability for Corps hydraulic concrete structures and/or to remediate cracked concrete monoliths. Remediation of hydraulic structures (e.g., locks, dams, approach walls, etc.) using post-tensioning (PT) seven-wire strand cables is a common approach. In Portland District, for example, $10 \%$ of the projects have multistrand anchors installed. Substantial improvements to protect multistrand anchor systems from corrosion have been made since they were first used in Corps projects more than 50 years ago, but the corrosion of older multistrand anchorage systems is still a major concern (Figure 1.2). Due to the high cost of remediation of hydraulic structures by post-tensioned ground anchorage, the loss in capacity of the seven-wire strand cables due to corrosion is of high importance.

The Corps of Engineers completed detailed inspections and lift-off tests in 2003 and 2008 at John Day Lock. Cornforth Consultants (2009) discusses 21 lift-off tests conducted on the 37-strand anchors at John Day Lock in 2008 and the processing of these field measurements taken to assess current PT anchorage capacity and the state of the anchors. The lift-off testing procedure and these results were summarized in Heslin et al. (2009). Figure 1.3 summarizes these lift-off tests conducted on the south lock wall of John Day Lock. 
Figure 1.1. Post-tensioned anchorage system remediation of John Day Lock in 1981 using 73 tie-down anchors.

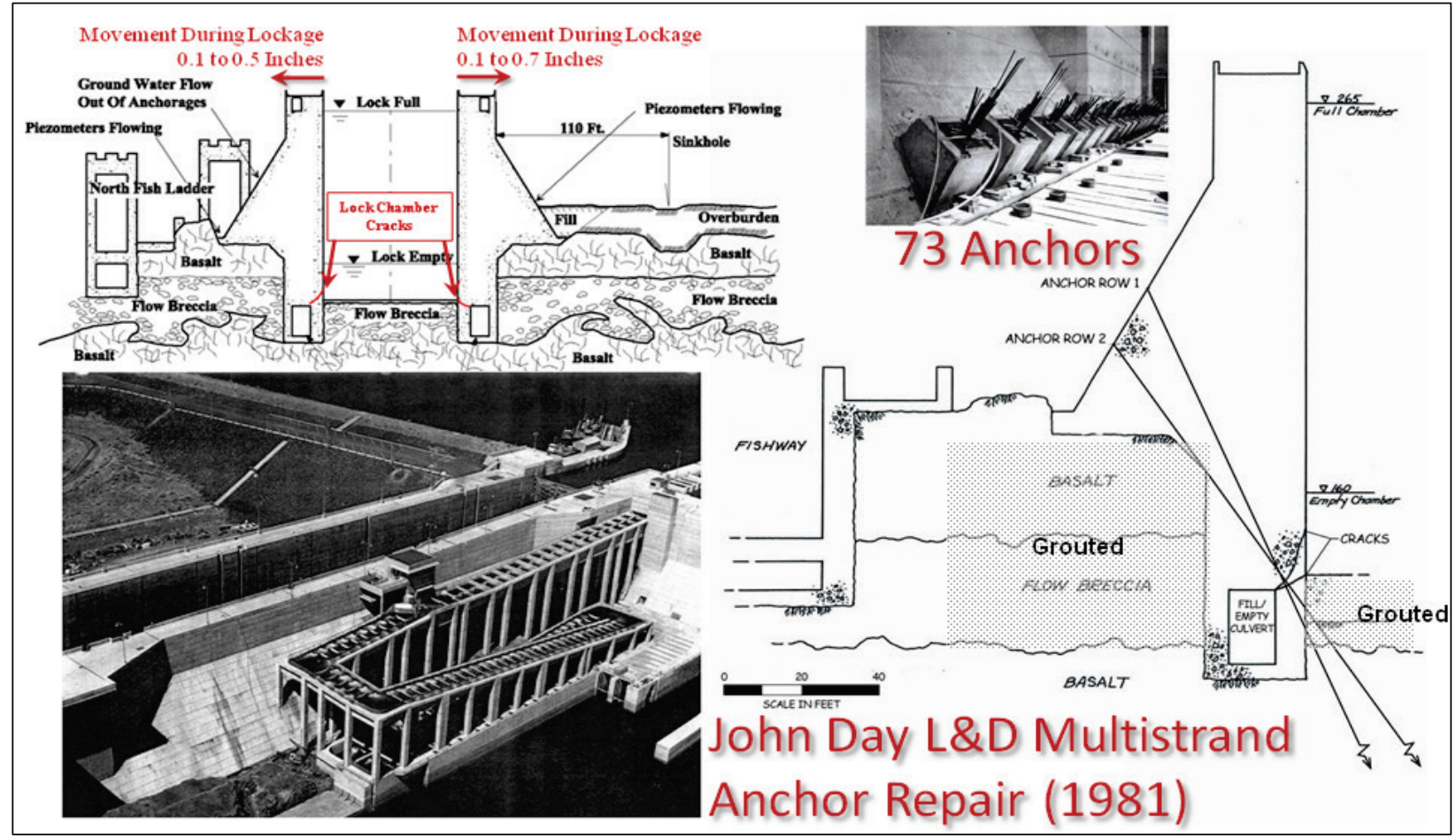

Cornforth Consultants (2009) and Heslin et al. (2009) discuss the threestage lift-off testing method. Figure 1.4 shows a typical lift-off test for the corroded anchor 11-32 that exhibits a reduced PT value of 920 kips.

Cornforth Consultants (2009) and Heslin et al. (2009) observe that the anchors can be grouped into damaged and undamaged tendons using visual inspection. For the anchors with undamaged tendons, the John Day lift-off loads were $85 \%$ to $90 \%$ of the values at installation due to stress relaxation. The damaged tendons had a significant reduction in PT from the PT value at installation. This can be seen in Figure 1.3 for the anchor measurements, which are highlighted in red and orange.

Portland District's assessment of the number of anchors with broken strands over time is shown at the middle right of Figure 1.2. The data indicate that more corroded strands will break over time; this observation is supported by the fact that inspections showed the number of anchors with visibly damaged strands increased by $11 \%$ between 2003 and 2008 . Cornforth Consultants' (2009) interpretation of 2008 John Day Lock data suggests that each year that passes would result in a $3 \%$ to $5 \%$ increase in the number of anchors with damaged strands. Heslin et al. (2009) observes that lift-off tests in 2008 had lift-off loads that were roughly $5 \%$ lower than the same anchors tested in 2003. 
Figure 1.2. The installation of a post-tensioned anchor system at John Day Lock, pictures of its (then) new anchor head and its current corroded anchor head spewing water, and rate of anchor loss with time due to corrosion.

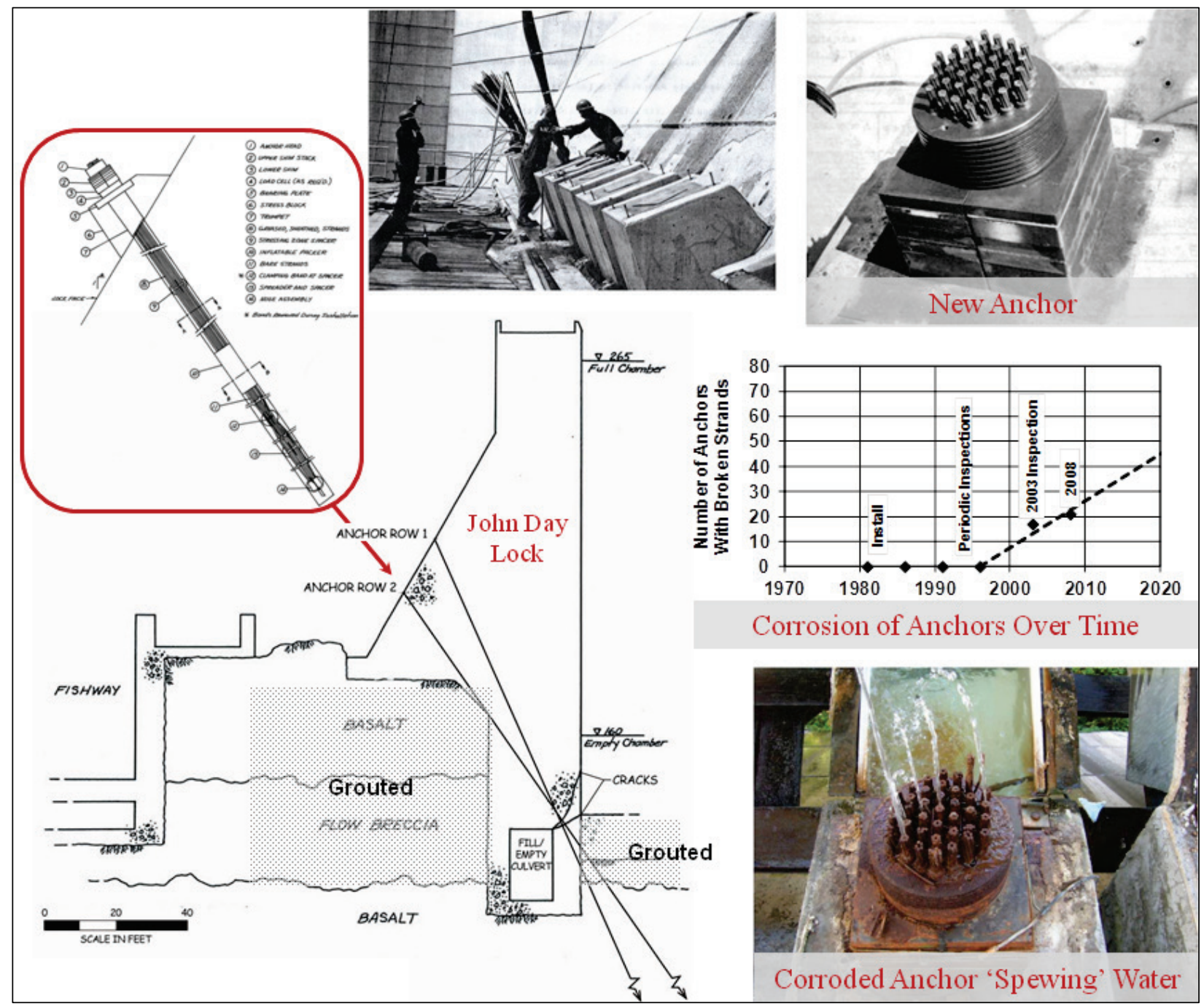


Figure 1.3. Inspection results for lift-off tests at the south lock wall at John Day Lock.



This report discusses recent advances in a laboratory-testing program to estimate PT seven-wire strand cable strength as a function of crosssectional material loss because of corrosion. Cable strength is measured by performing a pull test to failure on corroded specimens (Figure 1.5). An innovative morphological procedure using digital photography was developed for quantifying the geometrical properties of cable near their failure locations. A statistical assessment of pull-test data to failure of pristine and corroded cables is also included. An overview of corrosion rates for steel in various environments is also discussed. 
Figure 1.4. Example of a lift-off test for anchor 11-32 at the south lock wall at John Day Lock.

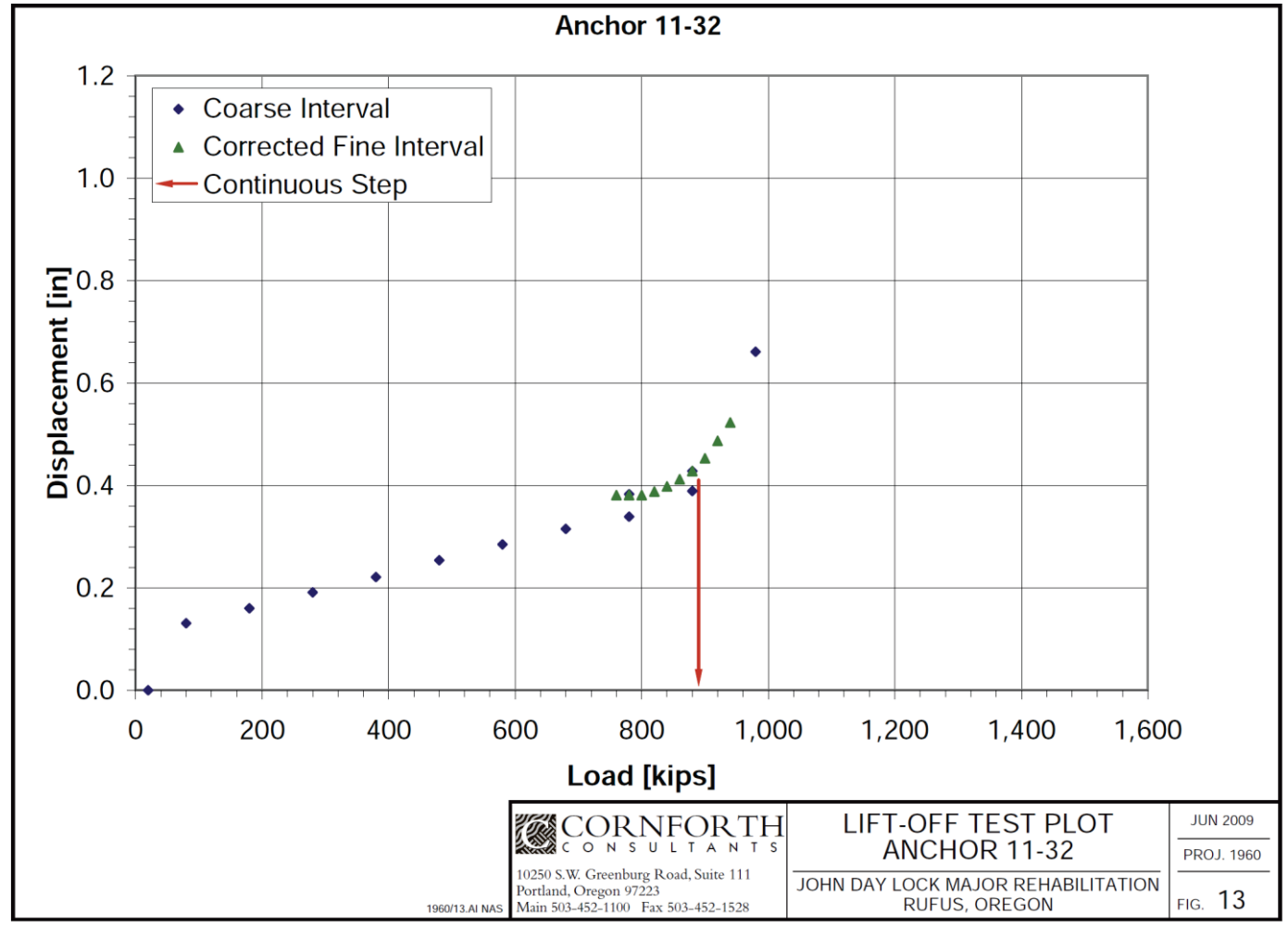

Figure 1.5. Results of pull tests to first failure of pristine and PT seven-wire strand cable with various levels of corrosion.

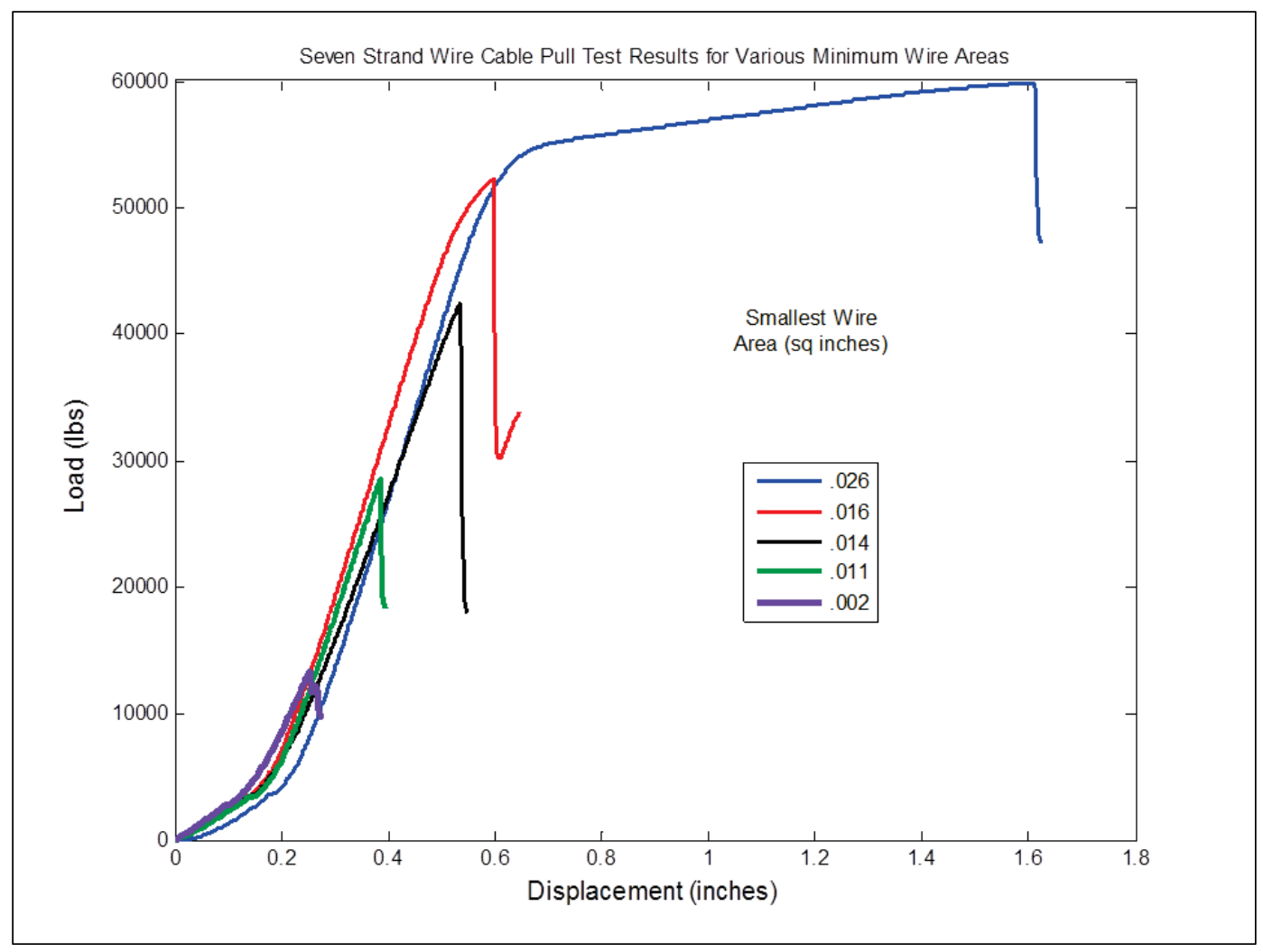




\subsection{Report Contents}

Chapter 2 discusses pull tests to failure conducted on pristine PT seven-wire strand cable. Also discussed in this chapter are twelve methods of gripping the cable, which were proposed and tested with the goal of binding the cable without rotation so that the cable would consistently break at a distance along the cable and away from the binding points.

Chapter 3 discusses the optical imaging system to determine morphological properties. This is needed because corrosion causes a change in the cross-section area and cross-section geometry of each strand of the PT seven-wire strand cable. This chapter summarizes Haskins et al.'s (2014) development of an innovative, yet practical, optical imaging system for scanning a pull-test specimen in order to assess the effect of the loss of cable cross-sectional area and alteration of cross-section geometry due to corrosion on the ability of the cable to withstand loads. It was applied successfully to 161 corroded pull-test cable specimens.

Chapter 4 discusses the U.S. Army Engineer Research and Development Center (ERDC) Laboratories accelerated corrosion procedure for a natural, yet accelerated form of cable corrosion used in this testing program.

Chapter 5 discusses the results for 22 pristine and 161 corroded PT sevenwire strand cable pull-tests to failure and the resulting statistical interpretation of the generated data.

Chapter 6 discusses research into corrosion-rate data and methods used for determining this rate. The corrosion process is discussed and the variables that affect multistrand cables are identified. Statistical procedures based on research and pull-test results are derived to estimate reduced cable capacity.

Chapter 7 provides a summary of research and the conclusions for this latest ongoing research effort. 


\section{Pristine Post-Tensioning, Seven-Wire Strand Cable}

\subsection{Seven-wire strand cable used in testing program}

Pull tests needed to be performed on pristine cable to establish baseline performance for the corroded specimen. These tests were performed on a Baldwin BLW 440,00o lb Universal Test Machine at the ERDC lab (Figure 2.1). The PT wires tested were 0.6 in. nominal diameter seven-wire strand cable. The American Society for Testing and Materials (ASTM) A416/A416M-12a standard states that this diameter wire cable must have a minimum breaking strength of $58,600 \mathrm{lbf}$. It also states that the steel area of the cable must be at least 0.217 in. ${ }^{2}$ and the difference in diameter between the central king wire and the outer cable can be no less than 0.004 in.

Figure 2.1 Pull tests performed on a Baldwin BLW 440,000 lb Universal Test Machine

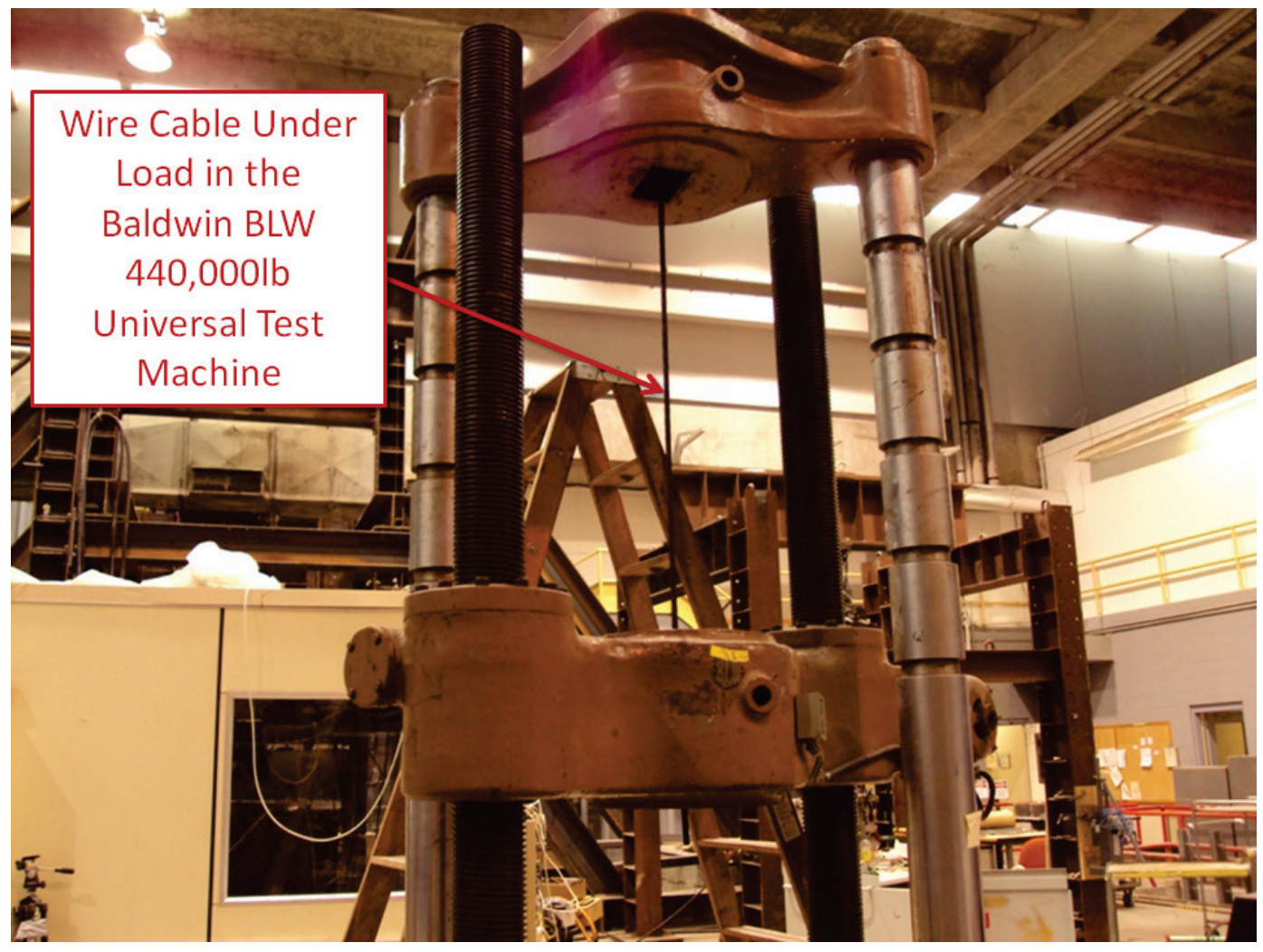


Bartoli et al. (2009) assumes that the diameters of the king wire and outer wires are the same, at 0.2 in., despite the ASTM constraints. This satisfies the ASTM area requirement, but not the difference measures. The authors of this report found that for the cable used in the ERDC test program, a 0.2 in. diameter is very close to accurate for the individual wires of the cables used in testing. Bartoli et al. (2009) also assumes a lay angle along the king wire for the outer wires of 7.9 degrees defining the twist about the king wire.

Measurements of the pristine cables ${ }^{1}$ at ERDC gave a king wire diameter of $0.204 \mathrm{in}$. and the area was calculated from this diameter with a value of 0.032685 in. ${ }^{2}$. The outer wires of the pristine cable had a diameter of 0.198 in. (0.006 in. difference from the king wire) and an area of 0.030791 in. ${ }^{2}$. The smaller diameter outer wires allow them to be twisted around the king wire and meet the ASTM difference requirement. Summing the areas of the 7 wires ( 1 king wire and 6 outer wires) gives a total area of 0.21743 in. ${ }^{2}$ for the entire cable, which is greater than the ASTM nominal area. The twist angle was assumed to be near the Bartoli value of 7.9 degrees, which has a bearing on the sonic wave research, discussed in Haskins et al. (2014). Because the difference of diameter was so small between the measured wire diameter (0.198 in.) and the Bartoli et al. (2009) estimate (0.2 in.), with a change of $0.002 \mathrm{in}$, a diameter of $0.2 \mathrm{in}$. was used in the statistical analysis of the pull-test results, with an extremely low change of accuracy.

\subsection{ERDC laboratory testing}

The pristine cables were very homogeneous, with very little variation along the length of the cable. This homogeneity complicated the pull testing because of how the cable needed to be gripped at the ends, where the tension load was applied to the cable. In order for these tests to provide the necessary information, the cable needed to break on an undamaged part of the cable and away from the wedges. However, the wedges provided by the manufacturer have serrations inside the wedge to better grip the cables. This feature complicated matters for a strand cable; when the ERDC testing team first tried to break the pristine cables, the serrations bit into the cable. With all the gripping pressure being concentrated in this small area, the wedge "bite" caused the cables to break at the wedges.

\footnotetext{
1 The post-tensioning, seven-strand wire cable was purchased from DYWIDAG Systems International, USA, Inc. at 320 Marmon Drive, Bolingbrook IL, 60440
} 
Preston (1985) observed that premature failure of the PT seven-wire strand cable occurs when using grips that are normally used for testing steel bars. These grips only have contact with a small part of the outside wires in a PT seven-wire strand cable. The resulting load per tooth from the grip is excessive and the wires fail in shear at a load below their actual tensile capacity. Each wire is more notch-sensitive than a steel bar. The true properties of a PT seven-wire strand cable can only be discovered if a proper gripping procedure is used that meets ASTM requirements.

\subsubsection{Gripping methods}

Twelve methods of gripping the cable were proposed and tested with the goal of binding it without rotation so that it would consistently break at a distance along the cable and away from the binding points (Table 2.1). These methods are discussed in more detail and illustrated below.

Table 2.1. Pull-test methods assessed for new post-tensioning seven-wire strand cables.

\begin{tabular}{|c|c|c|c|}
\hline Method \# & Method & Holding Method & Result \\
\hline 1 & Direct Pull Test & Wedges & Failure at wedge \\
\hline 2 & Epoxy & Wedges with quickset, steel-reinforced epoxy & Failure at wedge \\
\hline 3 & Epoxy Putty & Wedges with soft epoxy putty & $\begin{array}{l}\text { Squeeze putty out until failure } \\
\text { at wedge }\end{array}$ \\
\hline 4 & Mesh & Wedges with plastic-coated, aluminum mesh & $\begin{array}{l}\text { Cut through mesh and failure } \\
\text { at wedge }\end{array}$ \\
\hline 5 & $\begin{array}{l}\text { Copper Sheet } \\
\text { Buffer }\end{array}$ & $\begin{array}{l}\text { Wedges and } 6 \text { layers of } 0.0015 " \text { copper } \\
\text { sheet }\end{array}$ & $\begin{array}{l}\text { Some slippage and then } \\
\text { failure at wedge }\end{array}$ \\
\hline 6 & $\begin{array}{l}\text { Bronze Shim } \\
\text { Stock }\end{array}$ & $\begin{array}{l}\text { Wedges and one wrap of } 0.005 " \text { bronze shim } \\
\text { stock }\end{array}$ & $\begin{array}{l}\text { More slippage that copper } \\
\text { sheet buffer and then failure } \\
\text { at wedge }\end{array}$ \\
\hline 7 & $\begin{array}{l}30 \% \text { Wedge } \\
\text { teeth and epoxy }\end{array}$ & $\begin{array}{l}\text { Wedges with } 70 \% \text { teeth removal and } \\
\text { quickset, steel-reinforced epoxy }\end{array}$ & Cable slips free \\
\hline 8 & $\begin{array}{l}60 \% \text { Wedge } \\
\text { teeth }\end{array}$ & Wedges with $40 \%$ of teeth removal & $\begin{array}{l}\text { Cable slips then failure at } \\
\text { wedge }\end{array}$ \\
\hline 9 & $\begin{array}{l}60 \% \text { Wedge } \\
\text { teeth and epoxy }\end{array}$ & $\begin{array}{l}\text { Wedges with } 40 \% \text { teeth removal and } \\
\text { quickset, steel-reinforced epoxy }\end{array}$ & Failure at wedge \\
\hline 10 & $\begin{array}{l}\text { Altered wedge } \\
\text { with spread } \\
\text { wires }\end{array}$ & $\begin{array}{l}\text { Spreader bound in place to spread outside } \\
\text { wires from king wire, and wedge altered to } \\
\text { avoid stress concentration }\end{array}$ & Failure at wedge \\
\hline 11 & Grout & $\begin{array}{l}\text { Grout placed about cable in } 2 " \text { OD rigid } \\
\text { conduit }\end{array}$ & $\begin{array}{l}\text { Grout went to powder and the } \\
\text { cable was able to twist in } \\
\text { place until breaking occured }\end{array}$ \\
\hline 12 & $\begin{array}{l}\text { Wet sand in } \\
\text { aluminum grips }\end{array}$ & $\begin{array}{l}\text { Wedges holding hammered aluminum grips } \\
\text { tight against wet, packed sand on the cable }\end{array}$ & Successful \\
\hline
\end{tabular}


Method 1: Perform a direct pull test. As expected, the serrations in the wedges "bit" into the cable when pressure was applied to the wedge. These small cuts into the cable caused it consistently to break at one of the wedges.

Method 2: Using a quickset, steel-reinforced epoxy as a cushion around the cable to reduce the bite of the serrations in the wedges (Figure 2.2). As pressure was applied, the wedges bit through the epoxy and the cable, causing the cable to consistently break at one of the wedges.

Figure 2.2. Pull-test results of PT seven-wire strand cable surrounded by a quickset, steel-reinforced epoxy and the wedges.

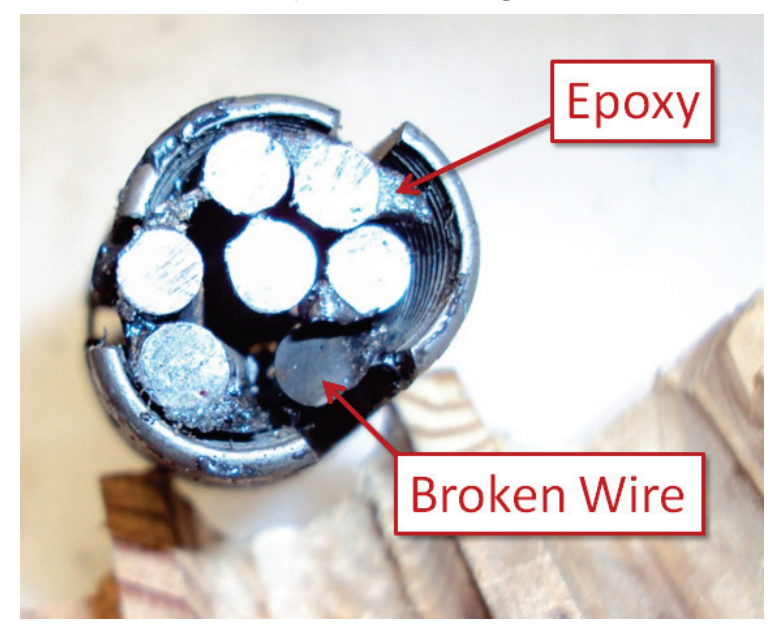

Method 3: Using a thick epoxy putty to act as a cushion around the cable to reduce the bite of the serrations in the wedges (Figure 2.3). As pressure was applied, the wedges eventually compressed the putty and bit through the epoxy and the cable, causing the cable to consistently break at one of the wedges.

Method 4: Using a plastic-coated aluminum wire mesh to act as a cushion around the cable to reduce the bite of the serrations in the wedges (Figure 2.4). In this case, the plastic coating was cut through and the wire provided additional stress on the cable, causing the cable to consistently break at one of the wedges. 
Figure 2.3. Pull-test results of PT seven-wire strand cable surrounded by epoxy putty and the wedges.

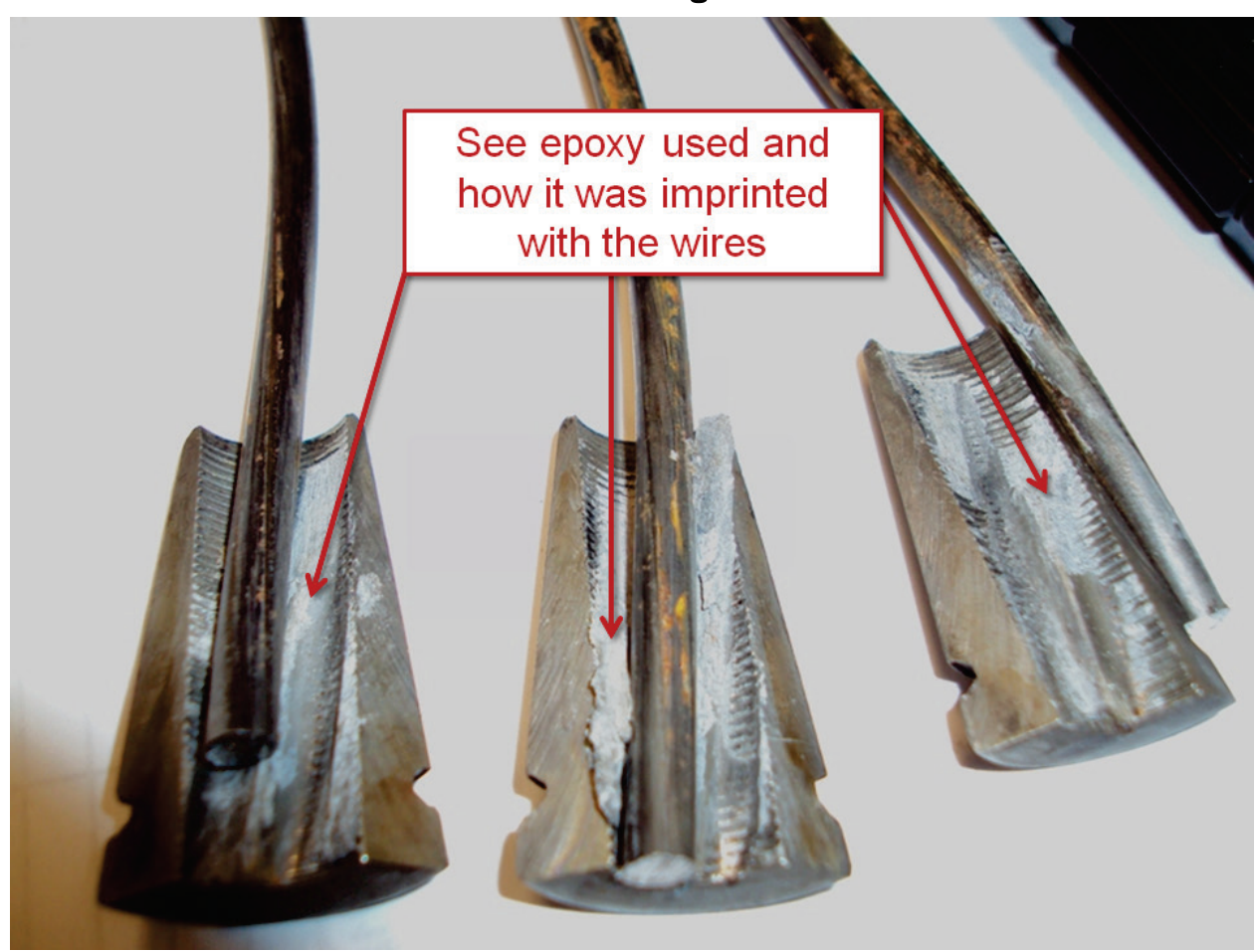

Figure 2.4. Pull-test results of PT seven-wire strand cable surrounded by aluminum wire mesh and the wedges.

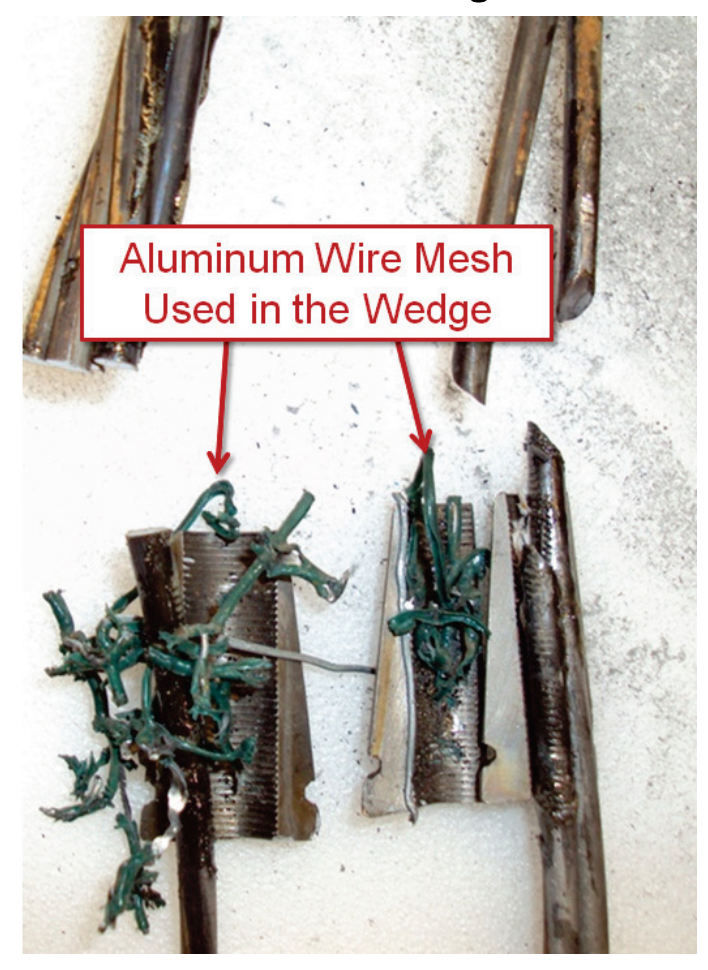


Method 5: Wrapping the cable with six layers of 0.0015 in. copper sheet to act as a cushion around the cable to reduce the bite of the serrations in the wedges (Figure 2.5). There was some slippage of the cable in the wedge with the copper sheathing, but as more load was applied, the slipping stopped. When slipping stopped, the cable was compressed, causing the cable to consistently break at one of the wedges.

Figure 2.5. Pull-test results of PT seven-wire strand cable surrounded by copper sheet layers and the wedges.

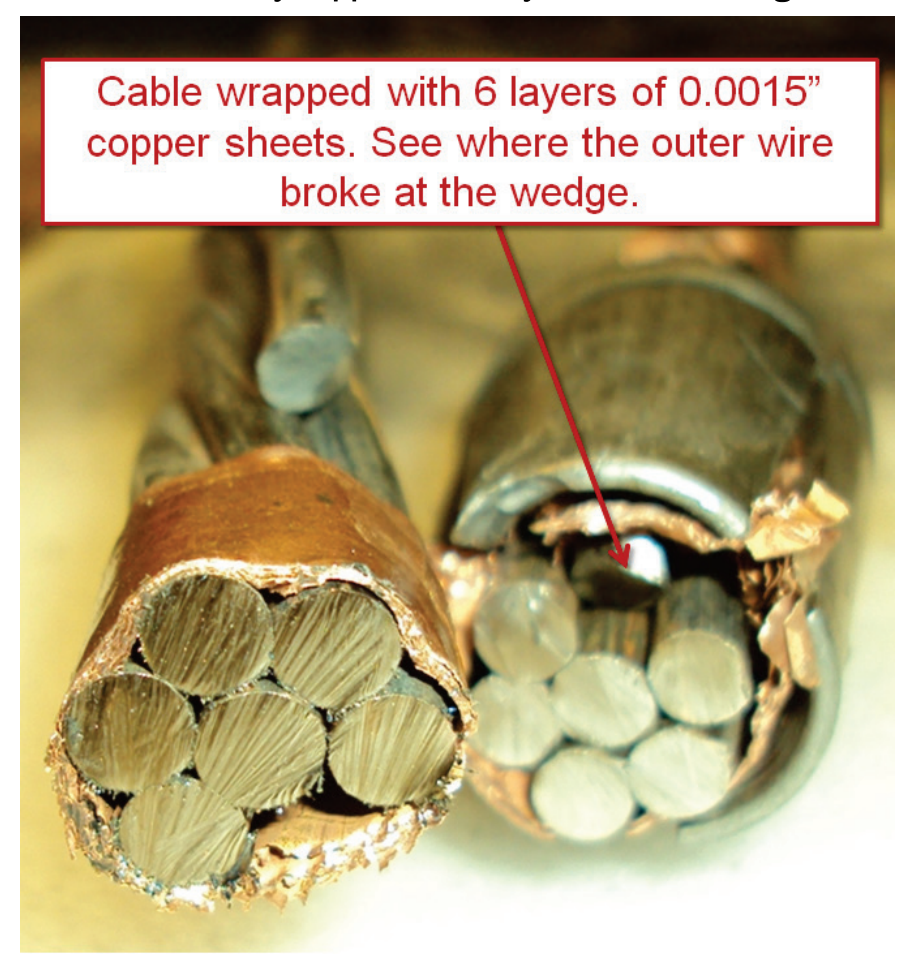

Method 6: Using one wrap of 0.005 in. bronze shim stock to act as a cushion around the cable to reduce the bite of the serrations in the wedges (Figure 2.6). Using this method, there was more slippage than with the copper sheet. However, the results were the same, with the serrations biting through the bronze shim and into the cable, causing the cable consistently to break at one of the wedges. 
Figure 2.6. Pull-test results of PT seven-wire strand cable surrounded by bronze shim stock and the wedges.

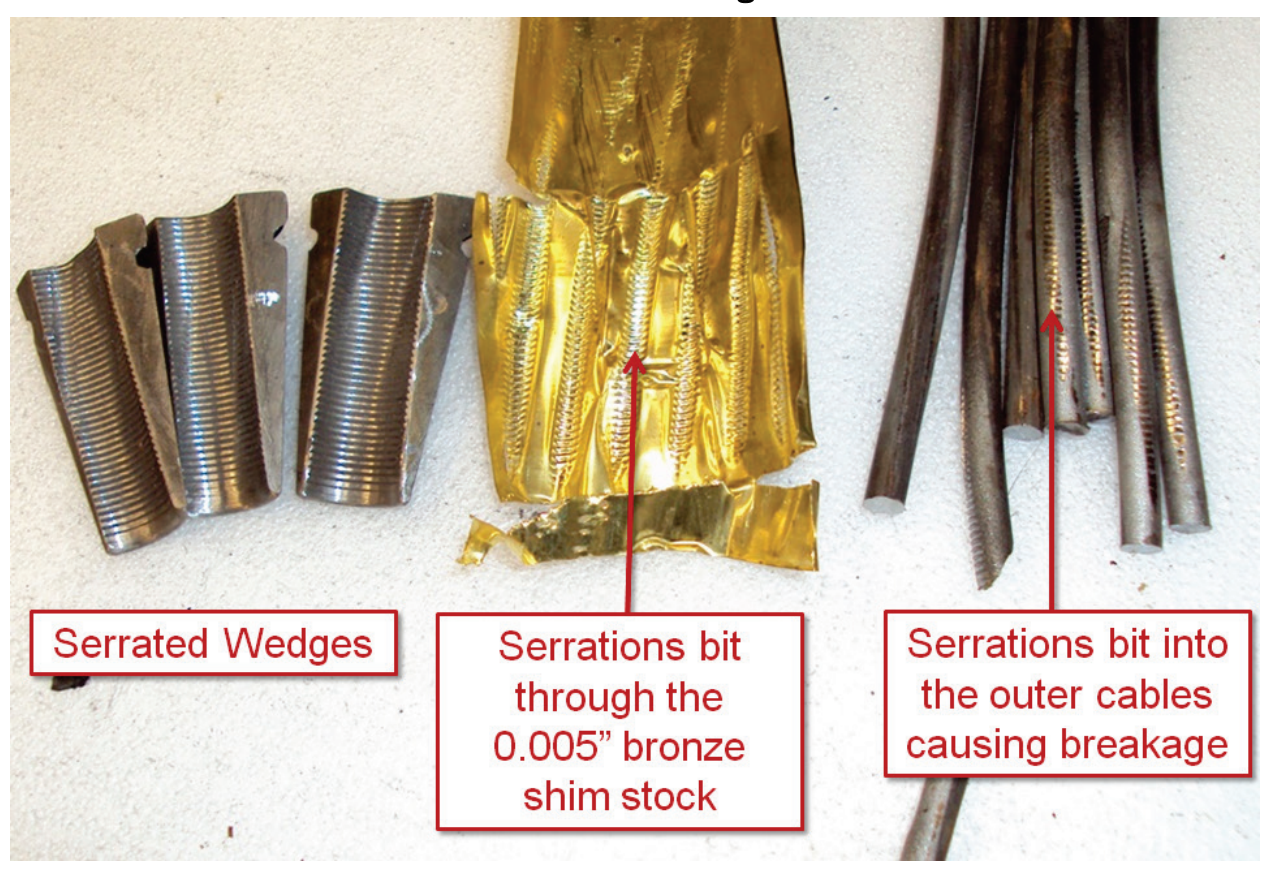

Method 7: Removing about 70\% of the serrations and using a quickset, steel-reinforced epoxy to secure the wedge (Figure 2.7). Without the serrations, the wedge could not grip the cable and the epoxy was not enough to keep the cable from slipping through the wedges.

Figure 2.7. Pull-test results of PT seven-wire strand cable surrounded by a quickset, steel-reinforced epoxy and $70 \%$ reduced wedges.

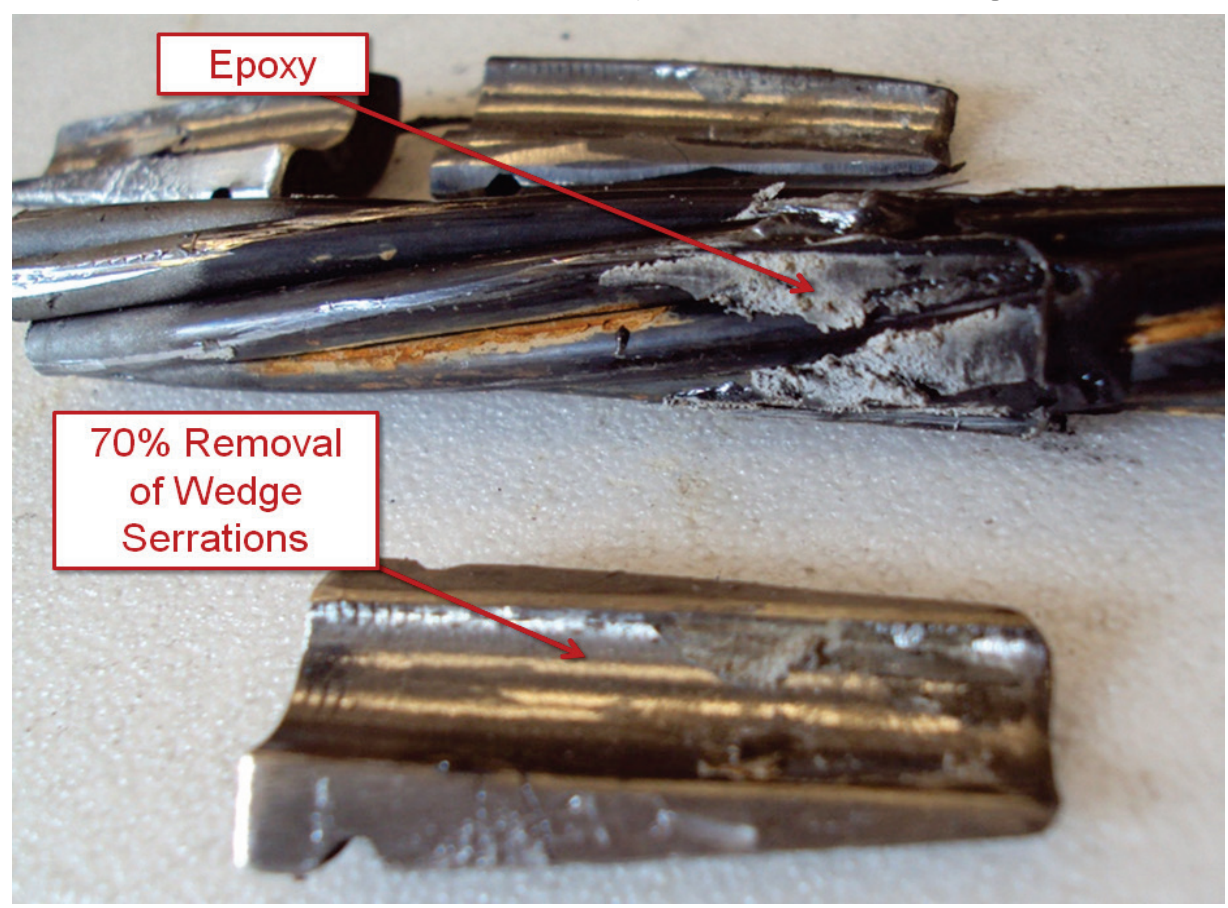


Method 8: Removing about 40\% of the serrations (Figure 2.8). There was a slight slippage of the cable in the wedge. When it gripped, the serrations bit into the cable, causing the cable to break consistently at one of the wedges.

Figure 2.8. Pull-test results of PT seven-wire strand cable with $40 \%$ reduced wedges.

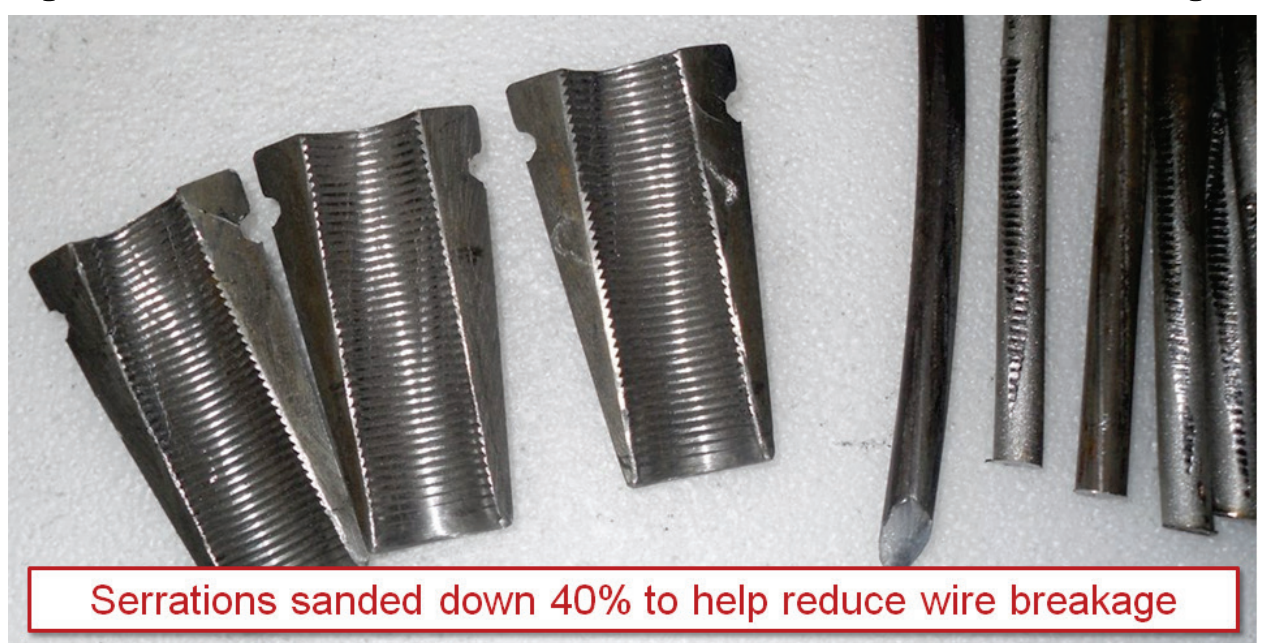

Method 9: Applying a thick coating of quickset, steel-reinforced epoxy used with new wedge with 60\% serrations (Figure 2.9). Allowed epoxy to seep into the individual wires on the cable and the epoxy ended up being 0.062 in. thick to keep serrations from biting into the cable, but this did not work. The serrations bit through the quick set epoxy and then the cable, causing the cable consistently to break at one of the wedges.

Method 10: Applying spreaders to flair the outer wires of the cable around the king wire so that the flared wire would bind further back in the wedge (Figure 2.10). The large back-end opening of the wedge was chamfered to reduce the possibility of a stress riser forming at the bind point (Figure 2.11). The inner part of the wedge was smoothed to prevent this as well. Unfortunately, this action weakened the previously used wedge, and resulted in the spread outside wires pushing into and breaking the wedge. In the first test, the first spreader had a long ramp and the second spreader had the same steep slope. The first test failed when the second spreader was pushed out of the cable (Figure 2.12). A second test was made with a longer second spreader hose clamp holding the spread wires to the spreader at the first and second end of the cable (Figure 2.13). The wires embedded themselves into the wedges and spreaders, but the assembly held (Figure 2.14). The cable still broke at the wedge. Notice the wedges and cables used in these tests had previously been used for failed pull tests. 
Figure 2.9. Pull-test results of PT seven-wire strand cable surrounded by a thick layer of quickset, steel-reinforced epoxy and with $40 \%$ reduced wedges.

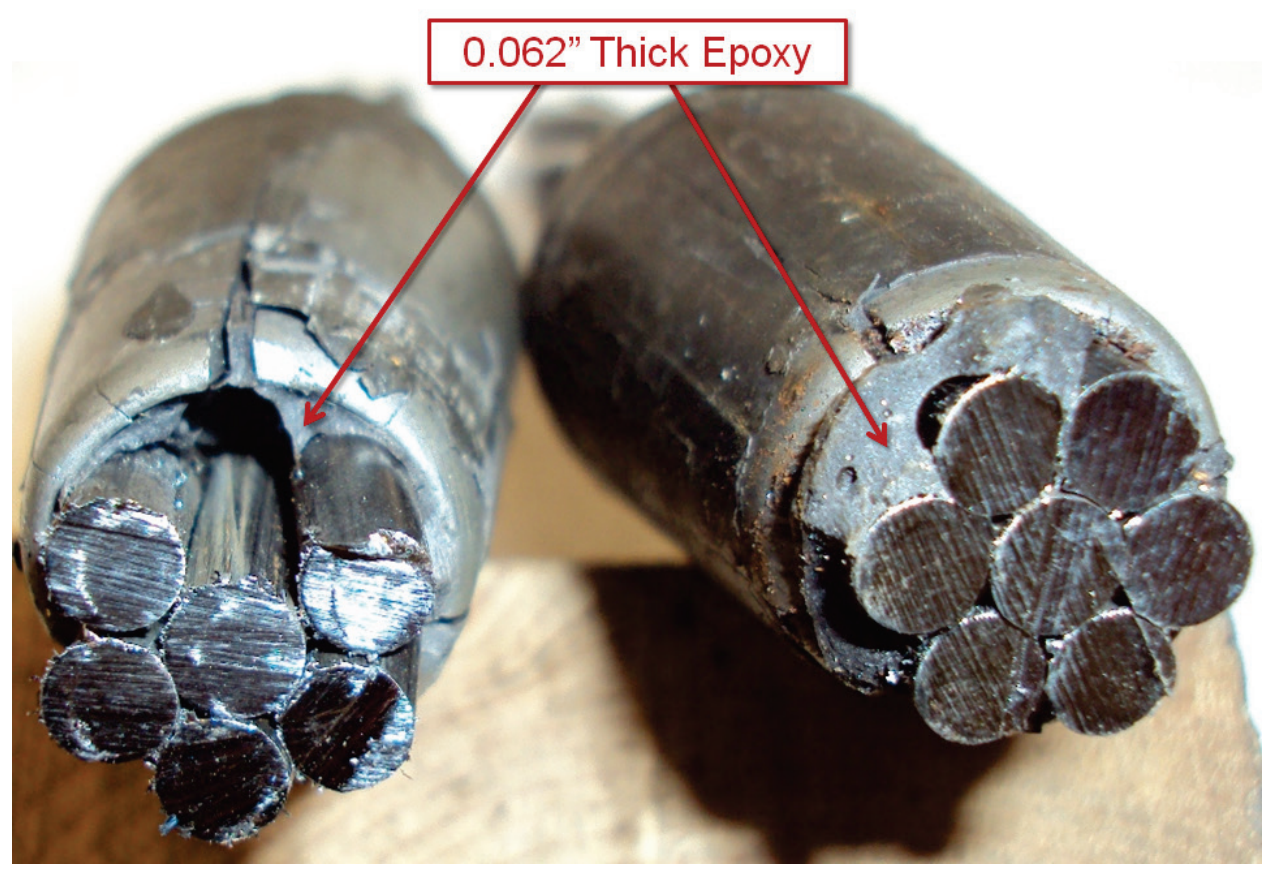

Figure 2.10. Spreader to be driven on the king wire with a steep slope.

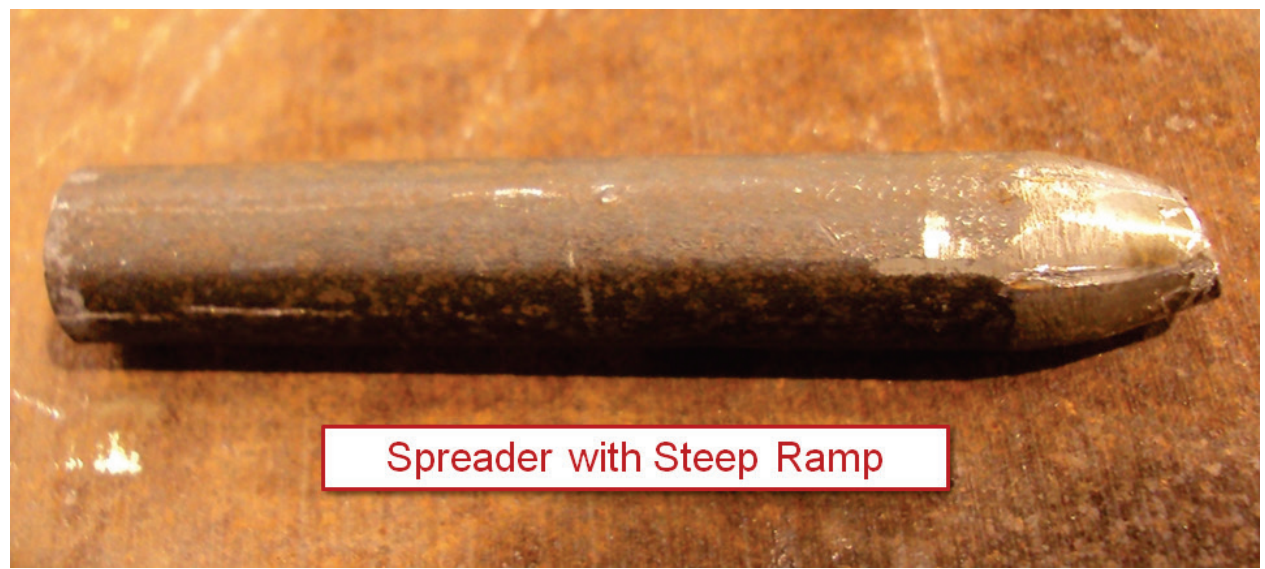


Figure 2.11. Altered wedge and wire with spreader after pull test.

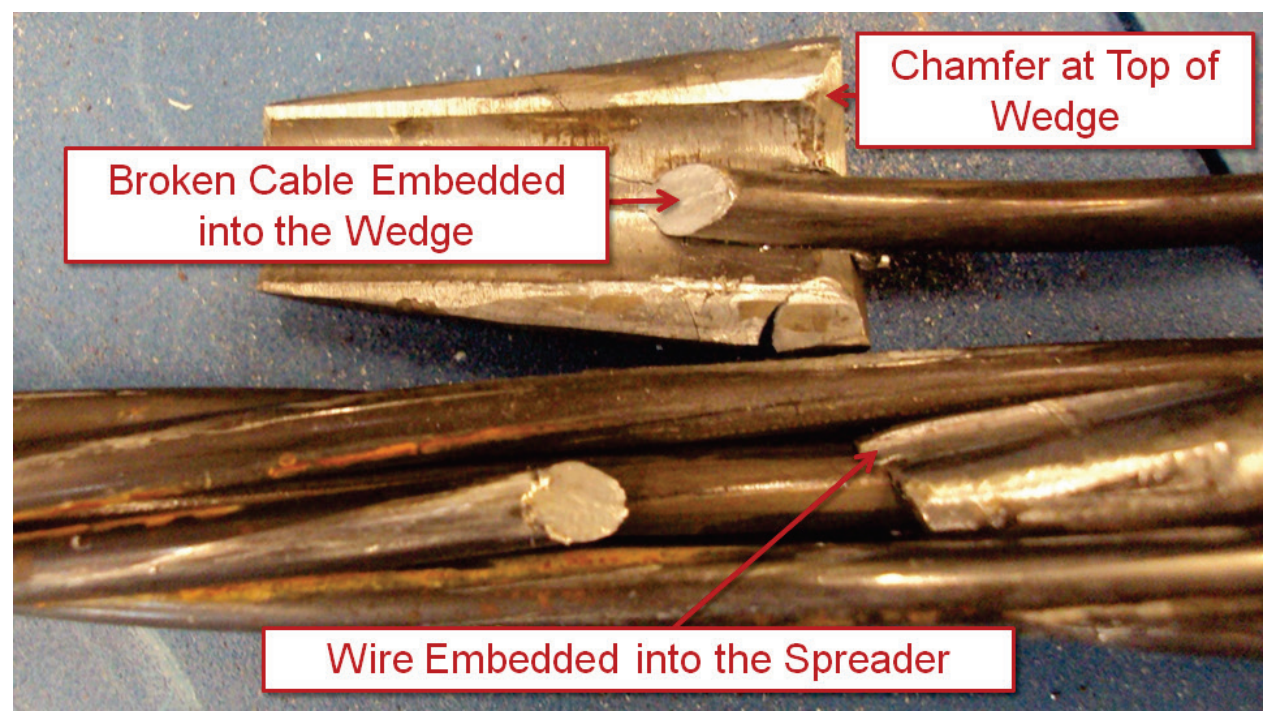

Figure 2.12. Connection details of wire with spreader and the interface with the wedge.

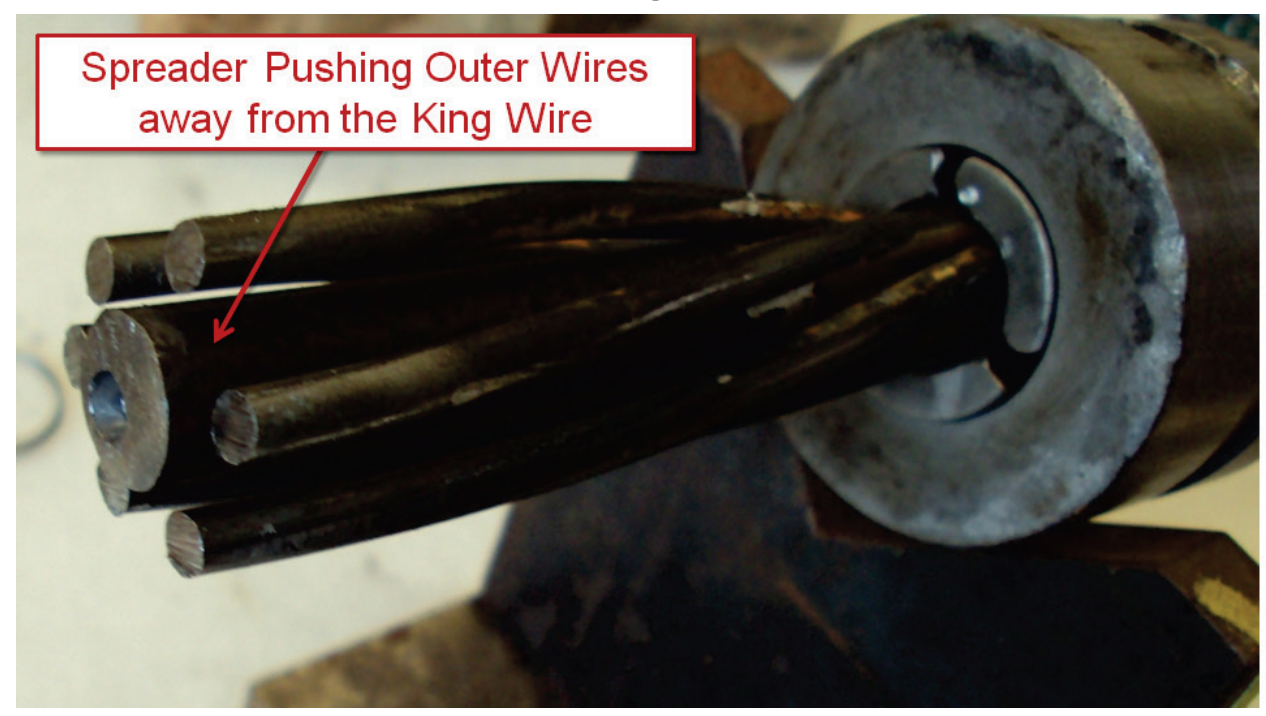


Figure 2.13. The addition of hose clamps to keep the spreader from being pushed off the king wire.

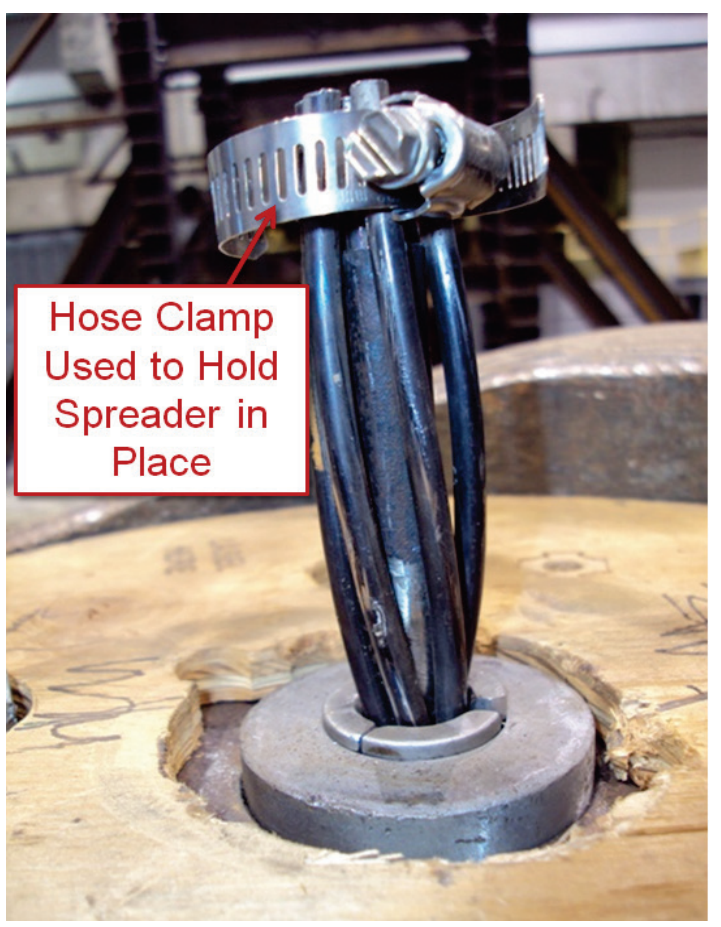

Figure 2.14. A better view of the spreader surrounding the king wire.

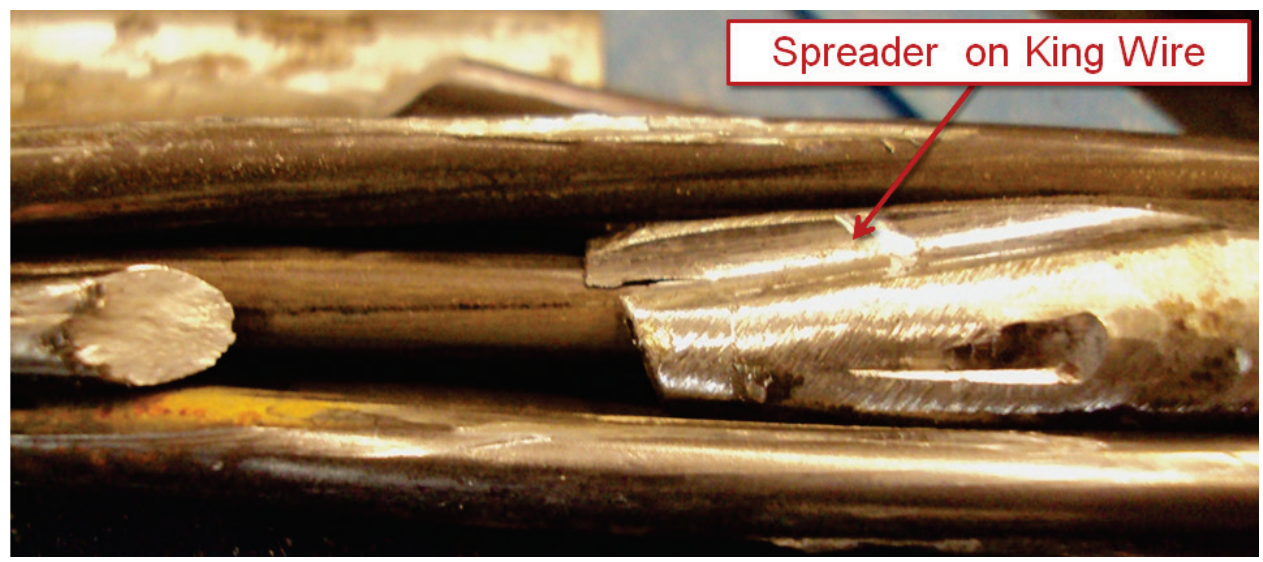

Method 11: Using a 2 in. outer diameter piece of rigid conduit $12 \mathrm{in.} \mathrm{long}$ with the cable placed through the center and grouted, with an expanding grout, into place (Figure 2.15). Additional effort was required to enable the pull tests with this setup (Figure 2.16a \& b). With this setup, the cable broke over $90 \%$ of the time near the middle. The only time involved after the conduit is cut to length will be the time required for the grout to set. Unfortunately, after the test, powdered grout was discovered. Cutting the conduit after a pull test revealed that the grout was turned to powder as the cable attempted to twist and unwind in the conduit sleeve (Figure 2.17). 
Because the cable was not kept taut, the test did not provide accurate results. Attempts were made to adjust the grout mixture in order to steady the cable to no success (Figure 2.18). Conversation with the grout manufacturers confirmed that the grout was behaving correctly in the circumstances.

Figure 2.15. PT seven-wire strand cable surrounded by grout and conduit.

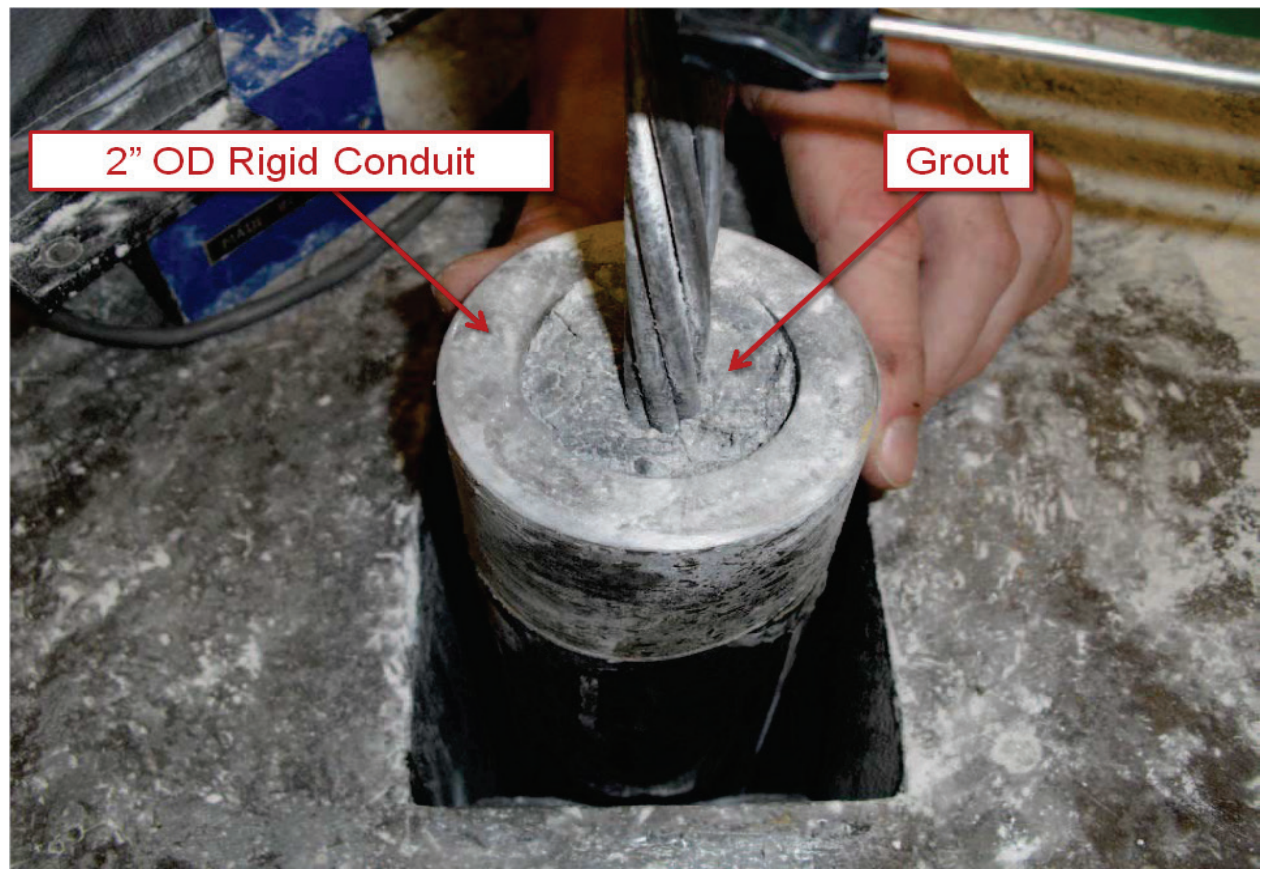

Figure 2.16. An adapter added to assist in wedging the grouted cable.

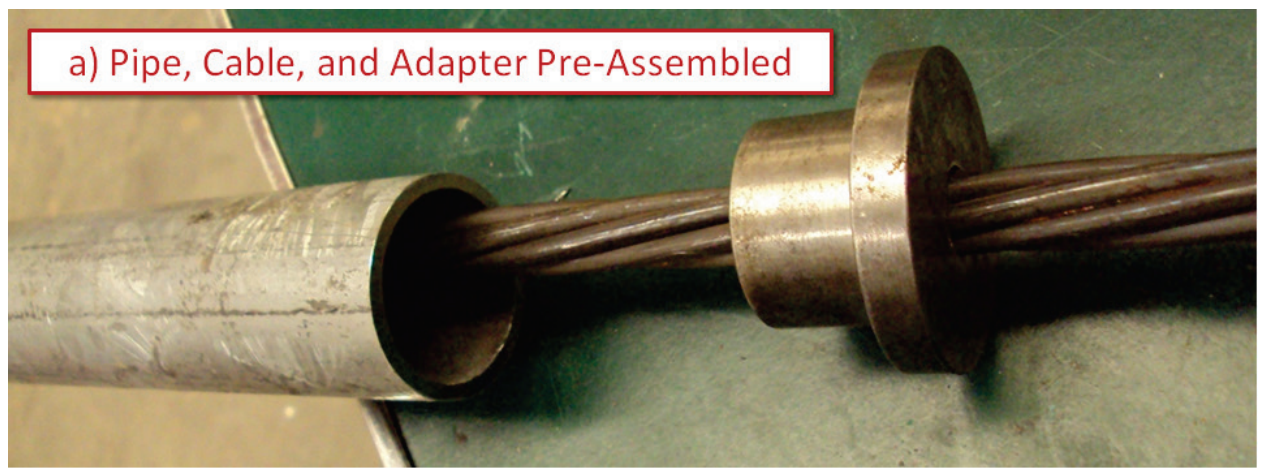

b) Pipe, Cable, and Adapter Assembled

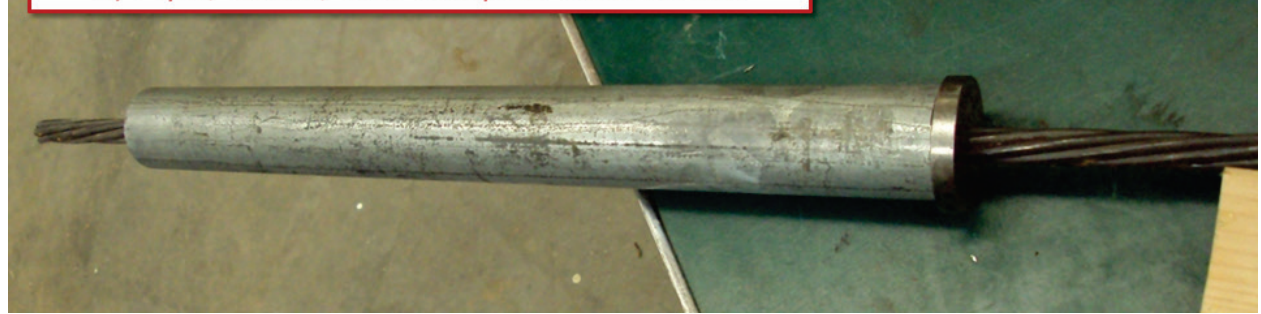


Figure 2.17. Examples of the grout turning to dust as the cable attempted to twist at the connection.

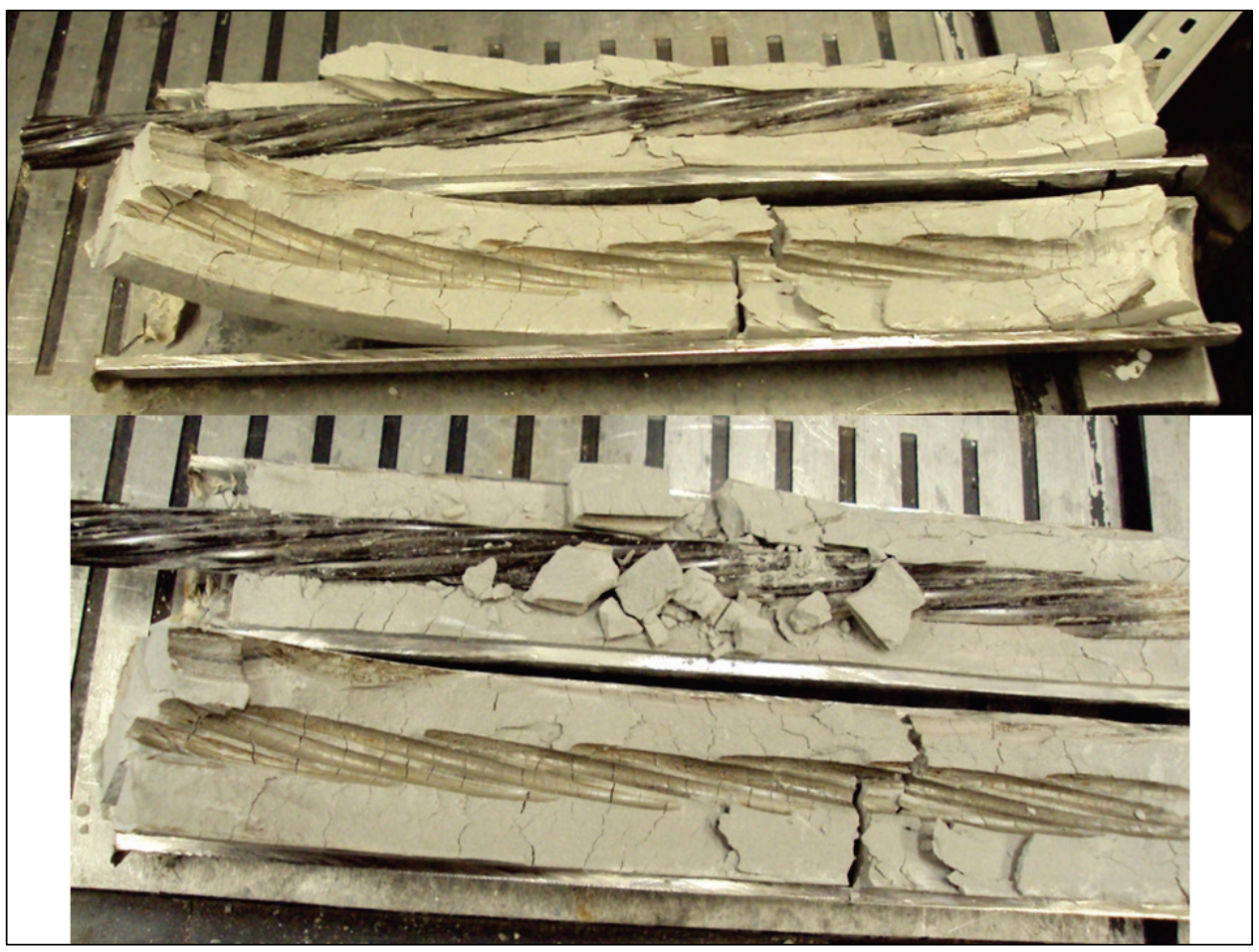

Figure 2.18. Tests made with different consistencies of grout.
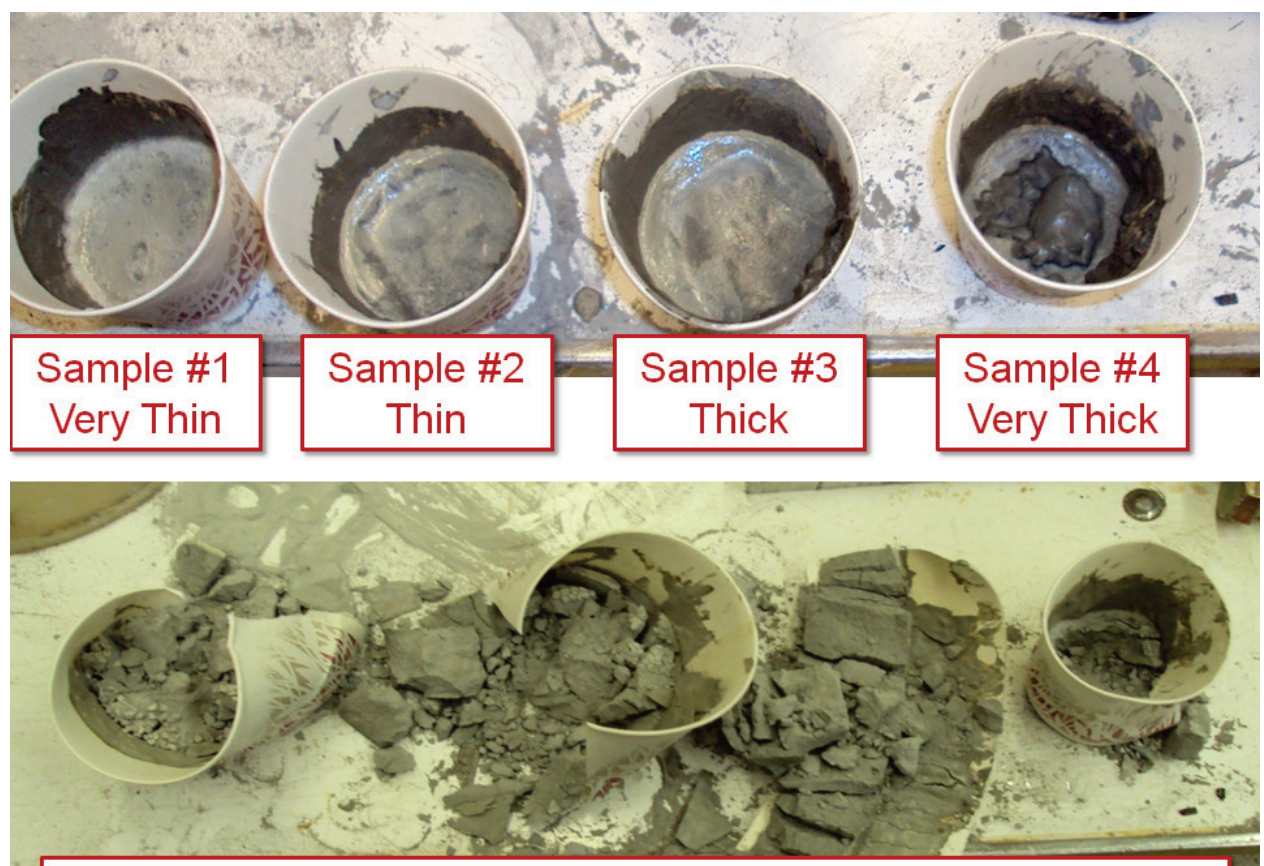

All Grout Consistency Samples Went Back to Powder 
Method 12: Based on the dissertation work of Robert Moser (2011), a light sand mixture was formed and bound around the cable with two aluminum strips formed into the shape of the wedges. Two 1.5 in. $x 8$ in. $x 0.125$ in. aluminum strips were shaped to the form of the large wedges seen in Figure 2.19. Hammering the aluminum strips into the wedges caused the scalloped indentations in the wedge to indent the aluminum, strengthening the grip of the aluminum strips within the wedge (Figures 2.19 and 2.20). Then light wet sand was mixed, formed around the cable, and the two aluminum pieces were cable-tied around the sand and cable directly across from each other (Figure 2.21). This method for gripping the pristine cable (Figure 2.22) produced consistent breakage in the middle part of the cable, but was very time consuming. In this case, the end length of cable was gripped by the aluminum and the sand enclosure was nearly $11 \mathrm{in}$. Cable failure occurred away from the grips. Then, the procedure was used on 22 pristine cable specimens. None of the failures occurred at the grips.

Figure 2.19. Hammering aluminum strips into the wedges to form grip points with the serrations.

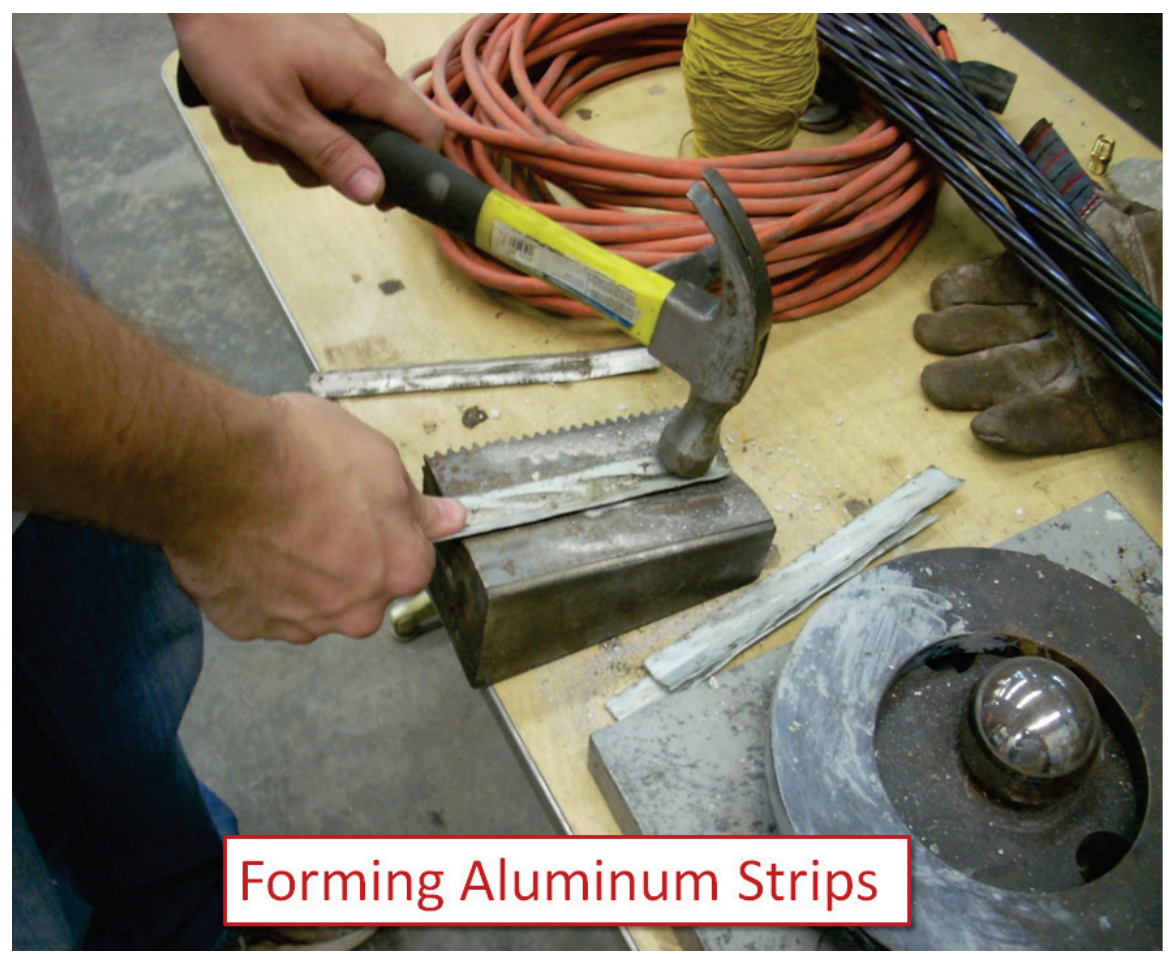


Figure 2.20. Hammered grip point details for the wedges. Note how the aluminum strip was hammered and the gripping surface, respectively.

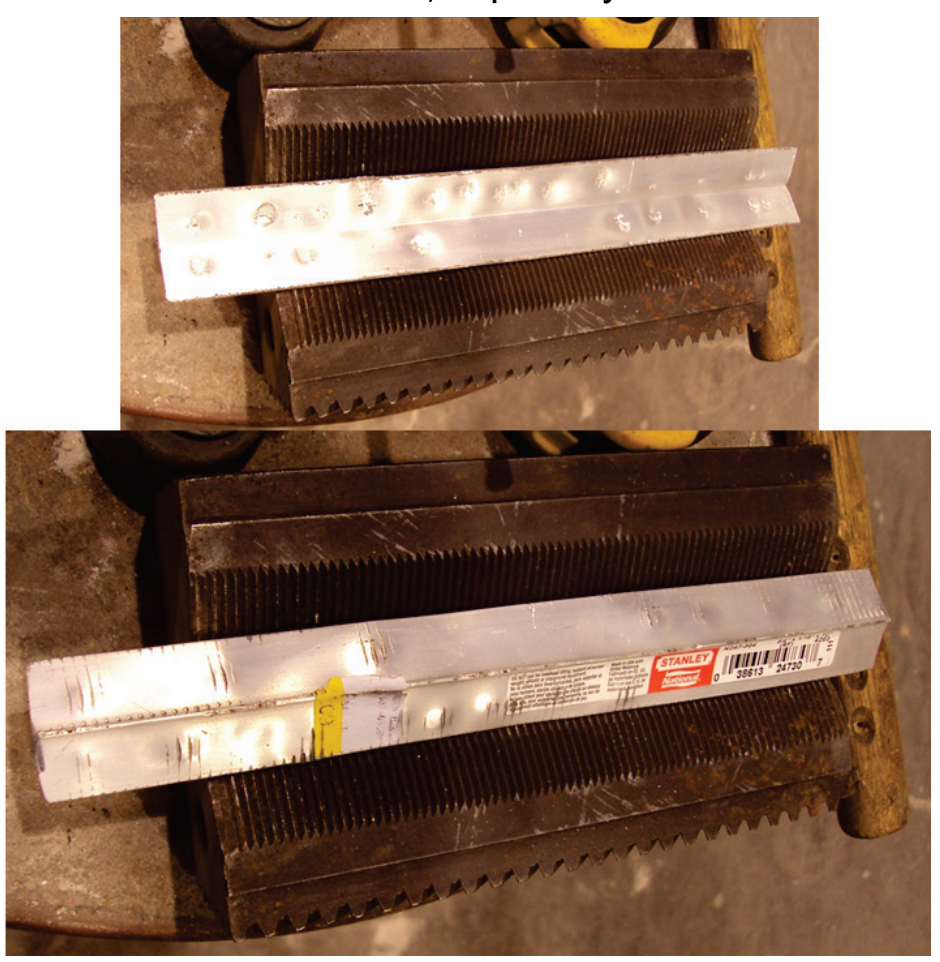

Figure 2.21. Detail of the cables being restrained with the aluminum strips and wet sand mixture.

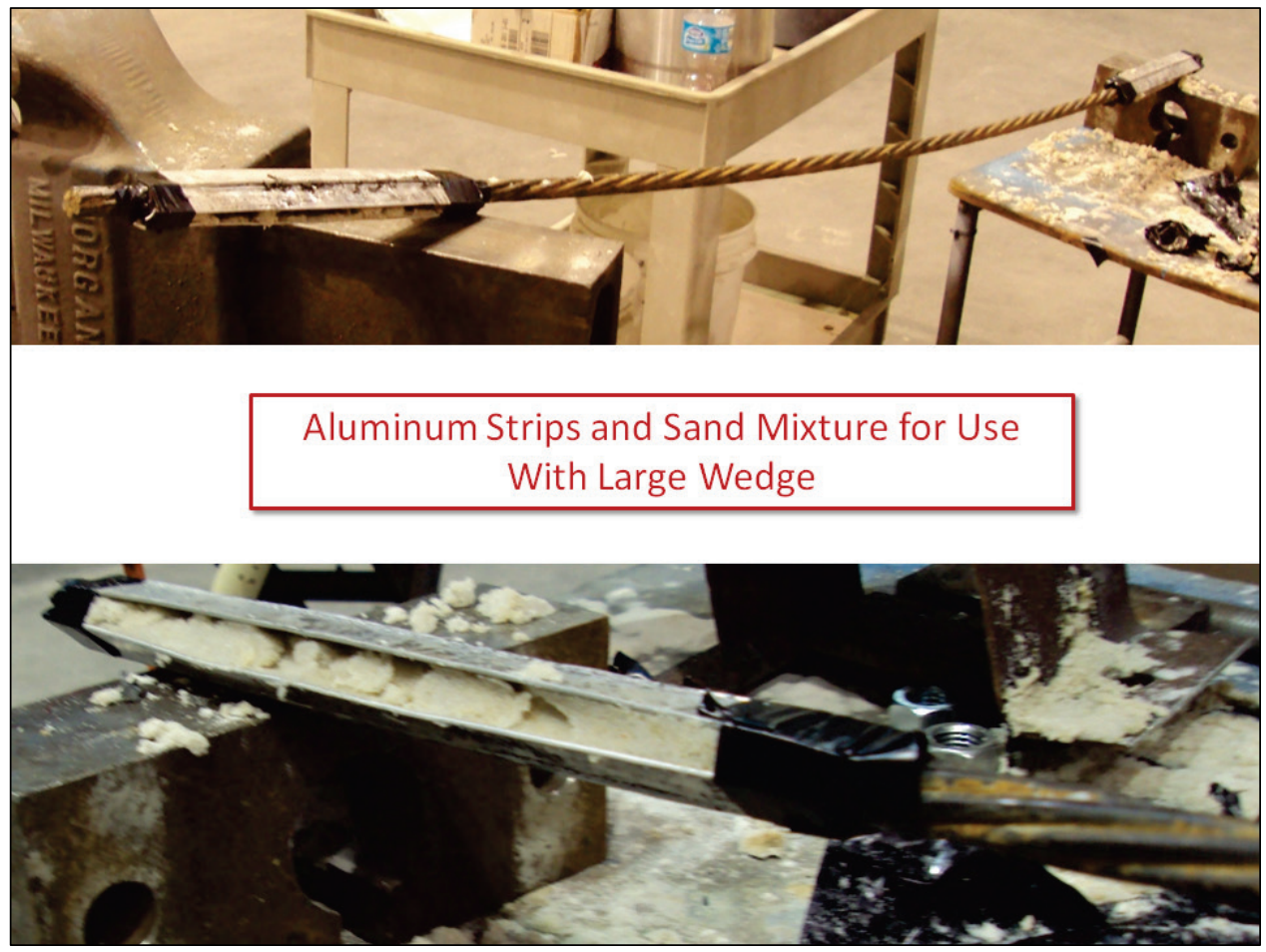


Figure 2.22. Aluminum strips with sand mixture restraining the PT seven-wire strand cable and being held in place by wedges.

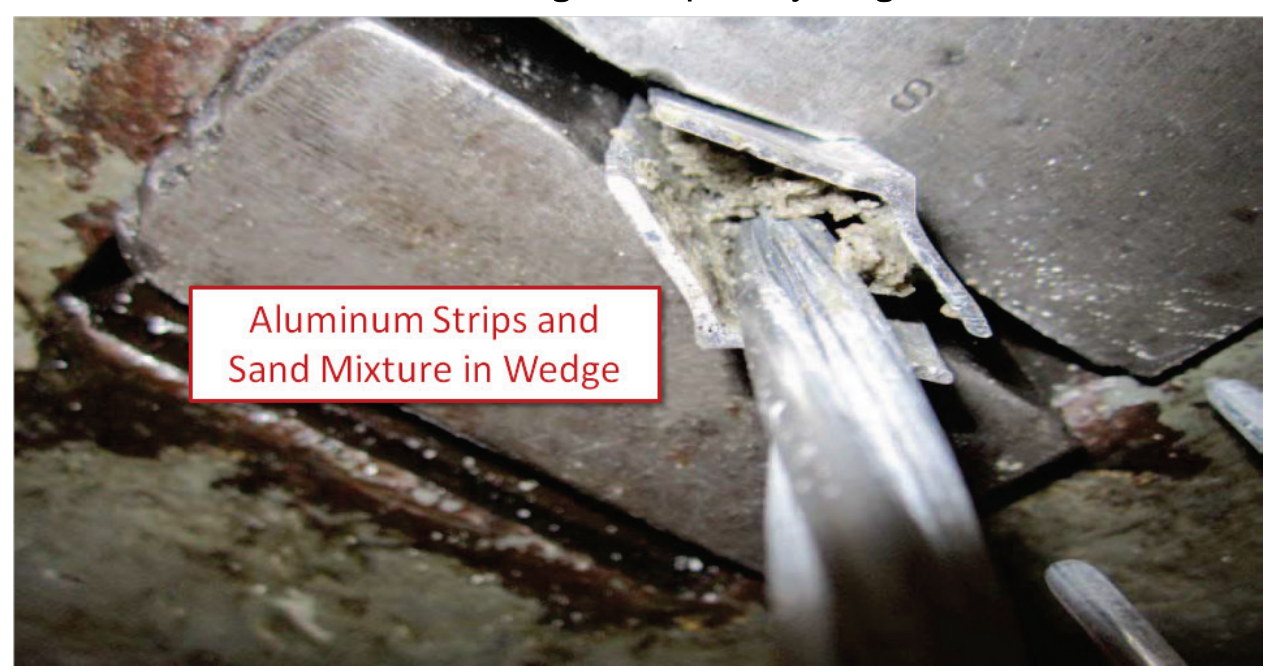

\subsubsection{Pull-Test Results}

Using the wedges with the aluminum strips bounding wet sand to grip the pristine cable, the pull tests were performed. As Figure 2.23 shows, when the cable separated, the strain immediately was released in the wires. The spring-back of this reaction caused the outer wires prior to the gripped end to unwrap about the king wire, forming a "bird cage" effect. The cable immediately below the birdcage simply slid along the king wire and kept its shape. Closer to the break point, the wires spread apart. Figure 2.24 shows a collection of successful pull tests with each end of the broken cable.

Figure 2.23. Example of “bird cage" effect for pulled cables.

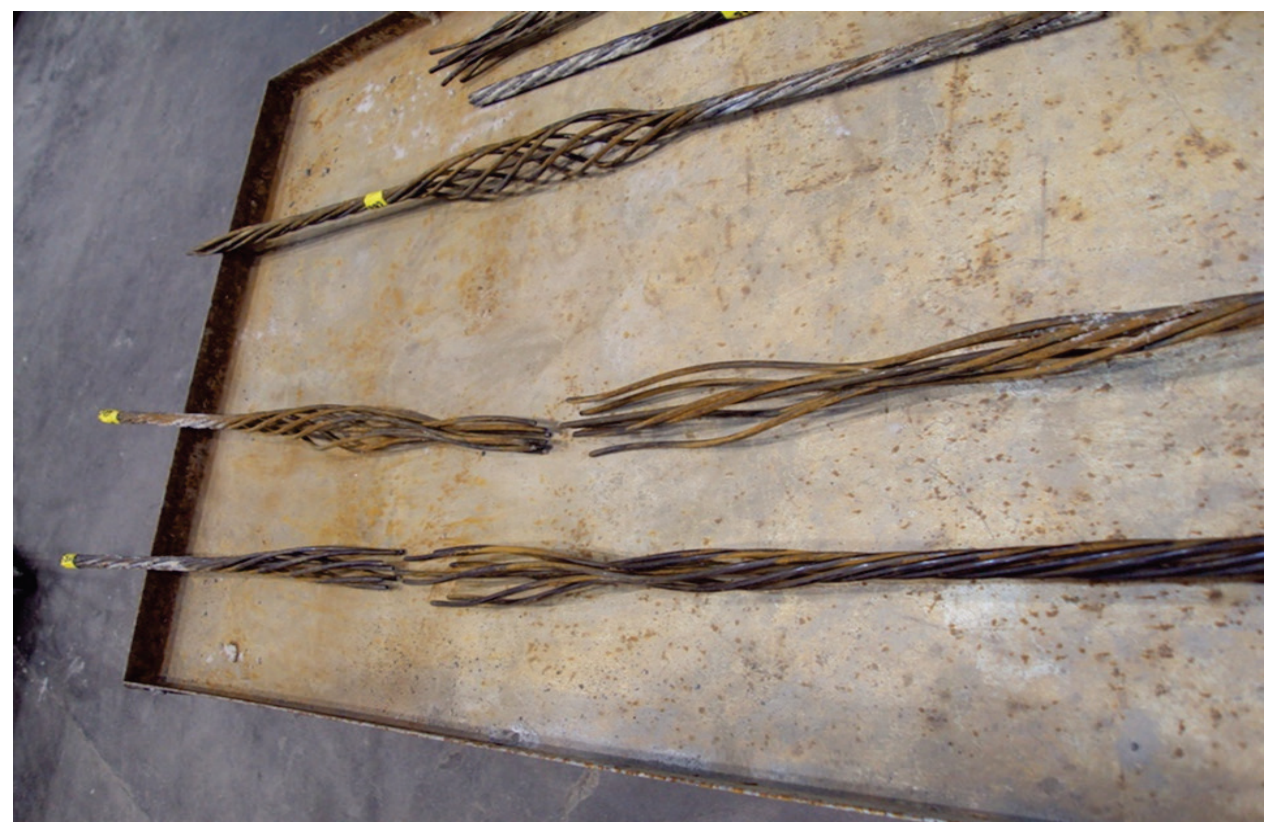


Figure 2.24. Successful pull-test results for corroded specimen.

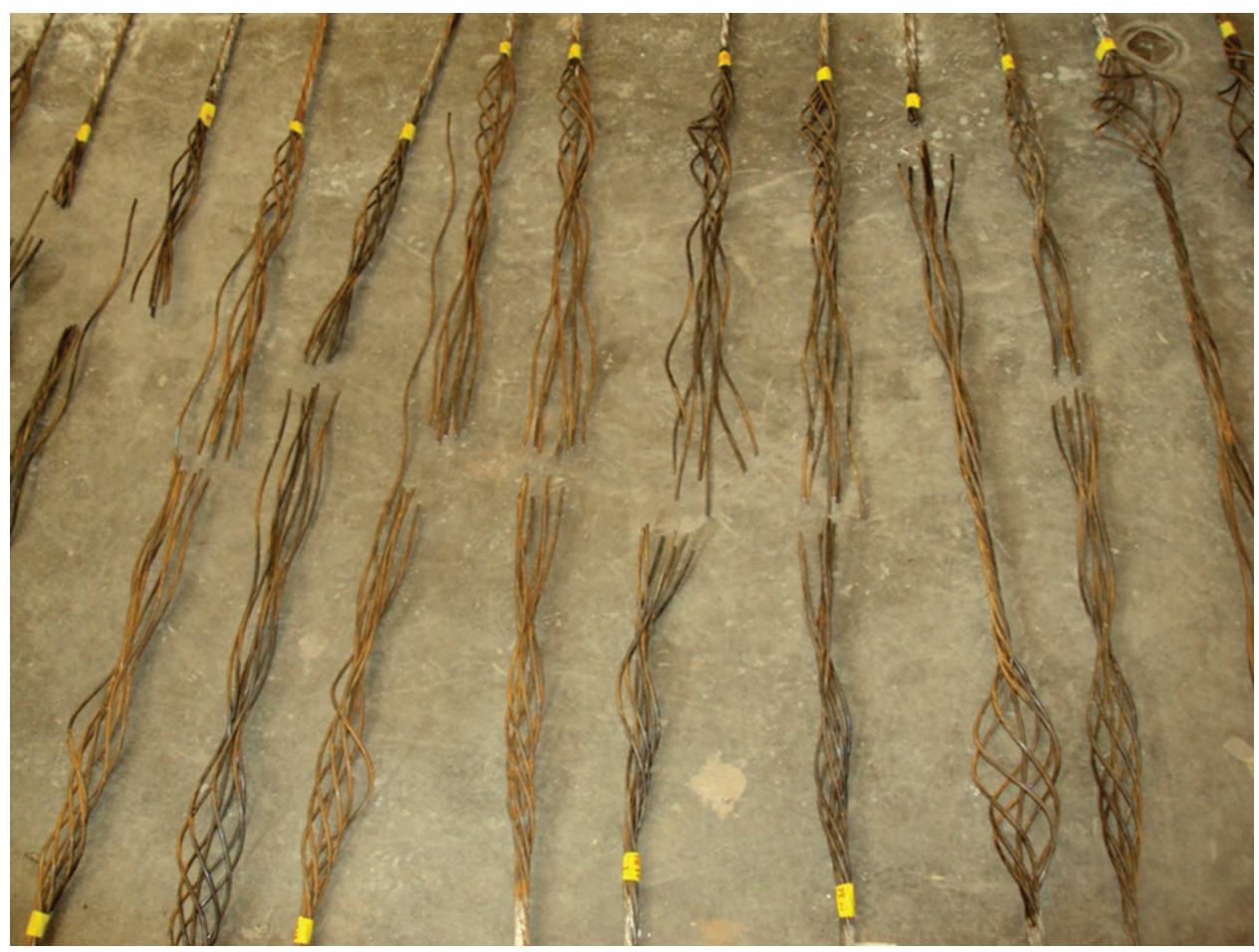

The pristine pull tests were completed with 22 successful cable pull tests to failure. The pull-tests resulted in PT seven-strand cable capacity values ranging from a low of $59,960 \mathrm{lb}$ to a high of $62,524 \mathrm{lb}$ (Table 2.2). The computed mean force for separation of the pristine PT seven-wire strand cable is $61,669 \mathrm{lb}$, with a standard deviation for the samples being $604 \mathrm{lb}$. The coefficient of variation (COV) equals 0.0098. Figure 2.25 shows a histogram of the pull-test results binned in 13 bins starting at a low number of $59,800 \mathrm{lb}$, with each bin range being $300 \mathrm{lb}$. The probability-density function is tallied by taking the number of samples that were counted in each bin range and dividing by a total number of 22 specimens. Observe that all 22 cables exceed the ASTM minimum breaking strength. Also displayed are the mean and pinned pull-test data at up to three standard deviations from the mean. Mapping a standard normal distribution to the data reveals that the data roughly follow that distribution.

Figure 2.26 shows the stress-versus-deformation plot for all of the pristine pull tests. Given the small range of deformation values, the curves for the successful pull tests are very similar. Table 2.3 lists additional testing information. 
Table 2.2. Pristine PT seven-wire strand cable pull-test peak results for 22 pull tests.

\begin{tabular}{|l|l|l|l|l|l|}
\hline Test Key & $\begin{array}{l}\text { Area } \\
\text { (sq. in.) }\end{array}$ & Tensile Strength & Peak Load (lb) & $\begin{array}{l}\text { Specimen Gauge } \\
\text { Length (in.) }\end{array}$ & Diameter (in.) \\
\hline CABLE PR-01 & 0.2181 & 284,760 & 62,106 & 56 & 0.527 \\
\hline CABLE PR-02 & 0.2181 & 284,420 & 62,032 & 56 & 0.527 \\
\hline CABLE PR-03 & 0.2181 & 285,760 & 62,324 & 56 & 0.527 \\
\hline CABLE PR-04 & 0.2181 & 284,520 & 62,053 & 54 & 0.527 \\
\hline CABLE PR-05 & 0.2181 & 285,150 & 62,191 & 52 & 0.527 \\
\hline CABLE PR-06 & 0.2181 & 284,180 & 61,980 & 52 & 0.527 \\
\hline CABLE PR-06-2 & 0.2181 & 286,680 & 62,524 & 52 & 0.527 \\
\hline CABLE PR-07 & 0.2181 & 284,770 & 62,108 & 52 & 0.527 \\
\hline CABLE PR-08 & 0.2181 & 283,100 & 61,745 & 52 & 0.527 \\
\hline CABLE PR-09 & 0.2181 & 280,620 & 61,204 & 52 & 0.527 \\
\hline CABLE PR-10 & 0.2181 & 283,590 & 61,851 & 52 & 0.527 \\
\hline CABLE PR-11 & 0.2181 & 283,360 & 61,800 & 52 & 0.527 \\
\hline CABLE PR-12 & 0.2181 & 283,480 & 61,827 & 52 & 0.527 \\
\hline CABLE PR-13 & 0.2181 & 283,620 & 61,857 & 52 & 0.527 \\
\hline CABLE PR-14 & 0.2181 & 281,390 & 61,371 & 52 & 0.527 \\
\hline CABLE PR-15 & 0.2181 & 274,940 & 59,964 & 52 & 0.527 \\
\hline CABLE PR-16 & 0.2181 & 276,810 & 60,373 & 52 & 0.527 \\
\hline CABLE PR-17 & 0.2181 & 281,450 & 61,385 & 52 & 0.527 \\
\hline CABLE PR-18 & 0.2181 & 283,010 & 61,725 & 52 & 0.527 \\
\hline CABLE PR-19 & 0.2181 & 282,010 & 61,507 & 52 & 0.527 \\
\hline CABLE PR-20 & 0.2181 & 282,950 & 61,711 & 52 & 0.527 \\
\hline CABLE PR-21 & 0.2181 & 280,020 & 61,073 & $61,668.68182$ & 52.63636364 \\
\hline Average & 0.2181 & $282,754.0909$ & & \\
\hline
\end{tabular}


Figure 2.25. Statistical distribution data of failure strength for 22 successful tests with a mapped normal distribution for comparison.

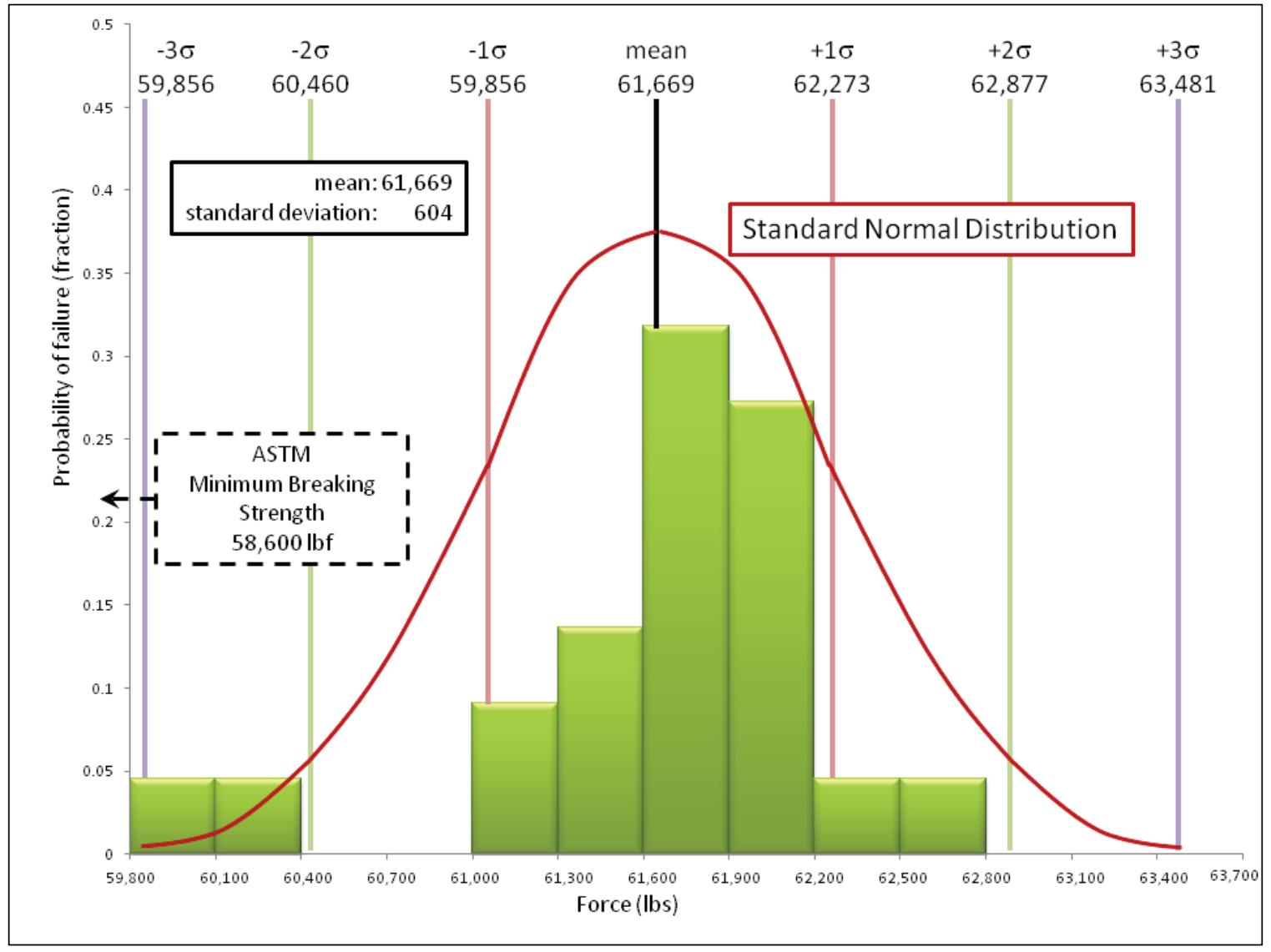


Figure 2.26. Pull tests were performed for a number of pristine samples, with uniform results for successful tests.

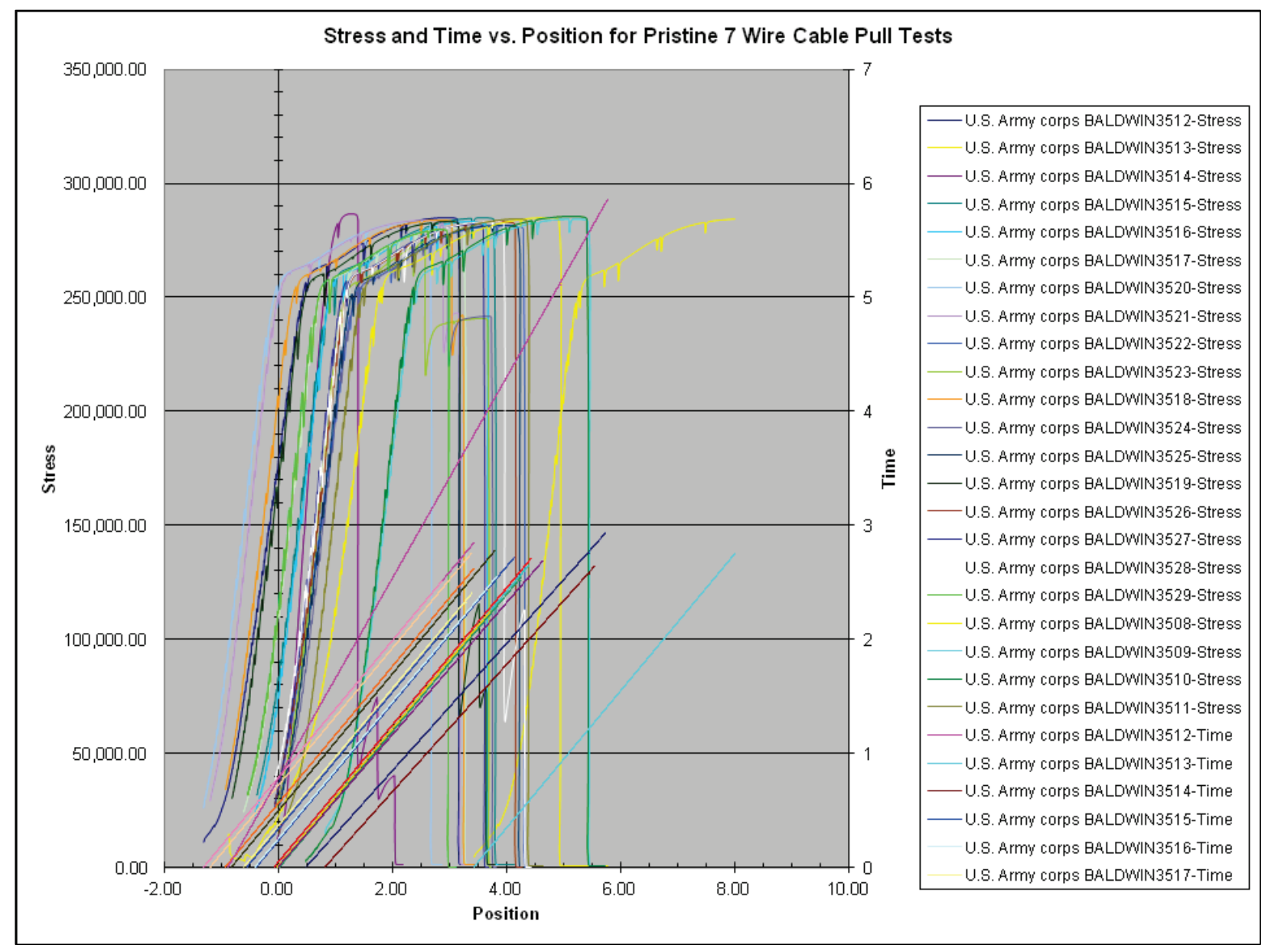


Table 2.3. Additional data for pristine PT seven-wire strand pull tests.

\begin{tabular}{|l|c|c|l|}
\hline \multicolumn{5}{|c|}{ Pristine Cable Pull Data } \\
\hline Cable \# & $\begin{array}{l}\text { Cable Break Point } \\
\text { (inches from bottom) }\end{array}$ & $\begin{array}{l}\text { Gauge Length } \\
\text { (in.) }\end{array}$ & Notes: \\
\hline PR-0 & 17 & 56 & \\
\hline PR-1 & 3 & 56 & \\
\hline PR-2 & $271 / 2$ & 56 & \\
\hline PR-3 & $161 / 2$ & 56 & \\
\hline PR-4 & 10 & 54 & \\
\hline PR-5 & 37 & 52 & \\
\hline PR-6 & 45 & 52 & \\
\hline PR-7 & 45 & 52 & \\
\hline PR-8 & 24 & 52 & \\
\hline PR-9 & 4 & 52 & \\
\hline PR-10 & $311 / 2$ & 52 & \\
\hline PR-11 & $311 / 2$ & 52 & \\
\hline PR-12 & $301 / 2$ & 52 & \\
\hline PR-13 & $291 / 2$ & 52 & 1 wire broke 1" from bottom \\
\hline PR-14 & 20 & 52 & \\
\hline PR-15 & $251 / 2$ & 52 & 1 wire broke 4" from bottom \\
\hline PR-16 & 25 & 52 & 1 wire broke 5" from bottom \\
\hline PR-17 & $91 / 2$ & 52 & \\
\hline PR-18 & $241 / 2$ & 52 & \\
\hline PR-19 & 44 & 52 & \\
\hline PR-20 & 11 & 52 & \\
\hline PR-21 & 7 & & \\
\hline & & 52 & \\
\hline
\end{tabular}




\section{Optical Imaging System to Determine Morphological Properties}

Corrosion causes a change in the cross-section area and geometry of each strand of the PT seven-wire strand cable. This chapter discusses the development of an optical imaging system for scanning a pull-test specimen in order to assess the effect of the loss of cable cross-sectional area and alteration of cross-section geometry due to corrosion on the ability of the cable to withstand loads.

\subsection{Optical scanning methodology}

The optical scanning method to determine the cross-section morphology properties is performed after a pull test. Pristine (non-corroded) samples were of such uniformity that optical scanning was not performed for the pristine pull tests.

The optical tests could not get the morphological data directly at the point of separation because of the plastic deformation of the wire when it started to separate, a process called "ductile necking." This ductile-necking region typically extended a few millimeters on either side from the point of separation. In addition, birdcage separation occurred at the point where the wire separated. In order to account for these effects, both sections of the separated wire were pulled together with clamps and the wires were cut immediately after the ductile-necking region. The two cut wires were polished and coated with white paint to increase the contrast for optical scanning, resulting in two optical scans with consequent morphological data for each pull test (Figure 3.1).

After the cables were pulled together, cut, and painted, each cable was placed in a tube that was black inside to ensure contrast when a light source was applied to the cut end of the cable. To calibrate the image, a thin dot template with a specific area was attached to the front of the cable and an image taken (Figure 3.2). This was done to prevent data loss due to imprecise positioning of the cable. Then the dot was removed without moving the cable, and an image was made of the cut end of the cable. 
Figure 3.1. Preparing a cable for optical scanning. The final cut and polished sample is on the left and a pulled-together, unsmoothed cable to the right.

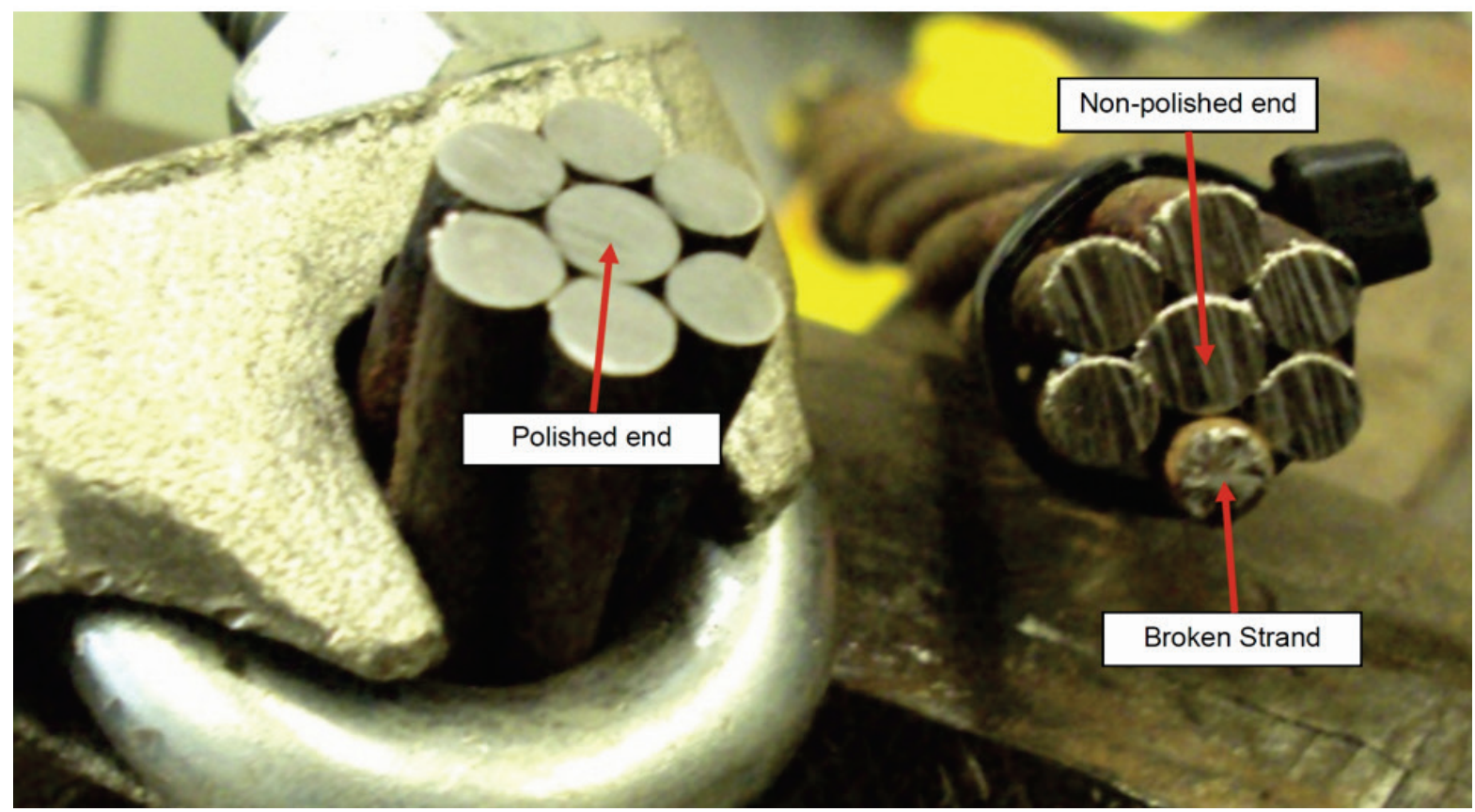

Figure 3.2. Optical scanning platform (also with a loaded sample and the thin dot template).

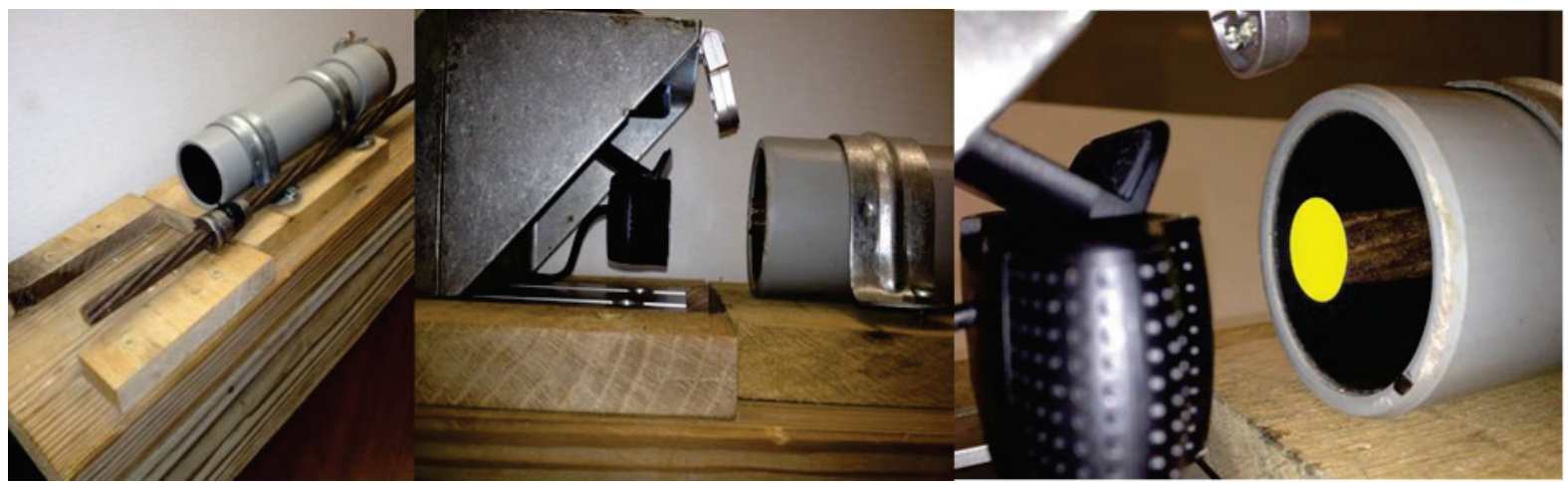

Image processing was used to provide an end view of the cable from the calibration image, and contrast thresholding provided an image where the cable end was white and the background was black (Figures 3.3 and 3.4). With the calibration image, the area of an individual pixel could be calculated. Individual wires could touch and interfere with the computational geometry techniques being used for determining the geometry of the individual wires. If this occurred, the image processing software would allow the user to segment the cable into individual wires by making infinitely thin cutting lines between the wires (Figures 3.5 and 3.6). Then the computational geometry engine would compute the areas, perimeters, eccentricities, long axis length, and short axis lengths of the individual wires (Figure 3.7). 
Figure 3.3. Optical scanning platform showing the scanning software.

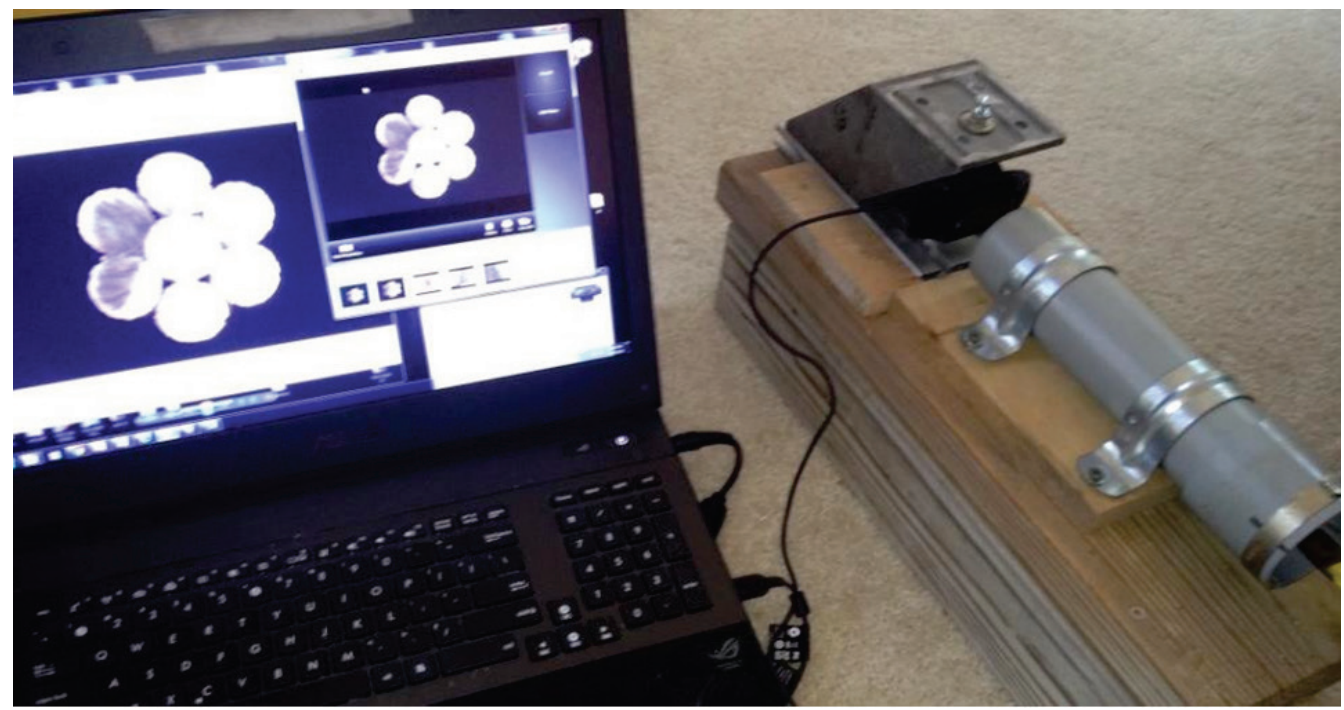

Figure 3.4. Using digital image processing to separate the wire ends from the background.

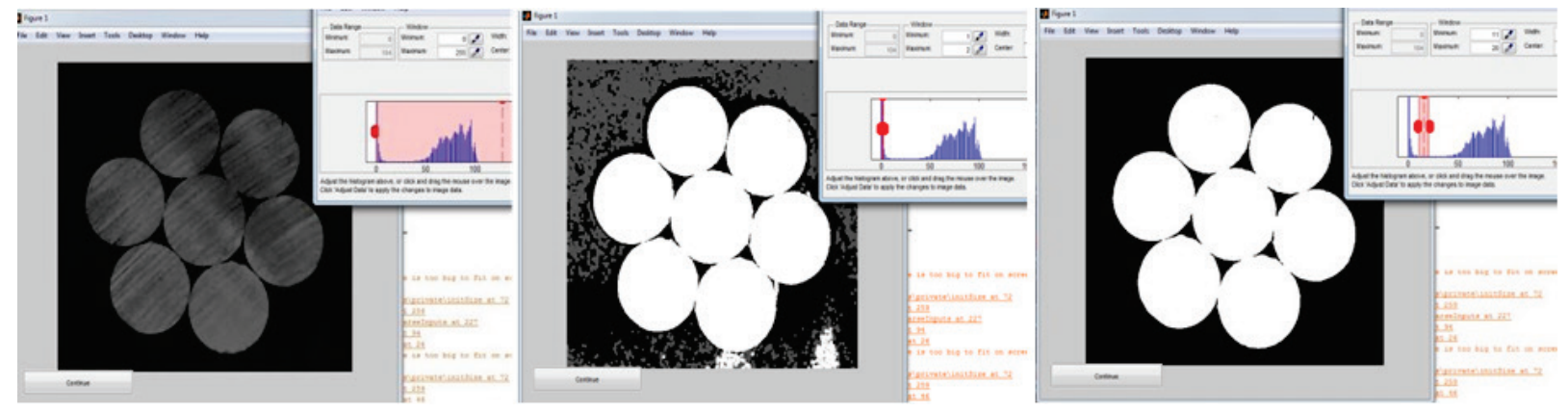

Figure 3.5. Using software to demark the individual cables in the image.

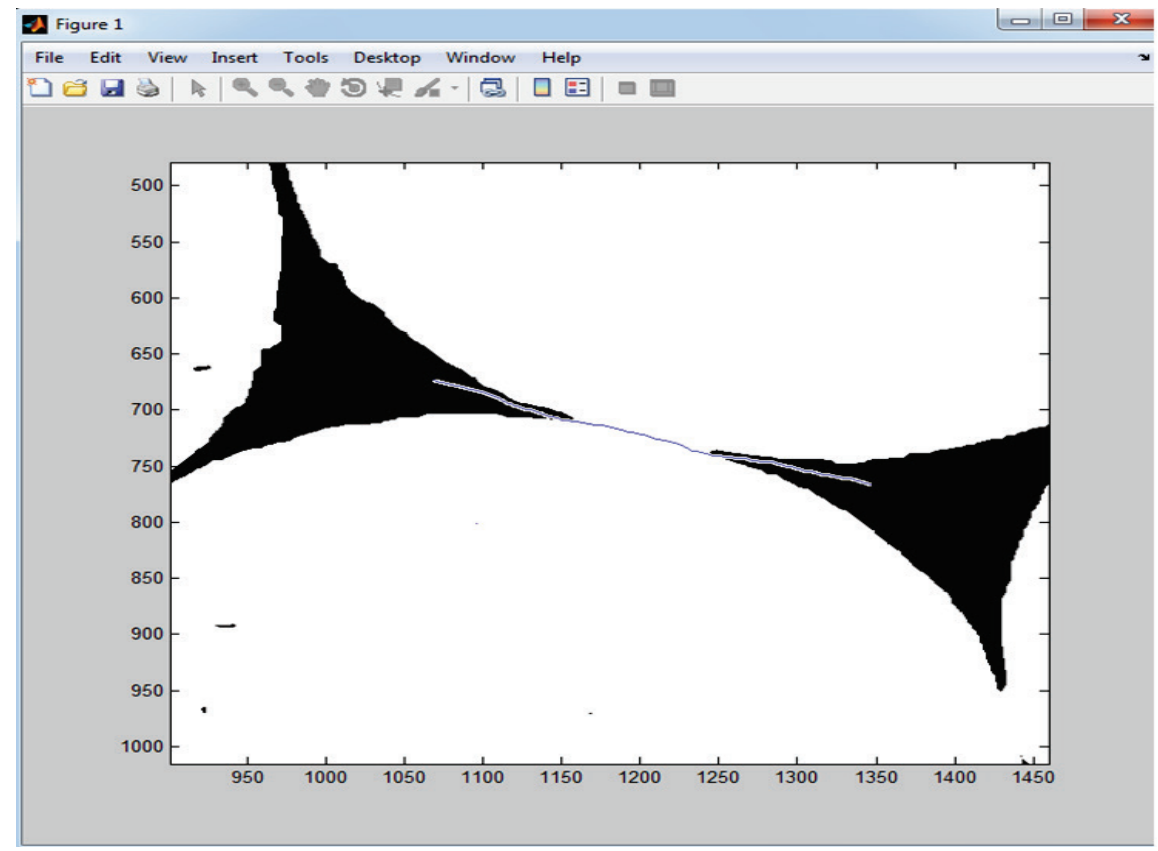


Figure 3.6. Using computational graphic techniques to complete the map of individual wires.

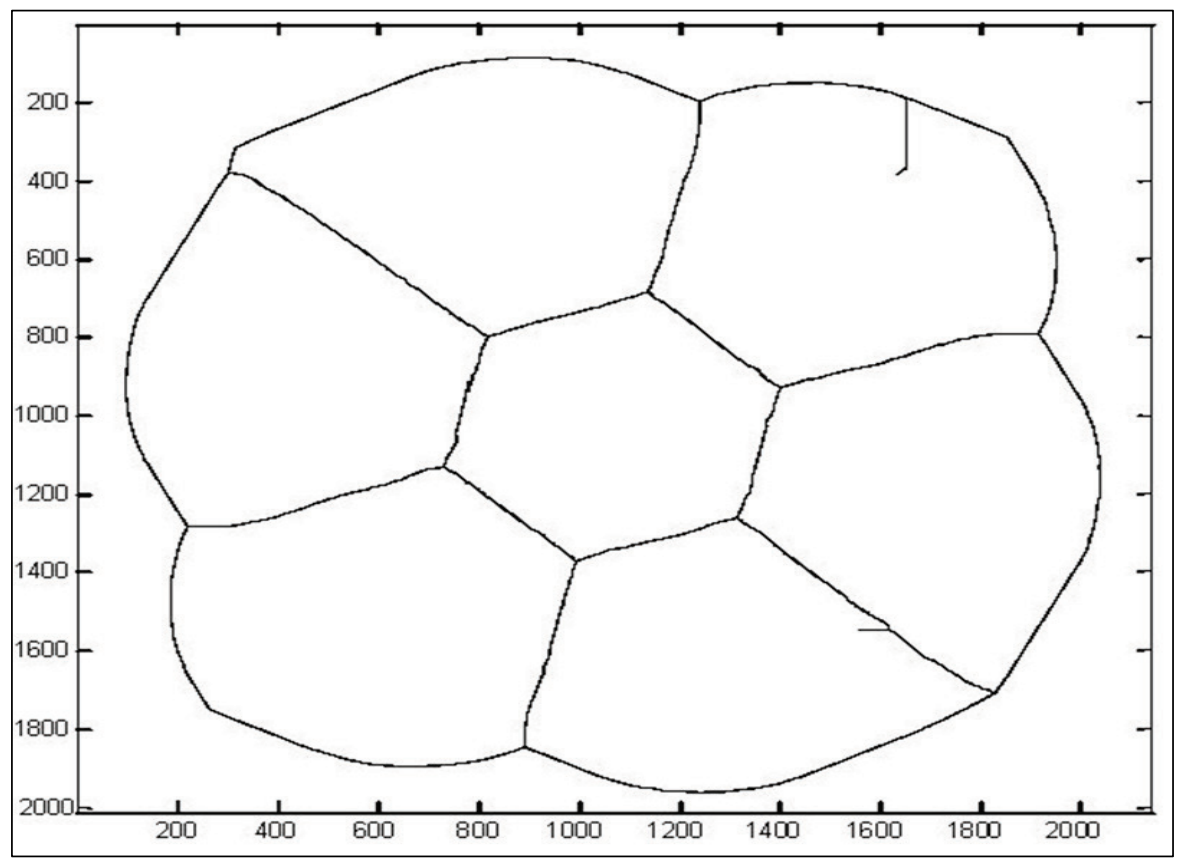

Figure 3.7. The results of optical scanning for PT seven-wire strand cable to determine loss of area and alteration of geometry due to corrosion.

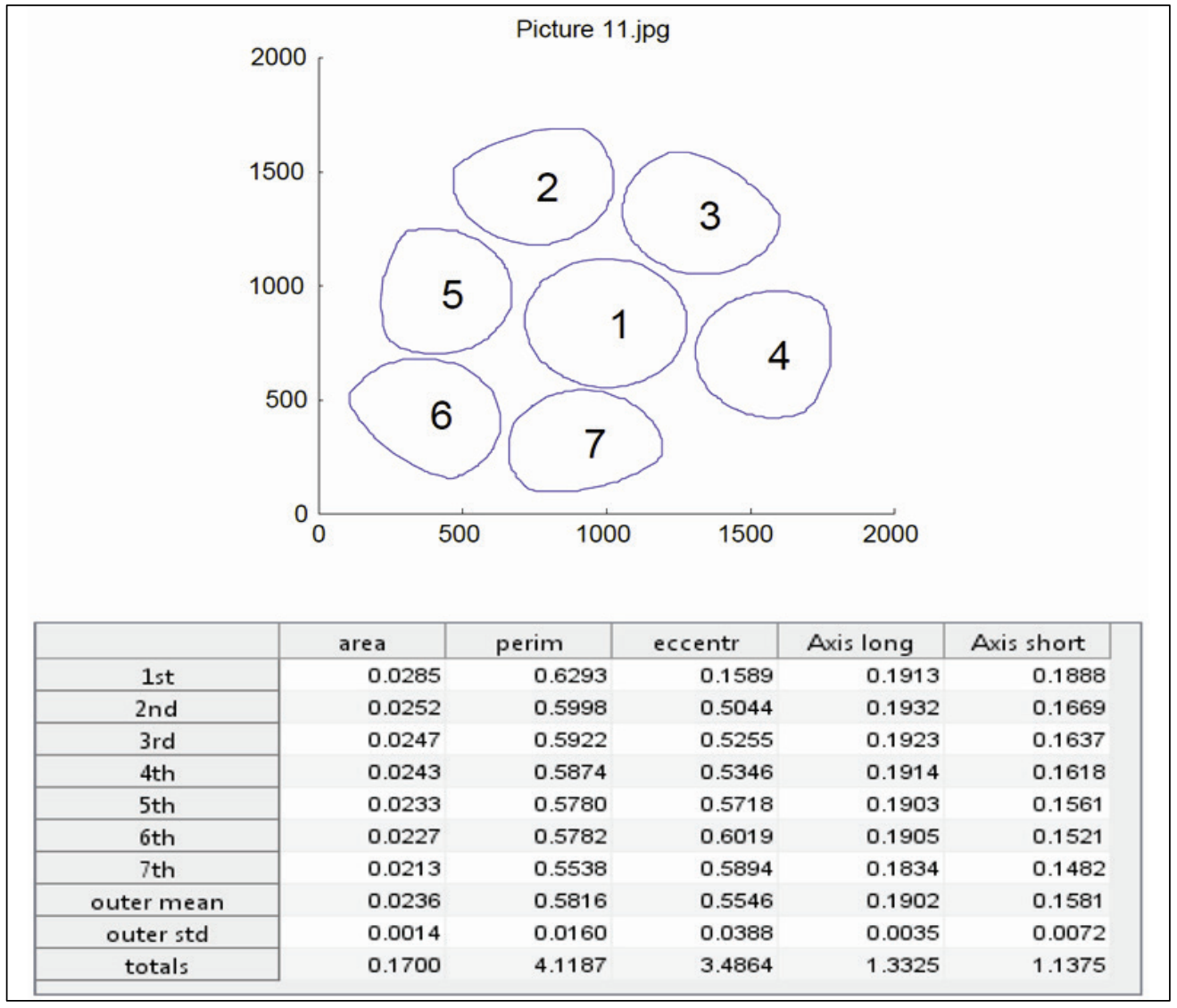




\subsection{Measures of morphological data from optical scanning}

Figures 3.8 and 3.9 show corroded and broken cables 25B_R and 45B_L, the pull-test results of load versus strain, the optical data, and the morphological data computed from the optical scan, proceeding from the bottom left in a counter clockwise order. Cable 25B_R was lightly corroded, while Cable 45B_L was more heavily corroded.

Looking at the graph of load versus strain, cable 25B_R was able to withstand more load, going into ductile failure with a peak load that is near to the guaranteed 58,600-lbf minimum breaking strength from ASTM A416/A416M-12a for new PT seven-wire strand cable. Cable 45B_L, which is visibly more corroded, goes into a brittle failure with a peak load that is less than $35,000 \mathrm{lb}$.

Figure 3.8. Optical scan data from the pull-test data for lightly corroded cable 25B_R.

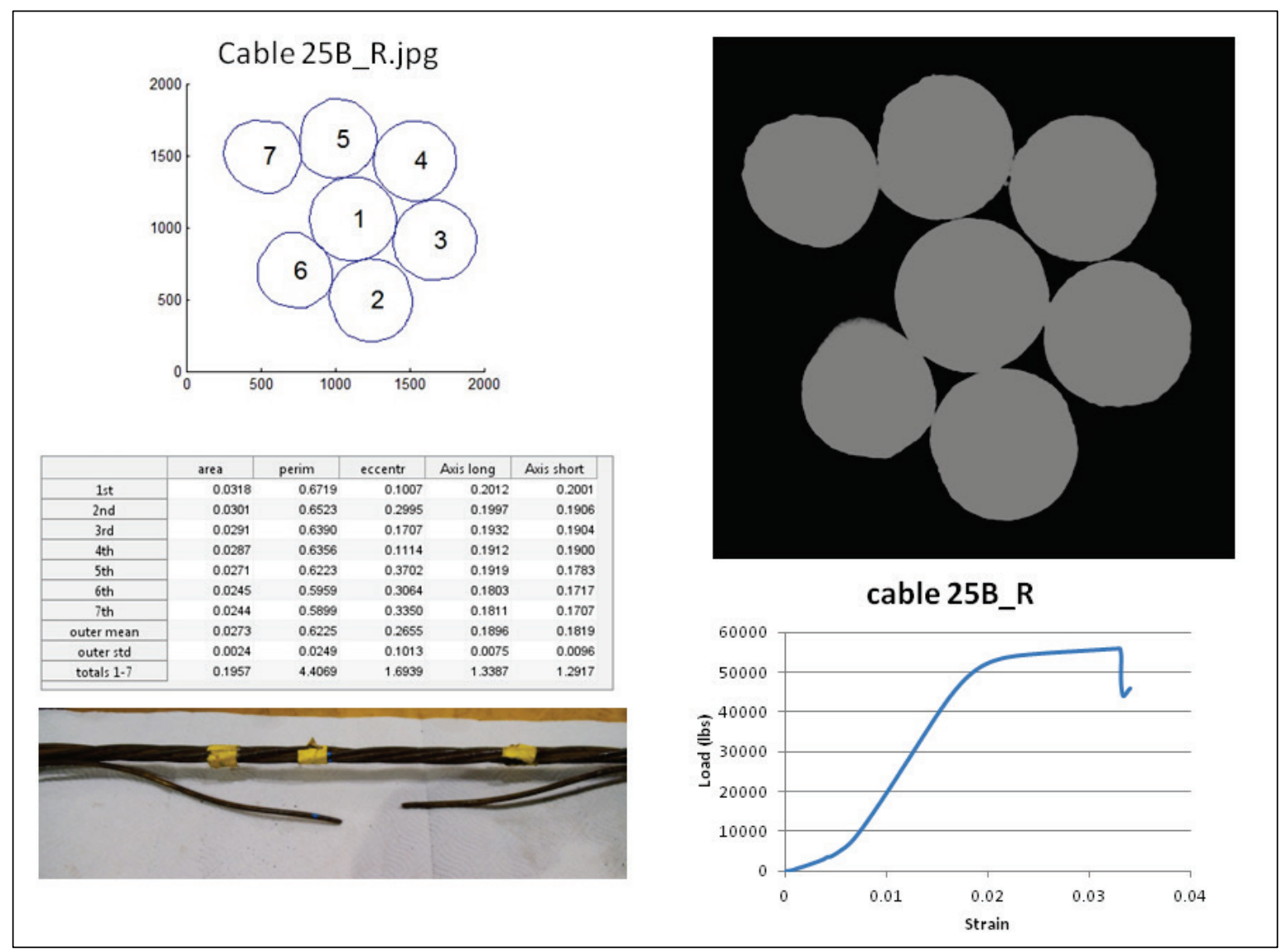


Figure 3.9. Optical scan data from the pull-test data for moderately corroded cable 45B_L.

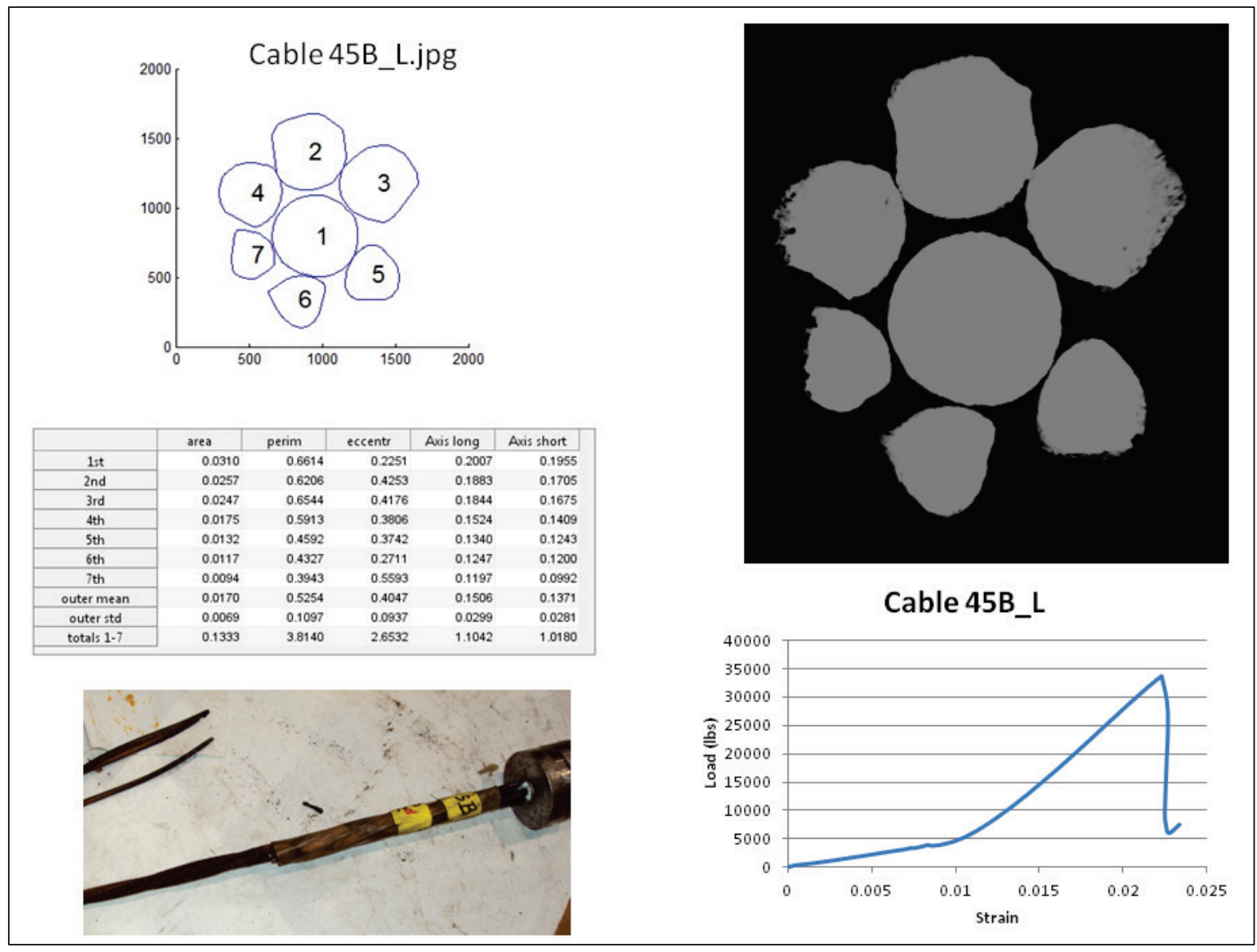

These figures also show the morphological data that is returned from an optical scan. For the cable and for each individual wire, the morphological data returned are the

- Area (in. $\left.{ }^{2}\right)$

- Perimeter (in.)

- Eccentricity

- Axis long (in.), and

- Axis short (in.)

The perimeter of each individual wire is determined by walking around the outer pixels of the optically scanned data. The area is determined by adding the normalized area of every pixel in the optically scanned data. The eccentricity, axis long, and axis short data are determined from the ellipse that has the same second moments as the optical region. 
The pristine pull-test samples were not optically scanned. Because of the uniform nature of the pristine samples, it was presumed that the pristine samples would all have circular outer wires with outer wire diameters of 0.2 in. and outer wire areas of 0.031416 in. ${ }^{2}$. 


\section{ERDC Laboratory Accelerated Corrosion Procedure}

Corrosion causes an uneven loss of cross-sectional area of a cable. Because the corrosion level is uneven, the cable wires can lose the circular geometric properties with the loss of cross-section area. Two methods suggested for simulating corrosion for the pull testing were: 1) adding defects to the cable by pinching, notching, and/or filing the cable or individual wires, and 2) using an accelerated natural electrochemical procedure to produce corrosion. The first method was considered and discarded as it did not produce statistically variant data that would occur in a natural setting; corrosion rarely occurs at a specific location on a cable. The following section discusses the procedure for a more natural, yet accelerated form of corrosion.

The accelerated corrosion system works by using a destructive electrochemical process, which releases iron from the steel surface (a process referred to as reverse cathodic protection). The wire samples were bathed in a salt-water solution that carried electrical potential. The saltwater solution was tap water combined with rock salt, or sodium chloride. The chlorides added to the destructive nature of the bath.

A direct current power supply was applied to the system by having the positive lead attached to the cable and the negative lead applied to a stainless steel grid submerged in the same solution.

A system was set up that introduced the additional catalysts of heat and aeration to the salt-water solution. This also helped to accelerate the corrosion and had the effect that, since the water had to be circulated, the corrosion was more even across the cable. This system allowed for the corrosion of 22 7-foot lengths of cable.

This system is seen schematically in Figure 4.1, and consists of the following components:

- Direct current power supply with positive lead attached to cables and negative lead attached to submerged stainless steel grid (Figure 4.2)

- Water heater 
- Reservoir tank with brine solution

- Pump for circulation and aeration

- A spacer to separate cables and anode from contact; this system has the capacity simultaneously to corrode 44 cables.

Figure 4.1. The first mechanism used for the accelerated corrosion of PT seven-wire strand cable.

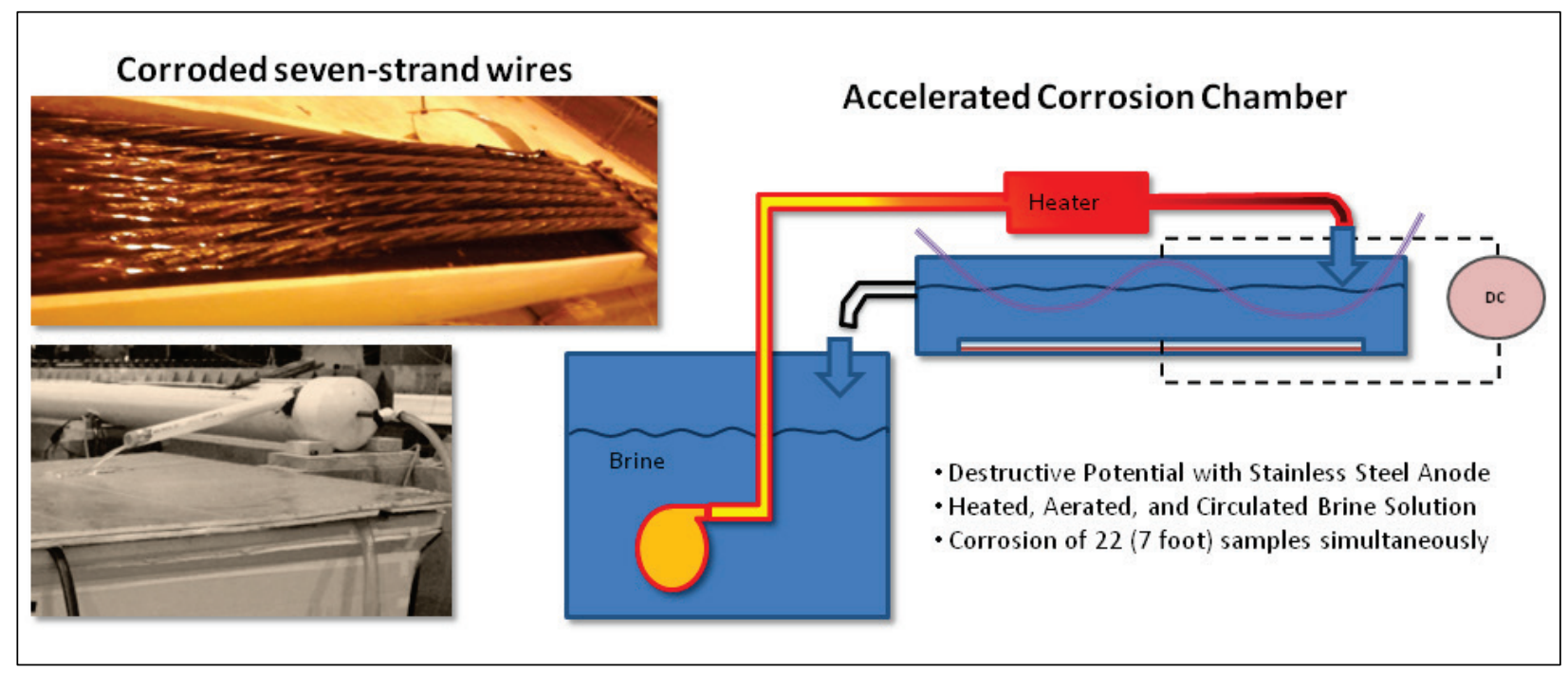

Figure 4.2. 10-amp generator connected to $3.5 \mathrm{ft}$ long corrosion specimen in the static saltwater tanks.

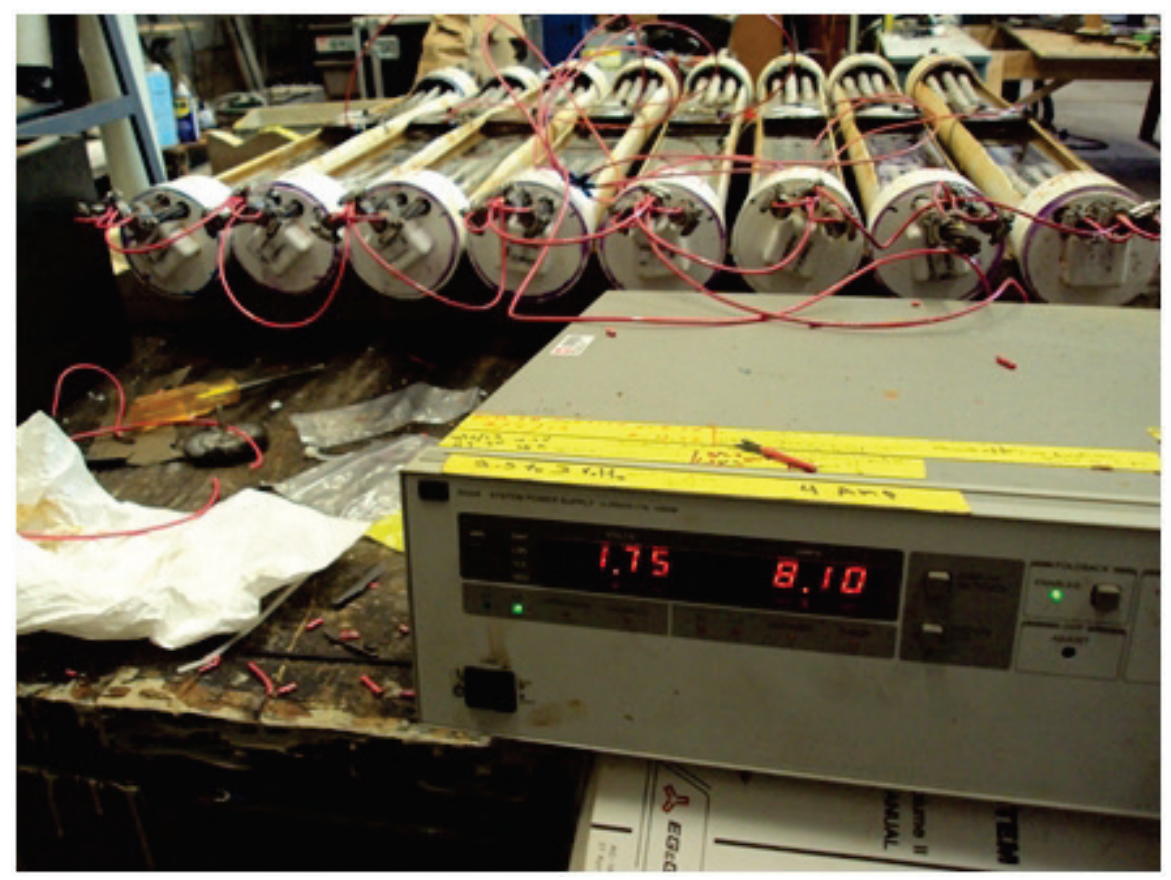


This method was run for 69 seven-foot cables. The seven-foot cables had the center of the cable pulled out of the salt-water solution so that after corrosion, the cables could be cut into two lengths that were a suitable length for the Baldwin BLW 44,00o lb Universal Test machine. It was determined later that multiple cables of a reduced length of $3.5 \mathrm{ft}$ could be corroded in parallel, speeding the corrosion and testing process. Since many specimens could be corroded in parallel and the catalyzing effect of the aerating and heating the water made only a small difference, the shorter cable corrosions were done without aerating or heating the water. Because the water was not flowing for these samples, the salt would precipitate out of the water, causing a more uneven corrosion of the cables. Where the salt collected on the cables, pitting was more noticeable. In addition, more attention was needed to clean the containers between samples.

In some of the more severely corroded cables, non-uniform corrosion was observed. This non-uniformity manifested itself as a deeper pitting on one side of the cable sometimes near mid-span, but more commonly at the waterline. The mid-span pits were thought to be a result of iron buildup in the bottom of the cable tank, and was addressed by more frequent inspection and cleanout. The waterline pits were thought to be a result of salt precipitation and higher oxygen levels, and were handled by protecting the cable in this area with a rust-preventative spray paint, which was covered by corrosion-inhibiting grease and sealed in heat shrink tubing. Initial investigations for corrosion system development indicated that the circulation process produced relatively smoother deterioration and that static tanks with high salt concentrations (precipitated) produced more aggressive pitting and higher losses for the same exposure times.

Figures 4.3 and 4.4 show the process and effects of the two ERDC lab acceleration methods for corrosion, long and short, respectively. Then, the corroded samples were put through a pull-test procedure using the Baldwin BLW 440,00o lb Universal Test Machine to determine their ultimate capacity in lbf. Pull-tests results were successful for 161 corroded PT seven-wire strand cable samples. The results of these samples and their optically scanned results are in Appendix A.

A procedure discussed in Haskins et al. (2014) was used to select target corrosion levels for the different groups of corroded cables. A broad range in corrosion levels resulted in a complete database of 161 corroded cable specimens to which a statistical regression is applied. Chapter 5 discusses the statistical analysis. 
Figure 4.3. The mechanism and process for the corrosion of long specimen.
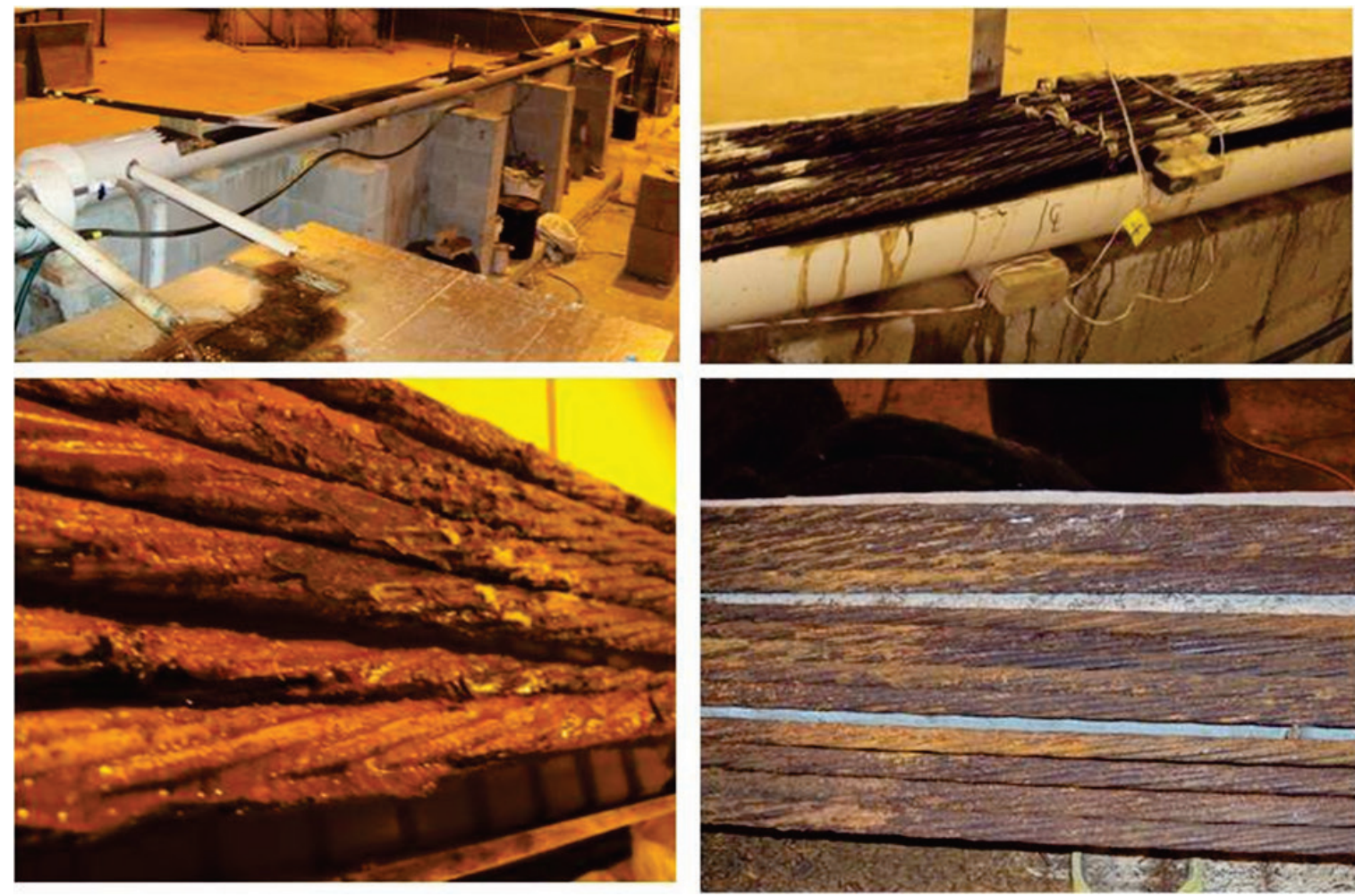

Figure 4.4. Before and after images of the short wire corrosion platform corroding several specimen simultaneously.

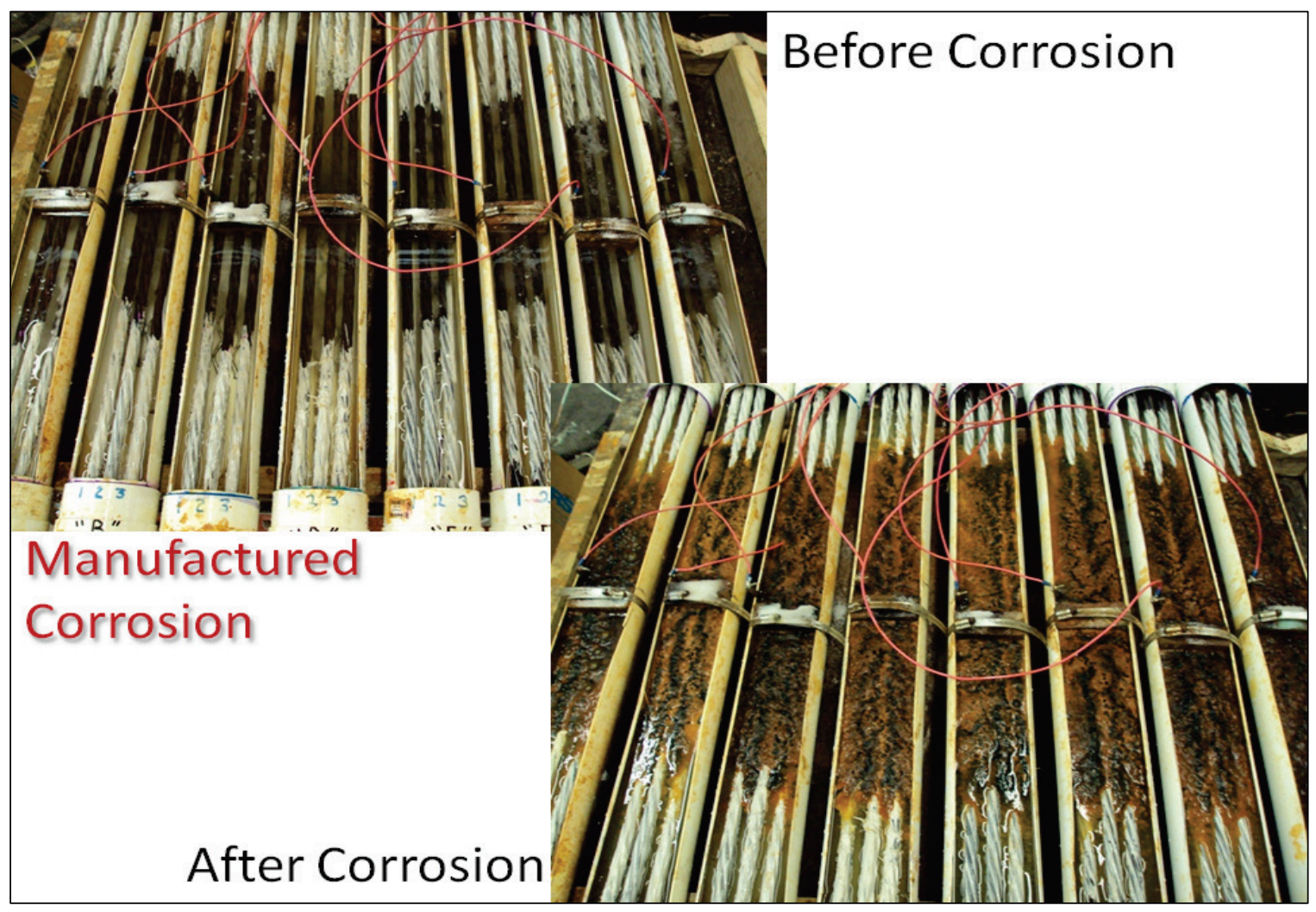




\section{Pull-Test Results for Pristine and Corroded PT Seven-Wire Strand Cable}

There were 161 acceptable pull test results of corroded PT seven-wire strand cables. Acceptable results may be defined as without breakage at the gripping bits or twist in the cables. There were 22 pull tests for pristine PT seven-wire strand cables with acceptable results. These 183 pull tests were combined to determine the correlations between the ultimate force at the point of failure of the cable and the morphological data, which was collected for the corroded samples and presumed for the pristine samples.

During the pull tests, it was assumed that the peak force was obtained before one of the outer wires separated, and that failure of the entire cable would soon occur in the cascade of separation of the other individual wires. Based on this rationale, it made sense to correlate cable capacity to the wire that was deemed likely to break first. Thus, the data were collected in each broken cable for the individual wire that had the least area and the individual wire that had the least axis short data (according to the morphological data).

The perimeter, eccentricity, and axis long data were ignored for the following reasons. First, the perimeter data was ignored because a long perimeter with low area could be obtained for highly eccentric shapes, or for highly concave shapes. Second, eccentricity could only provide shape information and not the cross-section area involved. Finally, the long axis was ignored because it was presumed that the wire would be more likely to separate along the shorter distance.

Figure 5.1 shows a plot of captured data with the vertical axis being the ultimate resisting force of the cable at breaking, and the horizontal axis is the area in square inches of the thinnest wire (minimum wire area) of the seven wires in the cable. Figure 5.2 shows the capacity versus the length of the short axis of the ellipse with the same second moments as the scanned data (henceforth called the minimum corroded wire short axis diameter, or minimum wire diameter) in inches, respectively. In these plots, the values using red squares are for the corroded data and the pristine data are shown in blue. The pristine data assume that the area and minimum wire diameter are 0.031416 in. ${ }^{2}$ and 0.2 in., respectively. 
Figure 5.1. Corroded and pristine data plotted by peak capacity and the area of the wire in the cable with the least area.

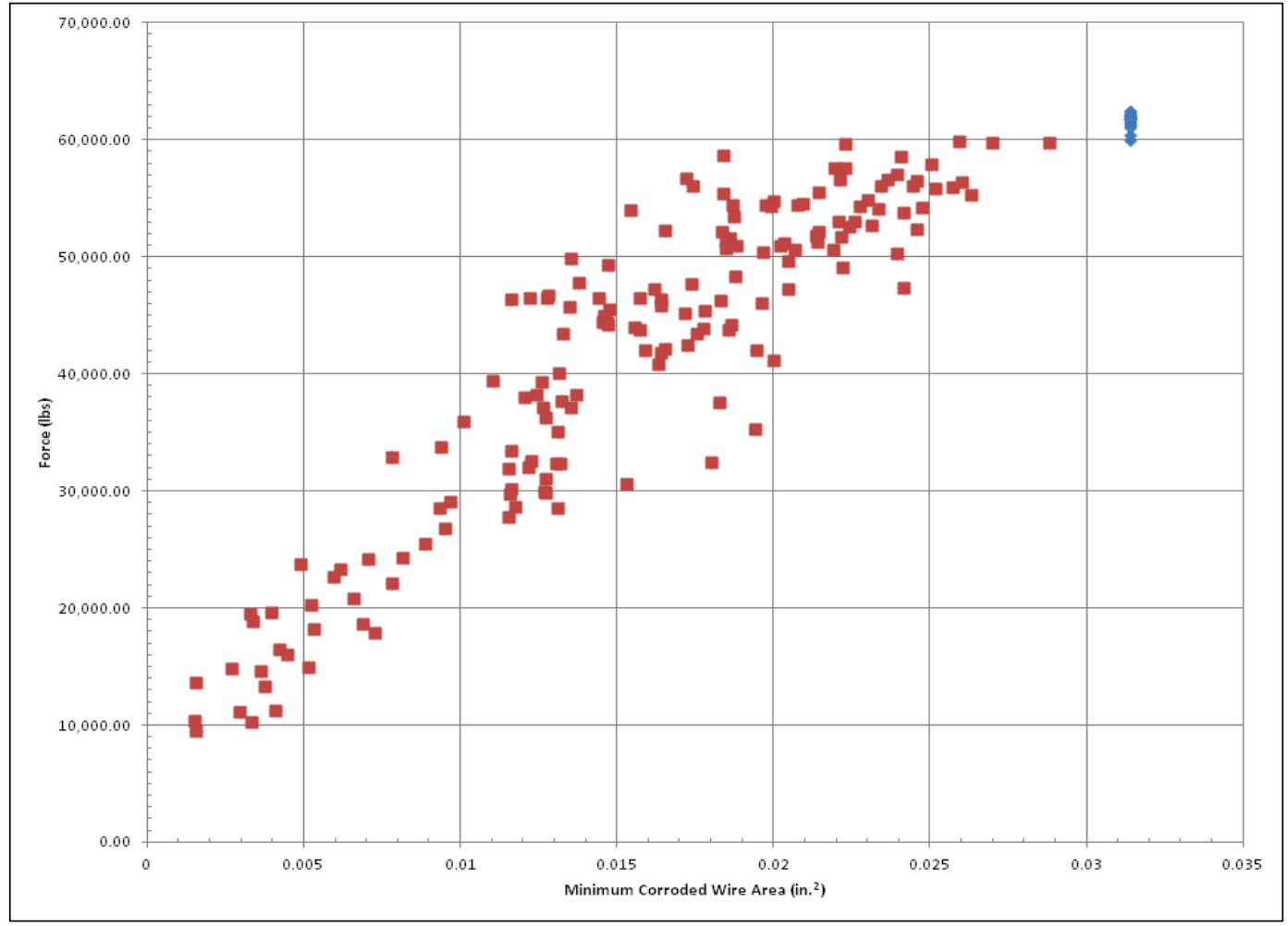

Figure 5.2. Corroded and pristine data plotted by peak capacity and the short axis diameter of the wire in the cable with the least short axis diameter.

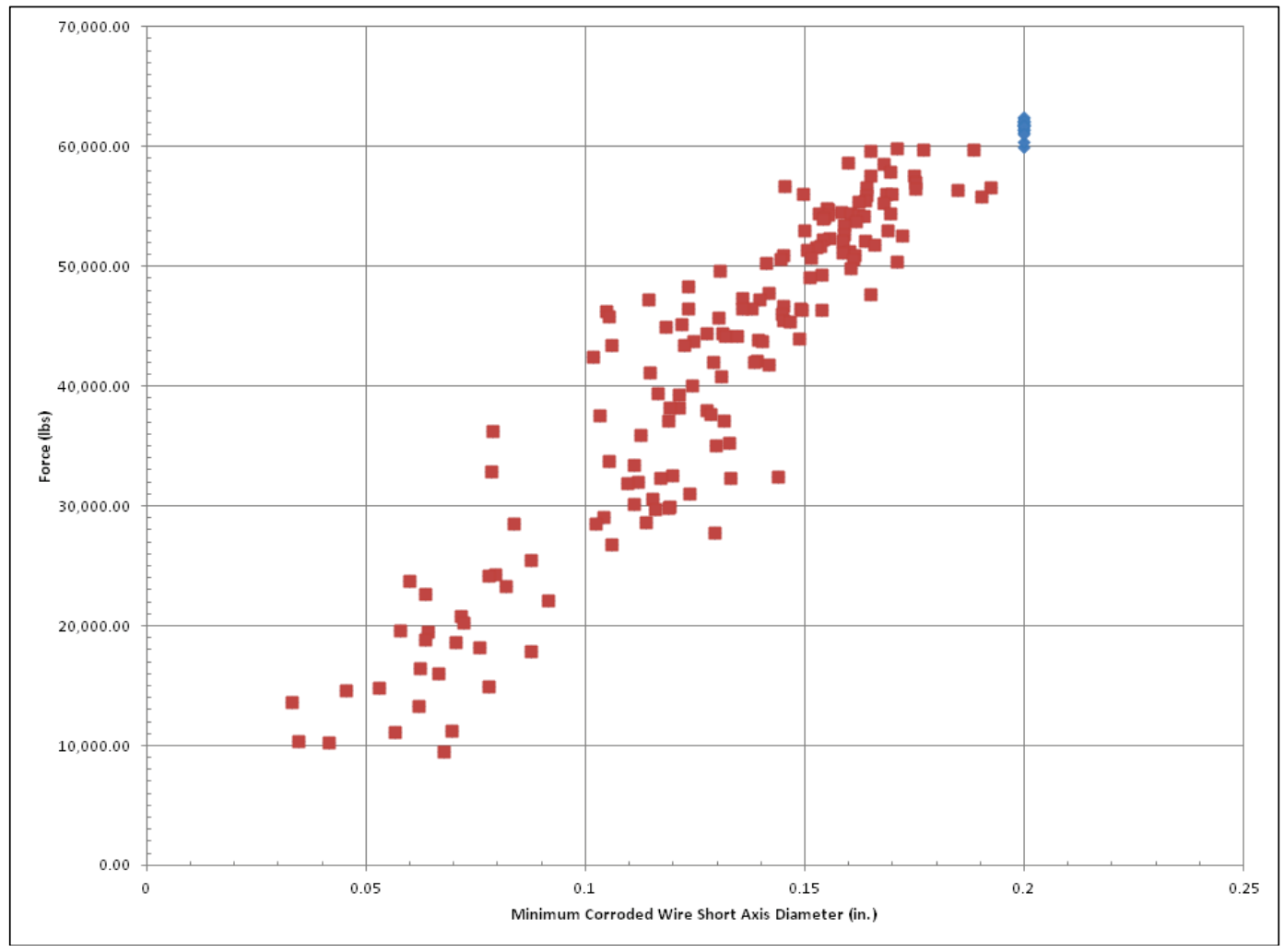


Although there is some spread in the corroded data and even a little spread in the pristine data, there is a noticeable correlation between the peak force and both the minimum wire area and diameter in the cable. This is because as the minimum wire area and diameter increase, the cable's capacity increases, which is expected. Statistically, the trend of the correlation could be determined by using a least-fit method with different forms of equations using the coefficient of determination $\left(\mathrm{R}^{2}\right)$ measure. The $\mathrm{R}^{2}$ measure is normalized to a value from 0.0 to 1.0, with an optimal $\mathrm{R}^{2}$ value of 1.0 meaning that the resulting fit curve lies directly on the data. The forms of the equations tested were the linear form, second-order polynomial, third-order polynomial, and the power function. Higher order polynomial functions were attempted, but the statistical data fit did not improve very much because the higher order terms did not add a significant contribution to the curve shape.

Figures 5.3 and 5.4 show the resulting linear trend lines for the minimum wire area and diameter data, with $\mathrm{R}^{2}$ values of 0.85 and 0.89 , respectively. Figures 5.5 and 5.6 show the $2^{\text {nd }}$ order polynomial trend lines with $\mathrm{R}^{2}$ values of 0.9 and 0.89 . Figures 5.7 and 5.8 show the $3^{\text {rd }}$ order polynomial trend lines with $\mathrm{R}^{2}$ values of 0.9 and 0.9. Figures 5.9 and 5.10 show the power function trend lines with $\mathrm{R}^{2}$ values of 0.9 and 0.87 . In general, the $\mathrm{R}^{2}$ fit of the data becomes better as the polynomial order increases. However, for the minimum wire area data, the $\mathrm{R}^{2}$ value shows a marked change from the linear form to the $2^{\text {nd }}$ order polynomial, but then has very little variation. For the minimal diameter data, the $\mathrm{R}^{2}$ value peaks for the polynomial forms of the equations.

There is additional information for determining the best-fit trend line for the minimum wire area and diameter data that must be taken into account. For this data, the minimum wire area and diameter will never exceed the values for the pristine cable, where no corrosion has occurred. Because the pristine data has very little variance, it is apparent that any trend line should approach close to the mean value for the pristine samples, which was previously calculated as a load of 61,669 pounds of force (lbf). At the point where the minimum wire area and diameter approach a value of 0.0 in. ${ }^{2}$ and 0.0 in., respectively, the only thing stated with certainty is that the cable has lost one corroded wire, but the capacity of the cable is guaranteed to be non-negative and most likely will still be a bit greater than $0.0 \mathrm{lb}$. 
Figure 5.3. Linear trend line fitting minimum wire area data.

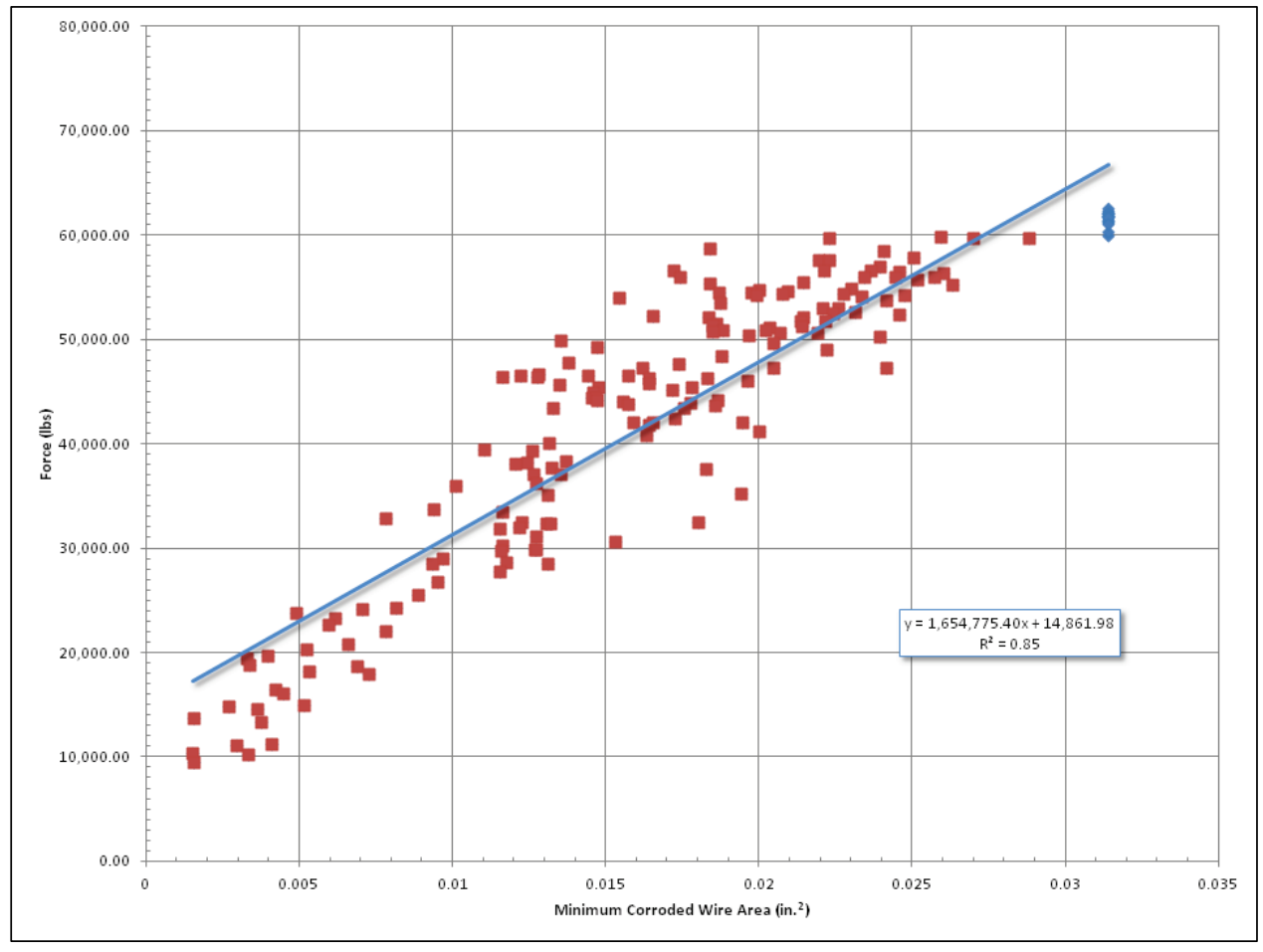

Figure 5.4. Linear trend line fitting minimum wire diameter data.

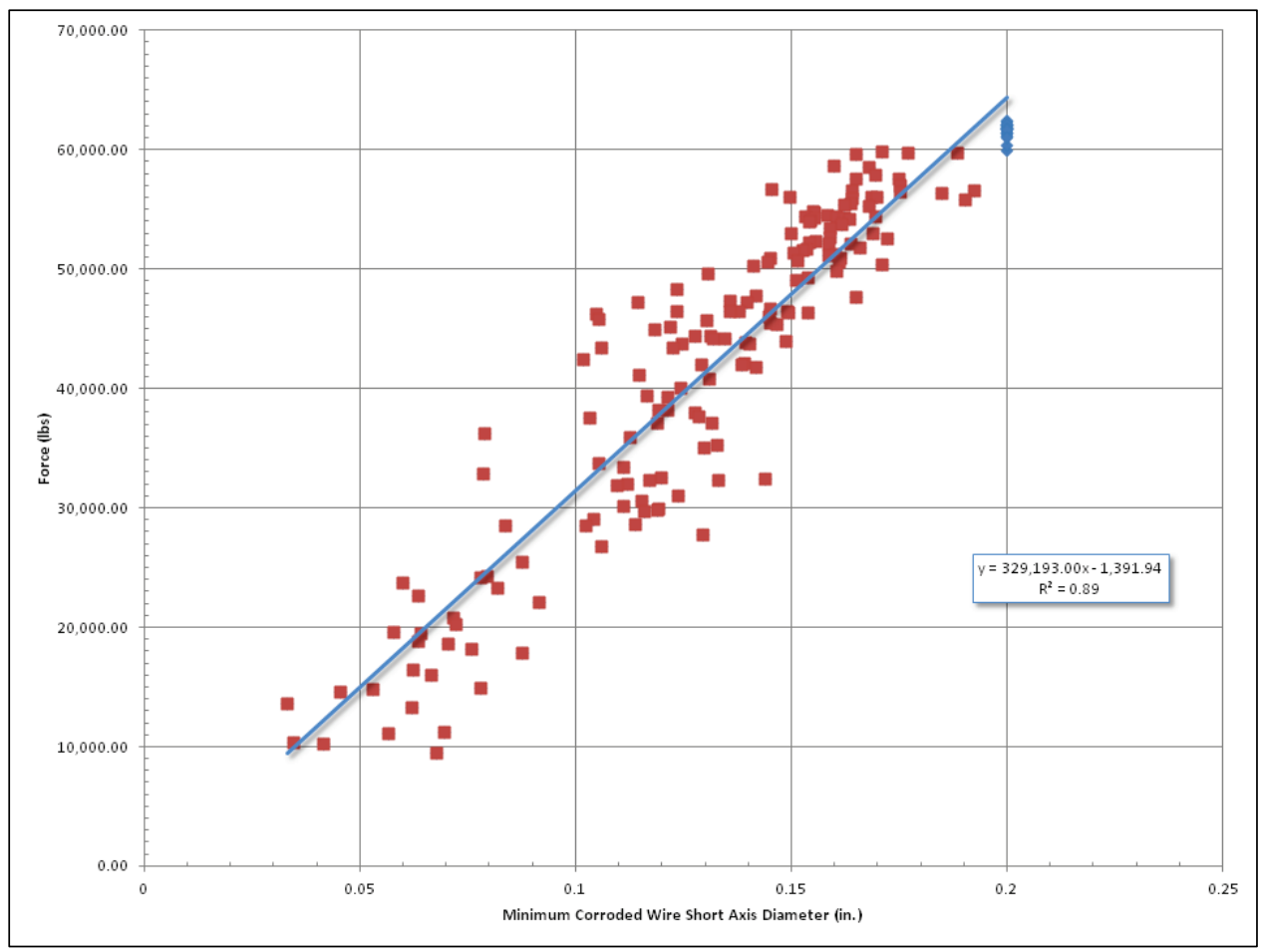


Figure 5.5. Second order polynomial trend line fitting minimum wire area data.

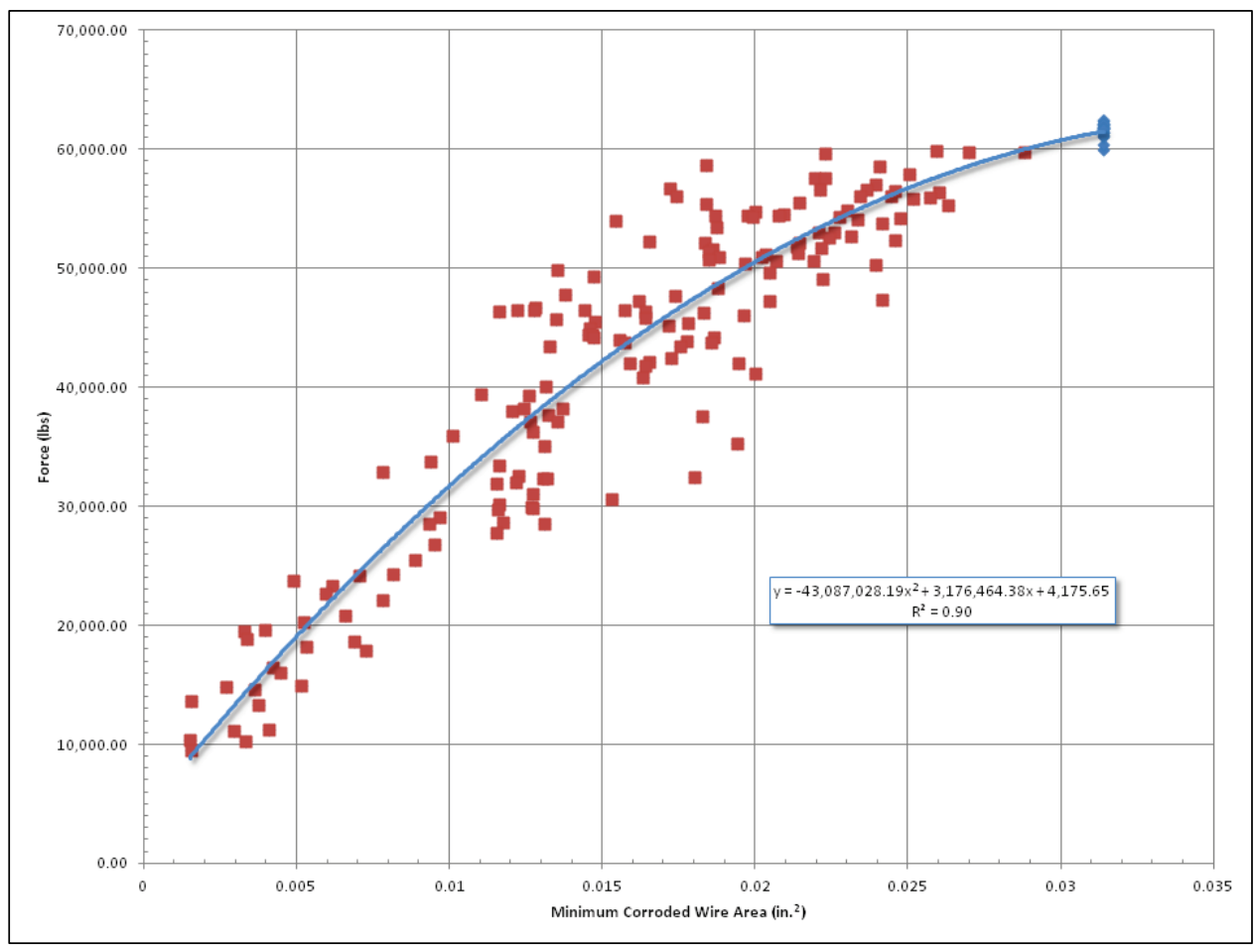

Figure 5.6. Second order polynomial trend line fitting minimum wire diameter data.

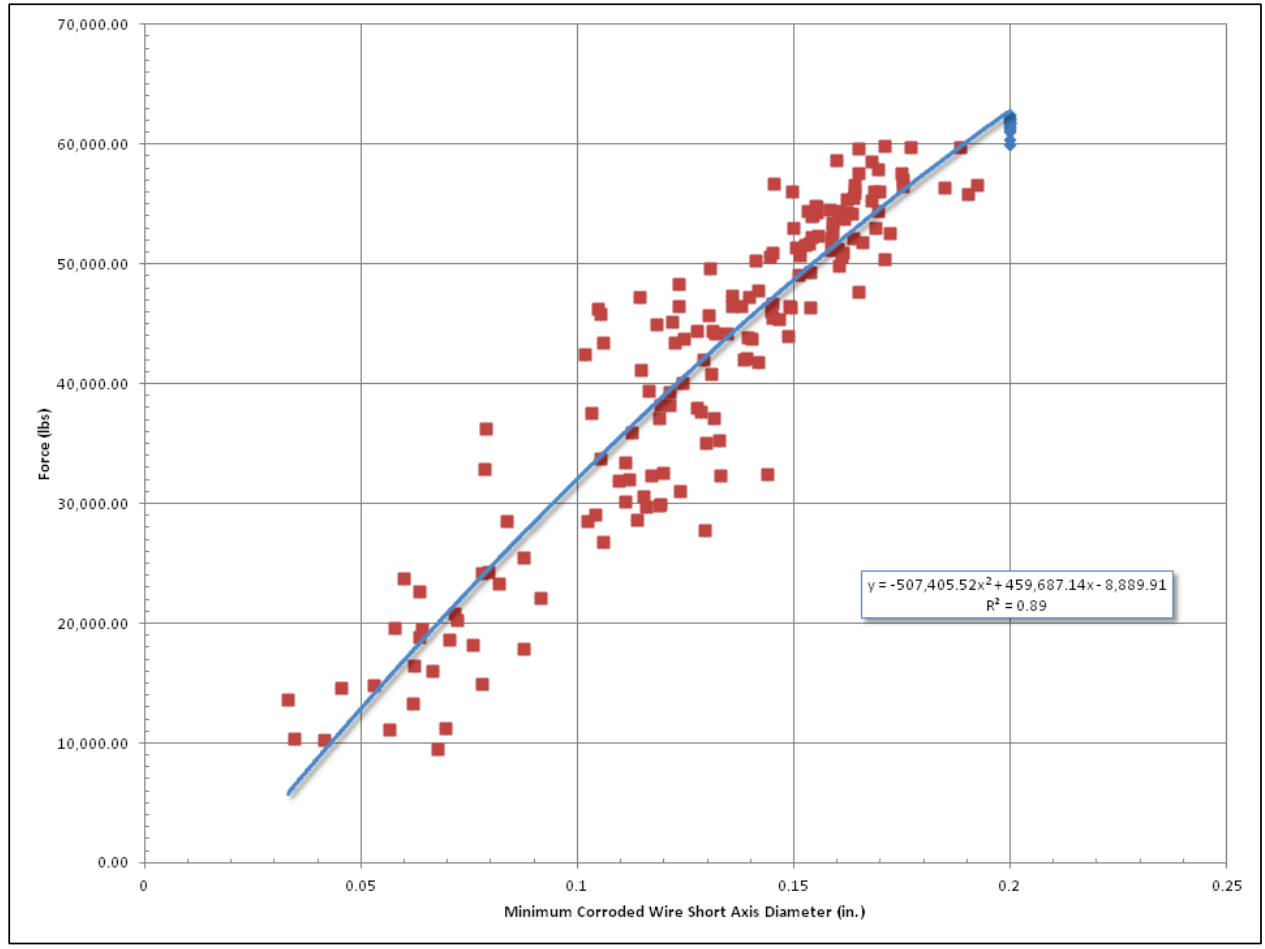


Figure 5.7. Third order polynomial trend line fitting minimum wire area data.

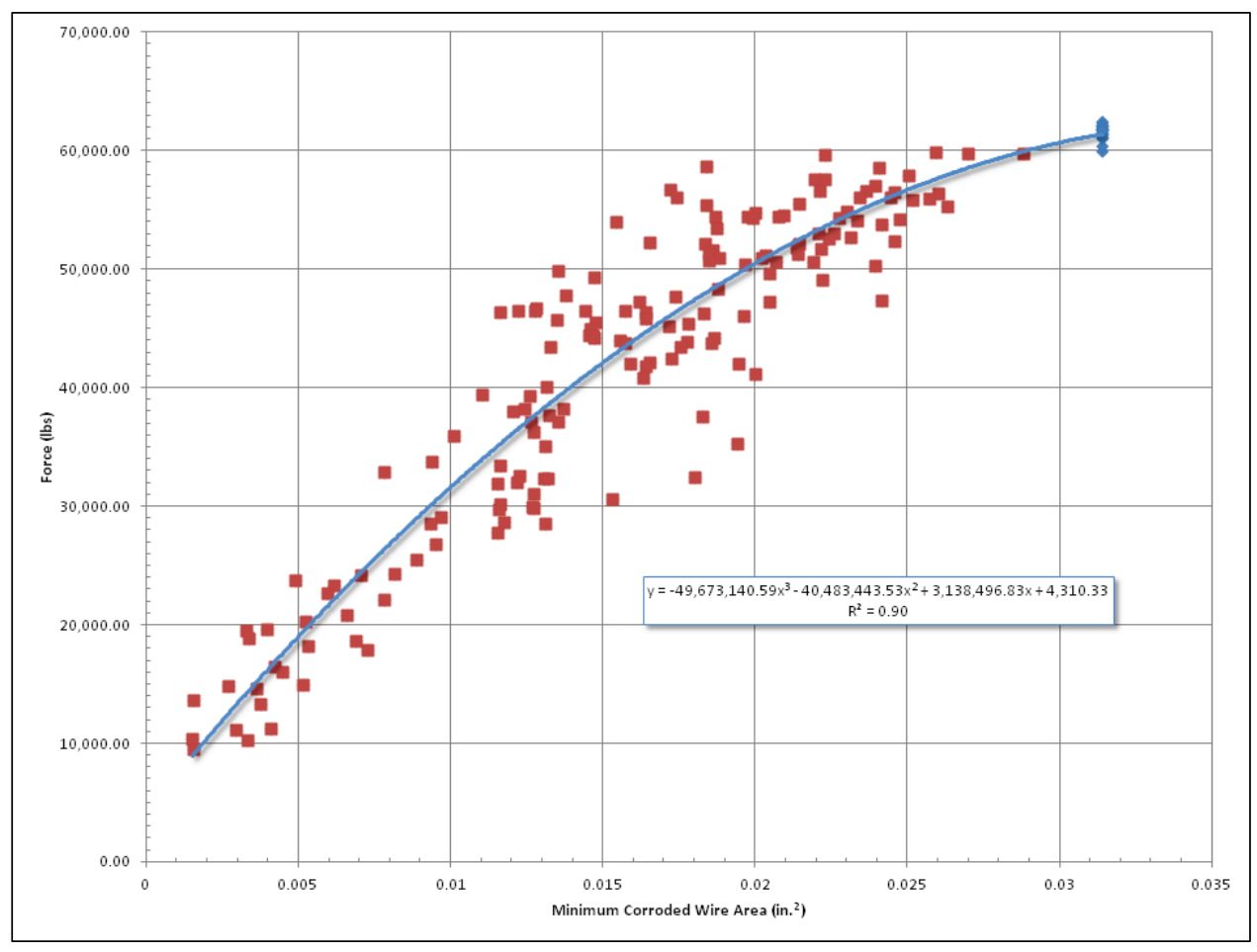

Figure 5.8. Third order polynomial trend line fitting minimum wire diameter data.

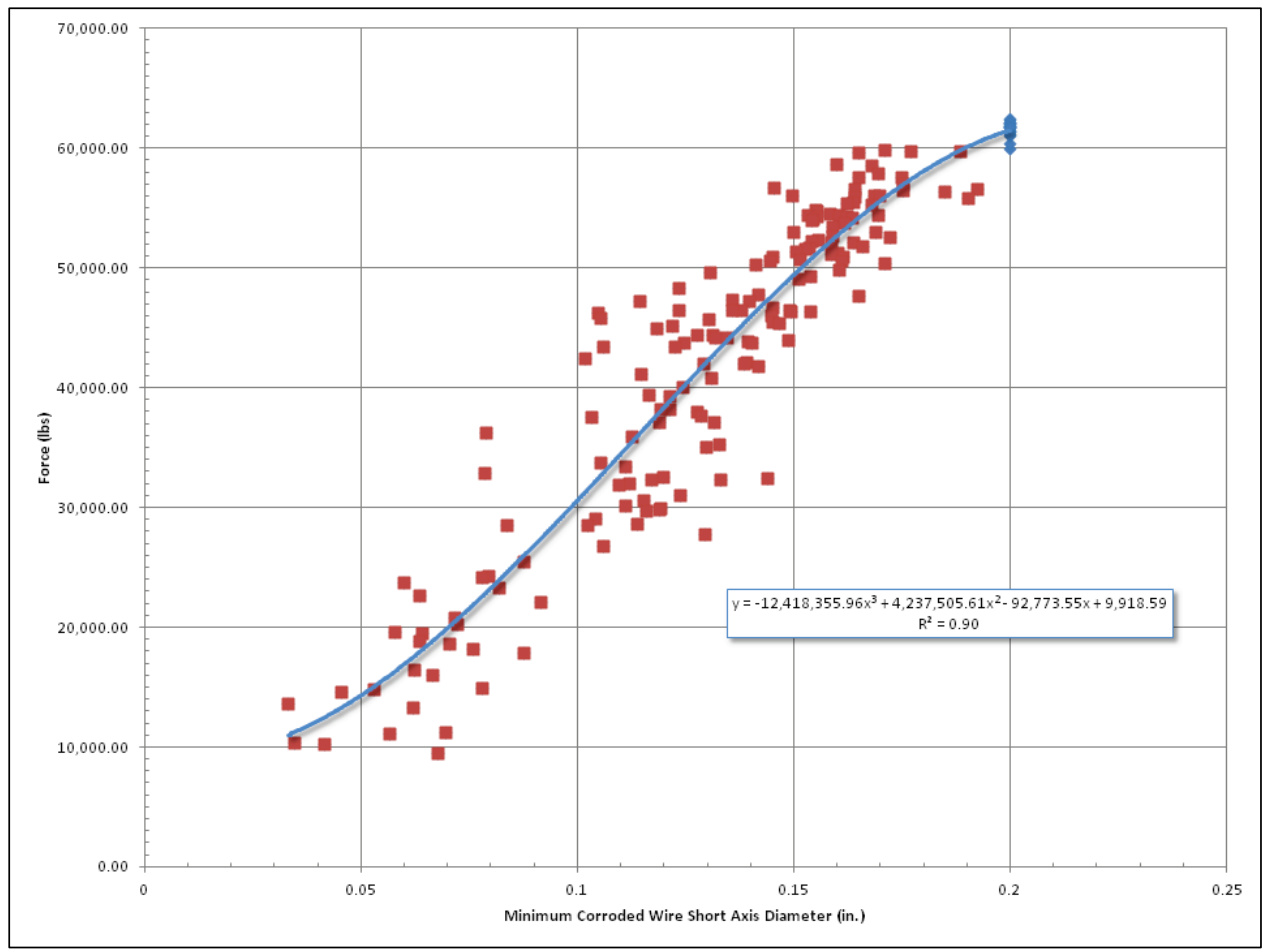


Figure 5.9. Power function trend line fitting minimum wire area data.

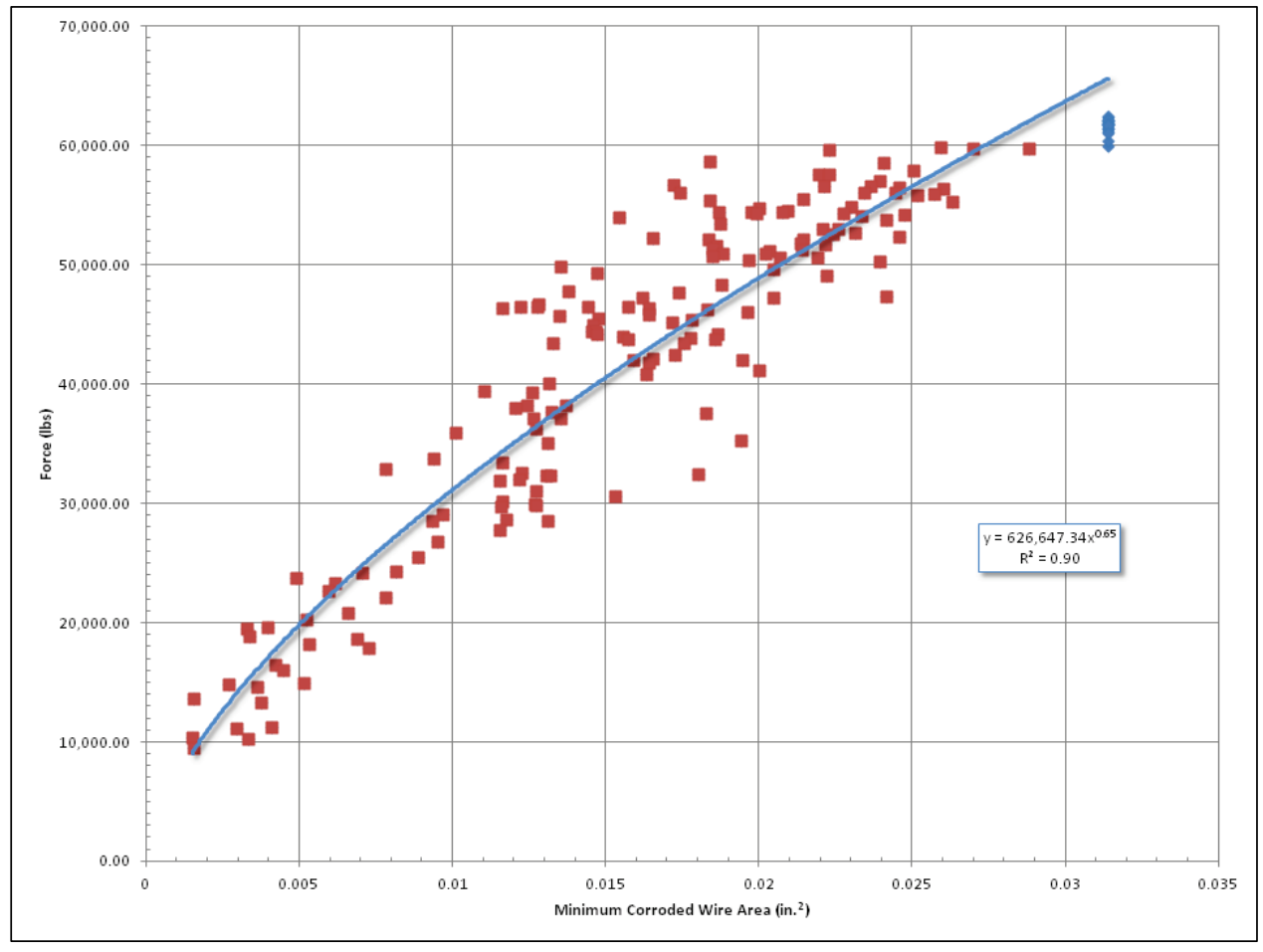

Figure 5.10. Power function trend line fitting minimum wire diameter data.

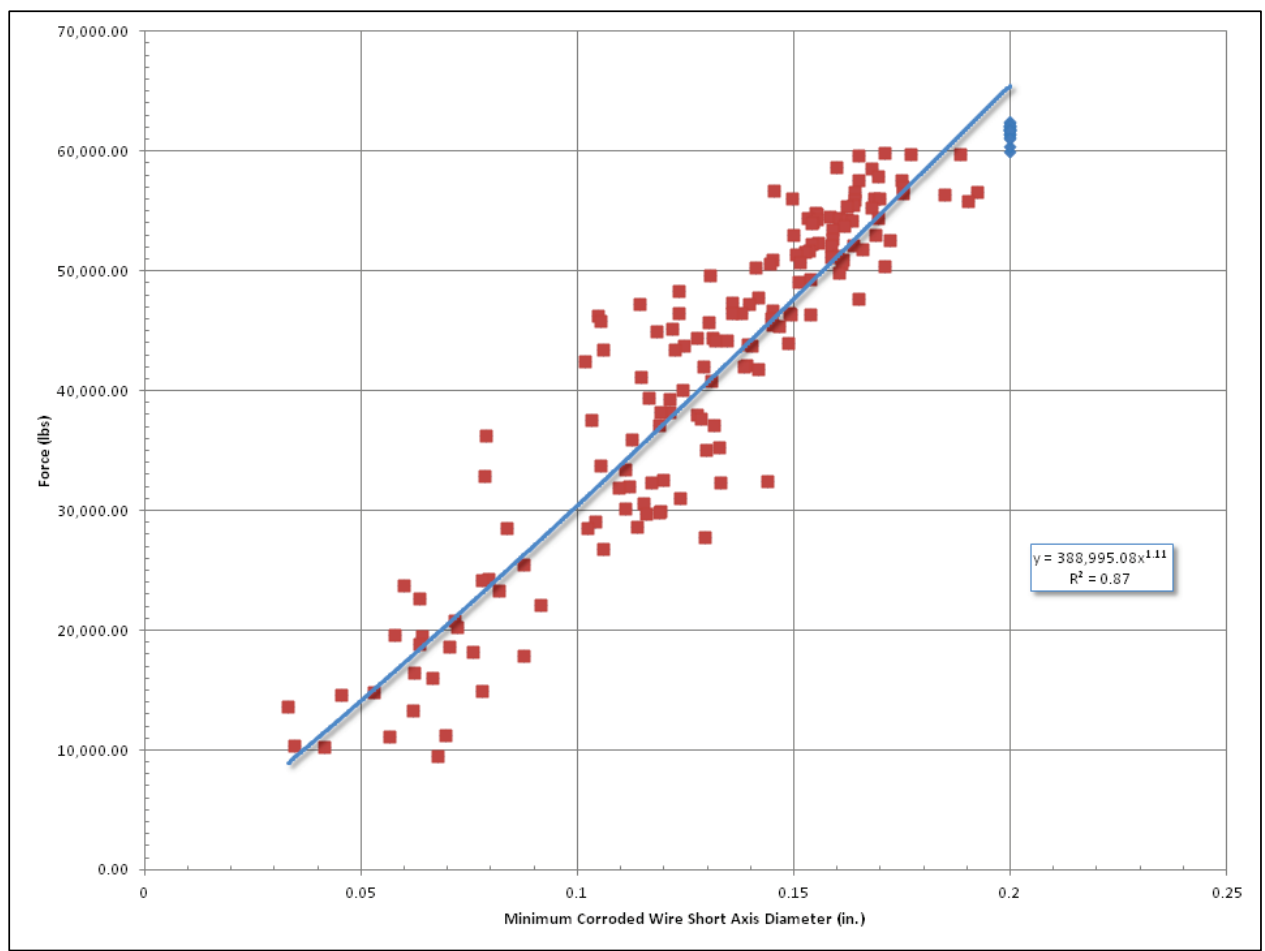


Tables 5.1 through 5.4 take each of the equation types: linear, polynomial order 2, polynomial order 3 , and power, with the parameters set using the $\mathrm{R}^{2}$ curve fitness. They determine the capacity of the cable when the minimum wire area and diameter are 0.0 in. ${ }^{2}$ and 0.0 in., and when the minimum wire area and diameter are $0.031416 \mathrm{in}^{2}$ and $0.2 \mathrm{in}$. These data are reported for these extent values, as well as the $\mathrm{R}^{2}$ term so that overall fitness can be determined. The trend line functions are evaluated for a full set of data (corroded wire samples and pristine wire samples) and for the corroded wire data only. As expected, the $\mathrm{R}^{2}$ values were higher for the inclusive (corroded and pristine) data sets, if only because the pristine data had very little variance.

The insight gained from these tables is that some of these equations, while having marginally better $\mathrm{R}^{2}$ values, are better at predicting the end-point data. The corroded-only data sets had consistently worse $\mathrm{R}^{2}$ data, as expected, but also consistently gave end-point data that was further from the mean pristine value (at the max area and max diameter ranges) of $61,669 \mathrm{lb}$ than the full data set with both corroded and pristine samples. This supports the viewpoint that pristine pull-test data need to be included in the database, as is the case for this study.

Examining Table 5.1 and Table 5.3, based on corroded and pristine sample data for minimal wire area and diameter, the functions that best estimate the data, including the endpoints, are the polynomial order 2 equation for the minimum wire area and the polynomial order 3 equation for the minimum wire diameter. These mean estimate functions are given as:

$$
y=-43,087,028.19 x^{2}+3,176,464.38 x+4,175.65
$$

for the minimum wire area calculation, where $y$ is the capacity (lb) and $x$ is the minimum wire area (in. ${ }^{2}$ ), and

$$
y=-12,418,355.96 x^{3}+4,237,505.61 x^{2}-92,773.55 x+9,918.59
$$

for the minimum wire diameter calculation, where $y$ is the capacity (lb) and $x$ is the minimum wire diameter (in.). 
Table 5.1. Trend line mapping of extent data for full minimal area data set.

\begin{tabular}{|l|c|c|c|}
\hline \multirow{2}{*}{\multicolumn{4}{|c|}{ Min Wire Area (corroded+pristine) }} \\
\cline { 1 - 3 } \multicolumn{1}{|c|}{ Method } & $\begin{array}{c}\text { Min area } \\
\text { range capacity } \\
\text { (Ib) }\end{array}$ & $\begin{array}{c}\text { Max area range } \\
\text { capacity (Ib) }\end{array}$ & \\
\cline { 2 - 3 } & 0 in. $^{2}$ & 0.031416 in. $^{2}$ & \multirow{2}{*}{$\mathbf{R}^{2}$} \\
\hline Linear & 14,862 & $66,848.41$ & 0.85 \\
\hline Polynomial Order 2 & $4,175.7$ & $61,442.1$ & 0.9 \\
\hline Polynomial Order 3 & $4,310.3$ & $61,413.39$ & 0.9 \\
\hline Power & 0 & $65,616.8$ & 0.9 \\
\hline
\end{tabular}

Table 5.2. Trend line mapping of extent data for corroded-only minimal area data set.

\begin{tabular}{|l|c|c|c|}
\hline \multicolumn{4}{|c|}{ Min Wire Area (corroded only) } \\
\cline { 1 - 3 } \multirow{2}{*}{ Method } & $\begin{array}{c}\text { Min area } \\
\text { range capacity } \\
(\mathbf{I b})\end{array}$ & $\begin{array}{c}\text { Max area range } \\
\text { capacity (Ib) }\end{array}$ & \\
\cline { 2 - 3 } & 0 in. $^{2}$ & 0.031416 in. $^{2}$ & \multirow{2}{*}{$\mathbf{R}^{2}$} \\
\hline Linear & 11,441 & $71,756.36$ & 0.85 \\
\hline Polynomial Order 2 & 3,745 & $60,368.36$ & 0.87 \\
\hline Polynomial Order 3 & 5,810 & $56,132.03$ & 0.87 \\
\hline Power & 0 & $67,377.6$ & 0.89 \\
\hline
\end{tabular}

Table 5.3. Trend line mapping of extent data for full minimal diameter data set.

\begin{tabular}{|c|c|c|c|}
\hline \multicolumn{4}{|c|}{ Min Wire Diameter (corroded+pristine) } \\
\hline \multirow[b]{2}{*}{ Method } & $\begin{array}{l}\text { Min diameter } \\
\text { range capacity } \\
\text { (lb) }\end{array}$ & $\begin{array}{c}\text { Max diameter } \\
\text { range capacity (lb) }\end{array}$ & \multirow[b]{2}{*}{$\mathbf{R}^{2}$} \\
\hline & 0 in. & $0.2 \mathrm{in.}$ & \\
\hline Linear & $-1,391.9$ & $64,446.7$ & 0.89 \\
\hline Polynomial Order 2 & $-8,889.9$ & $62,751.26$ & 0.89 \\
\hline Polynomial Order 3 & $9,918.6$ & $61,517.19$ & 0.9 \\
\hline Power & 0 & $65,554.67$ & 0.87 \\
\hline
\end{tabular}


Table 5.4. Trend line mapping of extent data for corroded-only minimal diameter data set.

\begin{tabular}{|l|l|l|l|}
\hline \multirow{4}{*}{\multicolumn{4}{|c|}{ Min Wire Diameter (corroded only) }} \\
\hline \multirow{2}{*}{ Method } & $\begin{array}{c}\text { Min diameter } \\
\text { Range } \\
\text { capacity (Ib) }\end{array}$ & $\begin{array}{c}\text { Max diameter } \\
\text { Range capacity (Ib) }\end{array}$ & \multirow{2}{*}{$\mathbf{R}^{2}$} \\
\cline { 2 - 4 } & \multicolumn{1}{|c|}{$\mathbf{0}$ in. } & \multicolumn{1}{c|}{$\mathbf{0 . 2}$ in. } & 0.87 \\
\hline Linear & $-3,689.4$ & 66,311 & 0.87 \\
\hline Polynomial Order 2 & $-4,990.8$ & $65,706.2$ & 0.87 \\
\hline Polynomial Order 3 & 11,813 & $59,961.76$ & 0.86 \\
\hline Power & 0 & $67,218.29$ & \\
\hline
\end{tabular}

Both of these functions have greater capacity values than $0.0 \mathrm{lb}$ at the lower extent of the curve and the closest capacity value to the $61,669 \mathrm{lb}$ for the upper extent. The authors judge the upper extent to be of far more importance when judging the appropriateness of the fit of the function. The lower extent capacity value for the polynomial order 2 equation for the minimum wire area is $4,175.7 \mathrm{lb}$, and the upper extent capacity value for the same is $61,442.1 \mathrm{lb}$. The lower extent capacity value for the polynomial order 3 equation for the minimum wire diameter is $9,918.6 \mathrm{lb}$, and the upper extent capacity value for the same is $61,517.9 \mathrm{lb}$.

Figures 5.11 and 5.12 show the statistical data based on the selected trend lines for the minimum wire area and minimum wire diameter. For each trend line equation, the standard error for the capacity (along the force axis) was determined.

The standard error for the capacity of the wire given the minimum wire area is

$$
S E_{\text {MinWireatrea }}=\sqrt{\frac{\sum_{1}^{\text {numsamples }}\left[\text { Capacity }_{\text {sample }}-\text { Predictor }_{(\text {Eqn 5.1) }}\left(\text { MinWireArea }_{\text {sample }}\right)\right]^{2}}{\text { numsamples }-1}}
$$

and the standard error for the capacity of the wire given the minimum wire diameter is

$$
S E_{\text {MinWireDiameter }}=\sqrt{\frac{\sum_{1}^{\text {numsamples }}\left[\text { Capacity }_{\text {sample }}-\text { Predictor }_{(\text {Eqq 5.2) }}\left(\text { MinWireDiameter }_{\text {sample }}\right)\right]^{2}}{\text { numsamples }-1}}
$$


Figure 5.11. The selected data trend line (polynomial order 2) for the minimum wire area correlation and its standard deviation $(\sigma)$ information and the $95 \%$ CDF level information.

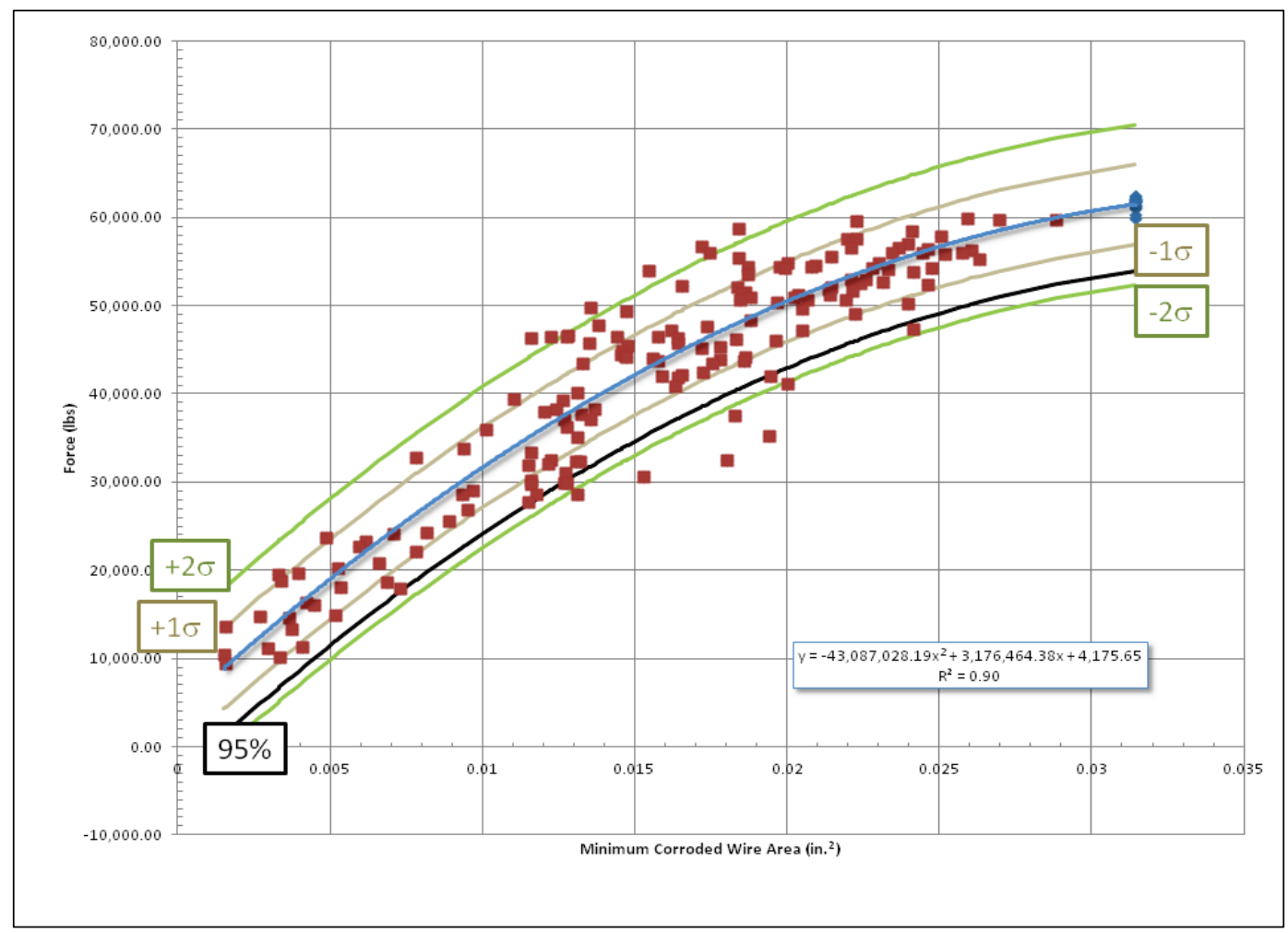

Figure 5.12. The selected data trend line (polynomial order 2) for the minimum wire diameter correlation and its standard deviation $(\sigma)$ information and the 95\% CDF level information.

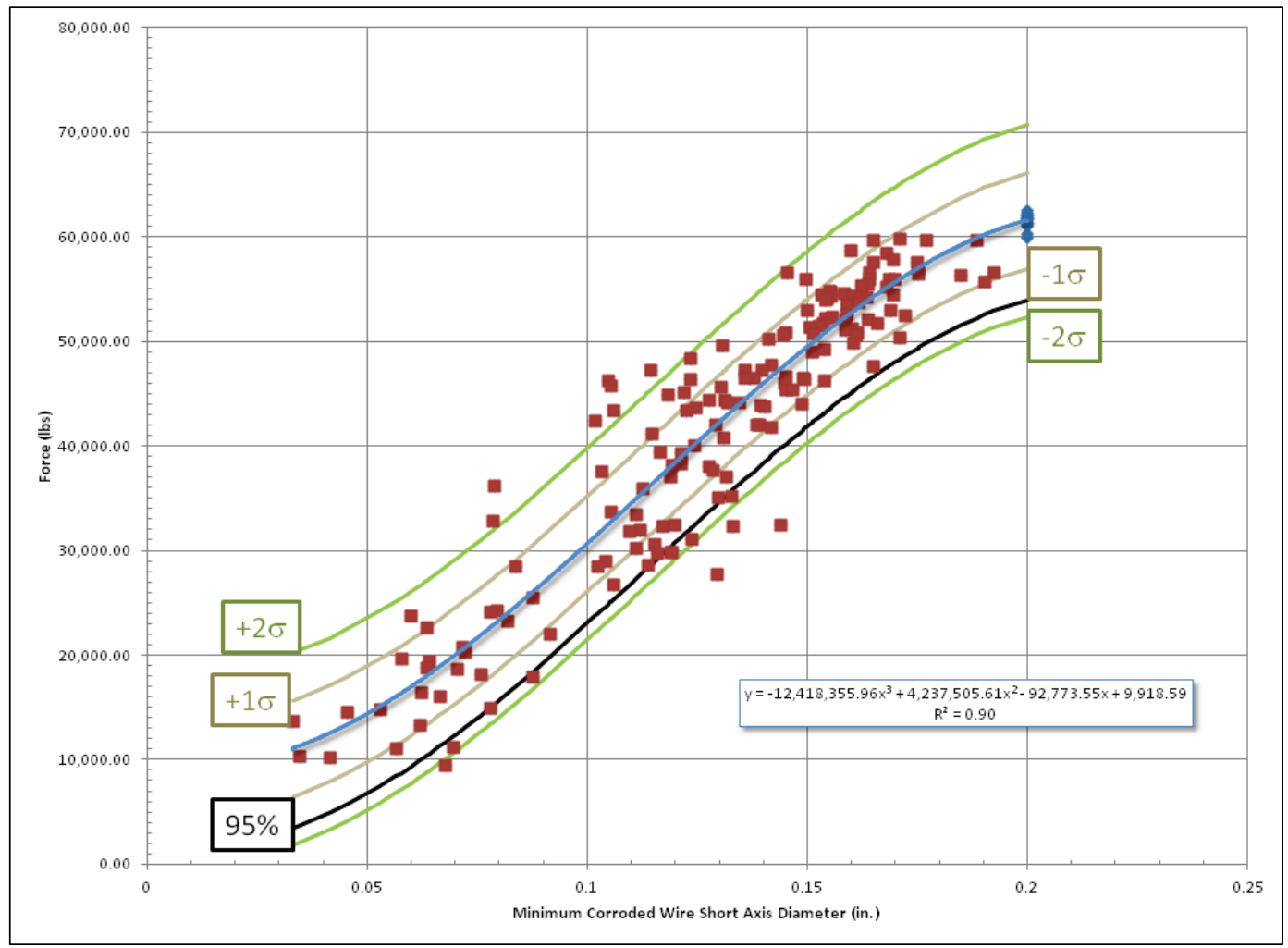


For the selected minimum wire area of the trend line equation, the samples had a standard error of 4,557 lb. For the selected minimum wire diameter trend line equation, the samples had a standard error of 4,589 lb. These standard errors vary by less than $1 \%$ from each other, and suggest that either correlation trend line would be as good as the other for predicting the capacity of a cable given the minimum cable area for the $1^{\text {st }}$ trend line equation and given the minimum wire diameter for the $2^{\text {nd }}$ trend line equation.

The minimum wire area of the trend line prediction for the 0.0 minimum wire area value gives a calculated cable capacity value of 4,175.7 lb in a parabolic $2^{\text {nd }}$ order polynomial curve. In addition, the minimum wire diameter trend line prediction for the 0.0 minimum wire diameter value gives a calculated capacity value of 9,918.6 lb in an exaggerated, S-shaped $3^{\text {rd }}$ order polynomial curve. From the optical scans of the wire ends, it was noticed that the outer wires' corrosion was rarely consistent, and that the inner king wire had much slower corrosion because the outer wires protected it. However, each wire of the cable is supporting the loading force in parallel, and the loss of any wire reduces the peak capacity of the cable. For this reason, it seems logical to the authors of this report that the parabolic $2^{\text {nd }}$ order polynomial curve for the minimum wire area is the best predictor of cable capacity.

In Figures 5.11 and 5.12, the green lines portray the $+-2 \sigma$ values for the trend lines, and the $+-1 \sigma$ values shown are in a tan color. The line giving $95 \%$ by the cumulative distribution function (CDF), where $95 \%$ of the values fall above that line, is shown in black.

The capacity ( $y$ in lb) equations for determining the +-2s trend lines, the +-1 s trend lines, the base trend line, and the $95 \% \mathrm{CDF}$ level trend line for the minimum wire area $(x)$ data can be computed using

$$
y=-43,087,028.19 x^{2}+3,176,464.38 x+4,175.65+b_{\text {MinWireArea }}
$$

where $b_{\text {MinWireArea }}$ is determined from Table 5.5 . 
Table 5.5. Basis for standard error of minimum wire area data.

\begin{tabular}{|l|l|}
\hline Relationship & b MinWireArea $_{(\mathrm{lb})}$ \\
\hline$-2 \sigma$ & -9114 \\
\hline $95 \%$ & -7519 \\
\hline$-1 \sigma$ & -4557 \\
\hline base & 0.0 \\
\hline$+1 \sigma$ & +4557 \\
\hline$+2 \sigma$ & +9114 \\
\hline
\end{tabular}

The capacity ( $y$ in lb) equations for determining the +-2s trend lines, the +-1 s trend lines, the base trend line, and the $95 \% \mathrm{CDF}$ level trend line for the minimum wire diameter $(x)$ data can be computed using

$$
y=-12,418,355.96 x^{3}+4,237,505.61 x^{2}-92,773.55 x+9,918.59+b_{\text {MinWireDiameter }}
$$

where $b_{\text {MinWireDiameter is determined from Table 5.6. }}$

Table 5.6. Basis for standard error of minimum wire diameter data.

\begin{tabular}{|l|l|}
\hline Relationship & bMinWireDiameter (lb) \\
\hline$-2 \sigma$ & -9178 \\
\hline $95 \%$ & -7572 \\
\hline$-1 \sigma$ & -4589 \\
\hline base & 0.0 \\
\hline$+1 \sigma$ & +4589 \\
\hline$+2 \sigma$ & +9178 \\
\hline
\end{tabular}




\section{Estimation of Embedded Seven-Strand Cable Post-Tension Capacity Loss Due to Corrosion}

\subsection{Background}

Post-tensioned rock anchors have been used in North America for over 40 years and have been continuously improved in designs, including corrosion resistance during this period; however, problems in the condition assessment remain (Bruce et al. 2006; Bruce and Wolfhope 2008). ERDC investigations described in this report have helped quantify the relationship between cross-sectional cable loss due to corrosion and load capacity for seven-strand post-tension cables. These investigations indicate that the load capacity is determined primarily by the smallest wire cross-section of the seven-strand assembly. A means or method to estimate remaining cross-sections for embedded cables is still needed desperately. One common approach is to attempt to estimate the ongoing corrosion rate and then attempt to integrate that non-linear quantity across in-service exposure time. For corroding rebar, half-cell potential, linear polarization, and corrosion potentials have proved moderately successful. For embedded post-tension cables, these methods are less informative, as indicated in the 2012 Florida Department of Transportation report (Azizinamini and Gull 2012). The aforementioned methods, as well as other existing condition assessment methods, are generally ill-suited for mass concrete applications. In typical massconcrete structures, the anchor head is typically the only portion of the post-tensioned cable where there is little or no concrete cover. Massconcrete structures, such as locks and dams, are also likely to have multiple moisture-penetration paths from sources such as filled lock chambers, filling culverts, ground water, and surface runoff. In the absence of a good direct non-destructive field assessment tool, a list of corrosion risk factors has been compiled. This approach is inherently flawed because of the difficulty in accurately assessing many of the critical inputs as well as the dependency of these variables on one another. Other technology sectors, such as ship hulls and pipe-lines, are using this approach, but their control and/or quantification of the corrosive environments is typically much better. For seven-strand, post-tension cable, one of the most critical and difficult-to-quantify factors is grout 
condition. This includes both the homogenous grout properties, as well as in homogeneities due to segregation, voids, etc.

This chapter describes the weaknesses of the anchor protection systems, particularly older protection systems. Probabilistic times to failure will be presented based upon corrosion rates that have resulted from the work of previous researchers.

The service life of structures can possibly be extended by the addition of anchorage systems, which are embedded in the base (bedrock) of the structure. These anchorages generally consist of bundles of cold rolled seven-strand cables (ASTM A416) that are loaded to about $60-80 \%$ of their tensile stress limit. The very high tensile stress on the cables may influence the susceptibility of the cable to corrosion as well as the rate of corrosion. Naaman (2004) reported that the average in-place stress of a posttensioned strand could be assumed to equal to about $147.068 \mathrm{ksi}$ $\left(1,014 \mathrm{~N} / \mathrm{mm}^{2}\right)$.

There is little reliable information published about the condition assessment of post-tensioned cable (or rods and bars) anchors. In the Corps of Engineers dams, condition assessment is done using a pull-off test that is expensive, dangerous, and, in some cases, destructive. A robust and reliable non-destructive (NDT) corrosion test method is still being researched (Haskins et al. 2014) and under development at ERDC.

Since post-tensioned cables are used extensively in bridge construction, the Federal Highway Department and various state highway departments have done most of the reliability research that has been done pertaining to PT systems. These studies primarily focus on bridges; therefore, the major corrosive materials present are chlorides because these are readily present from bridge salting and near sea/ocean proximity. For inland applications, this corrosion research information for high-chloride concentrations is of limited use.

As permanent anchorage services become older, the subject of anchor assembly failure becomes more important, particularly for anchorages installed over 30 years ago, which may have been designed with corrosionprotection considered inferior or inadequate by today's standards. An example would be relying on cement grout cover alone, where the grout has been injected remotely under pressure or by gravity displacement, to encase 
the tendon in situ. Even more recently installed anchorages are not immune to corrosion due to the employment of inappropriate protective materials and occasional shortcoming in the quality of workmanship, combined with an absence of rigorous quality assurance at the time of construction.

\subsection{Types of corrosion}

The corrosion process of prestressed steel tendons consists of two phases: (1) corrosion initiation and (2) corrosion propagation. Corrosion actually initiates when the protective oxide film that has formed around the steel member is compromised at and above a chloride concentration value or by lowering the $\mathrm{pH}$. The corrosion process produces rust products, loss of cross-sectional area and the reduction of concrete bond, all leading to rust staining, cracking and spalling of the structural components, reduction of structural capacity, and ultimately structural failure.

At least seven types of corrosion mechanisms are involved in prestressed anchorage corrosion (Hopwood and Havens 1984). All are invasive to the material, and include uniform corrosion, pitting corrosion, crevice corrosion, fretting, stress corrosion cracking, hydrogen cracking, and fatigue corrosion. In some cases, stress corrosion cracking, hydrogen (embrittlement) cracking, and fatigue corrosion are cracking processes that are produced by the other corrosion processes. Uniform corrosion of iron or steel usually involves an interaction between the iron hydrogen and oxygen. Contact of the steel with moisture is required to maintain uniform corrosion. The corrosion rate is dependent upon the amount of oxygen dissolved within the water and the temperature.

Hopwood and Havens (1984) identified the different forms of corrosion as:

- Pitting is a localized form of corrosive attack. The result of this type of attack is the formation of small but deep pits or holes. The corrosive rate of pits may be 100 times as great as that of uniform corrosion. There is little information available about the effect of pitting corrosion on the time-dependent reduction of cross-sectional area of posttensioned wires and the effect this has on wire load capacity. More research has been focused on pitting corrosion of reinforcing steel. There is also uncertainty about the failure modes associated for prestressing steel. Prestressing strands are also comprised of relatively small diameter wires that will suffer a larger proportion reduction in cross-sectional area than larger diameter bars experiencing the same 
corrosion rates (Darmanwan and Stewart 2007). Normally, pitting corrosion is experienced in environments where chloride ions are located such as salted bridges and highways, and seaside. However, both concrete and grout are generators of chloride salts.

- Crevice corrosion is due to the geometry of a local area where differences in oxygen concentration exist. This type of corrosion might be particularly present in anchor cables due to the helical structure of the stranded cable. The helical geometry includes interstitial spaces between the king wire and the outer wires.

- Fretting is a wear phenomenon occurring between two surfaces in motion but out-of-phase relative to one another.

- Stress corrosion cracking is a localized form of corrosive attack that consists of a corrosive attack such as pitting corrosions and the presence of a tensile force. Usually, stress corrosion cracking is characterized by branching and a transverse orientation to the applied tensile stress.

- Hydrogen stress cracking or hydrogen embrittlement is similar to stress corrosion cracking but is fueled by hydrogen, present in the metal or furnished by other corrosive mechanisms.

- Fatigue corrosion is cracking caused by a varying stress within a corrosive environment. Multiple types of corrosion or cracking may be present in anchor cable at any time.

- Other types of corrosion include biological and microbiological corrosion. There have been reports of biological and microbiological corrosion attacks in prestressed steel structures. Microbiologicalinfluenced corrosion of prestressing steel mainly due to bacteria has been reported in literature, while only a few papers report on the role of fungi in the corrosion failure of unbonded lubricated tendons (Filomena et al. 2013).

The authors of this report judged that the primary corrosion types that will affect anchor capacity are

- uniform corrosion across the surface, which reduces cross-sectional area evenly along the surface of each wire

- pitting, which is concentrated corrosion forming deep pits and affecting the area and the eccentricity of the cross-section area

- stress corrosion cracking due to tension on the cable, which allows pitting to form branches. 
The forensic investigation of John Day Lock anchorage revealed the presence of mildew (Ebeling et al. 2013), which can lead to microbiological corrosion. It was judged that this mildew was not likely to be a primary contributor for anchor corrosion at John Day.

\subsection{Pitting concerns}

Pitting is the type of corrosion that is cited most often in the technical literature. Most of these studies are concerned with corrosion of anchorage, decking, and girders of bridges. Pits can significantly reduce the capacity of post-tensioned cables by reducing the cross-section area and the inertial properties of the cross-section area of the cable. Observed pit depths of over $1 \mathrm{~mm}$ have been cited (Charng and Lansing 1982). Pits can also lead to stress corrosion cracking in post-tensioned anchorage, causing branching of pits, which lead to more concentrations of corrosion. Pitting affects the cross-section properties (area, second moment axes, etc.) of cables, as shown in Figures 5.11 and 5.12. Therefore, the loss of strength of the cable is primarily related to pit formation.

The electro-chemical mechanics behind pitting corrosion are well described in Lee and Zielske (2014), and that process is visually described in Figure 6.1. For steel structures in a wet environment, corrosion occurs when the oxygen concentration in the water and the chloride concentration exceed a certain value. The chlorides act as a catalyst to bind oxygen to the iron atoms in the steel structure, forming iron oxide (or rust). This releases electrons which move away from the corrosion to another part of the steel structure. The low resistance of the water outside of the steel allows this electrical process to continue. The corroded material can expand from 2 to 6 times the original material size (Broomfield 1997).

Figure 6.1. The process of pitting corrosion (after Lee and Zielske 2014).

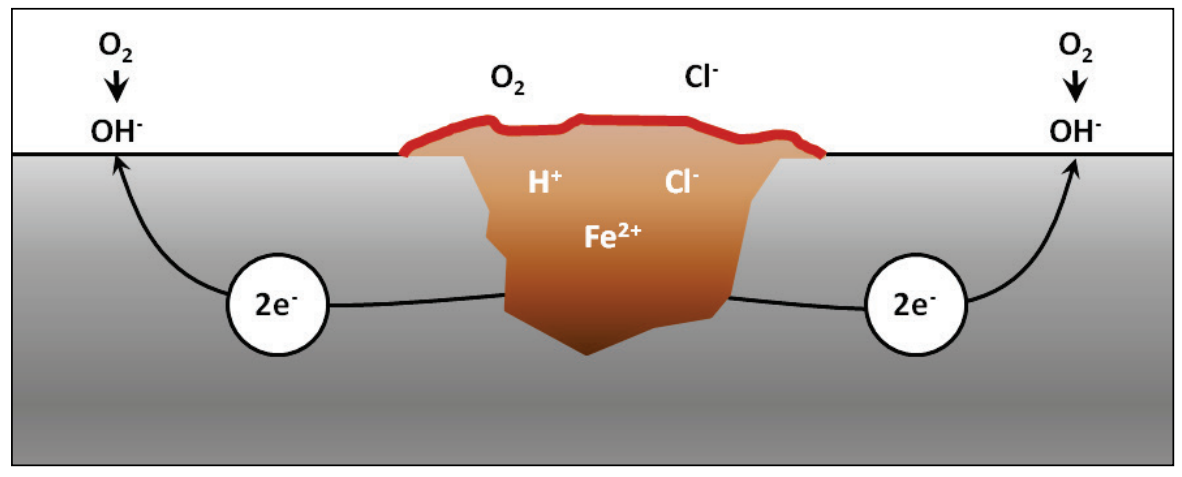




\subsection{Variables affecting pitting corrosion}

The rate that corrosion occurs is dependent on many conditions, some of which have been described above. Atmospheric corrosion of carbon steel occurs at about $0.0039 \mathrm{in} . / \mathrm{yr}(0.1 \mathrm{~mm} / \mathrm{yr}$ according to Charng and Lansing 1982) in environments free of strong chemical splash, spillage, or fumes. This type of corrosion occurs due to the presence of condensing moisture. The variables that affect the formation of this corrosion are (1) the $\mathrm{pH}$ balance of the environment and solution about the structure, (2) the concentration of oxygen in the solution about the structure, (3) the chloride and sulfate concentration in the solution about the structure, and (4) the temperature of the solution, which can affect the resistance of the solution. The following subsections discuss these variables and provide test results from several sources.

Unfortunately, it is nearly impossible to relate corrosion to just one variable. The variables are confounded, with the nonlinear response of one variable affecting the nonlinear responses of the other variables. In most of the literature, studies are made that return results from relationships between the variables. We will be looking at general trends of the variables, given various test results from the literature.

\subsection{1 pH}

\subsubsection{Effects of $\mathrm{pH}$}

The $\mathrm{pH}$ values in the environment surrounding the multistrand cable affect the corrosion rate of steel. $\mathrm{pH}$ measures the acidity of a chemical solution on a scale from o to 14, with a value of 7 being neutral. Acidic solutions have a value of less than 7 , and are more corrosive. Alkaline solutions have values greater than 7 , and are less corrosive. Since the discharge of hydrogen takes place in most corrosion reactions, acidity of the environment is one of the most important parameters in the corrosion process. In the case of ordinary iron or steel, the dividing line between rapid corrosion in neutral or alkaline solutions occurs at about $\mathrm{pH}=4.5$.

Figure 6.2 shows the corrosion rate for carbon steel in low-velocity oxygenated freshwater baths with varying $\mathrm{pH}$, with the rate being in micrometers per year. The carbon steel was immersed in air-saturated water and $\mathrm{NaOH}$ or $\mathrm{HCl}$ adjusted the $\mathrm{pH}$. The two curves reflect the corrosion rates at temperatures of $71.6{ }^{\circ} \mathrm{F}\left(22^{\circ} \mathrm{C}\right.$ - in blue $)$ and at $104{ }^{\circ} \mathrm{F}$ 
$\left(40^{\circ} \mathrm{C}-\right.$ in red). This graph indicates that higher corrosion rates occur with greater temperatures. It will later be shown that greater oxygen concentration in the water as in this test, and especially moving water, increases the corrosion rate. Collected data at different points are included in Table 6.1

Figure 6.2. Corrosion rate as a function of pH (after Charng and Lansing 1982 and Uhlig 1948).

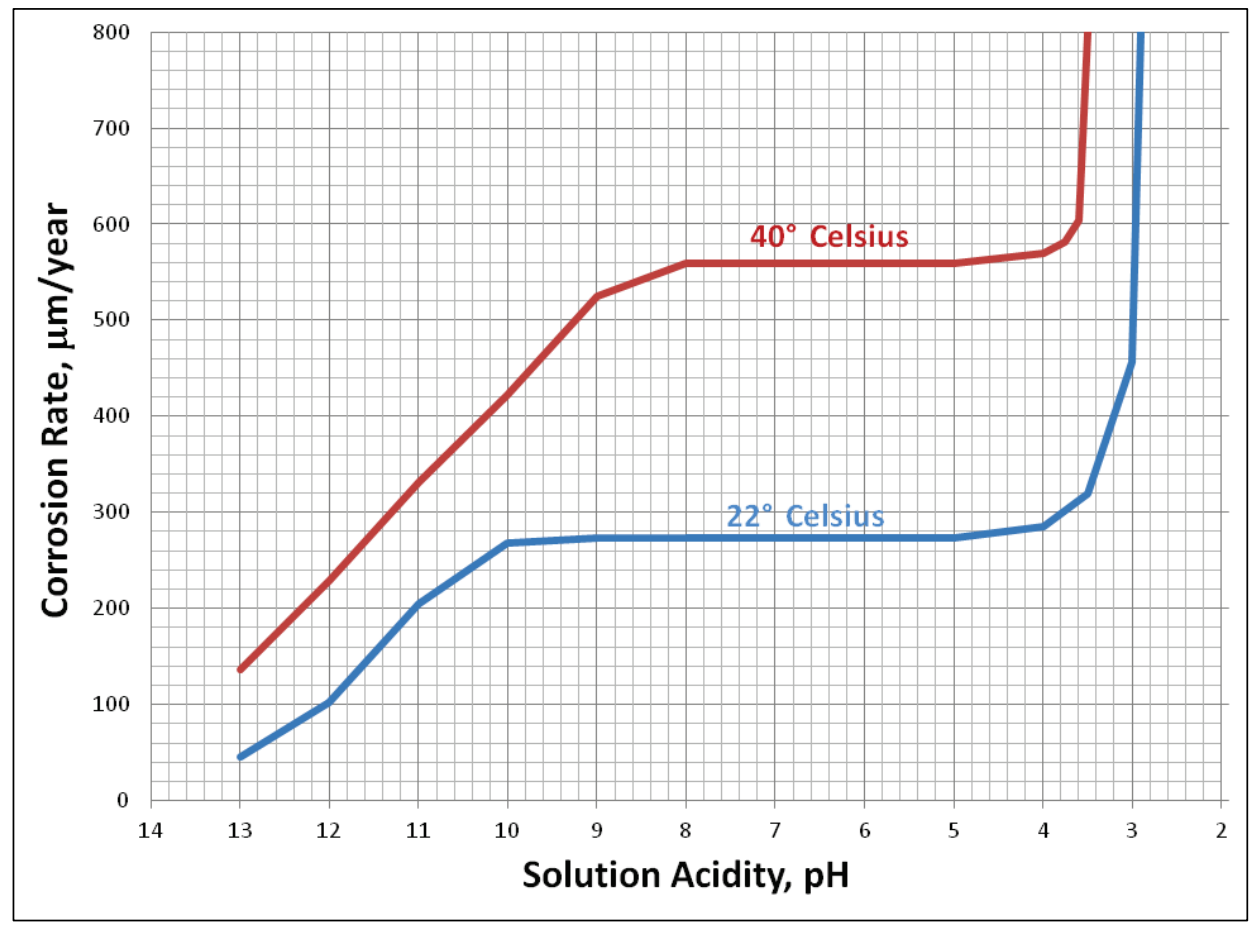

The trends for corrosion in both curves in Figure 6.2 have similar features, with values ramping up from the more alkaline $\mathrm{pH}$ range, from 13 to 8 for the $104^{\circ} \mathrm{F}\left(40{ }^{\circ} \mathrm{C}\right)$. Similarly, the $71.6^{\circ} \mathrm{F}\left(22^{\circ} \mathrm{C}\right)$ curve values are ramping up from the more alkaline $\mathrm{pH}$ range, from 13 to, and greater than, 10. The rate then levels off to a $\mathrm{pH}$ level of 4 for both curves, and then greatly accelerates for $\mathrm{pH}$ values less than 4 . At this point, the acidity of the solution with the steel causes the cable to act as a battery, which greatly increases the corrosion rate. 
Table 6.1. Corrosion rates for different pH levels at different temperatures for carbon steel tendon wires (after Charng and Lansing 1982).

\begin{tabular}{|l|l|l|l|l|}
\hline \multirow{2}{*}{$\mathrm{pH}$} & \multicolumn{2}{|c|}{ Corrosion Rate for $71.6^{\circ} \mathrm{F}\left(\mathbf{2 2}^{\circ} \mathrm{C}\right)$} & \multicolumn{2}{l|}{ Corrosion Rate for $104^{\circ} \mathrm{F}\left(\mathbf{4 0}^{\circ} \mathrm{C}\right)$} \\
\cline { 2 - 5 } & \multicolumn{1}{|c|}{ in./yr } & \multicolumn{1}{c|}{$\mu \mathrm{m} / \mathrm{yr}$} & \multicolumn{1}{c|}{ in./yr } & \multicolumn{1}{c|}{$\mu \mathrm{m} / \mathrm{yr}$} \\
\hline 13 & 0.0018 & 46 & 0.0054 & 137 \\
\hline 12 & 0.0040 & 103 & 0.0090 & 228 \\
\hline 10 & 0.0081 & 205 & 0.0130 & 331 \\
\hline 9 & 0.0106 & 268 & 0.0166 & 422 \\
\hline 8 & 0.0108 & 274 & 0.0207 & 525 \\
\hline 7 & 0.0108 & 274 & 0.0220 & 559 \\
\hline 6 & 0.0108 & 274 & 0.0220 & 559 \\
\hline 5 & 0.0108 & 274 & 0.0220 & 559 \\
\hline 4 & 0.0108 & 274 & 0.0220 & 559 \\
\hline 3.5 & 0.0113 & 285 & 0.0224 & 570 \\
\hline 3 & 0.0126 & 319 & 0.0315 & 800 \\
\hline 2.9 & 0.0180 & 456 & - & - \\
\hline
\end{tabular}

Investigations have been conducted that deal with the corrosion rates under specific environmental conditions (Griess and Naus 1975). These conditions varied from neutral solutions to increasing acidity. An example of this work is shown in Table 6.2. Assuming that the corrosion rate in the $2^{\text {nd }}$ and $3^{\text {rd }}$ columns are tangent values up to the 1,000 and 2,000 hour limits, respectively, the estimated corrosion at those times have been computed in the $4^{\text {th }}$ and $5^{\text {th }}$ columns. The first two rows contain information for a range of freshwater corrosions. The next two rows deal with chloride concentration, and the remaining rows deal with acidic solutions about the metal structure. Notice that the more acidic solutions greatly increase the corrosion rate. 
Table 6.2. Corrosion of tendon wires in different environments with restricted access to oxygen (after Griess and Naus 1975).

\begin{tabular}{|l|l|l|l|l|}
\hline Test Environment & $\begin{array}{l}1,000 \mathrm{hrs} \\
(\text { Corrosion Rate, } \\
\left.(\mu \mathrm{m} / \mathrm{yr})^{*}\right)\end{array}$ & $\begin{array}{l}2,000 \mathrm{hrs} \\
(\text { Corrosion Rate, } \\
\left.(\mu \mathrm{m} / \mathrm{yr})^{*}\right)\end{array}$ & $\begin{array}{l}\text { Corrosion after } \\
1,000 \mathrm{hrs} \\
(\mu \mathrm{m})\end{array}$ & $\begin{array}{l}\text { Corrosion after } \\
2,000 \mathrm{hrs} \\
(\mu \mathrm{m})\end{array}$ \\
\hline Potable Water & 5.8 & 5.3 & 0.6621 & 1.2671 \\
\hline Distilled water & 5.1 & 5.3 & 0.5822 & 1.1872 \\
\hline $0.01 \mathrm{M}^{* *} \mathrm{NaCl}^{* * *}$ & 6.4 & 9.7 & 0.7306 & 1.8379 \\
\hline $0.03 \mathrm{M} \mathrm{NaCl}^{* * *}$ & 6.6 & 7.9 & 0.7534 & 1.6552 \\
\hline $0.001 \mathrm{M} \mathrm{NaNO}_{3}^{* * * *}$ & 7.4 & 23.1 & 0.8447 & 3.4817 \\
\hline $0.01 \mathrm{M} \mathrm{NaNO}_{3}^{* * * *}$ & 11.2 & 8.1 & 1.2785 & 2.2032 \\
\hline $0.002 \mathrm{M} \mathrm{Na}_{2} \mathrm{SO}_{4}^{* * * * *}$ & 5.8 & 7.6 & 0.6621 & 1.5297 \\
\hline $0.02 \mathrm{M} \mathrm{Na}_{2} \mathrm{SO}_{4}^{* * * * *}$ & 7.6 & 13.2 & 0.8676 & 2.3744 \\
\hline $0.2 \mathrm{M} \mathrm{Na}_{2} \mathrm{SO}_{4}{ }^{* * * *}$ & 8.9 & 13.5 & 1.0160 & 2.5571 \\
\hline
\end{tabular}

*1= mpy $=25.4 \mu \mathrm{m} / \mathrm{yr}$

** $1 \mathrm{M}=1$ mole per liter

*** $\mathrm{NaCl}$ solution is saltwater

**** $\mathrm{NaNO}_{3}$ solution is nitric acid

${ }^{* * * * *} \mathrm{Na}_{2} \mathrm{SO}_{4}$ solution is sulfuric acid

\subsubsection{Grout raises $\mathrm{pH}$}

Because grouts and concretes use Portland cement, which is made by processing lime, the $\mathrm{pH}$ values for these materials is raised. In the field for grouts and concrete, typical $\mathrm{pH}$ values range from 9.0 to 13.6 (Lee and Zielske 2014). These high values for $\mathrm{pH}$ mean that, for grouted multistrand anchors, the high rates of corrosion in acidic environments do not apply.

\subsubsection{Chloride concentration}

It has been mentioned that chlorides serve as a catalyst in the corrosion process. Escalante and Ito (1990) state that while dissolved oxygen controls the rate of corrosion, chlorides affect the initiation of corrosion at a number of localized sites. The most common chloride mentioned in the corrosion literature is sodium chloride (salt). Because most of the corrosion papers are concerned with bridges, chlorides are typically introduced through seawater or efforts to de-ice the bridge for traction. Figure 6.3 shows the effect of concentrated sodium chloride in the water on corrosion. Sodium chloride for seawater is nearly $3 \%$ concentrated in the water and is therefore near the peak of the corrosion curve. 
This situation does not exist with multi-anchor systems. However, chlorides can be a part of the grout mixture that surrounds the seven-wire strand anchor cables. These chlorides are introduced either unintentionally (usually through contaminated water or aggregate) or intentionally, in an effort to control the curing process. These chlorides reach the steel through porosity of the grout in the presence of a head of water, or segregation of the grout mixture, during the insertion of the grout.

Corrosion initiation or depassivation occurs when the corrosion of the outer film on the steel outperforms the formation of a protective oxide barrier at the surface of the steel. When this limitation is reached, the iron oxides allow the electrolyte (in this case, water with chlorides) to penetrate to the uncorroded substrate, forming pits and accelerating the corrosion process. The general acceptance by Song and Shayan (1998) is that a critical chloride concentration exists that will initiate a breakdown in the passive film and allow serious corrosion of the "active" steel.

Figure 6.3. Corrosion rate as a function of sodium chloride concentration (after Roberge 2008 and Berry 1984).

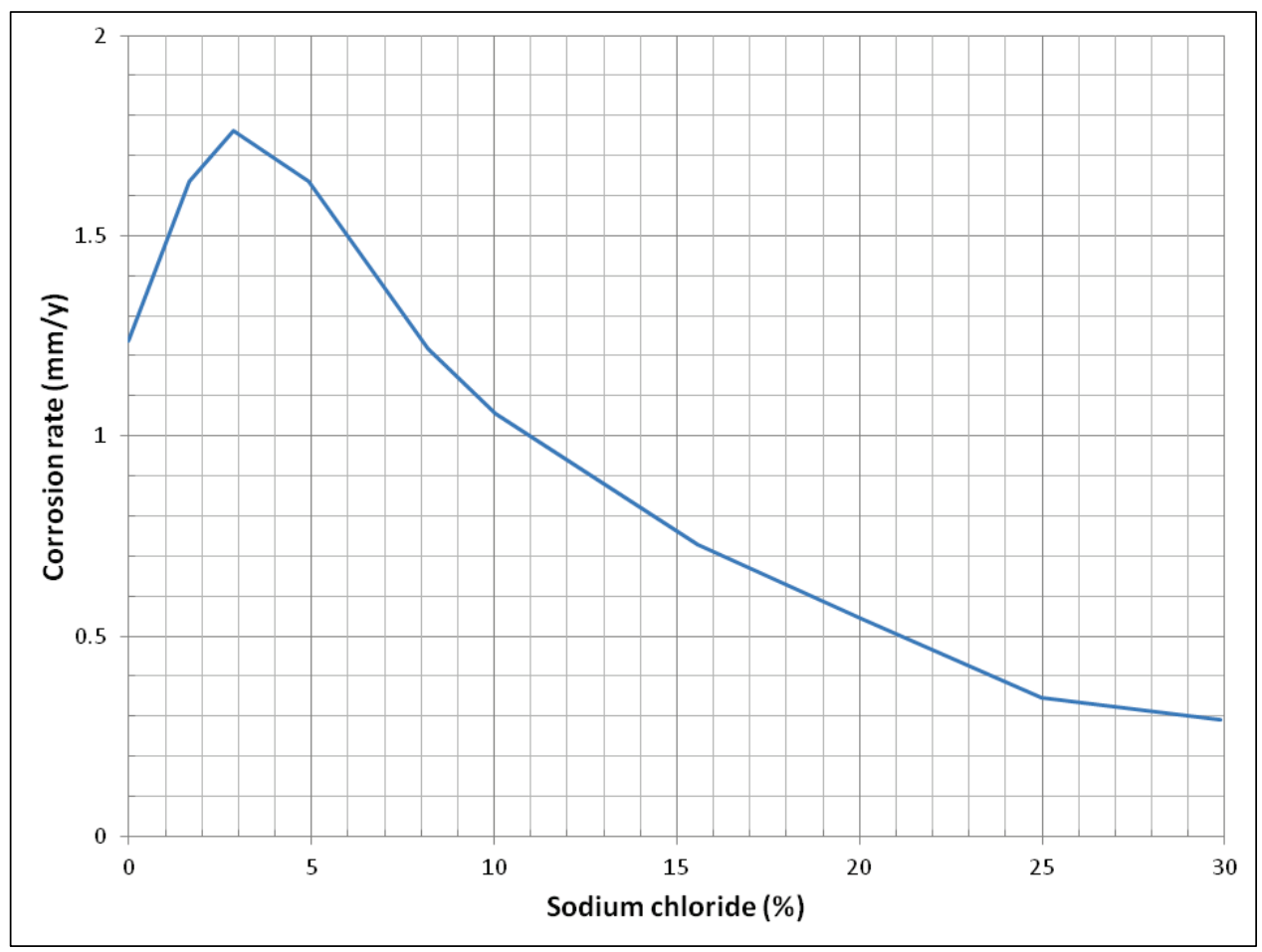

It is important to make not of the magnitude of chloride concentration that is has been measured when reviewing the corrosion literature. The three methods of measuring chloride concentration are (1) percentage per unit 
volume of solution (Trejo et al. 2009); (2) parts per million (ppm) per unit volume of grout (Wang et al. 1995); and, (3) ppm per unit volume of cement used in the grout, presumably before mixture (Lee and Zielske 2014).

Besides exploring the effect of voids in Table 6.4, Trejo et al. (2009) also explored the effect of chloride concentration in a fresh (tap) water solution on the reduced capacity of stressed and unstressed cables due to corrosion. Recall that the mean capacity of the pristine cables was measured as 60.5 kips $(269 \mathrm{kN})$. Looking only at information for orthogonal voids, which were associated with the greatest loss of cable capacity, Figure 6.4 shows the capacity of stressed and unstressed cables, assuming mean capacity for extremely low chloride concentrations (1.oE- $10 \%$ of solution). Both curves show a marked change in capacity starting at $0.001 \%$ chloride concentration in solution, to follow with a linear path in the log chart. This implies that corrosion has initiated with chloride concentrations less than $0.0001 \%$ in a solution.

Figure 6.4. Cable capacity in relation to chloride concentration in solution (derived from Trejo et al. 2009).

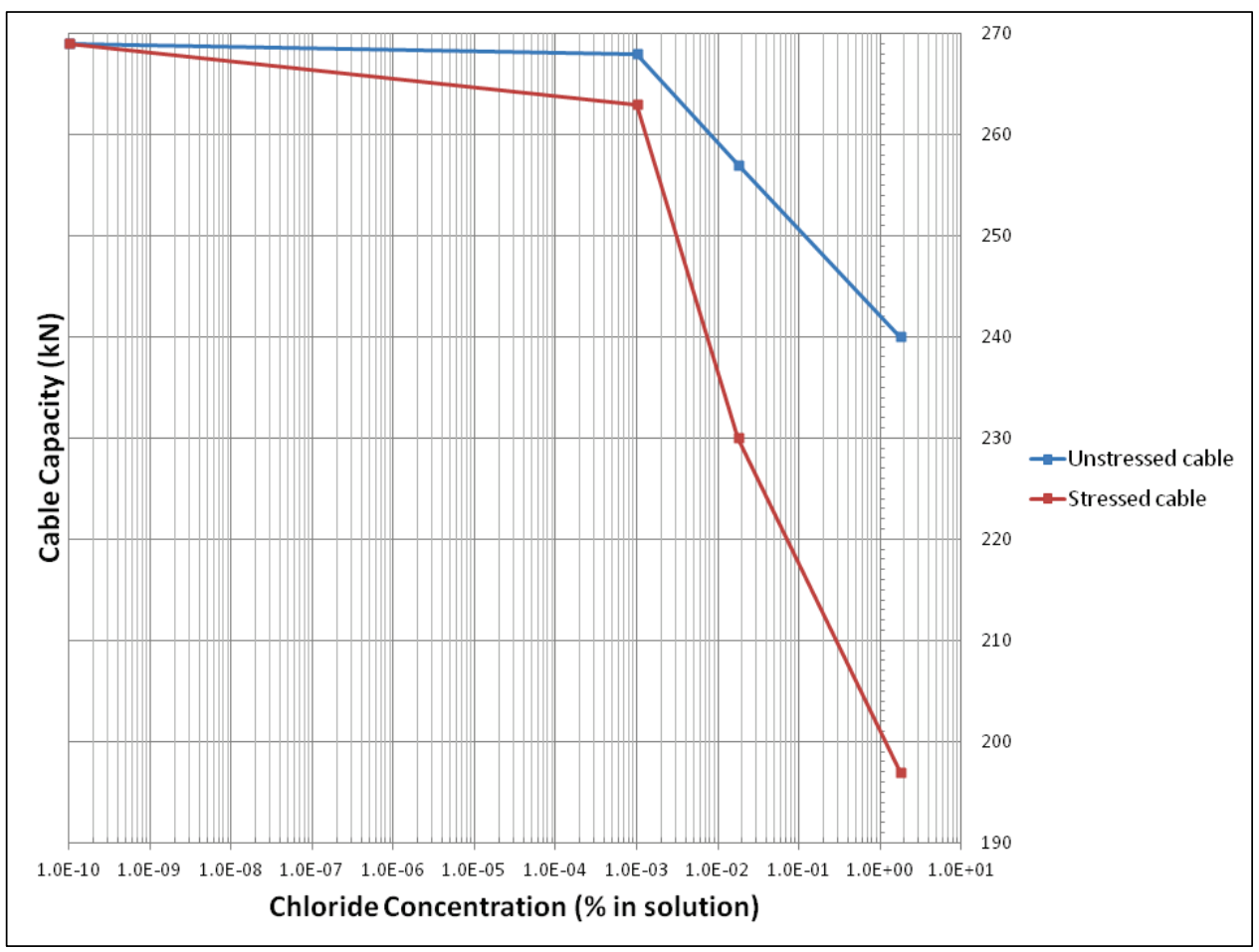

For the unstressed cable, the 18 times increase from $0.0001 \%$ chloride concentration to $0.018 \%$ concentration in solution reduces the capacity by nearly $5 \%$ from the mean capacity, whereas the 100 times increase from 
$0.018 \%$ to $1.8 \%$ chloride concentration in solution only reduces the capacity by another $5 \%$ of the mean capacity. For the stressed cable, the 18 times increase from $0.0001 \%$ chloride concentration to $0.018 \%$ concentration in solution reduces the capacity by nearly $14.5 \%$ from the mean capacity, whereas the 100 times increase from $0.018 \%$ to $1.8 \%$ chloride concentration in solution only reduces the capacity by another $12.2 \%$ of the mean capacity.

In Wang et al. (1995), it is mentioned that corrosion initiation of steel could occur with fresh water if the native chloride concentration of the surrounding grout exceeded a relatively small amount (e.g., $500 \mathrm{ppm}$ or $0.05 \%$ by volume of grout). If the grout is hydrated with freshwater, the chloride content of the pore water depends on the native chloride content of the water, the porosity of the hydrated grout (expressed as $\varepsilon$ ), and the chloride-binding isotherm of the system (Wang et al. 1995 and $\mathrm{Li}$ and Sagues 2001). Wang et al. (1995) and Li and Sagues (2001) recommend representative values of $\varepsilon=0.2$, concrete density $2 \mathrm{~g} / \mathrm{cm}^{3}$, with a bound/free chloride ratio of 10:1. Since the chlorides are leached from the grout into the penetrating solution, these numbers seem consistent with Trejo et al.'s (2009) chloride concentration per solution values.

The Lee and Zielske (2014) report suggests two limits for chloride concentrations in pre-mixed cement for grout that will encase posttensioned anchor cables. From their experiments, they interpreted that a $0.4 \%$ chloride concentration in cement for commercially mixed grout would be enough to initiate corrosion. When this threshold was reached in the experiments, rust spots began to form on the specimen and pits began to form beneath the rust spots.

Lee and Zielske (2014) also suggested a second threshold for corrosion propagation, $0.8 \%$ chloride concentration, in the premixed cement for commercially mixed grout. Per their measurements at this threshold, inspection of the specimens demonstrated that corrosion started to intensify in terms of number of pits and pit depth. With this chloride concentration in the cement, significant corrosion damage can be anticipated. Previous ACI limits had been set with the presumption that a level of existing chlorides per weight of cement was needed to provide enough acid-soluble chloride ions to continue corrosion once the oxide film had been removed. Post-Tensioning Institute (PTI 2012) also set limits for the mixing of grout to reduce chloride concentrations in grout. 
Besides monitored mixing, PTI only allowed mixing grout with potable water with less than 500-ppm chlorides and less than $0.08 \%$ chlorides per weight of mixed grout. A number of situations can affect these thresholds: carbonated grout, segregated grout, duct cracks, grout voids filled with water with or without chloride ions, or free sulfate ions in contact with the strands. In addition, lowering the $\mathrm{pH}$ by a small amount can make a significant difference for these thresholds (Wang et al. 1995).

\subsubsection{Oxygen concentration}

Figure 6.5 shows Charng and Lansing's (1982) plot of the effect of concentrated oxygen in a solution on the rate of corrosion. For these tests, carbon steel was immersed in slow moving water at $77^{\circ} \mathrm{F}\left(25^{\circ} \mathrm{C}\right)$, and with a pH that was greater than 7 and less than 10 . With no oxygen, the corrosion rate is o.o. The corrosion rate increases as more oxygen is dissolved into the solution until a peak is reached when the oxygen concentration reaches approximately $1.15 \%(11.5 \mathrm{ml} / \mathrm{l})$. At this point, the addition of dissolved oxygen begins to retard the corrosion rate for distilled water by reforming the oxide film on the steel at nearly the same rate as corrosion (Uhlig 1971). However, the addition of chlorides, as shown in the red curve of Figure 6.5, makes a very large difference in the curve. This growth rate starts the same, but seems to continue for much longer; implying that increasing oxygen concentration in water will continue to increase the corrosion rate linearly. For a $\mathrm{pH}$ value of 10 , the critical oxygen concentration for the peak corrosion rate occurs at $6 \mathrm{ml} / \mathrm{l}$.

Dissolved oxygen is one of the primary drivers in corrosion formation. Seawater is a highly corrosive environment, largely due to chlorides and uncontrolled acidity, but Table 6.3 shows that the corrosion rate for steel depends on the availability of oxygen to the steel (in this case steel wall systems). The highest corrosion range occurs in the range of sea spray and decreases with depth. 
Figure 6.5. Corrosion rate as a function of oxygen concentration (Charng and Lansing 1982).

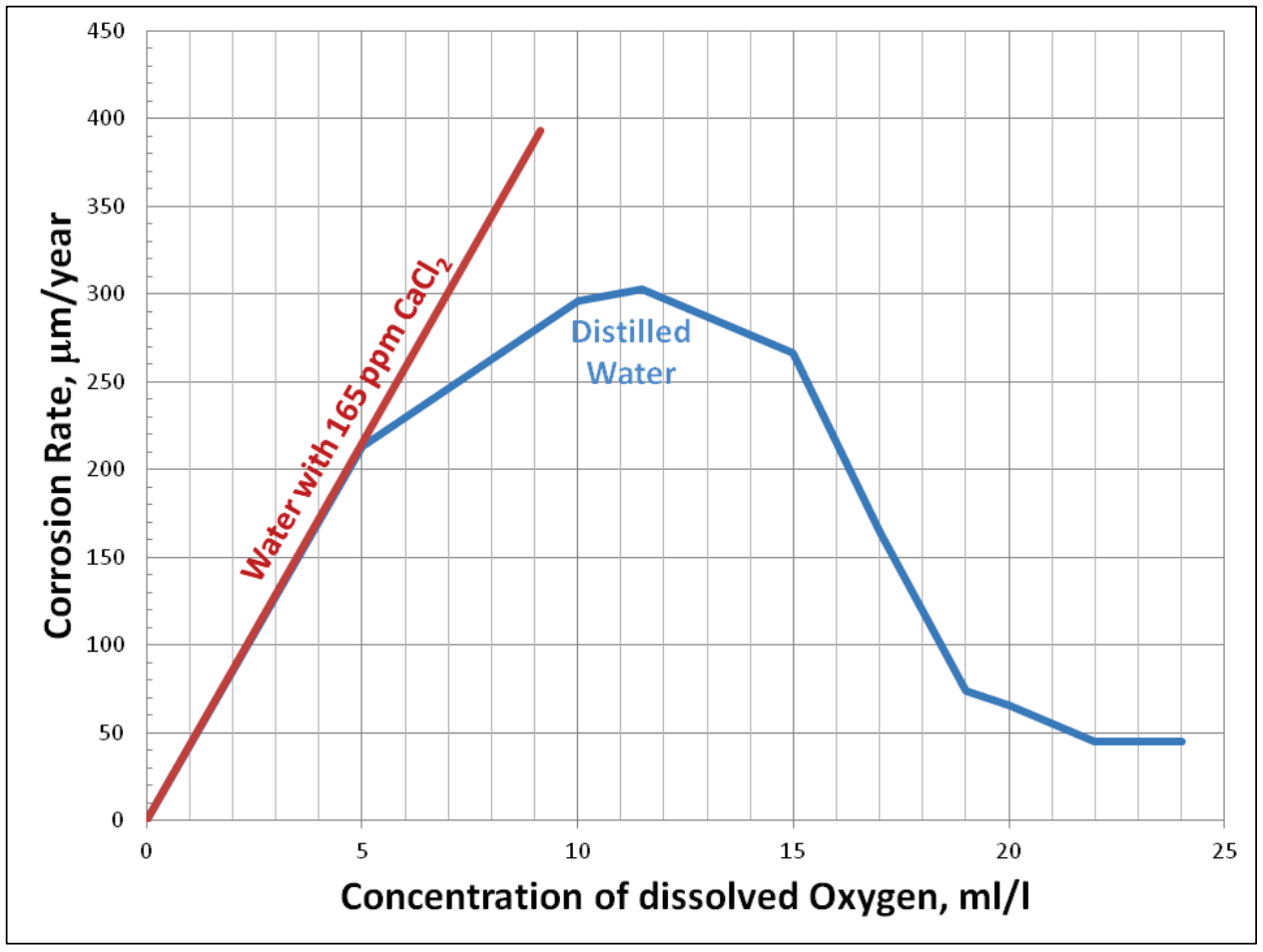

Table 6.3. Corrosion rates on coastal steel structures as a function of depth (after The Overseas Coastal Area Development Institute of Japan 2009).

\begin{tabular}{|c|c|c|}
\hline \multicolumn{2}{|r|}{ Corrosive Environment } & Corrosion rate $(\mathrm{mm} / \mathrm{yr})$ \\
\hline \multirow{4}{*}{$\begin{array}{l}\frac{0}{0} \\
\frac{0}{n} \\
\mathbb{D} \\
\infty\end{array}$} & High water level or higher & 0.3 \\
\hline & High water level to low water level - $1 \mathrm{~m}$ & $0.1-0.3$ \\
\hline & Low water level $-1 \mathrm{~m}$ to seabed & $0.1-0.2$ \\
\hline & Under seabed & 0.03 \\
\hline \multirow{3}{*}{$\begin{array}{l}\frac{0}{0} \\
\frac{0}{0} \\
\frac{0}{0} \\
\end{array}$} & Above ground and exposed to air & 0.1 \\
\hline & Underground (residual water level and above) & 0.03 \\
\hline & Underground (residual water level and below) & 0.02 \\
\hline
\end{tabular}

\subsubsection{Water velocity}

Moving water also has an effect on the corrosion rate of metals (Figure 6.6). This corrosion test was performed with a carbon-steel pipe carrying municipal water at $69.8^{\circ} \mathrm{F}\left(21^{\circ} \mathrm{C}\right)$. In this figure, it is shown that slow moving water $(<3.1496 \mathrm{in} . / \mathrm{sec}(0.08 \mathrm{~m} / \mathrm{sec})$ for smooth-surfaced metal and $<13.7795 \mathrm{in} . / \mathrm{sec}(0.35 \mathrm{~m} / \mathrm{sec})$ for rough-surfaced metal) increases the corrosion rates of metal by a significant amount. After peaking, the corrosion rates drop for smooth and rough surfaces. This drop becomes less steep for smooth surfaces, but reverses for rough surfaces. 
Figure 6.6. Corrosion rate as a function of solution velocity (after Charng and Lansing 1982).

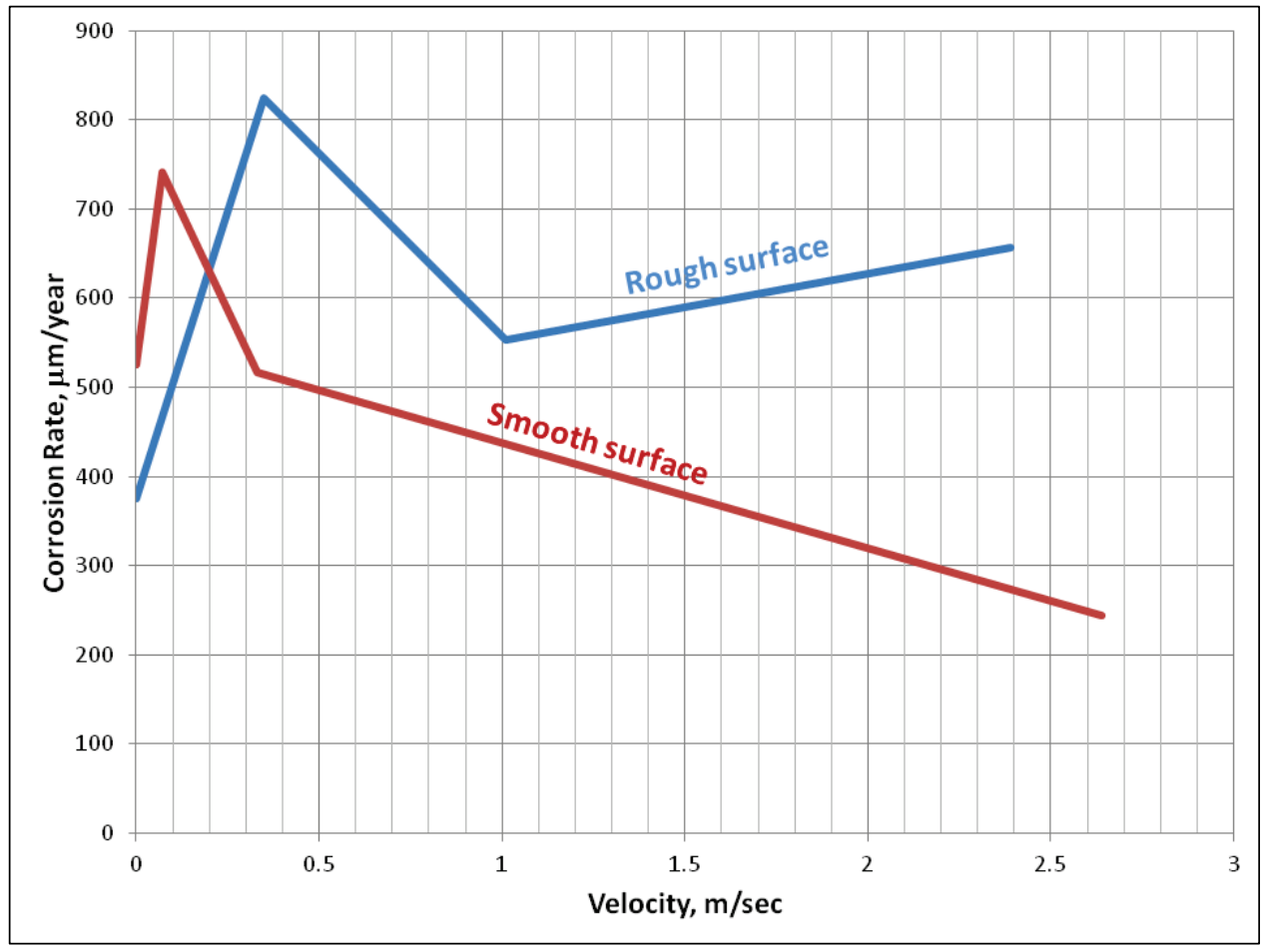

One possible cause for these curves is that a slow-moving solution introduces more dissolved oxygen to the surface of the metal. As the velocity increases, the oxygen does not stay in place as long for a chemical reaction to occur. For rough surfaces, higher velocities introduce turbulence, which starts to form pockets of slower-moving fluids close to the metal. This results in higher available oxygen concentration.

\subsubsection{Voids in grout}

When voids exist in grout, either due to a bad pour or due to grout decomposition, they allow oxygenated water and chlorides to come in contact with cables, enabling corrosion and a subsequent loss of cable capacity. Researchers such as Trejo et al. (2009) have conducted laboratory tests using 298 test samples to identify the statistically significant parameters that influence the corrosion activity and reduction in the tension capacity of post-tensioning strands. These tests were performed in a 12month period using $40.98 \mathrm{in}$. $(1,041 \mathrm{~mm})$ long, $0.591 \mathrm{in}$. (15 mm) diameter strand pieces meeting ASTM A416/A 416M-99 specifications obtained from the same spool, heat, and lot. The nominal cross-sectional area Aps of the strands was $0.000217 \mathrm{in}^{2}\left(0.140 \mathrm{~mm}^{2}\right)$. The strands with negligible corrosion were defined as as-received strands. The guaranteed ultimate 
tensile strength (GUTS) and average tension capacity of as-received strands were 58.675 and $60.473 \mathrm{kips}$ ( 261 and $269 \mathrm{kN}$ ), respectively. The nominal tensile stress $\mathrm{f}_{\mathrm{pu}}$ and average modulus of elasticity were $270 \mathrm{ksi}$ (1862 $\left.\mathrm{N} / \mathrm{mm}^{2}\right)$ and $215 \times 15.81 \mathrm{ksi}\left(215 \times 109 \mathrm{~N} / \mathrm{mm}^{2}\right)$, respectively. CLoss, which is defined as the percentage of capacity due to corrosion, is discussed in Table 6.4.

A percentile capacity loss (CLoss) greater than $3.1 \%$ indicates the meantension capacity is less than the guaranteed ultimate strength (GUTS) of the as-received strands.

Further noted under general observations by Trejo et al. (2009), PT strands are made of six outer wires helically wound around a center wire. This geometry results in interstitial spaces between the center wire and the outer wires. These spaces could lead to the initiation of crevice corrosion and other types of corrosion between the inner and outer wires due to the lack of oxygen availability in those spaces. This lack of oxygen availability slows the corrosion process. This condition could also lead to a more severe corrosion on the outer wires then on the center wire. Although challenges exist in correlating surface corrosion with remaining tension capacity in order to investigate this further, cables were ordered and subjected to accelerated corrosion to different degrees. With as-received cables, the mean capacity of the strands were $60.5 \mathrm{kips}(269 \mathrm{kN})$. Minor pitting corrosion can cause the tension capacity to fall below its as-received capacity down to 58.6857.78 kips (261-257 kN). As would be expected, further pitting corrosion (depth wise) results in a greater loss of capacity. In Trejo et al.'s research, the effect of stress conditions (i.e., unstressed and prestressed) in the NV, $\mathrm{PV}$, and OV sample conditions was assessed for the effect of stress level (see Table 6.4). ${ }^{1}$ Both stressed and unstressed cables experience similar capacity reduction when completely embedded in grout (NV condition). When voids were present (PV and OV samples), the stressed samples exhibited significantly higher capacity losses than corresponding unstressed samples. This capacity loss, due to higher stress levels, can be attributed to the possible synergistic effects of small surface-crack formation at axial stresses. The mean loss CLoss (\%) of the sample population (298) is shown in Table 6.4.

$1 \mathrm{NV}=$ no void exists

$\mathrm{PV}=$ void is parallel to the axis of the strands

$\mathrm{OV}=$ void is orthogonal to the axis of the strands 
Table 6.4. Mean, coefficient of variation (COV), and mean percentage loss (CLoss)* of capacity (abbreviated table after Trejo et al. 2009).

\begin{tabular}{|c|c|c|c|c|c|c|c|c|c|c|}
\hline \multirow{3}{*}{$\begin{array}{c}\text { Stress } \\
\text { Level } \\
\text { ksi } \\
\left(\mathrm{N} / \mathrm{mm}^{2}\right)\end{array}$} & \multirow[b]{3}{*}{$\begin{array}{l}\text { Void } \\
\text { Type }\end{array}$} & \multicolumn{9}{|c|}{ Chloride Concentration \% (of solution) } \\
\hline & & 0.0001 & 0.018 & 1.8 & $0.0001^{1}$ & 0.018 & 1.8 & $0.0001^{1}$ & 0.018 & 1.8 \\
\hline & & \multicolumn{3}{|c|}{$\begin{array}{l}\text { Mean Capacity } \\
\text { kips }(k N)\end{array}$} & \multicolumn{3}{|c|}{$\operatorname{cov} \%$} & \multicolumn{3}{|c|}{ CLoss \% } \\
\hline \multirow{3}{*}{$\approx 0.0$} & NV & $\begin{array}{l}59.35 \\
(264)\end{array}$ & $\begin{array}{l}59.12 \\
(263)\end{array}$ & $\begin{array}{l}56.43 \\
(251)\end{array}$ & 0.3 & 0.5 & 3.0 & 1.8 & 2.5 & 6.6 \\
\hline & PV & $\begin{array}{l}60.25 \\
(268)\end{array}$ & $\begin{array}{l}59.12 \\
(263)\end{array}$ & $\begin{array}{l}58.68 \\
(261)\end{array}$ & 3.3 & 0.6 & 2.3 & 0.0 & 2.3 & 2.9 \\
\hline & OV & $\begin{array}{l}60.25 \\
(268)\end{array}$ & $\begin{array}{l}57.78 \\
(257)\end{array}$ & $\begin{array}{l}53.95 \\
(240)\end{array}$ & 2.6 & 3.6 & 2.5 & 0.2 & 4.6 & 10.2 \\
\hline \multirow{3}{*}{$\begin{array}{l}149.969 \\
(1034)\end{array}$} & NV & & $\begin{array}{l}59.35 \\
(264)\end{array}$ & $\begin{array}{l}56.43 \\
(251)\end{array}$ & 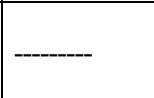 & 0.2 & 3.1 & 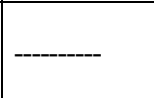 & 1.8 & 6.7 \\
\hline & PV & |-..-- & $\begin{array}{l}57.55 \\
(256)\end{array}$ & $\begin{array}{l}55.08 \\
(245)\end{array}$ & $-\ldots$ & 2.3 & 0.8 & ---- & 4.8 & 9.0 \\
\hline & OV & $\begin{array}{l}59.12 \\
(263)\end{array}$ & $\begin{array}{l}51.71 \\
(230)\end{array}$ & $\begin{array}{l}44.29 \\
(197)\end{array}$ & 0.5 & 2.4 & 2.2 & 2.3 & 14.4 & 27.0 \\
\hline \multicolumn{2}{|c|}{$\begin{array}{l}\text { As Received } \\
\text { Strands }\end{array}$} & \multicolumn{3}{|c|}{$60.47(269)$} & \multicolumn{3}{|l|}{3.1} & \multicolumn{3}{|c|}{-ב- } \\
\hline
\end{tabular}

1Samples were kept in standard room condition and not exposed to wet/dry cycles

---- indicates no test was done

NOTES:

1298 samples were tested in this 12-month strand corrosion (SC) test program

$21 \mathrm{ksi}=6.895 \mathrm{~N} / \mathrm{mm} 2$

Where NV = No Void exists; PV = Void is parallel to the axis of the strands; OV = Void is orthogonal to the axis of the strands.

The results indicate that corrosion for cables with grouts containing voids can affect the capacity of the cables and the orientation of the voids has an effect on the level of corrosion. These results also indicate the orthogonal voids have a greater effect than the parallel voids. For unstressed cables in a high-chloride environment, the reduction in capacity was nearly $10 \%$ greater, and for the stressed cables in a high-chloride environment, the reduction in capacity was nearly $20 \%$ greater. Orthogonal voids cause pitting to occur across the cross-sectional area of the cable, rather than along the cable. The percent difference in capacity of unstressed and corresponding stressed samples varied from $1.6 \%$ to as high as $18.7 \%$.

Moisture with negligible chlorides present, such as rainwater, induces an accelerated localized corrosion when void conditions are present. This negligible chloride moisture with void conditions results in reduced strand capacity up to $11.4 \%$ over a 12-month exposure period. 
The coefficient of variation (COV) is a normalized measure of dispersion of a probability distribution or frequency distribution. COV is mathematically defined as the ratio of the standard deviation $\alpha$ to the mean $\mu$ as

$$
\mathrm{COV}=\sigma / \mu
$$

It shows the variability in relation to the mean of the population. In Table 6.4, the variability, COV, is shown as a percentage of the 298 samples.

\subsubsection{Temperature}

Some temperature data have already been presented in Figure 6.2 and Table 6.1 (adapted from Charng and Lansing 1982). In the absence of additional data, the Figure 6.2 corrosion rate may be linearly interpolated for temperatures in the range of $71.6^{\circ} \mathrm{F}\left(22^{\circ} \mathrm{C}\right)$ to $104^{\circ} \mathrm{F}\left(40^{\circ} \mathrm{C}\right)$ as a function of temperature, as shown in Figure 6.7. The data in this figure demonstrate that because corrosion rate diminishes with the lowering of temperature, it may be conservative to use $71.6^{\circ} \mathrm{F}\left(22^{\circ} \mathrm{C}\right)$ corrosion rates cited in Table 6.1 for temperatures below $71.6^{\circ} \mathrm{F}\left(22^{\circ} \mathrm{C}\right)$. Conversely, it would not be conservative to use the $104^{\circ} \mathrm{F}\left(40^{\circ} \mathrm{C}\right)$ corrosion rates cited in Table 6.1 for temperatures above $104^{\circ} \mathrm{F}\left(40^{\circ} \mathrm{C}\right)$. From data gathered from Lee and Zielske (2014) in their Figure 88, it must be acknowledged that the corrosion-rate change with temperature is non-linear. Lee and Zielske (2014) posit that there is an inverse relationship between temperature and grout resistivity. Therefore, corrosion is slowed as the temperature is decreased.

Figure 6.8 shows the results of testing of corrosion in pipes using tap water with varying concentrations of dissolved oxygen (at very low levels). In this situation, the $\mathrm{pH}$ is uncontrolled and the water is moving slowly, so the amount of corrosion is much higher than the Charng and Lansing (1982) data from subsection 6.4.3. This chart reveals the trend for the increase of corrosion at low levels of oxygen concentration, but also reveals the nonlinear nature of the rate of change of the corrosion rate as the temperature increases in the solution from $48.2^{\circ} \mathrm{F}\left(9^{\circ} \mathrm{C}\right)$ to $48.2^{\circ} \mathrm{F}$ $\left(89.6^{\circ} \mathrm{C}\right)$ and to $122^{\circ} \mathrm{F}\left(50^{\circ} \mathrm{C}\right)$.

Figure 6.9 shows the derived nonlinear change in corrosion for four of the dissolved oxygen levels in Figure 6.8 with respect to temperature. Better approximations of the change in corrosion rate with temperature may be obtained by finding interpolating functions for these curves. 
ERDC/ITL TR-16-4

70

Figure 6.7. Linear interpolation of corrosion rate with respect to temperature for various $\mathrm{pH}$ values.

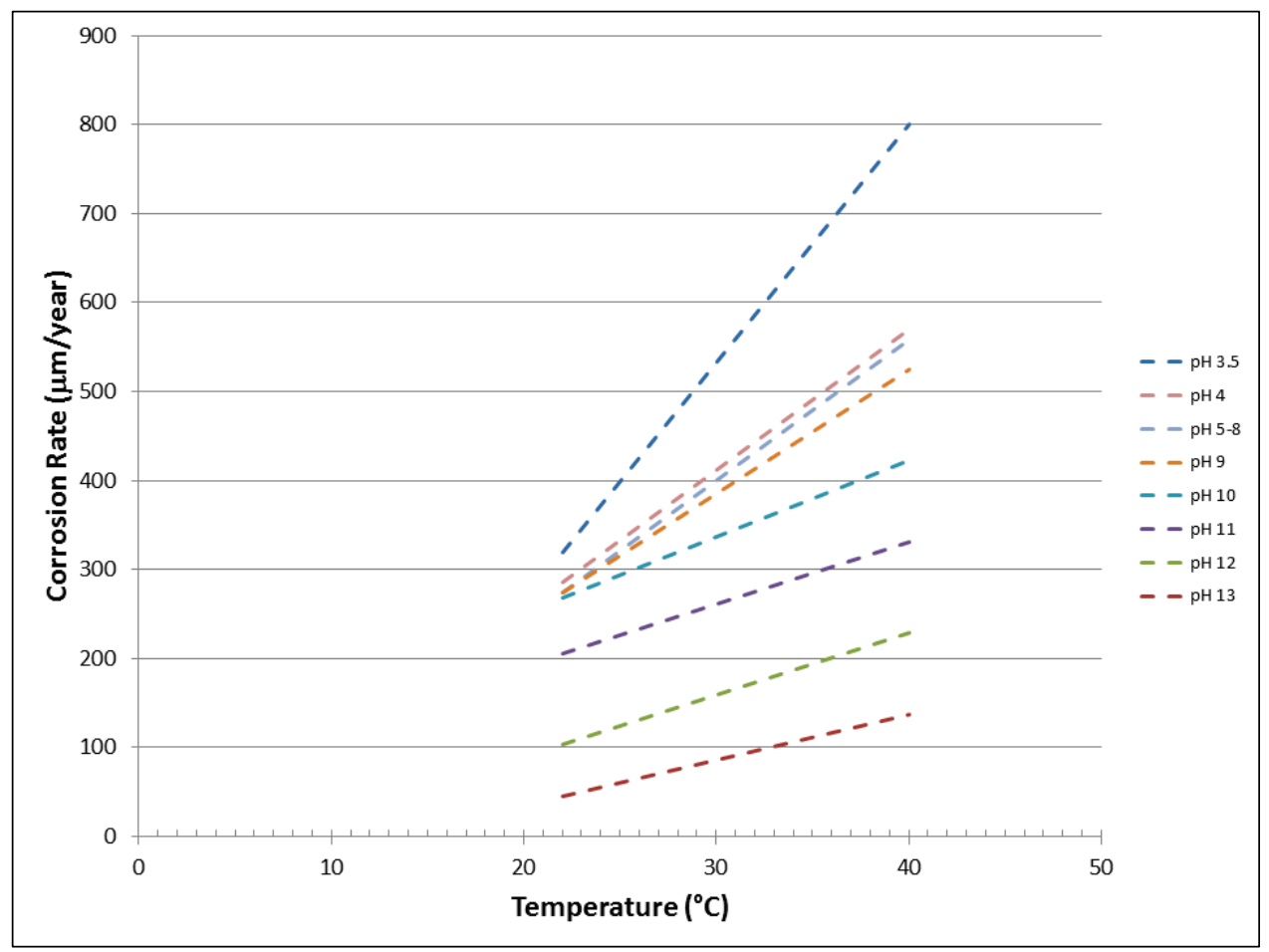

Figure 6.8. Corrosion rate in tap water with respect to dissolved oxygen at three different temperatures (after Roberge 2008 and Berry 1984).

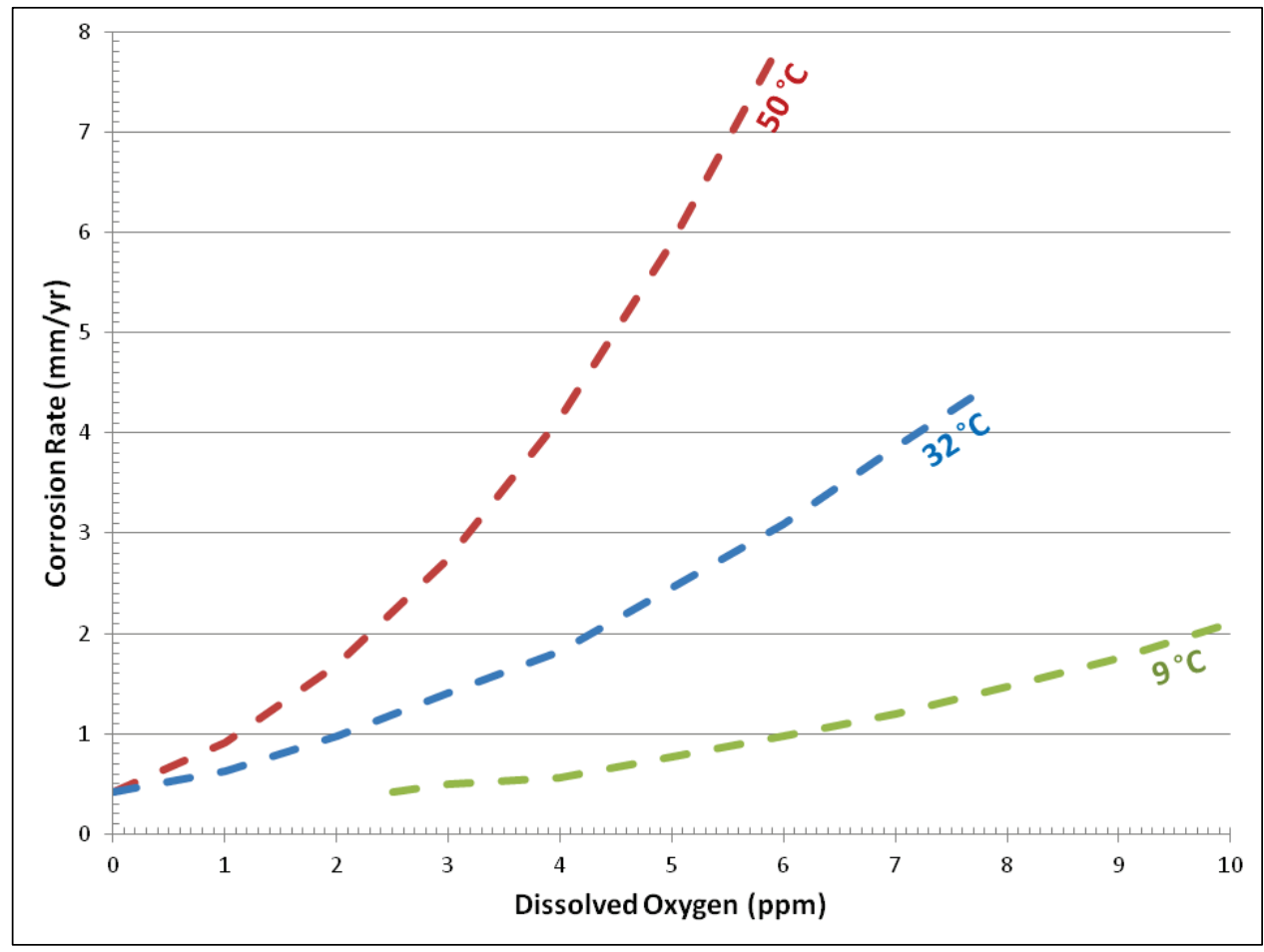


Figure 6.9. Change of corrosion rate as temperature increases (derived from the data used for Figure 6.8).

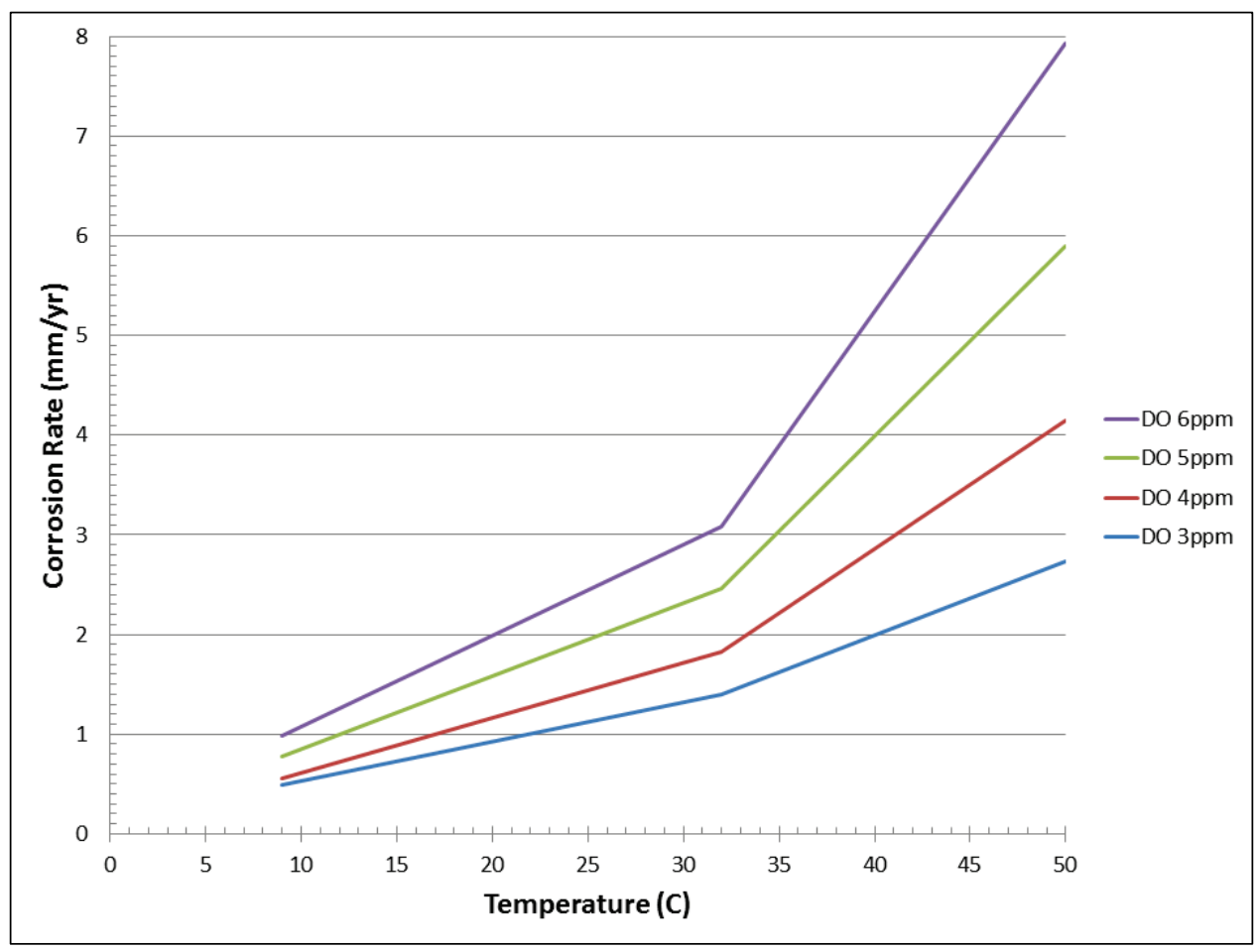

Melchers (2003) developed a probabilistic model for unpainted "at-sea" immersion corrosion of mild and low alloy steels based on fundamental corrosion mechanics. This four-phase, corrosion depth versus time model is nonlinear and defined by three distinct tangent-corrosion versus time (e.g., $\mathrm{mm} / \mathrm{yr}$ ) constants for the three different time segments in the model. In this paper, corrosion data recovered from field measurements is summarized and used to define the best estimate model parameters. These data were obtained from eleven projects in different parts of the world that are exposed to seawater and suffering corrosion. The initial, phase 1, kinetic reaction rate-controlled part of the corrosion-versus-time model is linear and ranges in values from 0.09 to $0.31 \mathrm{~mm} / \mathrm{yr}$. Observe that this range in values is consistent with the Table 6.3 high water level to low water level range in values. Additionally, the Melchers data clearly shows the temperature dependence of the value for kinetic-reaction rate as a function of temperature; the higher temperatures possess the higher the corrosion rate and vice versa. Melchers derived the following relationship for the kinetic corrosion rate, $r_{o}(\mathrm{~mm} / \mathrm{yr})$, as a function of temperature, $T$ (centigrade),

$$
r_{o}=0.0539 *[2]^{0.1 * T}
$$


This linear relationship defines the initial part of the corrosion depthversus-time relationship. Values for the other two tangent segments of corrosion-versus-time in Melchers' model are designated as $r_{a}$ and $r_{s}$. Like corrosion model parameter $r_{o}$, the values of $r_{a}$ show the same trend with higher values for higher sea temperatures as $r_{o}$ and also fall within the Table 6.3 high water level to low water level range in values. The third corrosion model parameter, $\mathrm{r}_{\mathrm{s}}$, also shows the same trend with higher values for higher sea temperatures as $r_{o}$ but are of a lower magnitude than the Table 6.3 high water level to low water level range in values. Equations (not given) were derived for $r_{a}$ and $r_{s}$ as a function of temperature. Here again, the dependency of corrosion rate on temperature is clearly demonstrated in the three corrosion rate parameters of $r_{o}, r_{a}$, and $r_{s}$ in Melchers' model. These at-sea corrosion rate values are above the freshwater values for corrosion rate.

\subsection{By-products of pitting corrosion}

\subsubsection{Current-density}

Because corrosion is an electro-chemical process, the release of electrons causes a current to be formed in the steel of the seven-strand wire cable. This effect occurs in the region around an individual pit as shown in Figure 6.1. Lee and Zielske (2014) refer to this effect as "micro-cell" behavior. However, also an effect occurs for the entire length of the cable. This is an induced current from all of the micro-cell currents that occur along the anchor cable, and is referred to as "macro-cell" behavior of the cable.

It is for this reason that corrosion rate is not only measured in penetration depth per year ( $\mathrm{mm} / \mathrm{yr}$ or $\mu \mathrm{m} / \mathrm{yr}$ ), but also in the current density, an electrochemical unit of measure, usually expressed as $i_{\text {corr, }}$, with units of $\left(\mu \mathrm{A} / \mathrm{cm}^{2}\right)$. Andrade et al. (1988), Bertolini et al. (2004), and others state that, in the case of steel, $10 \mu \mathrm{A} / \mathrm{cm}^{2}$ corresponds to an approximate loss of mass of $90 \mathrm{~g} / \mathrm{m}^{2} \mathrm{yr}$ and a penetration depth of $11.6 \mu \mathrm{m} / \mathrm{yr}$. Andrade et al. (2004) further characterized this relationship for volume loss due to corrosion $\left(V_{\text {corr }}\right)$ with the following equation.

$$
V_{\text {corr }}(\mathrm{mm} / \mathrm{yr})=0.0116 i_{\text {corr }}\left(\mu A / \mathrm{cm}^{2}\right)
$$

Lee and Zielske (2014) expanded on the general corrosion concept. Table 6.5 shows their interpretation of the corrosion-rate criteria. 
Table 6.5. Corrosion-rate criteria (after Lee and Zielske 2014).

\begin{tabular}{|c|c|c|}
\hline \multirow[b]{2}{*}{$\begin{array}{l}\text { Degree of } \\
\text { Corrosion }\end{array}$} & \multicolumn{2}{|c|}{ Corrosion Rate Criteria } \\
\hline & $\begin{array}{c}\text { Corrosion } \\
\text { Current Density } \\
\mu \mathrm{A} / \mathrm{cm}^{2}\left(\mu \mathrm{A} / \mathrm{in}^{2}{ }^{2}\right)\end{array}$ & $\begin{array}{l}\text { Corrosion } \\
\text { Penetration Rate } \\
\text { (mils/yr) }\end{array}$ \\
\hline Negligible & $<0.1(0.645)$ & $<0.046$ \\
\hline Low & $0.1-0.5(0.645-3.226)$ & $0.046-0.230$ \\
\hline Moderate & $0.5-1.0(3.226-6.452)$ & $0.230-0.460$ \\
\hline High & $>1.0(6.452)$ & $>0.460$ \\
\hline
\end{tabular}

This same general gage of corrosion criteria in terms of corrosion current density is also stated in Andrade et al. (2004).

Darmawan and Stewart (2007) have developed methods for determining the probability of pits of a certain depth forming given a certain current density. These methods, based on Gumbel distribution probabilistic functions, predict pit depth given variables of current density, length of cable, and time exposed to the current density.

Wang et al. (2005) suggest that a rough, possibly unconservative, indication of the corrosion rate may be obtained by measuring the macrocell current. The estimate may not be conservative because it assumes that the macro-cell current density is approximately the anodic galvanic current at the micro-cell level. One point to mention is galvanic response. For the anchor-head connection point, if the anchor cable is of a different material than any feature of the anchor head (e.g., wedges, plates), a galvanic response can cause one material to act as an anode and the other to act as a cathode. This galvanic response could accelerate corrosion at the top of the anchor (Wang et al. 2005).

At present, there are many methods for the determination of corrosion rates of metals, such as gravimetric-based mass loss, quartz crystal microbalance-based mass loss, electrochemical, electrical resistance, and solution analysis. The polarization measurement methods based on electrochemical concepts enable determination of instantaneous reaction rates at the electrode/solution interface, such as the exchange current density in case of electrode equilibrium and the corrosion current density in case of a corrosion system from a single experiment. All other methods require multiple measurements over time to provide information on the corrosion rate (Badea et al. 2010). 
The corrosion current, $\mathrm{I}_{\text {corr, }}$ in embedded steel rebar reinforcement is affected by many factors and can be expressed using a factorial approach as follows;

$$
I_{\text {corr }}=f\left(k_{1}, k_{2}, \ldots \ldots ., k_{n}\right)
$$

in which $\mathrm{k}_{1}, \mathrm{k}_{2}, \ldots \ldots . ., \mathrm{k}_{\mathrm{n}}$ represent the factors affecting corrosion attack and propagation, e.g., $\mathrm{pH}$ of the surrounding material, moisture content, oxygen, and carbonation.

In order to assess the condition of embedded steel reinforcement related to any ongoing corrosion, a recommended electrochemical test method for the estimation of the instantaneous corrosion current density, $i_{\text {corr, }}$ expressed in $\mu \mathrm{A} / \mathrm{cm}^{2}$ in large size concrete structures is the so-called polarization resistance, $\mathrm{R}_{\mathrm{p}}$, method. The values of $\mathrm{I}_{\text {corr }}$, can be used to assess the rate of degradation of concrete structures affected by reinforcement corrosion. However, they cannot give information on the actual loss in steel cross section. At present, it only can be assessed by means of direct visual observation (Andrade et al. 2005). Values of the free corrosion potential or half-cell potential $\mathrm{E}_{\mathrm{corr}}[\mathrm{V}]$ of the embedded reinforcing steel and of the electrical concrete resistance, $\mathrm{Re}_{\mathrm{e}}[\Omega]$, are obtained as preliminary steps of the $\mathrm{R}_{\mathrm{p}}$ measurements. Values of the concrete resistivity, $\rho[\Omega \mathrm{m}]$, can be calculated from $\mathrm{R}_{\mathrm{e}}$ values providing the geometrical arrangement of the electrodes enable this calculation.

Both parameters $\mathrm{E}_{\mathrm{corr}}$ and $\mathrm{R}_{\mathrm{c}}$ (or $\rho$ ) may be used to complement the reliability of the $i_{\text {corr }}$ measurements.

The test methods described in the present recommendation are suitable for on-site condition assessment of steel-reinforced concrete structures.

The methods can be applied regardless of the thickness of concrete cover and the rebar size or detailing. However, when the bars are electrically connected, only the corrosion of the closer layer of reinforcements facing the counter electrode (CE) can be measured. This closer reinforcement layer practically shields the penetration of the polarizing current to deeper-lying reinforcements. When rebar are electrically isolated, the steel bar that is connected to the instrument will be measured irrespective of its depth. 
The test method can be used at any time during the service life of the structure, and in any kind of climate, providing the temperature is higher than $0^{\circ} \mathrm{C}$. A very dry concrete surface of $\rho>1000 \Omega \mathrm{m}$ (a material has an electrical resistivity of one ohm meter if a one-meter cube of the material has a total resistance, face-to-face, of one ohm) makes the measurement difficult. Some pre-wetting may improve this. The $i_{\text {corr }}$ obtained by this test method may be used to calculate the loss in rebar cross section by means of integration of $i_{\text {corr }}$ during the propagation period, provided the initiation

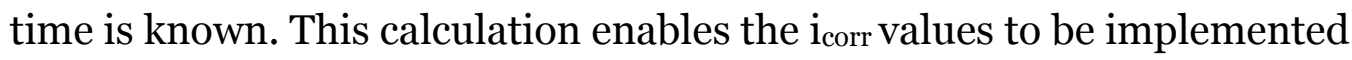
into structural models in order to assess the further development of the structural performance with respect to cover cracking, loss of bond, and loss of load-bearing capacity.

The corrosion current values icorr, in addition to the measurement of the corrosion potential $\mathrm{E}_{\mathrm{corr}}$, and of the concrete resistivity $\rho$, may be complemented by other data from the concrete, such as rebar diameter, chloride profile, depth of carbonation, porosity, temperature, cover thickness, exposure conditions, crack patterns, etc. These data can help in the evaluation and prediction of future performance of the structure.

The corrosion rate $\mathrm{V}_{\text {corr, }}$, or corrosion velocity, represents the volumetric loss of metal by unit of area and unit of time. In this recommendation, it is expressed in $\mathrm{mm} / \mathrm{yr}$, although other units may also be used. $\mathrm{V}_{\text {corr }}$ expressed in $\mathrm{mm} / \mathrm{yr}$ is obtained from the corrosion current in $\mu \mathrm{A} / \mathrm{cm}^{2}$ through Ohm's law and the density of steel.

Ohm's Law states that

$$
\mathrm{V}=\mathrm{IR}
$$

where, in this instance, $\mathrm{V}$ is the voltage (potential) in the circuit, $\mathrm{I}$ is the current in amperes, and $\mathrm{R}$ is the resistance (in ohms ) of the circuit.

Wagner and Traud (1938) showed that a simple relationship exists between the polarization resistance at the rest potential and the corrosion rate. In 1957, Stern and Geary emphasized the practical applicability of this relationship. Two specific techniques of corrosion detection using electrochemical methods have been developed. One technique is the Tafel extrapolation and the second technique is the Linear Polarization Resistance related to the Stern-Geary equation (Stern and Geary 1957). 
Both the Tafel extrapolation method and the Linear Polarization Resistance methods are well established. The use of these methods to determine the corrosion of steel reinforcement began around 1973. The Tafel extrapolation method is based on the fact that often, over a region at either side of the free corrosion potential ( $\mathrm{E}_{\mathrm{corr}}$ ), the current is proportional to the exponential of the potential. On a semi-logarithmic plot the response is linear, and the anodic and cathodic polarization curves are extrapolated to $\mathrm{E}_{\text {corr }}$ to obtain

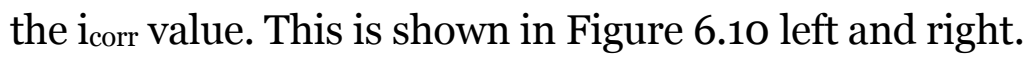

Figure 6.10. (1) exponential current curve related to potential voltage, (2) semi-logarithmic plot showing linear relationship.

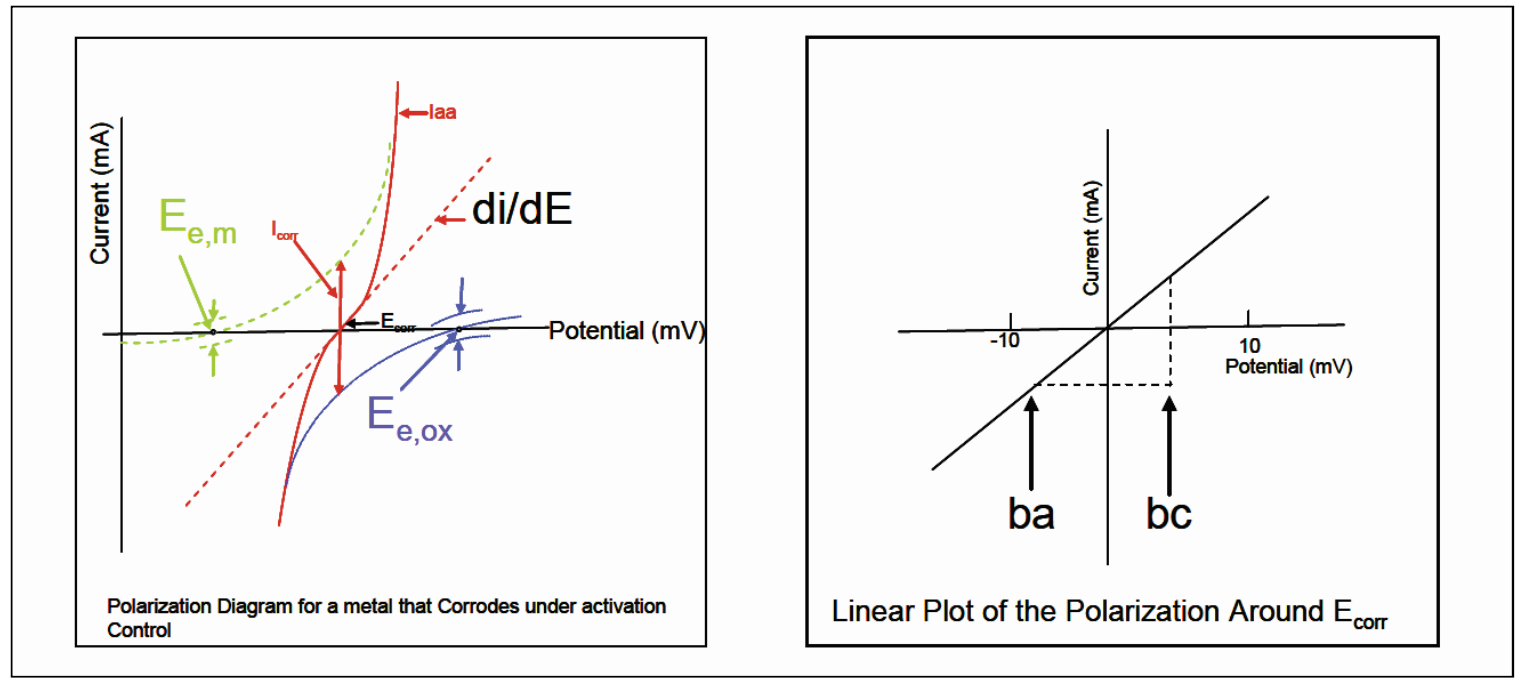

The Stern-Geary equation (Andrade 2004) for calculating the corrosion current $\mathrm{i}_{\text {corr }}$ can be formulated by

$$
\mathrm{i}_{\text {corr }}=\mathrm{B} / \mathrm{R}_{\mathrm{p}}
$$

where $B$ is the proportionality constant and $R_{p}$ is the polarization resistance.

In standard units:

$$
\text { Corrosion Rate }(\mathrm{CR})=\left(\left(\mathrm{I}_{\text {corr }} \mathrm{x} \text { E }\right) / \mathrm{A} \text { x D }\right) \times 128.67
$$

where CR is the corrosion rate (mils/yr), $\mathrm{E}$ is the equivalent weight of the corroding metal $(\mathrm{g}), \mathrm{A}$ is the area of the corroding electrode $\left(\mathrm{cm}^{2}\right)$, and $\mathrm{D}$ is the density of corroding metal $\left(\mathrm{g} / \mathrm{cm}^{3}\right)$. 
The proportionality constant B for a particular system can be determined or calculated from the slopes of the anodic and cathodic Tafel plots, ba, and bc, respectively.

$$
\mathrm{B}=\mathrm{ba} \times \mathrm{bc} / 2.3(\mathrm{ba}+\mathrm{bc})
$$

where ba and bc define the slopes of the line.

The range of linearity of the current-voltage curve (see Figure 6.10) of steel rebar embedded in concrete has been verified for potential ranges around 20-30 $\mathrm{mV}$ of $\mathrm{E}_{\text {corr }}$ (Andrade 2004).This relationship is linear for ranges of even $100 \mathrm{mV}$ in the case of very high corrosion rates.

The process is further explained in the following way: when a metal electrode is in equilibrium, the anodic (ia) currents and cathodic (ic) currents are equal and no net reaction occurs. In other words, during the corrosion of an electrically isolated metal sample, the total rate of oxidation must equal the total rate of reduction. If this equilibrium is altered by imposing an external voltage, the metal surface may become polarized. The metal can be either anodically polarized (electrons are withdrawn from the metal and a net anodic current will flow), or cathodically polarized (electrons are pushed into the metal and a net cathodic current will flow).

\subsubsection{Field measurements of current density}

An electrode is polarized when its potential is forced away from its value at open circuit or corrosion potential. Polarization of an electrode causes current to flow due to electrochemical reactions it induces at the electrode surface. The polarization resistance or $\mathrm{R}_{\mathrm{p}}$ is defined by the following equation, based on Faraday's equation.

$$
\mathrm{R}_{\mathrm{p}}=(\Delta \mathrm{E} / \Delta \mathrm{i})_{\Delta \mathrm{E} \rightarrow 0}
$$

where:

$\Delta \mathrm{E}=$ variation of the applied potential around the corrosion potential

$\Delta \mathrm{i}=$ the resulting polarization current 
Polarization resistance $\left(R_{p}\right)$ behaves like a resistor. It can be calculated by taking the inverse of the slope of the current potential curve at open circuit or corrosion potential.

$$
\Delta \mathrm{E} / \Delta \mathrm{i}=(\mathrm{ba} \times \mathrm{bc}) / 2.3 \times \mathrm{I}_{\text {corr }}(\mathrm{ba}+\mathrm{bc})
$$

Where the numbers ba and bc are empirical rate constants, or the Tafel constants, the relationship can be more simply expressed as:

$$
\mathrm{I}_{\text {corr }}=\mathrm{I} / \mathrm{E} \times \mathrm{B}
$$

where B is a constant.

The value of $I / E$ is the polarization resistance $R_{p}$ and can be illustrated in Figure 6.11. $R_{p}$ can be measured by placing a second electrode in the corroding fluid and connecting it to the corroding test electrode through an external power source.

In Figure 6.11, the auxiliary anode and the test anode are shown at the top and bottom of the circuit (shown as the circled $\mathrm{A}$ and $\mathrm{T}$ at the right of the circuit). The voltage $V_{\text {bat }}$ must be increased by $I^{*}\left(R_{s}\right)$ to overcome the initial offset potential, if the simple equivalent circuit is to be used as the primary measurement system.

A laboratory measurement system is shown in Figure 6.12.

When used on reinforced structures, in-situ, the problem is that the area of the counter electrode is much smaller than that of the working electrode (the reinforcement) and that the electrical signal tends to vanish with increasing distance. As a result, the measured effective polarization resistance cannot be converted to a corrosion rate, unless a second concentric counter electrode (a guard ring) is introduced to confine the current equivalent to the central counter electrode as shown in Figure 6.13. 
Figure 6.11. Equivalent electrical circuit measurement system for corrosion monitoring.

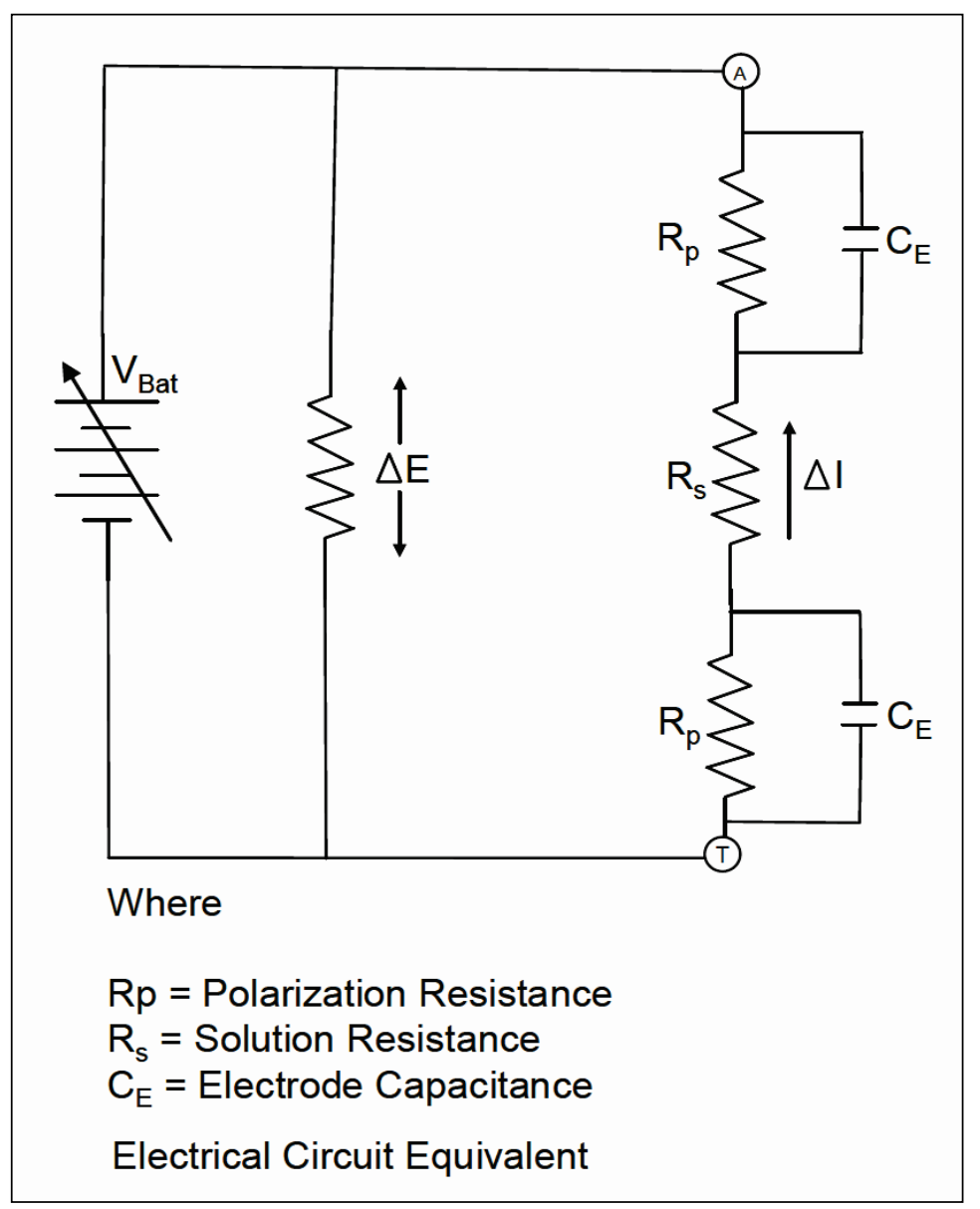


Figure 6.12. Laboratory setup for polarization measurement (Ahmad et al. 2014).

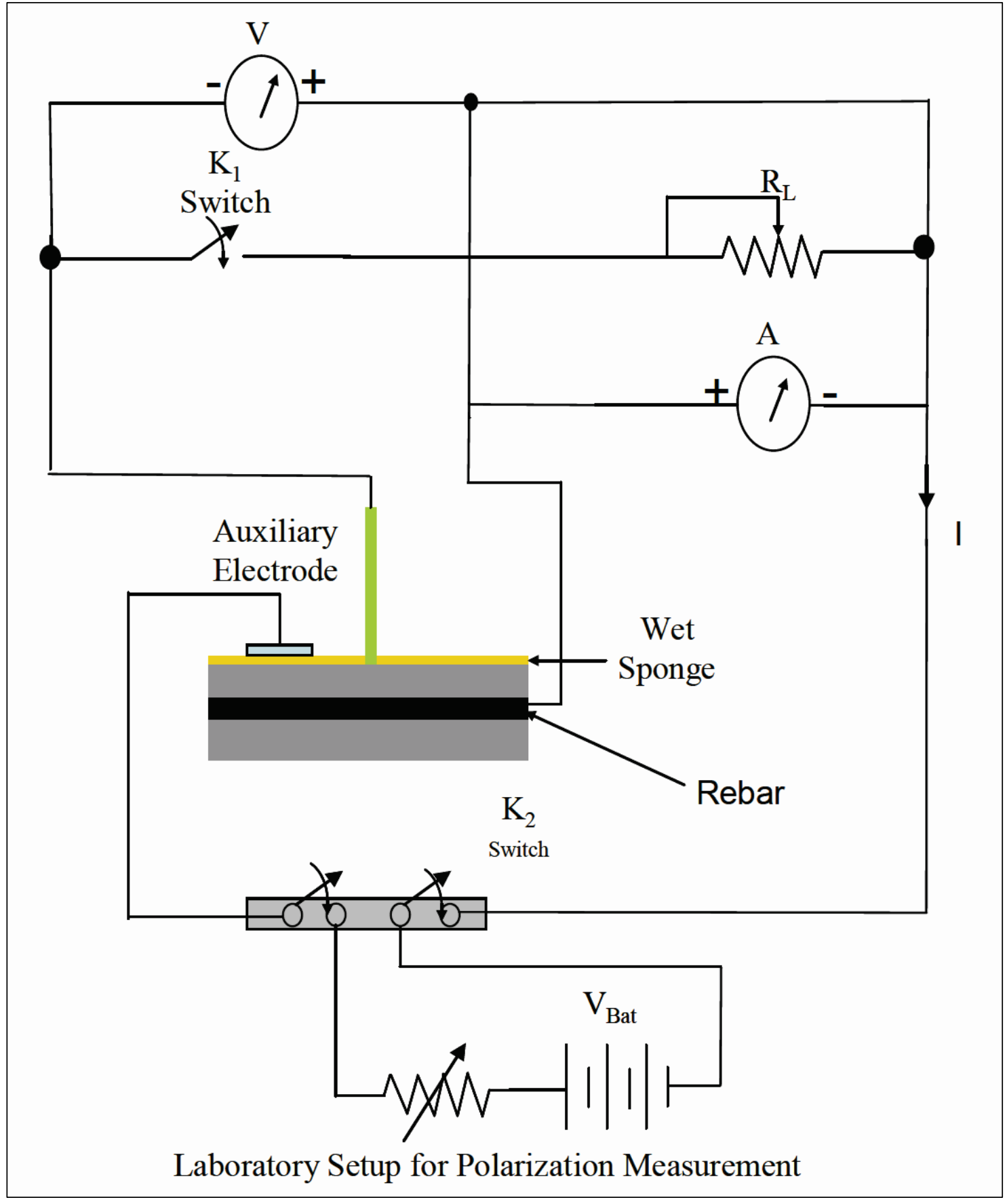

Where:

$$
\begin{aligned}
\mathrm{R}_{\mathrm{L}} & =\text { standard decade box } \\
\mathrm{V} & =\text { voltmeter }
\end{aligned}
$$

$\mathrm{K} 1 \& \mathrm{~K} 2$ = switches

R. E. = standard Cu/CuSo $4 /$ reference electrode as per ASTM C- 876 
C. E. = counter electrode

W. E. = working electrode (rebar)

$\mathrm{A}=$ ammeter capable of reading $0-200 \mathrm{uA}$ with at least count of $0.1 \mathrm{uA}$

$\mathrm{R}=$ ohmic Resistance of concrete

$\mathrm{I}=$ cathodic current applied to the rebar for polarization

$\mathrm{V}_{\text {Batt }}=$ battery potential

$\mathrm{R}_{\mathrm{cc}}=$ variable resistance to maintain constant current

Figure 6.13. Measurement probe with guard ring shown (after Kinghoffer 2014).

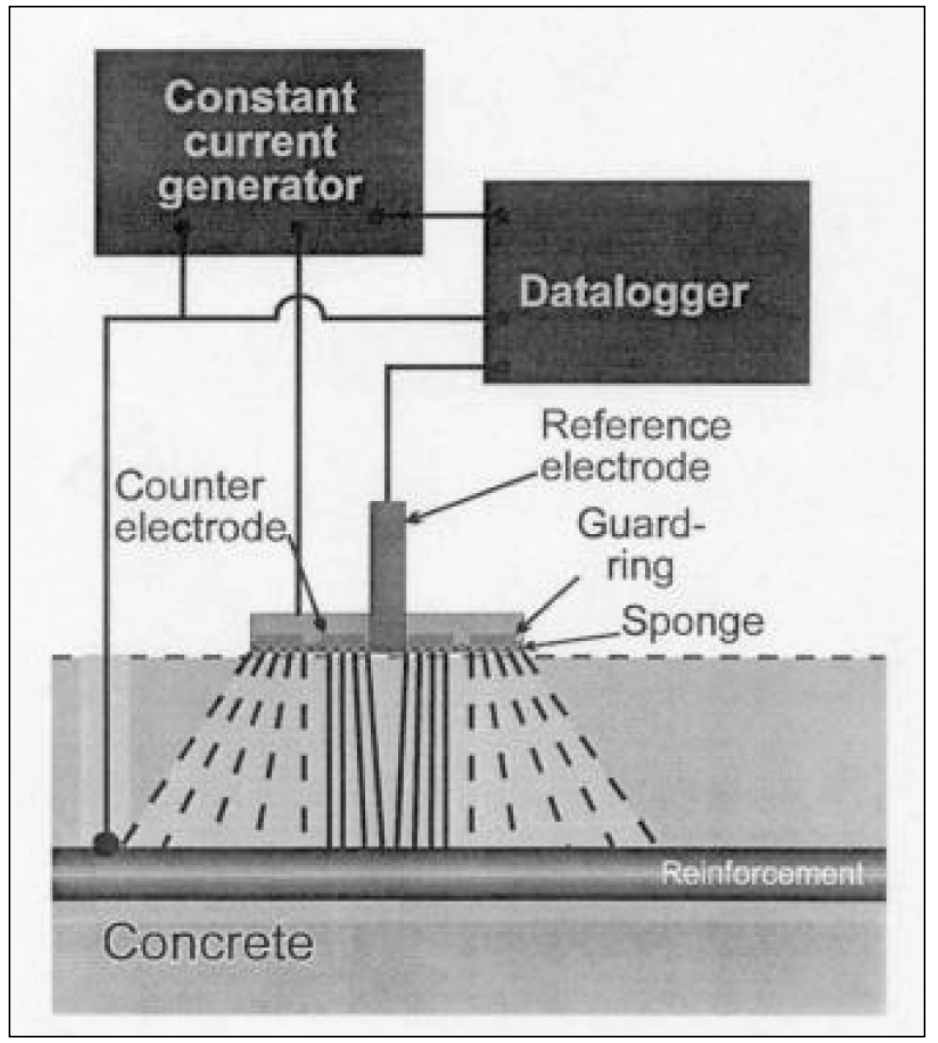

When the diameter of the corroding reinforcement and its exposed length are known, the confined reinforcement can be calculated.

\subsection{Predictive models for corrosion}

\subsubsection{Expert evaluation of standard deviation for corrosion rate}

Given the wide range of possible corrosion rates, as evidenced by the data reported in the literature, selecting a value for corrosion rate can be a challenge. Different tables found in the literature use different parameters to give estimates for corrosion rates. Complicating matters is the number 
of environments in which this corrosion can occur. One thing is sure; metal must be exposed to an electrolyte, typically water, before corrosion will occur.

This investigation has identified a wide variation in corrosion rates that are associated with a variety of interrelated parameters. Section 6.3 identified the four primary variables $(\mathrm{pH}$, oxygen concentration, chloride concentration, and temperature) that affect the corrosion rate. Tables were presented for expected corrosion rates given each of these variables and the environmental effects on these variables (i.e., water velocity affecting oxygen concentration).

It is important that the engineer have a grasp of the environment, especially with respect to these variables, where the corrosion will be made. Only with this information can a reasonable corrosion estimate occur. It would be best to proceed with the most precise measurements of the four variables as possible. Sensor packages exist for each of the variables affecting the electrolytic solution around the cable for estimating the corrosion rate (oxygen concentration, temperature, chloride concentration, and $\mathrm{pH}$ ). The following discussion covers these sensors and their limitations with respect to the difficult accessibility of the multistrand anchor system.

Oxygen Concentration Sensors: The most accurate measure of dissolved oxygen content to determine the corrosion rate of a multistrand anchor would involve measurements in the solution immediately in contact with the anchor. Unfortunately, this measure would be difficult to obtain, as the cables are typically surrounded by grout, and forming a void for the sensor next to the anchor cable could accelerate corrosion. For ungrouted ducts, water could be suctioned through a hole greater than 0.25 in. $(7 \mathrm{~mm})$ in the anchor head. In order to estimate dissolved oxygen content as accurately as possible, measurements could be taken in the back-fill for the mass concrete structure, in ports along the mass concrete structure, and in the pool acting on the water side of the mass concrete structure. These measures should provide a reasonable baseline for estimating oxygen concentration. One approach would be to average the measured values.

For determining dissolved oxygen content in water a luminescent dissolved oxygen (LDO) probe is used (Mitchell 2006). This probe's functionality is based on oxygen's ability to quench luminescence of a 
luminophorescent material at a specified rate, once the luminophore has been excited by an energy source. Oxygen that is present will extinguish the luminescence at a known value and convert this to dissolved oxygen content in $\mathrm{mg} / \mathrm{L}$.

The probe can be used in the field. The dissolved oxygen sensor is 1.81 in. $(46 \mathrm{~mm})$ in diameter, $8.73 \mathrm{in}$. $(223 \mathrm{~mm})$ long, and with a cable length of $16.4,32.81,49.21$, or $98.42 \mathrm{ft}(5,10,15$, and $30 \mathrm{~m}$, respectively). This same package can also contain a temperature sensor and the $\mathrm{pH}$ sensor. The service life of the dissolved oxygen probe in normal use is 1-2 yrs. The measurements and data collection can be automated. Because dissolved oxygen sensors are not identical between different companies or even within the same company, a calibration measurement in 100\% dissolved oxygen environment for the specified solution is performed. This is accomplished by taking a gallon-size Ziploc ${ }^{\circledR}$ bag with 2 in. of the reference water solution inside, sealing it, shaking the bag for $30 \mathrm{sec}$, and then letting the bag sit for $30 \mathrm{~min}$. Then the probe is held just above the water and a reference reading is performed and stored for the calibration.

It is also important to note that measurements at differing depths of the pool and ground water should be made. Water near the surface of the pool or groundwater will have a higher oxygen concentration than water at greater depths.

Temperature Sensors: Temperature is an important modifier of corrosion rate, primarily at the cap of the multistrand anchor system. Because the thermal energy is absorbed rapidly in dense materials, an ambient temperature is achieved with little depth of the multistrand anchor. In order to accurately measure the corrosive effects of temperature, the temperature measurement should be made just inside the pile cap. This measure could be made with water suctioned from the un-grouted cable system through a $0.25 \mathrm{in} .(7 \mathrm{~mm})$ port, as described for the oxygen concentration system. Of course, the sample should be tested immediately after withdrawal.

The temperature sensor is typically encased in the $\mathrm{pH}$ probe and in the dissolved oxygen probe, so the dimensions are the same as the $\mathrm{pH}$ probe and dissolved oxygen probe. Therefore, these measurements may also be made in the field. The type of sensor is a thermo couple, utilizing the potential difference between two metals at the same temperature. The 
temperature sensor is accurate to $\pm 0.3^{\circ} \mathrm{C}\left( \pm 0.54^{\circ} \mathrm{C}\right)$ and the operating range is $\mathrm{o}$ to $50^{\circ} \mathrm{C}$ ( 32 to $122^{\circ} \mathrm{F}$ ). The service life of the temperature sensor is 1-2 yrs with normal use. Because temperature sensors are not identical between different companies and even within the same company, a measurement using known reference is made to set the millivolts with that reference (known temperature), and thereby calibrate the instrument.

pH Sensors: The $\mathrm{pH}$ value of the electrolyte solution (water) surrounding the multistrand anchor cables should generally be high (alkaline) because fresh water is typically neutral and grout and concrete (using cement with lime) will raise the $\mathrm{pH}$. However, it is a good idea to be sure of this situation. In order to accurately measure $\mathrm{pH}$, the measurement should be made just inside the pile cap. This measure could be made with water suctioned from the un-grouted cable system through a $0.25 \mathrm{in}$. (7 $\mathrm{mm}$ ) port, as described for the oxygen concentration system. Of course, the sample should be tested immediately after withdrawal. If this option is not available, measurements in the pool and groundwater should be used in a manner similar to the oxygen-concentration test.

The $\mathrm{pH}$ sensor is a digital combination non-refillable, gel-filled probe with double junction reference and built-in temperature sensor (temperature sensor specifications above). Temperature can affect $\mathrm{pH}$ readings, so the reference temperature needs to be taken at the same time as the $\mathrm{pH}$ sample. The range of the $\mathrm{pH}$ sensor is $\mathrm{pH} \mathrm{2-14}$. The resolution of the $\mathrm{pH}$ sensor is 0.01 for a fast read (default) and 0.001 for a slow read. The user on the attached portable data computer selects the resolution. The $\mathrm{pH}$ probe is a combination probe with both reference electrode and indicating glass electrode, which assures that both electrodes are at the same temperature ( $\mathrm{pH}$ is temperature sensitive). The reference electrode always measures a $\mathrm{pH}$ of 7 . After sampling a reference liquid of known $\mathrm{pH}$, the indicating glass electrode takes the calibration data that compares the concentration of hydrogen ions in the reference and in the sample and displays the output of the probe which is the potential between the inside and outside of the membrane in millivolts. This voltage is proportional to the difference in $\mathrm{pH}$ in the inner solution and in the sample. Service life of the $\mathrm{pH}$ probe in normal use is 1-2 yrs. Because $\mathrm{pH}$ sensors are not identical between different companies and even within the same company, a measurement in two reference solutions is made to calibrate the instrument. The reference solutions are of known $\mathrm{pH}$ and are plotted 
millivolts versus $\mathrm{pH}$. These two points on the graph make a line where the millivolts output will be a corresponding $\mathrm{pH}$ value.

Testing Chloride Concentration: Chloride content of grout in posttensioned cable ducts is important to determine whether corrosion will initiate and propagate for the grouted cables. These measurements require a sample of grout from around the multistrand wires. This sample can be a disturbed sample (e.g., ground up through a drilling cycle) for this type chloride-content test. For samples that will be tested for $\mathrm{pH}$, it is important that the samples not be stored in glass containers, as glass is typically reactive to acidic or alkali environments, an effect leading to "glass etching." This reaction will cause the glasses' own ions to be leached into the sample or for ions in the sample to be added to the glass, affecting test readings. Plastics, such as approved Nalgene ${ }^{\mathrm{TM}}$ plastic lab ware, are not very reactive and will not add or subtract ions from the enclosed samples. It is also a good idea for the container to be sterilized before use to reduce the presence of biological agents that will affect the sample during shipment. Plastics are lighter than glass, unbreakable, and suitable for use with many chemicals at various temperatures.

It is also important that the grout sample maintain its relative humidity, as drying of the grout can cause a reduction of strength in the grout and loss of material. This humidity should not be applied due to saturation, but can be maintained by wrapping the sample in moist paper towels.

In the laboratory, the ASTM C1152 testing method (ASTM 2012) should be followed along with the ASTM C1218 testing method (ASTM 2008) to find the chloride content of the grout sample. ASTM C1152 uses a weak acid digestion of concrete or grout, which has been pulverized into a powder to leach chlorides into a solution. This solution is then analyzed for chloride content and that content is normalized as a \% by mass where $\left(\frac{\% \text { mass }}{100} *\right.$ $1000=p p m$ ) of the original concrete sample is digested (typically a $5-10 \mathrm{~g}$ sample). Since the solution is an acidified environment, all bound (i.e., those which are weakly bonded to the concrete microstructure and not available for corrosion) and unbound chlorides are measured. ASTM 1218 is similar to the above method of determining chloride content of grout but the chlorides are leached into deionized water rather than using an acid digestion. The main goal of this is to measure only chlorides that are unbound and freely available in the pore structure of the concrete or grout to participate in corrosion of steel. 
By measuring both acid (total) and water-soluble chlorides, the amount of bound chlorides can be determined. Both of these measurements specify the use of a chloride titration technique using a silver nitrate solution for the titration, which establishes the chloride concentration.

In places where these variables change significantly over time (i.e. salting of bridges to prevent icing, rainfall, changes in water levels), the corrosion rate may need to be expressed as a statistical distribution, especially since reintroduction of these variables may lead to "recharging" of the system for corrosion. Because corrosion is an electrolytic process, the process can be recharged by the reintroduction of the electrolyte (water), oxygen concentration, and/or chloride concentration.

For post-tensioned multistrand anchors placed at Corps lock structures, most anchor wires are surrounded by grout, but there are exceptions, such as John Day (Ebeling et al. 2013). Encasing the wires in grout raises the $\mathrm{pH}$, which leads to lower corrosion rates. If the grout mixture is well designed and properly installed, few voids will occur, lessening the chance of water approaching the surface of the cable. However, chlorides can be present in grout and if they exceed a threshold, can lead to the initiation of corrosion. If settlement or load-induced cracking of the hydraulic structure occurs, a path may be formed to allow water to reach the posttensioned cable. This external water source can leach chlorides from the grout surrounding the cable.

Corps structures are in a primarily a freshwater environment, which reduces the levels of chlorides in the solution around the cable in comparison with saltwater environments. Given the depths of penetration of the anchors in the mass concrete structures of locks, temperature variation occurs mostly near the top of the anchor.

Saltwater environments with exposed metal have the greatest corrosion rates. This is especially true in the spray region where the surface of the metal is exposed to high oxygen and chloride concentration droplets.

Once the engineer has determined the environment and has a range of measurements of the variables in that environment, the engineer can use the tables from the literature and experience to estimate the highest conceivable value (HCV) and lowest conceivable value (LCV) for the corrosion rate. 
For the freshwater environments and grouts surrounding multistrand wire anchor cables in Corps structures, the Table 6.2 (Griess and Naus 1975) provides an excellent base corrosion rate that can be scaled using the slope of the oxygen-concentration plot of Figure 6.5 (after Charng and Lansing 1982). For extreme temperatures at the top of the anchor, Figures 6.8 and 6.9 (Roberge 2008; Berry 1984) can be used to determine a scale factor that can be applied to the corrosion rate determined in the previous process.

Duncan and Wright (2005) and Dai and Wang (1992) describe a rule-ofthumb method for determining the standard deviation of a range of data (used in geotechnical engineering analyses). This method takes advantage of the fact that $99.74 \%$ of all values of a normally distributed parameter fall within 3 standard deviations $(\sigma)$ of the average. If we assume that the $\mathrm{HCV}$ and the LCV lay 3 standard deviations $(3 \sigma)$ from the average, the standard deviation can be given by

$$
\sigma=\frac{H C V-L C V}{6}
$$

This train of thought assumes an average value of

$$
\mu=\frac{H C V+L C V}{2}
$$

Christian and Baecher (2001) confidently gave evidence that even experienced engineers tend to over-estimate values, therefore leading to a too-narrow range between HCV and LCV. When this occurs, the $3 \sigma$ rule gives values for the coefficient of variation (COV) which are not conservative. The COV is the standard deviation $(\sigma)$ divided by the mean value $(\mu)$, Equation 6.1.

In the case of corrosion, general corrosion rates based on single variables will not account for the existence of area-reducing pits. Area-reducing pits are outliers to the general corrosion-area loss. Therefore, it might be better to assume that the engineer's best estimate for HCV-to-LCV contains less than $99.74 \%$ of all values (of a normal distribution). Depending on the engineer's judgment, it may contain less than $95.44 \%$ (i.e., $\pm 2 \sigma$ ) of all values or even less than $68.26 \%$ (i.e., $\pm 1 \sigma$ ) of all values. 
If the engineer is not confident of his or her ability to encompass $99.74 \%$ of the values with his or her best estimate for HCV-to-LCV, including outliers (e.g., due to pitting), it is possible to divide the range (HCV-LCV) by different values $(d)$, assuming that the range is only one standard deviation or two standard deviations from the average value. Table 6.6 shows the range, denominator, and the area of the total normal distribution covered by that range.

$$
\sigma=\frac{H C V-L C V}{d}
$$

Table 6.6. Divisors for different ranges on the normal distribution.

\begin{tabular}{|c|c|c|}
\hline Range of Standard Deviation & Divisor $(\boldsymbol{d})$ & Area of the Normal Distribution \\
\hline $\pm 1 \sigma$ & 2 & 0.6826 \\
\hline $\pm 2 \sigma$ & 4 & 0.9544 \\
\hline $\pm 3 \sigma$ & 6 & 0.9974 \\
\hline
\end{tabular}

Based on these results, the reduced cross-section radius of a corroded wire in a multistrand cable can be computed by taking the radius of the pristine wire and subtracting the specified corrosion rate (which may be drawn from a distribution), multiplied by the time that the wire has been corroded. This calculated value of the corroded radius can be used to calculate the reduced cross-section area, or it can be doubled to serve as an estimate of the minimum second-moment diameter of the wire. These values can be substituted into the functions for the curves in Figures 5.11 and 5.12, respectively, to determine the range of capacities of the corroded cable.

\subsubsection{Pitting corrosion prediction using current density}

In multiple papers by Darmawan et al. (2003-2010), they began using Gumbel EV-type I distribution functions to predict pit depth based on accelerated corrosion tests on single-strand and seven-strand wire cable. Their predictions were based on the results of laboratory tests that were performed so that the current density, $i_{\text {corr, }}$ could easily be captured. These test results are given in Table 6.7. 
Table 6.7 Darmawan et al. (2003-2010) base test results

\begin{tabular}{|c|c|c|c|c|c|c|c|c|c|c|c|}
\hline \multirow[b]{2}{*}{ Specimen } & \multirow[b]{2}{*}{$\begin{array}{l}\text { Toexp: } \\
\text { days }\end{array}$} & \multirow{2}{*}{$\begin{array}{l}\text { Icorrexp: } \\
\mu \mathrm{A} / \mathrm{cm}^{2}\end{array}$} & \multirow{2}{*}{$\begin{array}{l}\text { Lo: } \\
\mathrm{mm}\end{array}$} & \multirow{2}{*}{$\begin{array}{l}\text { Min } \\
\text { (a): } \\
\mathrm{mm}\end{array}$} & \multirow{2}{*}{$\begin{array}{l}\text { Max } \\
(a): \\
\mathrm{mm}\end{array}$} & \multicolumn{2}{|c|}{ a. $\mathrm{mm}$} & \multirow{2}{*}{$\begin{array}{c}R: \\
a / P_{a v}\end{array}$} & \multirow[b]{2}{*}{$\mu 0_{\exp }$} & \multirow[b]{2}{*}{ aoexp } & \multirow[b]{2}{*}{$\begin{array}{l}\text { No. of } \\
\text { samples }\end{array}$} \\
\hline & & & & & & mean & $\mathrm{COV}$ & & & & \\
\hline Wire-1 & 29 & 150 & 325 & 1.03 & 2.02 & 1.50 & 0.13 & 10.9 & 1.41 & 5.26 & 36 \\
\hline Wire-2 & 29 & 250 & 325 & 1.64 & 2.55 & 2.05 & 0.09 & 8.9 & 1.96 & 5.88 & 36 \\
\hline Wire-3 & 56 & 150 & 325 & 1.38 & 3.75 & 2.28 & 0.23 & 8.5 & 1.96 & 5.88 & 36 \\
\hline Strand-1 & 14 & 279 & 650 & 0.76 & 1.65 & 1.16 & 0.14 & 9.3 & 1.09 & 7.35 & 96 \\
\hline Strand-2 & 14 & 418 & 650 & 1.06 & 2.07 & 1.51 & 0.12 & 8.1 & 1.43 & 6.67 & 96 \\
\hline Strand-3 & 14 & 186 & 650 & 0.58 & 1.45 & 0.91 & 0.17 & 11.0 & 0.84 & 8.10 & 96 \\
\hline
\end{tabular}

$P_{a v}=0.0116 i_{\text {corr-exp }} T_{0-\exp }$

The basic Gumbel equation for percentage probability of corrosion to the depth $a$ is given as:

$$
f_{a}\left(T_{o-\exp }, i_{c o r r-\exp }, L_{0}\right)=\alpha_{0-\exp } e^{-\alpha_{0-\exp }\left(a-\mu_{0-\exp }\right)} e^{\left[-e^{-a_{0-\exp }\left(a-\mu_{0-\exp }\right)}\right]}
$$

This equation can predict pit depth given the experimental corrosion rate ( $\left.i_{\text {corr-exp }}\right)$, time that the experiment was run $\left(T_{\text {o-exp }}\right)$, length of cables in the experiment $\left(L_{o}\right)$, and Gumbel parameters $\left(\alpha_{o \text {-exp }}\right.$ and $\left.\mu_{o \text {-exp }}\right)$ determined in Table 6.7. This equation does not account for variation in the time of exposure, the current density, or even the length of the wire. The following equations remedy that situation.

In order to vary the length of the cable, the Gumbel parameters must be modified. The following equations show the change in the parameters.

$$
\mu=\mu_{0-\exp }+\frac{1}{\alpha_{0-\exp }} \ln \left(\frac{L}{L_{0-\exp }}\right) ; \alpha=\alpha_{0-\exp }
$$

Assuming constant corrosion rates, the time to achieve a pit depth, $T_{o}$, that is equivalent to the accelerated time to that same pit depth, $T_{o \text {-exp }}$, can be given by

$$
T_{\mathrm{o}}=\left(\frac{i_{\text {corr-exp }}}{i_{\text {corr }}}\right) T_{0-\exp }
$$


Assuming that the pit has a circular radius and is centered on the circumference of the wire, then the volume of the pit at time $T$ can be given by a scale factor $\lambda$ from any time $T_{o}$, as

$$
\text { Volume of pitat } T=\lambda \times \text { Volume of pit at } T_{0}
$$

where $\lambda$ is the ratio of increase in volume of corrosion products, derived as

$$
\lambda=\frac{\frac{\pi}{4}\left[D_{0}^{2}-\left(D_{0}-0.0232 i_{\text {corr }} T\right)^{2}\right]}{\frac{\pi}{4}\left[D_{0}^{2}-\left(D_{0}-0.0232 i_{\text {corr }} T_{0}\right)^{2}\right]}=\frac{T\left(D_{0}-0.0116 i_{\text {corr }} T\right)}{T_{0}\left(D_{0}-0.0116 i_{\text {corr }} T_{0}\right)}
$$

Assuming that the pit length remains the same and the pit depth is the only thing changed, the pit cross-section area can be given by

$$
A_{p i t}(T)=\lambda \times A_{p i t}\left(T_{0}\right)
$$

The pit depth is directly proportional to the pit area, given by

$$
\alpha \propto\left(A_{p i t}\right)^{0.54}
$$

for $4.3 \mathrm{~mm}$ and $5.03 \mathrm{~mm}$ diameter wire, leading to

$$
\alpha(T)=\lambda^{0.54} \alpha\left(T_{\mathrm{o}}\right)
$$

These modified Gumbel parameters that take into account variations in length, time of corrosion, and corrosion rate can be substituted into Equation 6.15 to give a value for the percentage probability of corrosion to pit depth $a$ for the varied length, time of corrosion, and corrosion rate.

$$
f_{a}\left(T, i_{\text {corr }}, L\right)=\frac{\alpha}{\lambda^{0.54}} e^{-a\left(\frac{\alpha}{\lambda^{0.54}}-\mu\right)} e^{-e\left(\frac{\alpha}{\lambda^{0.54}}-\mu\right)}
$$

Using Equations 6.16, 6.17, 6.18, 6.20, and 6.24, it is possible to determine a probability density function as any of the variables $\left(T, i_{c o r r}, L\right.$, and $\left.a\right)$ are changed. For instance, if one wanted to find the pit-depth probabilitydensity function given a certain site in the present, the length of an individual cable at the site is typically known $(L)$, so Equations 6.16 and 6.1017 can be used to determine the modified Gumbel parameters $(\mu, \alpha)$, 
given matching values from Table 6.7. If the time of corrosion initiation is known, $T$ is given as

$$
T=T_{\text {current }}-T_{\text {corrosion_initiation }}
$$

Otherwise, a rough estimate can be made from the time of installation of the cable, as

$$
T=T_{\text {current }}-T_{\text {installation }}
$$

The estimated measurement of the corrosion at the present time in current density for the site $\left(i_{c o r r}\right)$ is used in Equation 6.18 (with appropriate values from Table 6.7) to get a value for $T_{o} . T$ and $T_{o}$ can then be used in Equation 6.20 to determine $\lambda$.

$\alpha, \mu$, and $\lambda$ are then applied in Equation 6.24. The pit-depth probabilitydensity curve can be found by substituting various values for the pit depth (a) from 0.0 to the width of the cable. Figure 6.14 shows the results of using the Gumbel parameters for Wire 2 of Table 6.7. The time (T), length $(L)$, and current density ( $\left.i_{c o r r}\right)$ were not varied from the Table 6.7 values for Wire 2. In application, the process described above would be followed using the field values for $T, L$, and $i_{\text {corr }}$.

In order to estimate the pit area, the pit area is defined as being a circle of radius $a$, which is the pit depth, that is centered somewhere on the circumference of the individual wire (Figure 6.15). Giving the radius of the wire as $R$, the area $(A)$ is computed from Equation 6.27.

$$
A_{p i t}=a^{2} \cos ^{-1}\left(\frac{a}{2 R}\right)+R^{2} \cos ^{-1}\left(\frac{2\left(R^{2}\right)-a^{2}}{2\left(R^{2}\right)}\right)-\frac{1}{2} \sqrt{a^{2}\left\{4\left(R^{2}\right)-a^{2}\right\}}
$$

The remaining cross section of the wire has its original area minus the area computed in Equation 6.27. Figure 6.16 shows this relationship. The wire diameter in this case was $5.03 \mathrm{~mm}$ and the area was $19.87 \mathrm{~mm}^{2}$. 
Figure 6.14. Probability-density plot from Darmawan and Stewart (2007) equations for Table 6.7 Wire 2 properties.

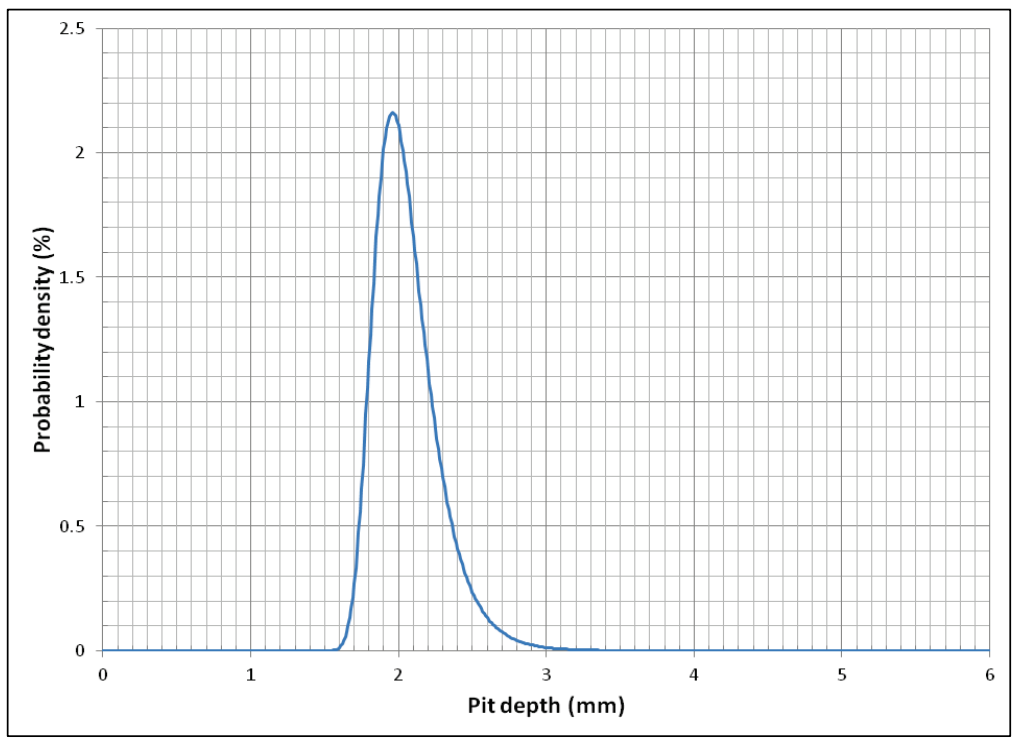

Figure 6.15. Relationship of the corrosion area with respect to the wire.

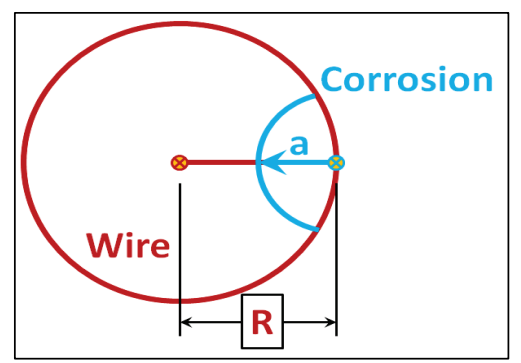

Figure 6.16. Probability density versus remaining wire area.

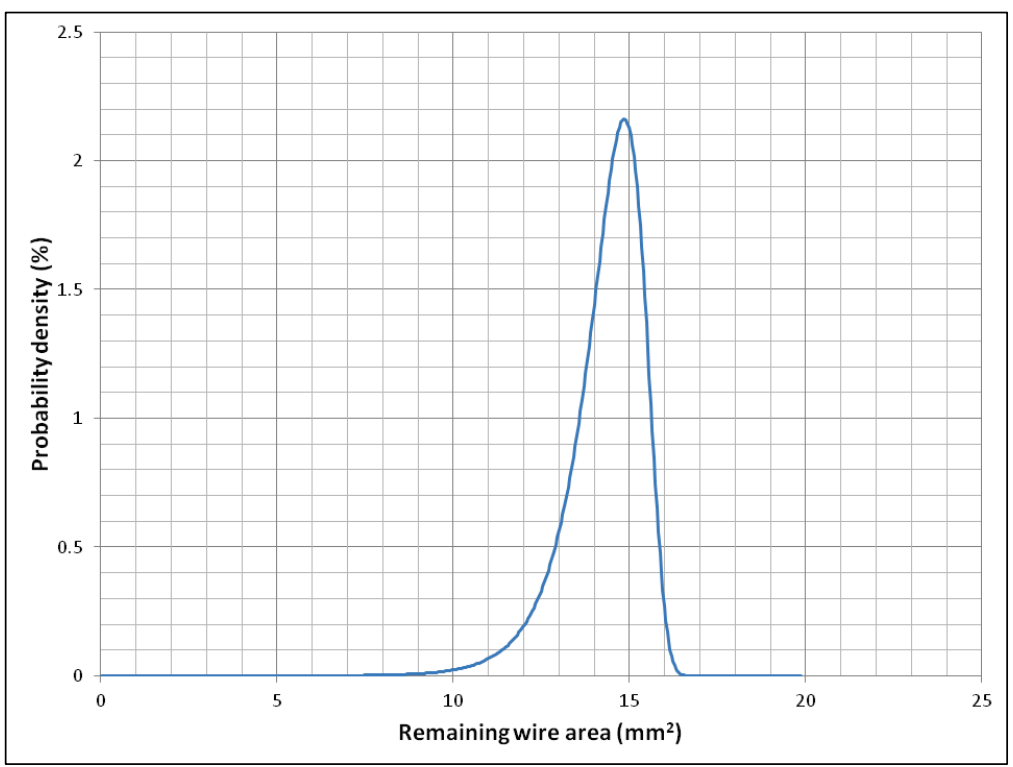


In a similar manner, the minimum second-moment wire diameter can be determined. This is simpler, since a good estimate is to subtract the pit depth $(a)$ from the original diameter of the wire $(R)$.

Once these values are determined, the remaining capacity and its distribution can be found by applying the areas and estimated minimum second-moment wire diameters into equations 5.5 and 5.6 of Chapter 5 , respectively. These two statistical distributions for remaining crosssectional area (Figure 6.16) and correlation of reduced capacity as a function of reduced cross-sectional area for a single wire, as assessed for the individual wire for seven-strand wire cable (Figure 5.11), provide statistical data for conducting a simulation-based analysis process for assessing the reduced capacity of corroded anchorage.

Alternatively, the Figure 6.17 statistical distribution and correlation of reduced capacity as a function of reduced minimum second-moment wire diameter for a single wire, as assessed for the individual wire for sevenstrand wire cable (Figure 5.12), also provides statistical data for conducting a simulation-based analysis process for assessing the reduced capacity of corroded anchorage.

Figure 6.17. Probability density versus remaining estimated minimum second-moment wire diameter.

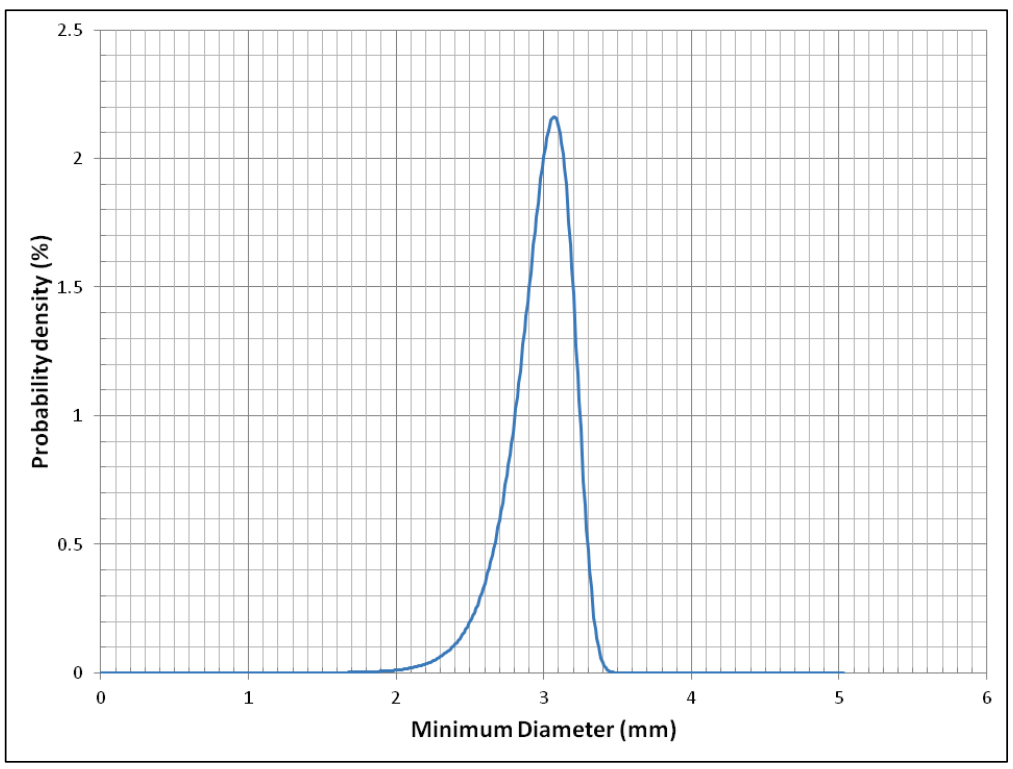




\subsection{Observations}

In order for steel to corrode, it needs to be in the presence of an electrolytic solution (typically water). This allows a current to form, allowing the chemical process of corrosion to occur. Once this condition is met, four variables affect the corrosion rate of the steel: $\mathrm{pH}$ of the solution, chloride concentration in the solution, oxygen concentration in the solution, and temperature.

Acidic environments, with a value on the $\mathrm{pH}$ scale less than the neutral value of seven, greatly accelerate corrosion. However, multistrand anchor cables are almost always encased in grout. Grout typically has high $\mathrm{pH}$ values (with values of 9 and 13.6 cited in the literature, e.g., Lee and Zielske 2014). Therefore, $\mathrm{pH}$ values have little effect on the corrosion of multistrand cables unless significant voids exist in the grout (to provide an environment for chemical concentrations to develop) and the solution is highly acidic. Even then, the alkalinity of the grout will raise the $\mathrm{pH}$ of the solution. The effect of $\mathrm{pH}$ is low for typical grout environments.

Chloride concentrations in the solution are of concern only in the fact that they are a catalyst for reactions between the oxygen and hydrogen in the solution and the iron in the cables. Of primary concern is the initiation of corrosion in the steel. An oxide film forms on the cables, resisting further corrosion in the metal. When the chloride concentration has reached a critical limit in the solution, this oxide film is removed from the steel, allowing corrosive pitting to occur. For freshwater multianchor systems, the amount of chlorides in the solution is low. However, chlorides can be introduced to the solution by leaching of the chlorides from the grout. Lee and Zielske (2014) determined the levels of chloride introduced to the grout to establish a limit for this initiation concentration (i.e., 0.4 percent by weight of cement). Lee and Zielske (2014) also found a second threshold corresponding to the concentration of chlorides that correspond to the level of catalyst that will facilitate corrosion propagation (0.8 percent chlorides by weight of cement). The multistrand environment for anchors on mass concrete freshwater structures will most likely have low concentrations of chlorides in the grout, due to PTI, ACI, and ASTM limits for grout mixtures (o.o8 percent by weight of grout).

Oxygen concentration in the solution gives the greatest indication of corrosion rate of steel. The concentration of oxygen in the solution bears an almost linear relationship to the corrosion rate, in the presence of 
chlorides (Figure 6.5). A baseline for low-oxygen corrosion can be found in Table 6.2. The amount of available concentrated oxygen in a solution can be affected to a large extent if the water is moving, although excessive motion tends to make less oxygen available. For multistrand anchorage in freshwater mass concrete structures, the availability of concentrated oxygen in the water is highly variable. Oxygen is available from surface water, ground water, and from the atmosphere-to-surface water interface within the top of the anchor region. For mass concrete structures with cracks, there is a possibility that moving water can be introduced into the anchorage duct, increasing the amount of oxygen available for corrosion.

Temperature can also have a great influence on corrosion rates, as shown in Figure 6.7 and Figure 6.9. However, in the case of multistrand anchors placed in mass concrete structures, the temperature will vary the most at the head of the anchor during the day, have less change in the freestressing length of anchorage, and very little change at the tendon-bond length of the anchorage. This leads to the conclusion that corrosion will typically have more effect at the top part of the anchor.

Corrosion rates are most often measured in two ways: (1) by the loss of volume per time (e.g., mm/year), and (2) the chemical reaction currentdensity (e.g., $\mu \mathrm{A} / \mathrm{cm}^{2}$ ). Loss of volume per time is often used to describe general corrosion. General corrosion rates attempt to measure the overall loss of volume due to corrosion of steel. It is assumed that this reduction occurs at the surface of the steel. Methods for estimating this general corrosion typically focus on one variable or the influence of pairs of variables. Current density can also be expressed as general corrosion, with $10 \mu \mathrm{A} / \mathrm{cm}^{2}$ roughly equivalent to $11.7 \mu \mathrm{m} /$ year of general corrosion (Andrade et al. 1988; Bertolini et al. 2004). Because this corrosion depth is given instantaneously to any point along the surface of the wire in the multistrand cable, the loss of cross-section area can be determined by assuming the reduced radius of the corroded wire is the radius of the pristine wire less the corrosion rate, multiplied by the time that corrosion has occurred. Given this loss of volume and the statistical evaluation of the pull-test results in Chapter 5 , a probability-based model that relates timebased corrosion to capacity loss is defined.

An alternative to general corrosion has been developed to estimate the probabilities of pitting corrosion, which is localized corrosion that affects the cross-section area of wires in a multistrand cable. This loss of cross- 
section area has the most influence on the capacity of the multistrand anchorage cables. Alternatively, the minimum second-moment radius of an individual corroded wire may be used to determine corroded-cable capacity. For a specified time during which corrosion has occurred, the length of cable, and the current density, the probability that a certain depth pit (and an estimate of its cross-section area) will occur can be calculated based on the Gumbel distribution, which is an extreme event distribution. Given these probabilities and the statistical evaluation of the pull-test results in Chapter 5, a probability-based model that relates timebased corrosion to capacity loss is defined. 


\section{Summary and Conclusions}

\subsection{Summary}

Over the past five decades, the U.S. Army Corps of Engineers has improved the effectiveness of its infrastructure by upgrading its projects through the installation of high-capacity, post-tensioned foundation anchors. These stressed-steel tendons have been used to strengthen hydraulic structures and to improve their serviceability and stability. Remediation has been required at some hydraulic structures to achieve structural stability and/or to remediate cracked concrete monoliths. Remediation of hydraulic structures (e.g., locks, dams, approach walls) using post-tensioning (PT) seven-wire strand cables is a common approach. In Portland District, for example, $10 \%$ of the projects have multistrand anchors installed.

Substantial improvements to protect multistrand anchor systems from corrosion have been made since they were first used in Corps projects more than 50 years ago, but the corrosion of older multistrand anchorage systems is still a major concern. Due to the high cost of remediation of hydraulic structures by post-tensioned ground anchorage, the loss in capacity of the seven-wire strand cables due to corrosion is of high importance.

This report summarizes results generated to-date from an ongoing research effort being conducted at ERDC to determine the capacity of pristine seven-wire strand cable and loss of capacity due to corrosion. The capacity was determined from pull-tests to failure on the Baldwin BLW 440,000 lb Universal Test Machine for pristine and corroded specimens. For the nearly homogeneous pristine specimens, it was discovered that the serrated pull-test wedges for the cables would artificially introduce an abrasion or series of small notches into the cable and cause the pull test to break at the gripping point. Failure along the cable and not within the zone of the Baldwin testing wedges is a requirement for this laboratory-testing program. Twelve methods for gripping the PT seven-wire strand cable were attempted. They were discussed in Chapter 2. The final gripping method that was devised provided consistent breaks away from the wedges and the most accurate, consistent results. Twenty-two pristine specimen pull tests were gathered and statistically analyzed. The mean and standard deviation for the strength of the pristine cable is $61,669 \mathrm{lb}$ and $604 \mathrm{lb}$, respectively, with a Coefficient of Variation of approximately $1 \%$. 
Next, the newly developed method for the determination of the crosssectional morphological properties of corroded PT seven-wire strand cables after a pull test was discussed (Chapter 3). This method used optical scanning to examine the cross-section of the broken end of the cable, just past the region of ductile necking of the individual wires before breaking. This method gathers the cross-section geometric properties of the corroded cable and could be used to indicate the cause of the failure through correlation.

The process for laboratory-accelerated corrosion of PT seven-wire strand cable was discussed next (Chapter 4). The proposed process, depending on electrochemical reactions of the anodized PT seven-wire strand cable suspended in a saline bath, and the resulting mechanism were illustrated and discussed. Each of the resulting corroded specimens was then subjected to pull testing to tension failure in ERDC's Baldwin BLW 440,00o lb Universal Test Machine, resulting in 161 acceptable tests. These tests were then optically scanned to determine the geometric crosssection properties of each cable specimen.

The 161 corroded cable data and the 22 pristine cable data were then combined for a statistical analysis in order to determine the correlation between the geometric properties and the capacity of the PT seven-wire strand cable (Chapter 5 ). The resulting 183 corroded and pristine cable data were plotted two ways:

1. The first is a plot (Figure 5.11) of the 183 data points with the vertical axis being the ultimate resisting force (in lbf) of the cable at breaking and the horizontal axis is the area of the thinnest wire (minimum wire area) of the seven wires in the cable (in inches ${ }^{2}$ ).

2. The second (Figure 5.12) is a plot by peak capacity versus the length of the short axis of the ellipse with the same second moments as the scanned data, referred to in this report as the minimum corroded wire short axis diameter, or minimum wire diameter (in inches).

Each set of data was then statistically processed. Although there was some spread observed by the authors of this report in the corroded data and even a little spread in the pristine data, there is a noticeable correlation between the peak force and both the minimum wire area and the minimum wire diameter in the cable. This correlation occurs because the cable's capacity increases as the minimum wire area and minimum wire 
diameter increase. The forms of the equations fit to the data were the linear form, second-order polynomial, third-order polynomial, and the power function. Higher-order polynomial functions were attempted, but the statistical data fit did not improve very much because the higher-order terms did not add a significant contribution to the curve shape. Statistically, the trend of the correlation is determined by using a least-fit method using the coefficient of determination $\left(\mathrm{R}^{2}\right)$ measure for the different forms of equations.

A careful examination of the fitting functions (linear, polynomial order 2, polynomial order 3 , and power), based on $\mathrm{R}^{2}$ values from Tables 5.1 and 5.3, and visual inspection of the curvature (Figures 5.3 through 5.10), revealed that the functions that best estimate the data including the endpoints, are the polynomial order 2 equation for the minimum wire area (shown in Figure 5.5) and the polynomial order 3 equation for the minimum wire diameter (shown in Figure 5.8). The resulting two mean relationships (i.e., base trend lines) are given by equations 5.1 and 5.2, respectively.

Trend line equations were determined for each of the two data sets and the standard error for the capacity (along the force axis) was determined. Figures 5.11 and 5.12 show the statistical data based on the selected trend lines for the minimum wire area and minimum wire diameter, respectively. The corresponding trend line equations are equations 5.5 and 5.6 , respectively. Tables 5.5 and 5.6 list values for the trend line coefficients bMinWireArea and bMinWireDiameter for a range of $+/-2 \sigma,+/-1 \sigma$ and the $95 \%$ trend line.

The trend line functions are evaluated for a full set of data (corroded wire samples and pristine wire samples) and for the corroded wire data only. As expected, the $\mathrm{R}^{2}$ values were higher for the inclusive (corroded and pristine) data sets, primarily because the pristine data had very little variance.

Additionally, the insight gained from the results in Tables 5.1 through 5.4 for the various trend line equations investigated is that some of these equations, while having marginally better $\mathrm{R}^{2}$ values, are better at predicting the end-point data. The corroded-only data sets had consistently worse $\mathrm{R}^{2}$ data, as expected, but consistently predicted end-point data that was further from the mean pristine value (at the max area and max diameter ranges) of $61,669 \mathrm{lb}$ than the full data set with both corroded and pristine samples. 
This supports the viewpoint that pristine pull-test data needs to be included in the data base, as is the case for this study.

A literature review was conducted to determine corrosion rates and the parameters that affect corrosion rates in the field. Given the complexity of the corrosion process, these parameters were often confounded in the estimations of corrosion. Using the definition of the chemical process, after the steel has been exposed to an electrolyte (e.g., water), this report has identified four primary parameters that affected the general corrosion rate of steel: $\mathrm{pH}$, chloride concentrations, oxygen concentrations, and temperature.

Low values for $\mathrm{pH}(<4)$ have the largest effect on corrosion. This is an environmental concern, but one that can be controlled. Grout has a very high $\mathrm{pH}$ and tends to balance the $\mathrm{pH}$ of the environment. Because the anchorage cables are encased in grout, $\mathrm{pH}$ was determined to have the least effect on corrosion. Chloride concentration had a bearing on when corrosion would occur, with defined limits for initiation of corrosion, as the oxide film was removed from the steel, and for the propagation of corrosion. However, once these limits were met, the chloride level did not provide a good estimate of corrosion. Oxygen concentrations, on the other hand, serve as a very good indicator of corrosion rate once corrosion has been initiated. Temperature serves to modify the corrosion rate, and has a greater effect for multistrand anchorage in mass concrete structures at the head of the anchor.

One of the side effects of corrosion is the creation of a current as volume is changed. The rate of this change is given in current density (e.g., $\mu \mathrm{m} / \mathrm{cm}^{2}$ ). This chemical measure of the corrosion rate is comparable to the physical loss of volume at the surface over time ( $\mathrm{mm} / \mathrm{year}$ ).

As the pull-tests and optical scanning revealed, the cross-section properties of each individual wire (area and minimal second-moment diameter) had the greatest effect on cable capacity. General corrosion assumed that this loss of area would be constant across the wire. Corrosion is rarely so even, and often involves the formation of pits, a local effect that can minimize cross-section area at some location along the wire. Using extreme value distributions, probabilistic methods have been developed for determining pit depth for a certain cable over time given a current density (Darmawan and Stewart 2007). 
Methods for stochastically estimating the reduced capacity due to general and pitting corrosion were outlined based on the corrosion rates. These estimates can be utilized in statistical lifetime analysis of a multistrand anchor.

\subsection{Conclusions}

This interim report, along with Ebeling et al. (2012, 2013) and Haskins et al. (2014), reflects the research progress made to date. In FY14, the authors were able to develop an extensive database of 183 pristine and corroded seven-wire strand cable pull-test specimens and reveal that their capacity relates to either the minimum wire area or the minimum wire diameter. The optical imaging system devised and successfully constructed late in FY13 was extensively used during this FY to define the values for minimum wire area or the minimum wire diameter of each of the 161 corroded cable specimens. Statistical procedures were applied to the resulting data, and trend line equations were derived that fit through both: (1) the capacity of the cable versus the area of the thinnest corroded wire (i.e., minimum wire area) of the seven wires in the cable (in inches ${ }^{2}$ ), and (2) the peak capacity versus the minimum corroded wire diameter (in inches).

Methods for estimating corrosion rates, both general corrosion and for the formation of pits have been presented. A general corrosion rate is determined by combining expertise and field measurements with multiple charts. For the freshwater environments and grouts surrounding multistrand wire anchor cables in Corps structures, the Table 6.2 (Griess and Naus 1975) provides an excellent base corrosion rate that can be scaled using the slope of the oxygen-concentration plot of Figure 6.3 (Charng and Lansing 1982). For extreme temperatures at the top of the anchor, Figures 6.6 and 6.7 (Roberge 2008 and Berry 1984) can be used to determine a scale factor that can be applied to the corrosion rate determined in the previous process. A highest conceivable value (HCV) and lowest conceivable value (LCV) are determined and a distribution is built from this range. This distribution can then be used to determine remaining cable area to be applied to the Figure 5.11 and 5.12 distributed ranges for cable capacity.

The alternative methods used the corrosion rate expressed as current density to determine the probability of pit-depth formation, using a Gumbel extreme value distribution, given cable length and length-of-time corrosion has occurred (Darmawan and Stewart 2007). This pit depth can 
be used to determine corroded area or the minimum short-axis, secondmoment diameter of the cable that can be applied to the Figure 5.11 and 5.12 to determine the remaining cable capacity.

Given the complexity of corrosion, these methods provide a range of values in a distribution for the determination of corrosion depth. From these stochastic values, individual wire areas and minimum secondmoment diameters can be computed. These values, in conjunction with the wire-test data from Chapter 5 , can be used to determine the range of capacities that that wire is able to withstand. These processes can be used in a simulation technique to determine the likelihood that the anchor loss of capacity will reach a limit over time.

A wire failure is typically going to occur when material loss reaches a critical threshold for the tension state of the strand. For a bonded case, which is typical for grouted multistrand systems, this strand will likely continue to provide some tensioning function at a reduced load across the remaining wires. In an unbonded case, the load shedding will be much greater, hence a smaller residual load. This amount is dependent on the unbonded gauge length. The amount of increased load transferred to the adjoining strands once a failure occurs is dependent on the details of the anchorage system and the nature of its structural loading. The procedures for determining individual seven-strand wire cable capacity described in Chapter 6 are based on the conservative unbonded case.

In-situ stress levels are difficult to estimate and only measureable in certain scenarios. For example, a pull-off test of an entire 37-strand anchor head at John Day Lock and Dam was used on several occasions to estimate collective remaining tension levels in the anchor heads (Ebeling 2012). A number of factors affect actual post-tension levels of in-situ anchorages. These include operator and equipment error in setting initial levels; iterative tensioning of multistrand anchorages; relaxation of the steel cable; creep and shrinkage of the concrete; and thermal and load variations, etc. In a retrofit scenario of older concrete, the reduction of initial stress due to these factors can be assumed to be in the range of $5-10 \%$ for low-relaxation cable. Estimating additional losses of $2.5-10 \%$ due to creep and other factors, the nominally applied $70 \%$ load leads to resulting load levels for the 0.6 in. ( $15.24 \mathrm{~mm}$ ) diameter strand of 36,500 to $41,000 \mathrm{lb}$ (162.36 to $182.377 \mathrm{kN}$ ). Since field failures generally occur when cable cross-sections become critical for the applied load levels, a dashed line bounding region 
has been superimposed on the cross-section versus ultimate tensile strength data in Figures 7.1 and 7.2. The upper dashed lines in each figure correspond to $67.5 \%$ load, and the bottom dashed lines correspond to $60 \%$ load. The intersection of the mean wire area and mean wire diameter (from Figure 7.1 and Figure 7.2, respectively) with the range of expected in-situ load levels can be used as a means of estimating the critical area and diameter where in-service cables will fail. From the data in Figure 7.1 the minimum wire area at expected field loads will range from 0.0122 in. ${ }^{2}$ $\left(7.87 \mathrm{~mm}^{2}\right)$ to 0.0146 in. $^{2}\left(9.42 \mathrm{~mm}^{2}\right)$. From Figure 7.2 the diameters will on average range from 0.115 in. $(2.92 \mathrm{~mm})$ to $0.127 \mathrm{in} .(3.23 \mathrm{~mm})$ at failure.

As material losses occur and move cross sections to the left along the horizontal axis, the allowable load will be generally reduced according to the statistical fitting data previously discussed. When cross sections cross the allowable level determined here, failure of the seven-strand cable will likely occur.

Figure 7.1. Bounding the minimum corroded wire area measure with the limiting force values of 41 kips and 36.5 kips.

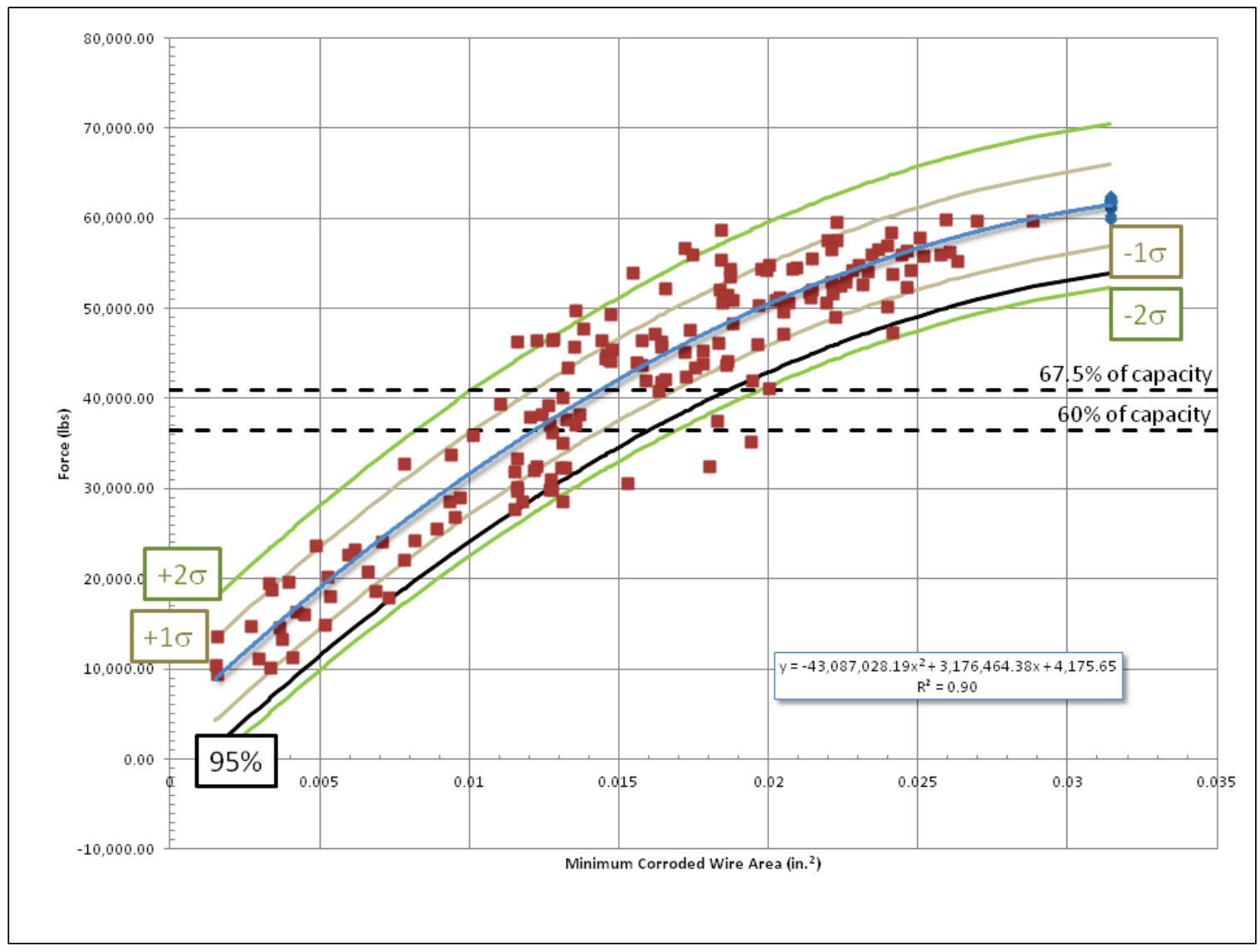


Figure 7.2. Bounding the minimum corroded wire short axis diameter measure with the limiting force values of 41 kips and 36.5 kips.

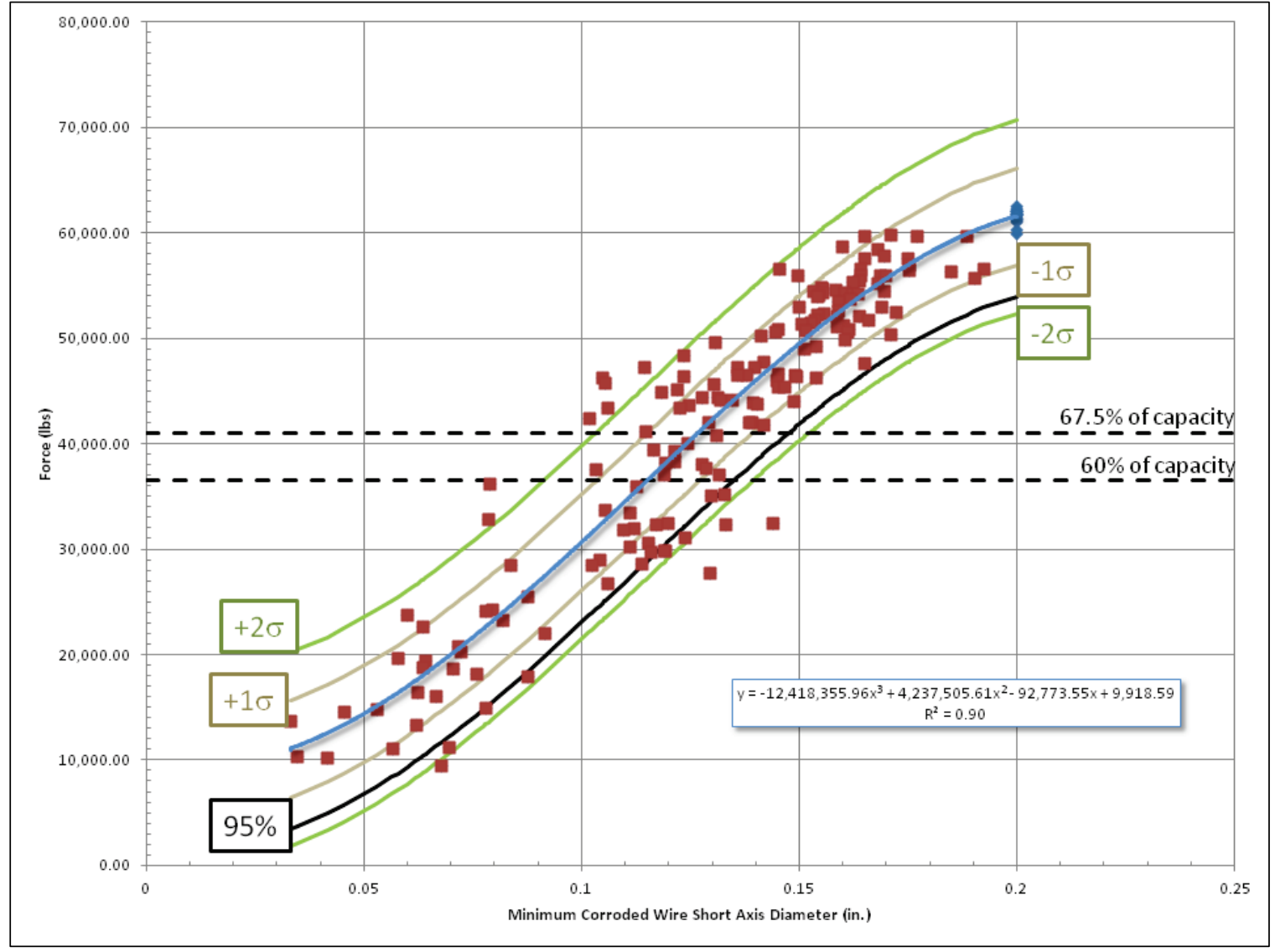

This situation is concerned only with an individual seven-strand, posttensioned, wire anchor cable. For a full anchor system, simulation runs would need to be performed to estimate corrosion for multiple cables.

The green curves shown in Figure 7.2 represent two standard deviations from our mean minimum diameter. They are used to determine the minimum and maximum cable diameters for failure at the expected $60 \%$ load level (due to long-term losses from creep, etc., discussed above). This load level is depicted by the lower dashed black line of Figure 7.2. This produces minimum diameters of $0.1428 \mathrm{in}$. (3.626 $\mathrm{mm}$ ) for $-2 \sigma$ and 0.0947 in. $(2.406 \mathrm{~mm})$ for $+2 \sigma$ from the mean. These values are subtracted from the original perimeter cable diameter of $0.2 \mathrm{in}$. $(5.08 \mathrm{~mm})$, resulting in expected minimum and maximum section losses of $0.0572 \mathrm{in}$. (1.454 mm) and $0.1053 \mathrm{in}$. (2.674 mm) for the $-2 \sigma$ and $+2 \sigma$ curves, respectively. This same procedure can be used to interpret mean value for the area section losses in Figure 7.1. 
Chapter 6 provides a discussion of corrosion rates of steel in various environments. Corrosion loss rate is specified in either current density or incursion depth per year. For Imperial units the incursion loss is measured in mils/yr $(25.4 \mu / \mathrm{yr})$. From Figure 7.2, the maximum diameter of the corroded cable before failure can be determined from the intersection of the $67.5 \%$ load capacity line and the mean-2 $\sigma$ curve, resulting in a value of $0.1524 \mathrm{in}$. $(3.87 \mathrm{~mm})$. This corresponds to a $0.0476 \mathrm{in}$. $(1.21 \mathrm{~mm})$ diameter loss from the $0.2 \mathrm{in} .(5.08 \mathrm{~mm})$ cable. The same method can be used to find the minimum corroded diameter before failure from the intersection of the $60 \%$ load capacity line and mean $+2 \sigma$ curve, resulting in a value of 0.0913 in. (2.32 mm). This corresponds to a $0.1087 \mathrm{in}$. $(2.76 \mathrm{~mm})$ diameter loss. Figure 7.3 provides a rough indication of the maximum and minimum time in years to cable failure as a function of loss rate in mils/yr, using the diameter loss values of 0.0476 in. (1.21 mm) (blue curve) and 0.1087 in. ( $2.76 \mathrm{~mm}$ ) (red curve).

Figure 7.3. A rough indication of the maximum and minimum time in years to cable failures as a function of loss rate in mils per year.

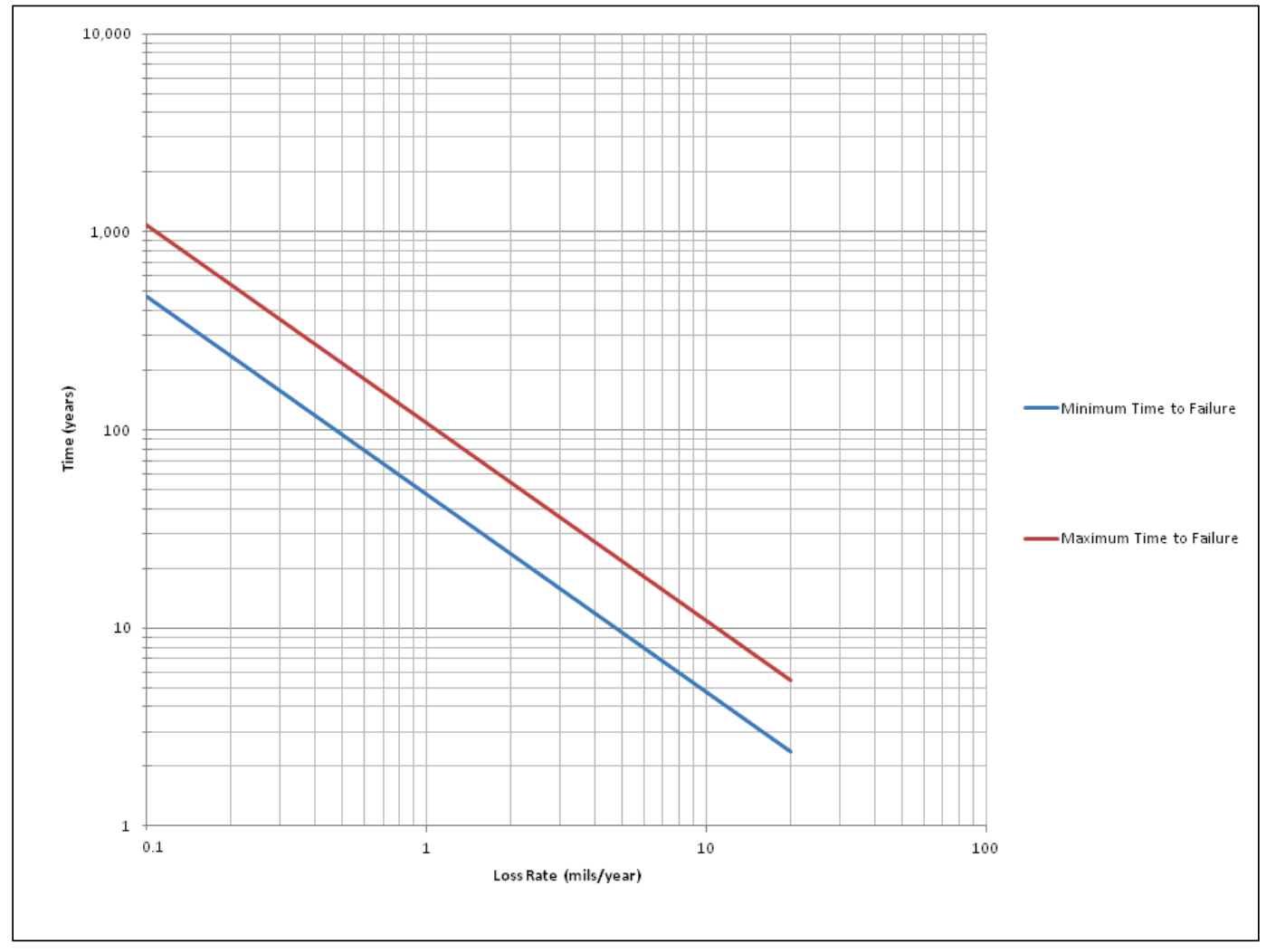




\section{References}

Ahmad, S., M. Abdul, A. Jibran, A. Azad, and M. Maslehuddin. 2014. A simple and reliable setup for monitoring corrosion rate of steel rebars in concrete. Dhahran, Saudi Arabia: Civil and Environmental Engineering Department, King Fahd University of Petroleum and Minerals. http://www.hindawi.com/journals/tswj/2014/525678/

Andrade, C., and C. Alonso. 2004. Test methods for on-site corrosion rate measurement of steel reinforcement in concrete by means of the polarization resistance method. Materials and Structures, 37:623-643. www.labcorr.net/publicaciones/mecprotar.pdf

American Society for Testing and Materials (ASTM). 2012. Standard specification for steel strand, uncoated seven-wire for prestressed concrete. Designation: A416/A416M-12a.

2012. Standard test method for acid-soluble chloride in mortar and concrete. Standard C1152/C1152-03 (Reapproved 2012). West Conshohocken, PA: ASTM International.

2008. Standard test method for water-soluble chloride in mortar and concrete. Standard C1218/C1218-99 (Reapproved 2008). West Conshohocken, PA: ASTM International.

Azizinamini, A., and J. Gull. 2012. Improved inspections techniques for steel prestressing/post tensioning strand, FDOT Contract BDK80 977-13, Final Report Volume 1, Florida International University Miami, Miami, FL. Sponsoring Agency: Florida Department of Transportation Tallahassee, Fl. http://www.dot.state.fl.us/research-center/Completed_Proj/Summary_MNT/FDOT-BDK80-97713-rptvol1.pdf

Badea, G. E., A. Caraban, M. Sebesan, S. Dzitac, P. Cret, and A. Setel. 2010. Polarization measurements used for corrosion rates determinations. Oradea, Romania: University of Oradea National Geothermal Research Center. http://www.energycie.ro/archives/2010/n1-1-14.pdf

Bartoli, A., S. Salamone, R. Phillips, C. Nucera, and F. L. Scalea. 2009. Health monitoring to detect failure of prestressing (PS) cables in segmental boxgirder bridges. Report No. SSRP 0906. California Department of Transportation (Caltrans). University of California, San Diego/La Jolla, California: Department of Structural Engineering

Berry, W. E. 1984. Water corrosion. Corrosion basics: an introduction, L. S. Vandelinder and A.D. Brasunas editions. Houston TX: NACE International.

Bertolini, L., B. Elsener, P. Pedeferri, and R. Polder. 2004. Corrosion of steel in concrete: prevention, diagnosis, repair. Weinham, Germany: Wiley-VCH

Broomfield, J. P. 1997. Corrosion of steel in concrete, understanding, investigation and repair. Boca Raton, FL: Chapman and Hall. 
Bruce, D., J. Wolfhope, and J. Wullenwaber. 2006. Rock anchors for dams: A five-year update. http://www.geosystemsbruce.com/v20/biblio/282\%20\%20USSD\%205yr\% 20Anchor\%20Update\%20Final\%202012-12-10.pdf

Bruce, D., and J. S. Wolfhope. 2008. 40 years of rock anchors for dams in North America- lessons learned. Portland, OR: Twenty-eighth Annual USSD Conference. April 28 - May 2. http://ussdams.com/proceedings/USSDProceedings2008.pdf

Charng, T., and F. Lansing. 1982. Review of corrosion causes and corrosion control in a technical facility. DSN Engineering Section. NASA Code 311-03-41-91. National Aeronautics and Space Administration, Jet Propulsion Laboratory. Pasadena, CA: California Institute of Technology. http://ipnpr.jpl.nasa.gov/progress_report/4269/69title.htm

Christian, J. T., and G. B. Baecher. 2001. Factors of safety and reliability in geotechnical engineering, Journal of Geotechnical and Geoenvironmental Engineering.

Cornforth Consultants, Inc. 2009. Anchor inspection and lift-off testing: John Day Dam navigation lock. letter report submitted to David Scofield of Portland District.

Dai, S. H., and M. O. Wang. 1992. Reliability analysis in engineering applications. New York, NY: Van Nostrand Reinhold.

Darmawan, M. S., and M. G. Stewart. 2003. Spatial variability of pitting corrosion and its effect on the reliability of prestressing wires. Application of statistics and probability in civil engineering. Millpress, Rotterdam, Holland.

Darmawan, M. S., and M. G. Stewart. 2005. Spatial time-dependent reliability analysis of corroding pretensioned prestressed concrete bridge girders. Structural Safety 29. Elsevier, www.elsevier.com/locate/strusafe.

Darmawan, M. S., and M. G. Stewart. 2006. Effect of spatially variable pitting corrosion on structural reliability of prestressed concrete bridge girders. Institute of Engineers, Australia. Australian journal of structural engineering, 6(2).

Darmawan, M. S., and M. G. Stewart. 2007 Effect of pitting corrosion on capacity of prestressing wires. Magazine of concrete research, 59(2): 131-139. http://dosen.narotama.ac.id/wp-content/uploads/2012/03/Effect-of-pitting-corrosion-oncapacity-of-prestressing-wires.pdf

Darmawan, M. S. 2009. Pitting Corrosion Model for Partial Prestressed Concrete (Pc) Structures in a Chloride Environment. IPTEK, The Journal of Technology and Science, 20(3).

Darmawan, M. S. 2010. Probabilistic Assessment of Pitting Corrosion Effect on Flexural Strength of Partial Prestressed Concrete Structures in a Chloride Environment. Journal of Civil Engineering and Architecture, 4(2) (Serial No. 27). New York, NY: David Publishing.

Duncan, J. M., and S. G. Wright. 2005. Soil strength and slope stability. Somerset, NJ: Wiley and Sons. 
Ebeling, R. M., R. W. Haskins, D. H. Scofield, J. E. Hite, and R. W. Strom. 2012. Posttensioned multistrand anchorage capacity deterioration due to corrosion: John Day Lock project. ERDC/CHL CHETN-IX-28. Vicksburg, MS: U.S. Army Engineer Research and Development Center.

Ebeling, R. M., R. W. Strom, J. E. Hite, R. W. Haskins, and J. A. Evans. 2013. Assessing corrosion damage and corrosion progression in multistrand anchor systems in use at Corps projects. ERDC TR-13-3. Vicksburg, MS: U.S. Army Engineer Research and Development Center.

Escalante, E., and S. Ito. 1990. Measuring the rate of corrosion of steel in concrete. ASTM STP 1065, Ann Arbor, MI: ASTM International.

Filomena, D. 1., G. Campanella, E. Proverbio, and C. Urzi. 2013. Laboratory tests of fungal biocorrosion of unbonded lubricated post-tensioned tendons. Department of biological and environmental sciences, Viale F.Stagno d'Alcontres, 31, 98166 Messina, Italy, Diparttimento di Ingegneria Elettronica, Chimica e Ingegneria Industriale, C/di Dio, 98166 Messina, Italy.

Griess, J. C., and D. J. Naus. 1975. Corrosion of steel tendons used in prestressed concrete pressure vessels. Oak Ridge, TX: Oak Ridge National Laboratory. http://www.osti.gov/scitech/servlets/purl/6490079

Haskins, R. W., J. A. Evans, and R. M. Ebeling. 2014. Corrosion induced loss of capacity and development of a guided wave condition assessment method for multistrand anchor systems used in Corps projects. ERDC/ITL TR-14-2. Vicksburg, MS: U.S. Army Engineer Research and Development Center.

Heslin, G., D. A. Bruce, G. S. Littlejohn, and T. Westover. 2008. Performance of aging post-tensioned rock anchors in dams. In Proceedings, ASDSO Northeast Regional Conference. 14-16 June, State College, PA.

Hopwood, T., and J. H. Havens. 1984. Corrosion of cable suspension bridges. Research Report UKTRP-84-14, Kentucky transportation research program College of Engineering, University of Kentucky, Lexington, Kentucky, State of Kentucky and the FHWD. http://www.ktc.uky.edu/files/2012/09/1984-Corrosion-of-Cable-SuspensionBridges-UKTRP-84-14.pdf

Kinghoffer, O. 2014. In situ monitoring of reinforcing corrosion by means of electrochemical methods. FORCE Institute. Park Allé 345, DK-2605 Brøndby, Denmark http://germann.org/TestSystems/GalvaPulse/nordic_concrete_95.pdf

Lee, S. K., and J. Zielske. 2014. An FHWA special study: post-tensioning tendon grout chloride thresholds. Report No. FHWA-HRT-14-039. McLean, VA: Federal Highway Administration.

Li, L., and A. Sagues. 2001. Chloride corrosion threshold of reinforcing steel in alkaline solution-open- circuit immersion tests. Corrosion, 57(1):19.

Melchers, R. E. 2003. Probabilistic model for marine corrosion of steel for structural reliability assessment. American Society of Structural Engineers. Journal of Structural Engineering, 129(11):1484-1493. 
Mitchell, T. O. 2006. Luminescence based measurement of dissolved oxygen in natural waters. Loveland: Hach Company.

Moser, R.D. 2011. High-strength stainless steels for corrosion mitigation in prestressed concrete: Development and evaluation. Ph.D Dissertation. Atlanta, GA: Georgia Institute of Technology.

Naaman, A. E. 2004. Prestressed concrete analysis and design, second edition, pp. 1072. Techno Press: Ann Arbor, Michigan. http://www.scribd.com/doc/120445591/Prestressed-Concrete-Analysis-and-Design-by$\underline{\text { Naaman }}$

The Overseas Coastal Area Development Institute of Japan. 2009. Technical standards and commentaries for port and harbor facilities in Japan.

Post-Tensioning Institute. 2012. Specification for grouting of post-tensioned structures. PTI M55.1-12, Farmington Hills, MI.

Preston, H. K. 1985. Testing 7-wire strand for prestressed concrete - The state of the art. PCI Journal, May-June 1985.

Roberge, P. 2008. Corrosion engineering: principles and practice. New York, NY: McGraw-Hill.

Song, G., and A. Shayan. 1998. Corrosion of steel in concrete: causes, detection and prediction - a state of the art review. Review Report 4. ARRB Transport Research Limited, Vermont South VIC, Australia.

Stern, M., and A. Geary. 1957. Electrochemical Polarization I. A theoretical analysis of the shape of polarization curves. Journal of the Electrochemical Society, 104(1):5663. http://jes.ecsdl.org/content/104/1/56.full.pdf

Trejo, D., R. G. Pillai, M. B. D. Hueste, K. F. Reinschmidt, and P. Garboni, P. 2009. Parameters influencing corrosion and tension capacity of post-tensioning strands. ACI Materials Journal 106(2).

Uhlig, H. H. 1948. Iron and Steel. In: The Corrosion Handbook. New York, NY: John Wiley and Sons.

Uhlig, H. H. 1971. Corrosion and corrosion control: an introduction to corrosion science and engineering. New York, NY: John Wiley and Sons.

Wagner, C., and W. Traud 1938. On the interpretation of corrosion processes through the superposition of electrochemical partial processes and on the potential of mixed electrodes. $Z$ Electrochem, 44: 391.

Wang, H., A. Sagüés, and R. G. Powers. 2005. Corrosion of the strand-anchorage system in post-tensioned grouted assemblies. Houston, TX: NACE International, Publications Division. 


\section{Appendix A: Table of Capacity and Optical Post-Processed Pull Test Results for the 161 Corroded and 22 Pristine Specimens}

The following table contains the resulting 183 pull-test results.

Table A.1. Optically Post-Processed, Pull-Test Results.

\begin{tabular}{|c|c|c|c|c|}
\hline Sample \# & $\begin{array}{l}\text { Pristine }(\mathrm{P}) \\
\text { or Corroded } \\
\text { (C) }\end{array}$ & Peak Load (lb) & $\begin{array}{l}\text { Minimum Wire } \\
\left.\text { Area (in. } .^{2}\right)\end{array}$ & $\begin{array}{l}\text { Minimum Wire } \\
\text { Diameter (in.) }\end{array}$ \\
\hline 1 & C & 59849 & 0.025922 & 0.17085 \\
\hline 2 & C & 59767 & 0.026977 & 0.17686 \\
\hline 3 & C & 59732 & 0.02883 & 0.18849 \\
\hline 4 & C & 59670 & 0.022274 & 0.16497 \\
\hline 5 & C & 58691 & 0.018415 & 0.15968 \\
\hline 6 & C & 58518 & 0.024091 & 0.16804 \\
\hline 7 & C & 57908 & 0.025067 & 0.16937 \\
\hline 8 & C & 57629 & 0.021968 & 0.17473 \\
\hline 9 & C & 57537 & 0.022274 & 0.16497 \\
\hline 10 & C & 57009 & 0.023948 & 0.17531 \\
\hline 11 & C & 56661 & 0.017211 & 0.14549 \\
\hline 12 & C & 56640 & 0.02211 & 0.164 \\
\hline 13 & C & 56565 & 0.023645 & 0.19222 \\
\hline 14 & C & 56449 & 0.024597 & 0.17519 \\
\hline 15 & C & 56334 & 0.026041 & 0.18491 \\
\hline 16 & C & 56031 & 0.02344 & 0.16864 \\
\hline 17 & C & 56005 & 0.017441 & 0.14955 \\
\hline 18 & C & 56002 & 0.024449 & 0.16965 \\
\hline 19 & C & 55967 & 0.025735 & 0.16417 \\
\hline 20 & C & 55796 & 0.025185 & 0.1902 \\
\hline 21 & C & 55513 & 0.021461 & 0.16366 \\
\hline 22 & C & 55398 & 0.018389 & 0.16226 \\
\hline 23 & C & 55271 & 0.026331 & 0.16786 \\
\hline 24 & C & 54847 & 0.023018 & 0.1549 \\
\hline
\end{tabular}




\begin{tabular}{|c|c|c|c|c|}
\hline Sample \# & $\begin{array}{l}\text { Pristine (P) } \\
\text { or Corroded } \\
\text { (C) }\end{array}$ & Peak Load (Ib) & $\begin{array}{l}\text { Minimum Wire } \\
\text { Area (in. }{ }^{2} \text { ) }\end{array}$ & $\begin{array}{l}\text { Minimum Wire } \\
\text { Diameter (in.) }\end{array}$ \\
\hline 25 & C & 54784 & 0.020019 & 0.15529 \\
\hline 26 & C & 54585 & 0.020931 & 0.15823 \\
\hline 27 & C & 54474 & 0.019772 & 0.1531 \\
\hline 28 & C & 54433 & 0.018694 & 0.16942 \\
\hline 29 & C & 54406 & 0.020777 & 0.16033 \\
\hline 30 & C & 54334 & 0.02278 & 0.15543 \\
\hline 31 & C & 54295 & 0.019918 & 0.16235 \\
\hline 32 & C & 54251 & 0.024757 & 0.16339 \\
\hline 33 & C & 54062 & 0.023333 & 0.15446 \\
\hline 34 & C & 53969 & 0.015445 & 0.15421 \\
\hline 35 & C & 53795 & 0.024148 & 0.16147 \\
\hline 36 & C & 53484 & 0.018719 & 0.1589 \\
\hline 37 & C & 53037 & 0.022099 & 0.14987 \\
\hline 38 & C & 52985 & 0.022577 & 0.16879 \\
\hline 39 & C & 52642 & 0.023136 & 0.15896 \\
\hline 40 & C & 52546 & 0.022407 & 0.17202 \\
\hline 41 & C & 52382 & 0.024601 & 0.15558 \\
\hline 42 & C & 52227 & 0.016559 & 0.15411 \\
\hline 43 & C & 52171 & 0.021445 & 0.16383 \\
\hline 44 & C & 52113 & 0.018355 & 0.15865 \\
\hline 45 & C & 51785 & 0.021375 & 0.16573 \\
\hline 46 & C & 51728 & 0.022148 & 0.1535 \\
\hline 47 & C & 51563 & 0.018616 & 0.15268 \\
\hline 48 & C & 51404 & 0.018493 & 0.15033 \\
\hline 49 & C & 51228 & 0.021392 & 0.16013 \\
\hline 50 & C & 51174 & 0.020343 & 0.15856 \\
\hline 51 & C & 50924 & 0.020234 & 0.14514 \\
\hline 52 & C & 50913 & 0.018816 & 0.1613 \\
\hline 53 & C & 50732 & 0.018472 & 0.15136 \\
\hline 54 & C & 50657 & 0.020673 & 0.14432 \\
\hline 55 & C & 50608 & 0.021925 & 0.16107 \\
\hline 56 & C & 50382 & 0.019656 & 0.17085 \\
\hline 57 & C & 50275 & 0.023948 & 0.14124 \\
\hline
\end{tabular}




\begin{tabular}{|c|c|c|c|c|}
\hline Sample \# & $\begin{array}{l}\text { Pristine (P) } \\
\text { or Corroded } \\
\text { (C) }\end{array}$ & Peak Load (lb) & $\begin{array}{l}\text { Minimum Wire } \\
\left.\text { Area (in. }{ }^{2}\right)\end{array}$ & $\begin{array}{l}\text { Minimum Wire } \\
\text { Diameter (in.) }\end{array}$ \\
\hline 58 & C & 49835 & 0.013545 & 0.16046 \\
\hline 59 & C & 49629 & 0.020482 & 0.13061 \\
\hline 60 & $C$ & 49300 & 0.014729 & 0.15366 \\
\hline 61 & C & 49075 & 0.022217 & 0.15109 \\
\hline 62 & C & 48340 & 0.018797 & 0.12338 \\
\hline 63 & C & 47751 & 0.013806 & 0.14163 \\
\hline 64 & $C$ & 47677 & 0.017374 & 0.16489 \\
\hline 65 & $C$ & 47341 & 0.024154 & 0.13559 \\
\hline 66 & $C$ & 47251 & 0.020487 & 0.13957 \\
\hline 67 & C & 47242 & 0.016212 & 0.1142 \\
\hline 68 & C & 46650 & 0.012799 & 0.14515 \\
\hline 69 & C & 46519 & 0.012234 & 0.13788 \\
\hline 70 & C & 46502 & 0.014432 & 0.14911 \\
\hline 71 & $C$ & 46485 & 0.015747 & 0.13559 \\
\hline 72 & $C$ & 46462 & 0.01278 & 0.12349 \\
\hline 73 & $C$ & 46399 & 0.011614 & 0.14923 \\
\hline 74 & $C$ & 46330 & 0.016417 & 0.15383 \\
\hline 75 & C & 46255 & 0.018319 & 0.1048 \\
\hline 76 & $C$ & 46022 & 0.019637 & 0.14472 \\
\hline 77 & $C$ & 45797 & 0.016427 & 0.10536 \\
\hline 78 & C & 45695 & 0.013487 & 0.13025 \\
\hline 79 & $\mathrm{C}$ & 45461 & 0.014771 & 0.14507 \\
\hline 80 & $C$ & 45386 & 0.017817 & 0.14652 \\
\hline 81 & $C$ & 45207 & 0.017184 & 0.1218 \\
\hline 82 & $C$ & 44953 & 0.014584 & 0.11834 \\
\hline 83 & $C$ & 44421 & 0.014566 & 0.12773 \\
\hline 84 & $C$ & 44367 & 0.014668 & 0.13125 \\
\hline 85 & $C$ & 44194 & 0.018635 & 0.13167 \\
\hline 86 & $C$ & 44162 & 0.014737 & 0.13459 \\
\hline 87 & C & 43994 & 0.015585 & 0.14875 \\
\hline 88 & C & 43918 & 0.017784 & 0.13935 \\
\hline 89 & $C$ & 43761 & 0.015746 & 0.14038 \\
\hline 90 & C & 43721 & 0.018579 & 0.12468 \\
\hline
\end{tabular}




\begin{tabular}{|c|c|c|c|c|}
\hline Sample \# & $\begin{array}{l}\text { Pristine (P) } \\
\text { or Corroded } \\
\text { (C) }\end{array}$ & Peak Load (Ib) & $\begin{array}{l}\text { Minimum Wire } \\
\text { Area (in. }{ }^{2} \text { ) }\end{array}$ & $\begin{array}{l}\text { Minimum Wire } \\
\text { Diameter (in.) }\end{array}$ \\
\hline 91 & C & 43459 & 0.01329 & 0.12237 \\
\hline 92 & C & 43416 & 0.017563 & 0.10591 \\
\hline 93 & C & 42492 & 0.017252 & 0.10168 \\
\hline 94 & C & 42113 & 0.01655 & 0.13917 \\
\hline 95 & C & 42030 & 0.015903 & 0.12897 \\
\hline 96 & C & 42028 & 0.019445 & 0.13844 \\
\hline 97 & C & 41819 & 0.016405 & 0.14171 \\
\hline 98 & C & 41197 & 0.019997 & 0.11467 \\
\hline 99 & C & 40865 & 0.016325 & 0.1308 \\
\hline 100 & C & 40085 & 0.013131 & 0.12431 \\
\hline 101 & C & 39429 & 0.011043 & 0.11654 \\
\hline 102 & C & 39290 & 0.012621 & 0.12118 \\
\hline 103 & C & 38268 & 0.013685 & 0.12134 \\
\hline 104 & C & 38242 & 0.012434 & 0.11924 \\
\hline 105 & C & 38047 & 0.012049 & 0.12744 \\
\hline 106 & C & 37703 & 0.013249 & 0.12861 \\
\hline 107 & C & 37607 & 0.018285 & 0.10331 \\
\hline 108 & C & 37148 & 0.01354 & 0.13162 \\
\hline 109 & C & 37105 & 0.012663 & 0.11888 \\
\hline 110 & C & 36249 & 0.012748 & 0.078921 \\
\hline 111 & C & 35975 & 0.010116 & 0.1126 \\
\hline 112 & C & 35273 & 0.01942 & 0.13258 \\
\hline 113 & C & 35036 & 0.013129 & 0.12967 \\
\hline 114 & C & 33754 & 0.0093983 & 0.10523 \\
\hline 115 & C & 33439 & 0.011609 & 0.11097 \\
\hline 116 & C & 32844 & 0.0078141 & 0.078576 \\
\hline 117 & C & 32546 & 0.01226 & 0.11963 \\
\hline 118 & C & 32472 & 0.017999 & 0.14379 \\
\hline 119 & C & 32343 & 0.013059 & 0.11708 \\
\hline 120 & C & 32334 & 0.013206 & 0.13299 \\
\hline 121 & C & 32010 & 0.01217 & 0.11188 \\
\hline 122 & C & 31916 & 0.011528 & 0.10955 \\
\hline 123 & C & 31081 & 0.012718 & 0.12374 \\
\hline
\end{tabular}




\begin{tabular}{|c|c|c|c|c|}
\hline Sample \# & $\begin{array}{l}\text { Pristine (P) } \\
\text { or Corroded } \\
\text { (C) }\end{array}$ & Peak Load (lb) & $\begin{array}{l}\text { Minimum Wire } \\
\text { Area (in. }{ }^{2} \text { ) }\end{array}$ & $\begin{array}{l}\text { Minimum Wire } \\
\text { Diameter (in.) }\end{array}$ \\
\hline 124 & C & 30606 & 0.015299 & 0.11529 \\
\hline 125 & C & 30214 & 0.011609 & 0.11097 \\
\hline 126 & C & 29926 & 0.012681 & 0.11927 \\
\hline 127 & C & 29887 & 0.012748 & 0.11888 \\
\hline 128 & C & 29712 & 0.011592 & 0.11586 \\
\hline 129 & C & 29028 & 0.0096805 & 0.10424 \\
\hline 130 & C & 28649 & 0.011749 & 0.11367 \\
\hline 131 & C & 28565 & 0.013123 & 0.083632 \\
\hline 132 & C & 28557 & 0.0093511 & 0.1024 \\
\hline 133 & C & 27724 & 0.011524 & 0.12952 \\
\hline 134 & C & 26814 & 0.0094904 & 0.10605 \\
\hline 135 & C & 25519 & 0.0088855 & 0.087584 \\
\hline 136 & C & 24257 & 0.0081461 & 0.07945 \\
\hline 137 & C & 24193 & 0.0070628 & 0.077809 \\
\hline 138 & C & 23738 & 0.004878 & 0.059938 \\
\hline 139 & C & 23304 & 0.0061779 & 0.081841 \\
\hline 140 & C & 22677 & 0.0059639 & 0.063542 \\
\hline 141 & C & 22078 & 0.0078376 & 0.091567 \\
\hline 142 & C & 20795 & 0.0065929 & 0.071687 \\
\hline 143 & C & 20301 & 0.0052382 & 0.072054 \\
\hline 144 & C & 19636 & 0.0039537 & 0.057779 \\
\hline 145 & C & 19476 & 0.0033025 & 0.064089 \\
\hline 146 & C & 18846 & 0.0033872 & 0.063325 \\
\hline 147 & C & 18639 & 0.0068747 & 0.070276 \\
\hline 148 & C & 18151 & 0.0053226 & 0.075676 \\
\hline 149 & $C$ & 17899 & 0.0072868 & 0.087563 \\
\hline 150 & $C$ & 16409 & 0.0042033 & 0.062263 \\
\hline 151 & C & 16034 & 0.0044628 & 0.06639 \\
\hline 152 & $C$ & 14903 & 0.0051578 & 0.077858 \\
\hline 153 & $C$ & 14808 & 0.0026888 & 0.052852 \\
\hline 154 & C & 14589 & 0.003641 & 0.045335 \\
\hline 155 & C & 13658 & 0.0015706 & 0.033068 \\
\hline 156 & C & 13313 & 0.0037382 & 0.061851 \\
\hline
\end{tabular}




\begin{tabular}{|c|c|c|c|c|}
\hline Sample \# & $\begin{array}{l}\text { Pristine }(\mathrm{P}) \\
\text { or Corroded } \\
\text { (C) }\end{array}$ & Peak Load (lb) & $\begin{array}{l}\text { Minimum Wire } \\
\left.\text { Area (in. } .^{2}\right)\end{array}$ & $\begin{array}{l}\text { Minimum Wire } \\
\text { Diameter (in.) }\end{array}$ \\
\hline 157 & C & 11274 & 0.0040931 & 0.069442 \\
\hline 158 & C & 11152 & 0.0029548 & 0.056461 \\
\hline 159 & $C$ & 10408 & 0.0015164 & 0.03462 \\
\hline 160 & C & 10217 & 0.0033446 & 0.041573 \\
\hline 161 & C & 9466 & 0.0015477 & 0.067789 \\
\hline 162 & $P$ & 62106 & 0.031415927 & 0.2 \\
\hline 163 & $\mathrm{P}$ & 62032 & 0.031415927 & 0.2 \\
\hline 164 & $\mathrm{P}$ & 62324 & 0.031415927 & 0.2 \\
\hline 165 & $P$ & 62053 & 0.031415927 & 0.2 \\
\hline 166 & $P$ & 62191 & 0.031415927 & 0.2 \\
\hline 167 & $P$ & 61980 & 0.031415927 & 0.2 \\
\hline 168 & $\mathrm{P}$ & 62524 & 0.031415927 & 0.2 \\
\hline 169 & $P$ & 62108 & 0.031415927 & 0.2 \\
\hline 170 & $P$ & 61745 & 0.031415927 & 0.2 \\
\hline 171 & $P$ & 61204 & 0.031415927 & 0.2 \\
\hline 172 & $P$ & 61851 & 0.031415927 & 0.2 \\
\hline 173 & $\mathrm{P}$ & 61800 & 0.031415927 & 0.2 \\
\hline 174 & $P$ & 61827 & 0.031415927 & 0.2 \\
\hline 175 & $P$ & 61857 & 0.031415927 & 0.2 \\
\hline 176 & $\mathrm{P}$ & 61371 & 0.031415927 & 0.2 \\
\hline 177 & $\mathrm{P}$ & 59964 & 0.031415927 & 0.2 \\
\hline 178 & $P$ & 60373 & 0.031415927 & 0.2 \\
\hline 179 & $P$ & 61385 & 0.031415927 & 0.2 \\
\hline 180 & $P$ & 61725 & 0.031415927 & 0.2 \\
\hline 181 & $P$ & 61507 & 0.031415927 & 0.2 \\
\hline 182 & $P$ & 61711 & 0.031415927 & 0.2 \\
\hline 183 & $P$ & 61073 & 0.031415927 & 0.2 \\
\hline
\end{tabular}




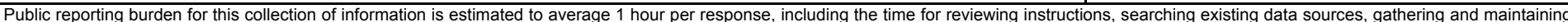

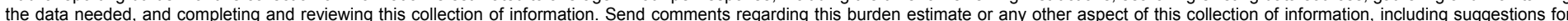

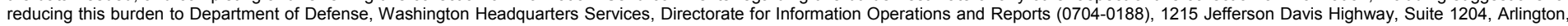

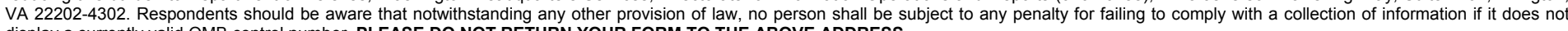
display a currently valid OMB control number. PLEASE DO NOT RETURN YOUR FORM TO THE ABOVE ADDRESS.
1. REPORT DATE (DD-MM-YYYY) 2. REPORT TYPE
December 2016 TR
3. DATES COVERED (From - To)

\section{TITLE AND SUBTITLE}

Corrosion Induced Loss of Capacity of Post-Tensioned Seven Wire Strand Cable Used in Multistrand Anchor Systems Installed at Corps Projects

5a. CONTRACT NUMBER

5b. GRANT NUMBER

5c. PROGRAM ELEMENT NUMBER

\section{AUTHOR(S)}

Robert M. Ebeling, Barry C. White, James A. Evans, Richard W. Haskins, and

Ernest L. Miller

\section{5d. PROJECT NUMBER}

5e. TASK NUMBER

5f. WORK UNIT NUMBER

L9C833

7. PERFORMING ORGANIZATION NAME(S) AND ADDRESS(ES)

8. PERFORMING ORGANIZATION REPORT NUMBER

Information Technology Laboratory

US Army Engineer Research and Development Center

ERDC/ITL TR-16-4

3909 Halls Ferry Road

Vicksburg, MS 39180-6199

9. SPONSORING / MONITORING AGENCY NAME(S) AND ADDRESS(ES)

10. SPONSOR/MONITOR'S ACRONYM(S)

U.S. Army Corps of Engineers

Washington, DC 20314-1000

11. SPONSOR/MONITOR'S REPORT NUMBER(S)

\section{DISTRIBUTION / AVAILABILITY STATEMENT}

Approved for public release; distribution is unlimited.

\section{SUPPLEMENTARY NOTES}

\section{ABSTRACT}

Over the past five decades, the U.S. Army Corps of Engineers has been upgrading its projects by installing high-capacity, post-tensioned foundation anchors, typically with seven-wire strand cables. The purpose of these anchors has been to achieve structural stability for Corps hydraulic concrete structures (e.g., locks, dams, approach walls) and/or to remediate cracked concrete monoliths. Substantial improvements to protect multistrand anchor systems from corrosion have been made in the past five decades, but the corrosion of older multistrand anchorage systems is still a major concern.

This report discusses a laboratory-testing program for the estimation of post-tensioning (PT), seven-wire strand cable strength as a function of corroded cross-sectional material loss. Pull tests were performed to gather reduced cable strength measurements. An innovative morphological procedure using digital photography was developed by U.S. Army Engineer Research and Development Center (ERDC) researchers for quantifying the cross-section geometrical properties of cables near their failure locations. The laboratory-testing program also included a successful series pull test to failure on pristine specimens for a control set of data, and the issues encountered are detailed. A statistical assessment of pull-test data to failure of pristine and corroded cables is used to establish a correlation between cross-section properties, corroded and pristine, and the cable strength.

An overview of the corrosion process and the variables, ranked by contribution in Corps structures, which determine corrosion rate at each of the multistrand cables, is provided. Further, methods for estimating cable capacity under load were developed using the provided best-fit curves from the laboratory pull tests.

15. SUBJECT TERMS (See reverse)

\section{SECURITY CLASSIFICATION OF:}

\section{a. REPORT}

UNCLASSIFIED

b. ABSTRACT
UNCLASSIFIED

c. THIS PAGE UNCLASSIFIED

17. LIMITATION
OF ABSTRACT
UNCLASSIFIED

18. NUMBER OF PAGES

127 19a. NAME OF RESPONSIBLE PERSON Robert M. Ebeling

19b. TELEPHONE NUMBER (include area code) 6016343458 
15. SUBJECT TERMS (concluded)

Accelerated corrosion

Digital photography

Capacity

Morphological procedure

Corrosion

Morphology Post-tensioned

Seven-wire strand cable

Post-tensioning

Strength

Pull test 